Universidade de Brasília

Instituto de Psicologia

Departamento de Psicologia Clínica

Programa de Pós-Graduação em Psicologia Clínica e Cultura

\title{
Avaliação de Risco em Casos de Violência Contra a Mulher Perpetrada por Parceiro Íntimo
}

\author{
Marcela Novais Medeiros \\ Orientador: Prof. Dr. Marcelo Tavares.
}

Brasília/DF

2015 
Universidade de Brasília

Instituto de Psicologia

Departamento de Psicologia Clínica

Programa de Pós-Graduação em Psicologia Clínica e Cultura

\section{Avaliação de Risco em Casos de Violência Contra a Mulher Perpetrada por Parceiro Íntimo}

Marcela Novais Medeiros

Trabalho apresentado ao Programa de PósGraduação em Psicologia Clínica e Cultura, como requisito para a obtenção do título de Doutor em Psicologia Clínica e Cultura.

Orientador: Prof. Dr. Marcelo Tavares.

Brasília/DF

2015 
Universidade de Brasília

Instituto de Psicologia

Departamento de Psicologia Clínica

Programa de Pós-Graduação em Psicologia Clínica e Cultura

Avaliação de Risco em Casos de Violência Contra a Mulher Perpetrada por Parceiro Íntimo

Banca Examinadora:

$\operatorname{Prof}^{\mathrm{a}} \mathrm{Dr}^{\mathrm{a}}$ Valéria Cristina de Albuquerque Brito (Membro externo: Centro Universitário UDF e Ministério da Saúde).

$\operatorname{Prof}^{\mathrm{a}} \mathrm{Dr}^{\mathrm{a}}$ Cristina Viana Moreira dos Santos (Membro Externo: Universidade Paulista UNIP-GO).

Prof $^{\mathrm{a}} \mathrm{Dr}^{\mathrm{a}}$ Lia Zanotta Machado (Departamento de Antropologia - UnB).

$\operatorname{Prof}^{\mathrm{a}} \operatorname{Dr}^{\mathrm{a}}$ Gláucia Ribeiro Starling Diniz (PPG-PsiCC, Instituto de Psicologia - UnB)

Prof. Dr. Marcelo Tavares (Orientador, PPG-PsiCC, Instituto de Psicologia - UnB).

Dr. Fábio Pereira Angelim (Suplente, membro externo: Supremo Tribunal de Justiça).

Brasília/DF, 2015 
Este trabalho é dedicado a todas as mulheres com experiências de violência na relação íntima. 


\section{Agradecimentos}

Ao meu orientador Dr. Marcelo Tavares pela sua generosidade intelectual e disponibilidade para dialogar. Seu acompanhamento contínuo do trabalho e auxílio no tratamento dos dados fomentaram meu crescimento intelectual e minha evolução profissional.

À Dr ${ }^{\mathrm{a}}$ Gláucia Starling Diniz cujo incentivo e colaboração foram determinantes para iniciar esse desafio e dele não desistir. Agradeço também por ter sido figura afetuosa e de sabedoria.

Ao Dr. Thiago André Pierobom de Ávila, Dr ${ }^{\mathrm{a}}$ Mariana Fernandes Távora e Dr ${ }^{\mathrm{a}}$ Carla Zen pela oportunidade de participar de ricas discussões sobre avaliação de risco no MPDFT e pelo auxílio no contato com profissionais da rede.

Aos membros das bancas de qualificação e de defesa de tese pelas leituras atentas e sugestões que enriqueceram o trabalho.

Aos profissionais participantes da pesquisa, por encontrarem tempo em suas agendas para colaborarem com essa pesquisa, por compartilharem suas práticas, angústias e desafios. Obrigada também por mostrarem que por mais difícil que possa ser trabalhar com pessoas em situação de violência, é possível acreditar em uma vida com menos violência e em relações de gênero mais igualitárias e solidárias.

Aos meus colegas do Programa de Pesquisa e Assistência a Violência - Pav Gardênia do Hospital Regional do Gama, Adair Fernandes, Nielma Batista, Quione Rodrigues, Mariana Quintino, Sueley Freitas, Ednancy Moura, Rosa Célia, Kedma Diase, Sandeli Dionisio, pelo apoio, compreensão e carinho que sempre recebi. 
Aos colegas do grupo de estudos e pesquisa NEGENPSICC, em especial a Fabrício Guimarães e Luiz Henrique Aguiar, pela parceira em atividades de prevenção e atendimento a mulheres em situação de violência e pelas valiosas contribuições durante a pesquisa.

Aos meus ex-alunos das turmas de psicologia jurídica do Instituto de Educação Superior de Brasília - IESB, pelas indagações e questionamentos sobre a psicologia jurídica e a avaliação de risco. Tais momentos foram imprescindíveis para que pudesse amadurecer minhas reflexões.

Aos meus pais, Vilson Medeiros e Regina Novais, que além de carinho e dedicação, sempre investiram na minha educação, permitindo que eu conquistasse minha formação profissional. Obrigada por serem grandes incentivadores em todos os projetos da minha vida e por estarem sempre presentes, acolhendo minhas angústias e comemorando minhas vitórias.

À Isabela Novais, minha irmã e querida companheira de toda a vida, por me ajudar a acreditar que o esforço vale a pena, que a formação e investimento profissional são uma das nossas maiores riquezas e que é possível assumir diversas responsabilidades ao mesmo tempo.

A todos os meus familiares, amigos e amigas, pela acolhida de minhas angústias, torcida e ajuda em diversas fases do trabalho. Em especial, agradeço a: Eliane Novais, Gercina Novais, Isabela Novais, Paulo César, Gabriela Novais, Raíssa Novais, Ana Sheila, Gabriela Tânnus, Gabriela Brito, Francielly Rosa, Roberta Cancella, Manoela Nogueira, Maíra Rodeiro, Luciana Garcia, Luciana Maia, Maíra Ribeiro, Luísa Reis, Maísa Guimarães e Célia Pereira. 
Ao meu namorado Fábio Reis, por ser meu apoio e parceria constante, pelo amor, escuta e abraços apertados nos momentos de angústia. Obrigada por me incentivar e me ajudar a superar minhas limitações e a enfrentar os desafios. Agradeço também a sua família pela acolhida e cuidado.

A todos que contribuíram com sugestões, fizeram críticas, compartilharam materiais e ofereçam apoio para coleta de dados.

Muito obrigada! 


\section{Resumo}

O objetivo deste estudo foi o de desenvolver uma lista de verificação para avaliar o risco de violência contra a mulher perpetrada pelo parceiro íntimo. Essa lista pode ser útil para prever a recorrência e a escalada de violência, evitando assim lesões graves ou resultados letais. Os itens foram desenvolvidos com base em uma revisão da literatura sobre a avaliação de risco da violência; uma entrevista em grupo focal; e entrevistas individuais. A validade de conteúdo de 100 itens que descrevem ou estão relacionados a comportamentos violentos foi avaliada por uma classificação $Q$-sort da letalidade presumida do item. Todos os participantes eram profissionais que trabalham com a avaliação da violência doméstica em agências de proteção da Rede Distrito Federal. Havia treze participantes do grupo; sete entrevistados; e vinte e oito respondentes da $Q$ sort de 100 itens cujos pontos de vista foram contrastados com os de seis pessoas de fora da rede de proteção à violência. A literatura indicou a importância crescente das abordagens estruturadas baseadas em evidências para a investigação de fatores de risco. Três ferramentas de avaliação de risco disponíveis são proeminentes na literatura internacional: a Danger Assessment (DA), a Spousal Assault Risk Assessment (SARA) e

o Revised Domestic Violence Screening Instrument (DVSI-R). Nenhum desses instrumentos, usado isoladamente, foi considerado suficiente para contemplar todas as dimensões de risco percebidas como relevantes pelos praticantes de protecção violência do Distrito Federal. Foram feitas sugestões para itens e fatores de risco relacionados à vítima, às dinâmicas relacionais, ao autor da violência e a sua relação com o sistema de justiça. Os 100 itens sobre violência foram classificadas em três categorias: risco extremo, risco grave e risco moderado. Dois juízes independentes avaliaram estes itens 
como comportamentais ou subjetivos. Itens comportamentais foram classificados como tendo maior potencial letal do que os itens subjetivos. A maioria dos itens de risco extremo foi relacionada ao agressor. Problemas de saúde mental, perfil da vítima, bem como de abuso e dependência de álcool e drogas foram predominantemente avaliados como fatores com menor potencial para causar danos. A conclusão é que o potencial desses itens para a avaliação do risco pode muito bem depender mais dos itens comportamentais e objetivos, relacionados com o ofensor, do que dos itens mais subjetivos, dos relacionadas com a vítima ou com o padrão de uso de alcool e drogas. No entanto, esses itens precisam ser testados quanto a seu valor preditivo em estudos longitudinais de mulheres que vivem em relações violentas.

Palavras-chave: Avaliação de Risco; Checklist; Validade Conteúdo. 


\begin{abstract}
The objective of this study was to develop a checklist to assess the risk of violence against women perpetrated by an intimate partner. Such a list may be useful to predict the recurrence and escalation of violence, thus preventing serious injuries or lethal outcomes. The items were developed based on a review of the literature on violence risk assessment; a focused group interview; and individual interviews. Content validity of 100 items describing or related to violent behaviors was assessed by a Q-sort rating of presumed item lethality. All participants were practitioners working with the assessment of domestic violence in protective agencies of the Federal District Network. There were thirteen group participants; seven interviewees; and twenty-eight respondents to the Qsort of 100 items whose views were contrasted to those of six persons outside the violence protection network. The literature indicated the increasing importance of structured evidence based approaches to the investigation of risk factors. Three risk assessment tools available are prominent in the international literature: the Danger Assessment (DA), the Spousal Assault Risk Assessment (SARA) and the Revised Domestic Violence Screening Instrument (DVSI-R). None of these instruments, if used alone, were deemed to contemplate all risk dimensions considered relevant by the Federal District violence protection practitioners. Suggestions were made for items and risk factors related to the victim, to the relational dynamics and to the perpetrator of violence and his relationship with the justice system. The 100 violence related items were sorted into three categories: extreme risk, serious risk and moderate risk. Two independent judges rated these items as behavioral or subjective. Behavioral items were classified as having greater lethal potential than subjective items. Most extreme risk
\end{abstract}


items were related to the offender. Mental health issues, victim profile, as well as alcohol and drug abuse and dependence were predominantly assessed as factors with less potential to cause damage. The conclusion is that these items potential for the assessment of risk may well rest on the more behavioral, objective items related to the offender rather than the more subjective items or those related to the victim or the pattern of drug and alcohol use. However, these items need to be tested for their predictive potential in longitudinal studies of women living in violent relationships.

Keywords: Risk Assessment; Checklist; Content Validity. 


\section{Sumário}

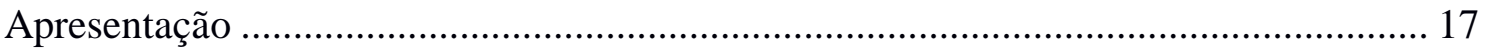

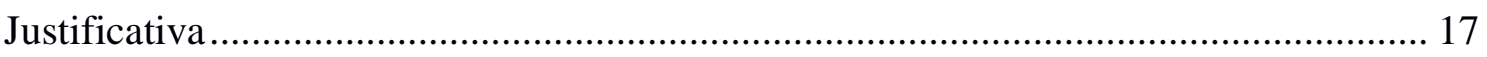

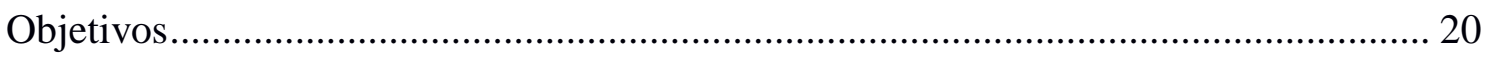

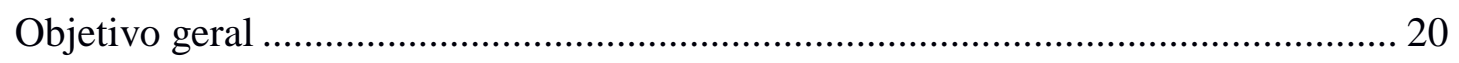

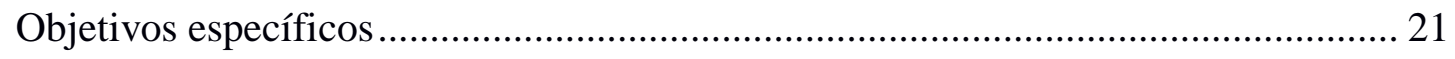

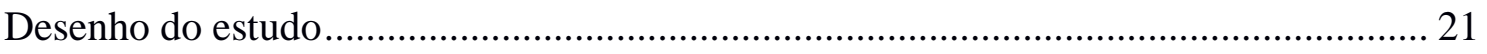

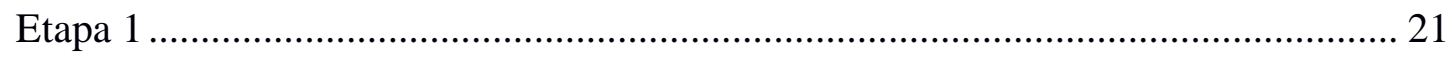

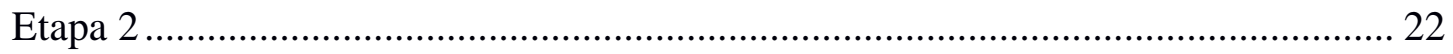

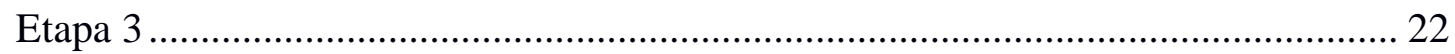

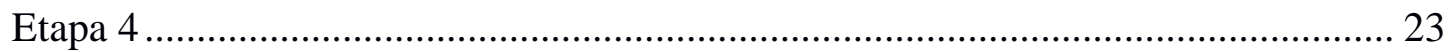

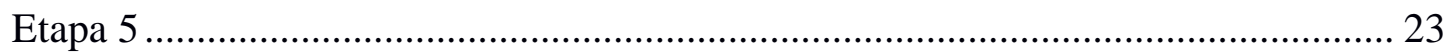

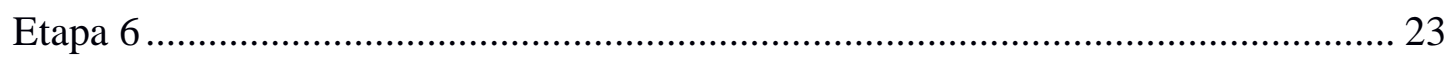

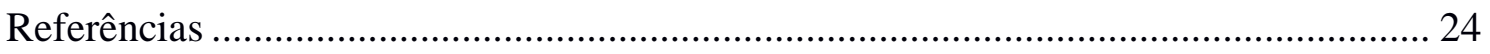

Artigo 1 - Avaliação de risco nas relações de intimidade................................................ 26

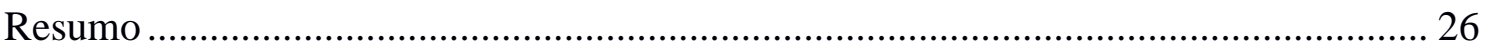

Desenvolvimento do Campo ............................................................................... 30

Estratégias de avaliação de risco .......................................................................... 33

Principais Instrumentos de avaliação de Risco.............................................................. 36 
Revised Domestic Violence Screening Instrument (DVSI- R).

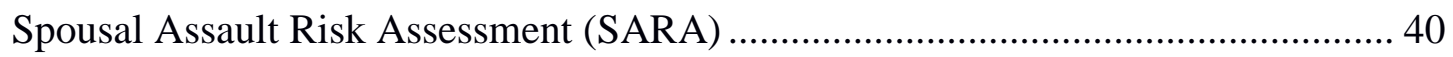

Similaridades e diferenças entre os DA, DVSI-R e SARA ...................................... 42

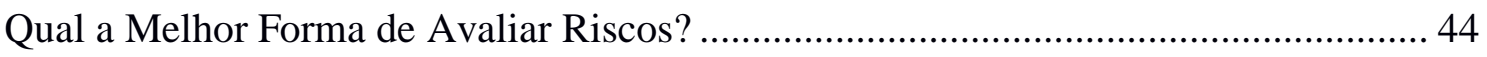

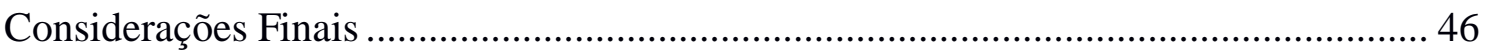

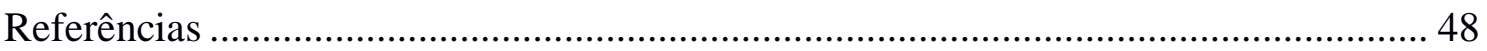

Artigo 2 - Avaliação de risco: atuação profissional em casos de violência contra mulher

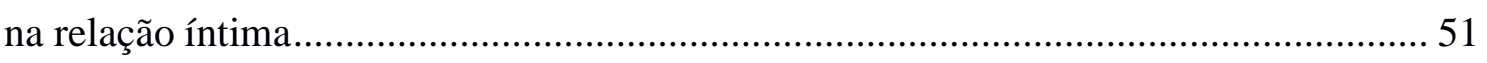

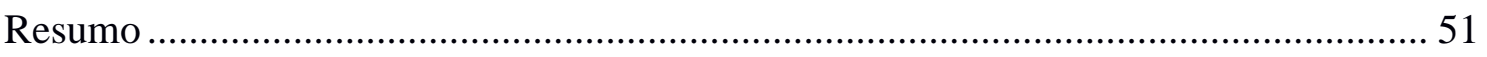

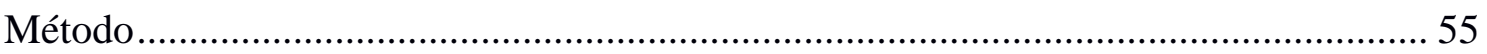

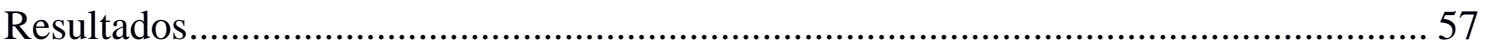

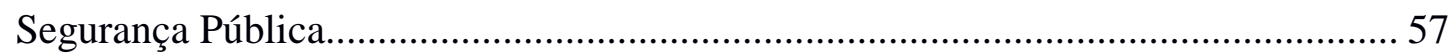

Poder Judiciário e Ministério Público ....................................................................... 59

Sistema de Saúde e Sistema Socioassistencial ........................................................ 61

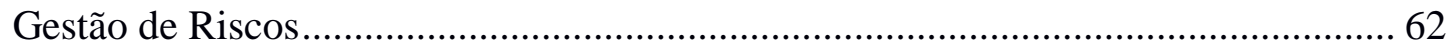

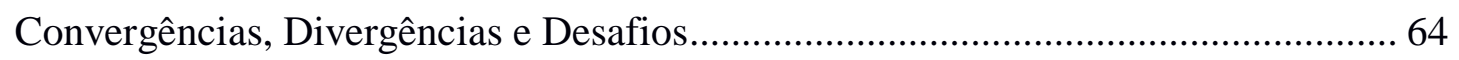

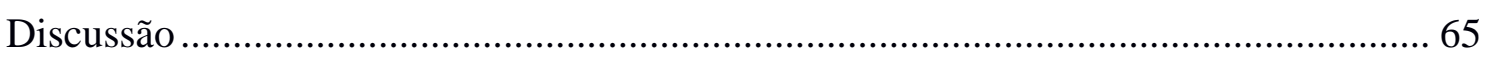

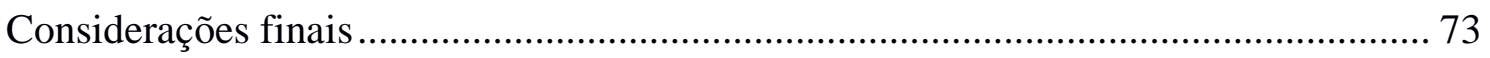

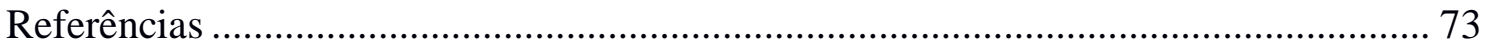


Artigo 3 - Dimensões da avaliação de risco de violência contra mulher na relação íntima

Resumo

Método 85

Resultados e Discussão. 86

Avaliação dos Itens dos Instrumentos 86

(1) Perfil do autor da violência e perfil da vítima. 87

(2) Conflitos interpessoais 88

(3) Violência contra a parceira na presença de outros 89

(4) Uso de álcool e/ou drogas 90

(5) Escalada da violência 91

(6) Intervenção para pessoas em situação de violência 92

(7) Meio de agressão 92

(8) Percepção sobre a violência 94

(9) Experiências de violência na família de origem 95

(10) Filhos de outra relação íntima 95

(11) História Criminal. 95

(12) Separação/divórcio 97

(13) Outras violências. 98

(14) Situação ocupacional. 99 
Artigo 4 - Construção e validação de conteúdo de checklist de avaliação de risco de violência contra parceira íntima.

Resumo

Método

$Q$-sort

Classificação dos itens quanto à subjetividade

Análise dos dados

Resultados

Dados demográficos

Distribuição de Periculosidade

Risco extremo....

Risco grave

Risco moderado

Diferenças de gênero

Diferenças entre profissionais e sociedade civil 
Diferenças entre profissionais psicossociais e profissionais jurídicos e da segurança

Discussão e considerações finais

Referências

Considerações Finais

Anexo 1 - Livre tradução para fins de estudo do instrumento Revised Domestic

Violence Screening Instrument-DVSI-R

Anexo 2 - Livre tradução para fins de estudo do instrumento Spousal Assault Risk

Assessment - SARA

Anexo 3 - Versão em português do instrumento Danger Assessment- DA-R.

Anexo 4 - Checklist de avaliação de risco

Anexo 5 - Fotos de material de apoio usado no $Q$-sort

Anexo 6 - Distribuição dos itens em conformidade com curva normal

Anexo 7 - Tabela com média de periculosidade dos itens

Anexo 8 - Comparação entre grupo de mulheres e grupo de homens 


\section{Apresentação}

\section{Justificativa}

O presente estudo surgiu da experiência acadêmica e profissional da pesquisadora no atendimento a mulheres em situação de violência. Como aluna do Curso de Mestrado do Programa de Pós-Graduação em Psicologia Clínica e Cultura, do Instituto de Psicologia, da Universidade de Brasília, desenvolveu a pesquisa "Violência conjugal: repercussões na saúde mental de mulheres e na de suas/seus filhas/os adultas/os jovens". Este estudo foi de natureza qualitativa, sob a forma de estudo de casos múltiplos exploratórios e objetivou compreender as possíveis repercussões da violência contra a mulher nas relações íntimas na saúde mental de mulheres e na de suas filhas e de seus filhos que cresceram em ambientes familiares marcados pelos conflitos violentos.

A análise dos dados mostrou que determinadas ações da magistratura, decorrentes do entendimento da Lei $n^{0} 11.340 / 2006$, conhecida como Lei Maria da Penha - LMP, foram fator de proteção da saúde mental. Outros eventos de vida, tais como o atendimento inadequado por parte de profissionais que compõem a rede de proteção à mulher em situação de violência e o isolamento social, não contribuíram para a promoção da saúde mental. Também não impediram que violências mais graves ocorressem, mesmo após a busca de ajuda profissional e da separação judicial do casal.

Durante a prática profissional da pesquisadora como psicóloga na rede de atendimento a pessoas em situação de violência, desafios encontrados destacaram a necessidade de ampliar a compreensão sobre como identificar riscos na experiência 
dessas mulheres. Era recorrente a ocorrência de violência, mesmo após a inserção da paciente nessa rede de atendimento. Outra dificuldade encontrada era a falta de parâmetros para identificar e comunicar à paciente a situação de perigo percebida.

A violência sofrida por mulheres em suas relações íntimas não é uma situação somente do âmbito pessoal, mas uma questão da ordem social. Mulheres, em virtude de sua condição feminina, são mais vulneráveis a violências cometidas pelo namorado ou companheiro ao longo de relações de namoro e casamento formal ou informal (Diniz, 1999). Pesquisa realizada pela Organização Mundial de Saúde em conjunto com a London School of Hygiene and Tropical Medicine mostrou que aproximadamente 35\% dos assassinatos de mulheres no mundo todo foram cometidos por parceiros íntimos. Em contraste, apenas 5\% dos assassinatos de homens tiveram como autoras parceiras íntimas (Stöckl et al., 2013).

Essa vulnerabilidade feminina a violências nas relações de intimidade tem relação com a organização social de gênero ligada ao regime patriarcal. No âmbito desse regime, há a hierarquia entre masculino e o feminino com a superioridade dos homens nas relações. Essa desigualdade contribui para a legitimação do uso da violência pelos homens contra mulheres e para a naturalização desse tipo de manifestação (Saffioti, 2004).

A ocorrência de ciclos de violência marcados por reiterados episódios de agressões é característica da violência contra a mulher nas relações de intimidade. Essa reincidência é acompanhada do escalonamento da intensidade e da frequência da violência, podendo resultar em danos psíquicos, em danos físicos e na morte de mulheres (Walker, 1999). O homicídio de mulheres em virtude questões de gênero é chamado de femicídio (Garcia, Freitas, Silva, \& Höfelmann, 2013). As pesquisadoras 
Jane Capute e Diana Russel (1992, p. 15) no texto "Femicide: sexista terrorism against women" definem femicídio como " $[. .$.$] a mais extrema forma de terrorismo sexista, de$ ódio, de desprezo ou de senso de propriedade das mulheres" (livre tradução).

Mesmo com avanços institucionais e legislativos em prol da proteção de mulheres em situação de violência, entraves ainda são encontrados para garantia da segurança delas. Pesquisa realizada pelo IPEA (Cerqueira, Matos, Martins \& Pinto Junior, 2015) mostrou que a implantação da LMP produziu efeitos estatísticos significativos na redução do femicídio, impedindo uma elevação maior nas taxas homicídio de mulheres. Mas a efetividade dessa lei não se deu se forma uniforme, sendo maior nas regiões Sul e Sudoeste. Também não garantiu a segurança de milhares de mulheres, já que de 2006 a 2011 a taxa de homicídio de mulheres ficou entre 4 e 5 (por 100 mil mulheres).

O femicídio e outras formas de violência contra a mulher requerem para seu enfrentamento a ação integrada do sistema de saúde, sistema de Justiça, segurança pública, sistema socioassistencial e sistema educacional. A segurança deve ser tema central no oferecimento de ajuda especializada para mulheres em situação de violência perpetrada por parceiro íntimo. A garantia dessa segurança exige uma árdua atuação dos profissionais da rede de atendimento a pessoas em situação de violência. Faz-se necessário identificar a situação de violência, avaliar o risco, gerir os riscos e punir o agressor (Grams \& Magalhães, 2011). Conforme defende Maria José Santos (2010, p. 49), é:

[...] necessário que após o reconhecimento da situação de violência, do perigo que comporta para os intervenientes e da existência de risco de agravamento, [que] se procurem fatores que possam ajudar a determinar o grau de gravidade dessa 
violência, bem como da probabilidade de que mantenha ou se agrave.

A identificação de riscos e seu manejo têm sido estudados pela comunidade científica sob a forma de avaliação de risco desde a década de 1970 e indicada como uma tarefa que deve ser feita tanto no contexto de serviços de Saúde, quanto no contexto da Justiça (Haggard-Grann, 2007). A combinação de técnicas, com o uso concomitante do julgamento clínico e de instrumentos que apresentem fatores de risco identificados por meio de pesquisa científicas tem-se mostrado eficaz para a avaliação de risco.

No Brasil, há uma ausência de estudos sobre avaliação de risco, o que resulta na escassez de estratégias e de orientações para a população brasileira, estabelecidas com base em pesquisas empíricas. Nesse contexto, justifica-se a realização do presente estudo, que foi orientado pela seguinte questão de pesquisa: como profissionais de segurança e de assistência na rede de atendimento a mulheres em situação de violência consideram o conteúdo dos itens em relação à dimensão de risco?

\section{Objetivos}

\section{Objetivo geral}

O objetivo geral dessa pesquisa é a construção de checklist de avaliação de risco de violência contra a mulher perpetrada pelo parceiro íntimo orientado para a identificação do risco de reincidência e agravamento de violências, com possibilidade de essa violência resultar em ferimentos graves ou ser letal. 


\section{Objetivos específicos}

1. Investigar aspectos relevantes da literatura científica contemplados em instrumentos de avaliação de risco de violência perpetrada pelo parceiro íntimo.

2. Investigar como é realizada a avaliação de risco nos serviços que compõem a rede de atendimento a pessoas em situação de violência.

3. Elaborar uma checklist de avaliação de risco de violência contra mulher perpetrada pelo parceiro íntimo.

4. Verificar a validade de conteúdo da checklist de avaliação de risco, a partir da avaliação de juízes.

\section{Desenho do estudo}

\section{Etapa 1}

A primeira etapa do estudo consistiu na revisão de literatura especializada sobre avaliação de risco nas relações de intimidade. Foi realizada busca em bases de dados eletrônicos, especificamente no Proquest, MedLine, Lilacs. Também realizou-se busca no Google Acadêmico e em sites de órgãos nacionais e internacionais que abordam a temática da violência contra a mulher.

A partir da análise da literatura, identificaram-se os instrumentos Danger Assessment (DA), Revised Domestic Violence Screening Instrument (DVSI-R) e Spousal Assault Risk Assessment (SARA), disponíveis em língua inglesa. Também foi localizada 
uma versão traduzida da DA disponibilizada pela autora. Foi realizada a tradução do DVSI-R e da SARA.

\section{Etapa 2}

Realizou-se um grupo focal com treze participantes e uma entrevista individual para conhecer o campo de avaliação de risco no Distrito Federal e as percepções de profissionais acerca dos conteúdos dos itens dos instrumentos $D A, D V S I-R$ e SARA. Os profissionais que participaram dessa etapa da pesquisa foram selecionados e convidados a participar do estudo durante reuniões mensais de profissionais que atendem mulheres em situação de violência contra a mulher e que objetivavam discutir os casos atendidos pelos no contexto de serviços da rede de atendimento a pessoas em situação de violência.

\section{Etapa 3}

Realizou-se a aplicação de um questionário contendo itens dos instrumentos $D A$, DVSI-R e SARA. Os participantes deveriam assinalar em uma escala do tipo Likert a importância dos itens para uma avaliação de risco. Quinze psicólogos e sete assistentes sociais responderam a esses questionários durante curso de formação em serviço oferecido pela Subsecretária de Assistência Social, no qual a pesquisadora atuou como palestrante. A análise dos questionários demonstrou que os participantes atribuíram valores extremos a todos os itens. Isso dificultou a análise da relevância dos itens e apontou a necessidade de adoção de outra estratégia metodológica. 


\section{Etapa 4}

Foram realizadas entrevistas individuais com seis profissionais da rede de atendimento. Tais entrevistas foram feitas de modo a contemplar profissionais que não participaram da segunda etapa do estudo. Os participantes foram selecionados pela pesquisadora entre sua rede social composta por colegas trabalho ou indicados por eles.

\section{Etapa 5}

Os instrumentos DA, DVSI-R e SARA foram analisados pela pesquisadora. Também foi realizada a análise do grupo focal e das entrevistas individuais. Os dados obtidos embasaram a construção de 100 itens para compor uma checklist de avaliação de riscos.

\section{Etapa 6}

Foi realizada a validação de conteúdo da checklist de avaliação de risco construída. Nesse processo foi utilizada a metodologia Q, com uso do Q-sort (técnica distribuição-Q) para avaliar as percepções e concordância entre os peritos acerca dos itens que compõem a checklist.

Participaram dessa fase do estudo 34 profissionais. Dentre eles, treze foram selecionadas pela pesquisadora dentre sua rede social composta por colegas trabalho, amigos e membros do Núcleo de Estudos de Gênero e Psicologia Clínica (NEGENPSIC) do Laboratório de Estudos em Saúde Mental e Cultura do Instituto de Psicologia da Universidade de Brasília e coordenado pela professora Gláucia Diniz.

Os outros 21 profissionais que participaram dessa fase do estudo foram identificados a partir de reuniões intersetoriais coordenadas pelo Núcleo de Gênero Pró- 
Mulher do Ministério Público do Distrito Federal e Territórios, cujo objetivo era a construção de um projeto de proteção integral à mulher em situação de violência doméstica com diretrizes de avaliação de risco. A pesquisadora foi convidada para participar dessas reuniões por desenvolver o presente estudo de doutoramento. Alguns profissionais que estiveram presentes nas reuniões que ocorreram no mês de novembro e dezembro de 2015 foram convidados a participar dessa fase da pesquisa. Esses participantes fizeram indicações de outros profissionais que na opinião deles deveriam participar do estudo por terem experiência profissional e/ou acadêmica relevante na área de violência contra mulher.

\section{Referências}

Diniz, Gláucia Ribeiro Starling. (1999). Condição Feminina: Fator de risco para saúde mental? In Maria das. Graças da Paz \& Alvaro Tamayo (Orgs.). Escola, saúde e trabalho: Estudos psicológicos (pp.181-197). Brasília: Editora UnB.

Capute, Jane \& Russel, Diana. (1992). Femicide: sexist terrorism against women. In Jill Radfors \& Diana Russell (orgs). Femicide: the politics of woman killing. Ney York: Twayne Publishers.

Cerqueira, Daniel; Matos, Mariana; Martins, Ana Paula Antunes; Pinto Junior, Jony. (2015). Avaliando a efetividade da Lei Maria da Penha. Instituto de Pesquisa Econômica Aplicada: Rio de Janeiro.

Garcia, Leila Posenato; Freitas, Rolim Santana de; Silva, Gabriela Drummond Marques da \& Höfelmann, Doroteia Aparecida. (2013). Violência contra a mulher: feminicídios no Brasil. Disponível em: http://www.ipea.gov.br/portal/images/stories/PDFs/130925_sum_estudo_feminicidio_leilagarcia.p df

Grams, Ana Clara \& Magalhães, Teresa (2011). Violência nas relações de intimidade. Avaliação de Risco. Revista Portuguesa do Dano Corporal, 22, 75-98.

Haggard-Grann, Ulrika. (2007). Assessing violence risk: a review and clinical recommendations. Journal of Counseling and Development, 85 (3), 294-302.

Saffioti, Heleieth I. B. (2004). Gênero, patriarcado, violência. São Paulo: Editora Perseu Abramo.

Santos, Maria José M. Lopes dos (2010). A perícia médico-legal nos casos de violência nas relações de intimidade - contributo para a qualidade. Dissertação de Mestrado, Universidade do Porto, Portugal. 
Avaliação de risco de violência contra a mulher

Stöckl, Heidi; Devries, Karen; Rotstein, Alexandra; Abrahams Naeemah; Watts, Campbell; Moreno, Charlotte Garcia. (2013). The global prevalence of intimate partner homicide: a systematic review. Lancet, 382 (9895), 859-865.

Walker, Leonore E. A. (1999). The Battered woman syndrome (2. ed.). United States of America: Spring Publishing Company. 


\title{
Artigo 1 - Avaliação de risco nas relações de
}

\author{
intimidade
}

\section{Marcela Novais Medeiros}

Apresentado como parte integrante de tese de doutoramento do Programa de Pós-Graduação em Psicologia Clínica e Cultura do Departamento de Psicologia Clínica, Instituto de Psicologia, Universidade de Brasília.

\section{Resumo}

A segurança pessoal é tema central no oferecimento de ajuda especializada para mulheres em situação de violência perpetrada pelo parceiro íntimo. Frente à complexidade do tema, o presente texto discute estratégias de avaliação de risco. A análise da literatura apontou uma mudança de paradigma no processo de avaliação de risco com a crescente valorização de abordagens estruturadas que se baseiam na investigação de fatores de risco identificados por meio de pesquisas científicas. Dentre os instrumentos de avaliação de risco disponíveis na literatura internacional destacam-se a Danger Assessment (DA), a Spousal Assault Risk Assessment (SARA) e o Revised Domestic Violence Screening Instrument (DVSI-R). Independente da estratégia de avaliação escolhida, é preciso capacitação profissional para conduzir avaliações de risco.

Palavras-chave: Avaliação de Risco; Instrumentos; Violência Perpetrada pelo Parceiro Íntimo. 
A segurança é um tema central no oferecimento de ajuda especializada para mulheres em situação de violência perpetrada por parceiro íntimo. A garantia dessa segurança exige uma árdua atuação dos profissionais da rede de atendimento a pessoas em situação de violência. Os desafios encontrados no atendimento a mulheres em situação de violência destacam a necessidade de aprimorar o processo de identificação dos riscos na experiência dessas mulheres, de comunicar com elas sobre a situação de perigo percebida e de acionar mecanismos de proteção para evitar a recorrência de violência após a sua inserção na rede de atendimento a vítimas.

Movimentos feministas e de mulheres no Brasil lutaram ao longo das décadas de 1970 e 1980 para dar visibilidade à vulnerabilidade feminina a violências e para construir políticas públicas em favor da defesa dos direitos fundamentais das mulheres. Essa luta foi basilar para que o Estado brasileiro assumisse o compromisso de enfrentar essa violência por meio da adoção de um conjunto de estratégias para prevenir esse fenômeno, punir autores desse tipo de violência e oferecer assistência às vítimas e aos familiares (Bandeira \& Thurler, 2009; Brasil, 2007; Carneiro, 2003; Griebler \& Borges, 2013; Medeiros \& Puga, 2007; Melo \& Teles, 2003).

A manipulação afetiva, a ameaça de dilapidação do patrimônio, as privações arbitrárias da liberdade, o espancamento e a tentativa de femicídio são atos que podem ser vistos como um continuum de violência que pode variar em grau de severidade e letalidade. Tais ações pertencem a uma mesma linha de atos violentos que podem resultar no óbito. O homicídio pode ser o pior dos resultados em situações de violência nas relações íntimas (Garcia, Freitas, Silva \& Höfelmann, 2013; Grams \& Magalhães, 2011). Em alguns casos, a escalada de violência pode resultar na morte de ambos os 
parceiros, sob a forma de homicídios seguidos de suicídios (Grams \& Magalhães, 2011; Teixeira, 2009).

O homicídio de mulheres é denominado, nos estudos de gênero, como femicídio. Esse termo foi cunhado para diferenciar os assassinatos femininos dos masculinos e destacar que a maioria das mortes de mulheres tem íntima relação com a lógica sexista marcada pela apropriação dos corpos das mulheres e pelo exercício da dominação masculina. Analba Teixeira (2009) alerta que os homens que cometem femicídio contra suas companheiras não são considerados perigosos para a sociedade. Esse tipo de crime compreendido nas décadas de 1970 e 1980 como crimes motivados pela defesa da honra, são, frequentemente, entendidos pelos juristas e pela sociedade civil na atualidade como ação motivada por emoção violenta. Este processo decorre da ideia de posse, poder e controle sobre a mulher.

Pesquisas revelam a alta ocorrência de femicídio no Brasil. A pesquisa realizada pelo Instituto de Pesquisa Econômica Aplicada (IPEA) mostra que, nos anos de 2009 a 2011, foram registrados 13.071 femicídios no Sistema de Informações sobre Mortalidade do Ministério da Saúde (Garcia, Freitas, Silva \& Höfelmann, 2013). O relatório "Mapa da violência 2012 - Atualização: homicídio de mulheres no Brasil" (Waiselfisz, 2012a) revela que, entre os anos de 1980 e 2010, houve 91 mil homicídios de mulheres. No ano de 1980, a taxa de homicídio foi de 2,3 para cada 100 mil mulheres, enquanto que em 2010 esse número aumentou para 4,6 óbitos por 100 mil habitantes. Esse estudo demonstrou, ainda, que, no ano de 2011, o lar foi o ambiente de maior risco de violência física para mulheres e que o principal agressor era parceiro íntimo atual ou passado. Estes dados alertam para os riscos vivenciados por mulheres em suas relações afetivas. O escalonamento da violência é fato conhecido no sistema de 
proteção e carrega o potencial de um desfecho letal. Jacquelyn Campbell e colaboradores (2003) apontam que grande parte dos femicídios de mulheres por parte de seus parceiros íntimos ocorreu em um relacionamento marcado por reiteradas violências físicas.

A relevância de se estudar modelos de avaliação e identificação do risco pode ser constatada a partir do fato de que a maior parte das mulheres indicadas para o sistema de proteção já passou ou ainda está em situação de violência conjugal, e frequentemente sofre com a reincidência de atos de violência nas relações íntimas. Um estudo de fatores preditivos da reincidência de violência contra a mulher nas relações íntimas pode contribuir para a avaliação realizada por profissionais da assistência no trabalho de proteção a essas mulheres. Pode também favorecer o desenvolvimento de políticas públicas para proteção das vítimas. Do ponto de vista institucional, pode favorecer a escolha do modelo de avaliação mais adequado para as necessidades de cada serviço. Do ponto de vista pessoal das mulheres, o processo de elaboração durante a avaliação do risco pode favorecer o reconhecimento dos fatores preditivos da reincidência da violência e a conscientização das vítimas, assim diminuindo o impacto da tendência a subestimar ou minimizar o risco e facilitando a mobilização de recursos protetivos pessoais, interpessoais, institucionais e sociais.

Meios válidos de estimar o risco de reincidência de violência são necessários para aumentar a probabilidade de sucesso de estratégias de proteção dessas mulheres. Frente à complexidade do tema, o presente texto apresentará alguns fundamentos das estratégias estruturadas e não estruturadas de avaliação de risco. Três instrumentos entre os mais importantes da abordagem estruturada serão detalhados para exemplificar. Também teceremos considerações sobre a capacitação profissional requerida para uso 
desses instrumentos. Neste texto, não serão abordados os instrumentos que objetivam avaliar o risco de sofrer outras formas de violência, tais como: violência coletiva ou extrafamiliar ou violência doméstica diversa da violência entre parceiros íntimos.

A avaliação de risco é um “(...) processo de recolha de informação, acerca das pessoas envolvidas, para tomar decisões de acordo com o risco de reincidência da violência" (Almeida \& Soeiro, 2010, p. 180). Em outras palavras, faz referência ao "registro detalhado de informações para fazer essas valorações de risco" (Acosta, 2013, p. 17, livre tradução). Envolve técnicas de predição de violência para estimar a possibilidade de comportamentos violentos (Andrés-Pueyo \& Echeburúa, 2010). A avaliação de risco é uma atividade que permite o reconhecimento do perigo existente, a promoção da conscientização de pessoas envolvidas (Santos, 2010) e a intervenção adequada para evitar ou extinguir o risco (Andrés-Pueyo \& Echeburúa, 2010; Santos, 2010). Pode ser utilizada como técnica complementar aos tratamentos já dispensados a vítimas e autores de violência em ambientes assistenciais e jurídico-criminais (AndrésPueyo \& Echeburúa, 2010).

\section{Desenvolvimento do Campo}

As avaliações de risco de violência tiveram suas origens no âmbito da Psiquiatria (Campbell, 2005). A Psiquiatria Forense, desde os seus primórdios, interessou-se pelo estudo da personalidade dos criminosos e pelo comportamento violento apresentado por pessoas com transtorno mental. No antigo regime francês, a Medicina aproximou-se da Justiça, no intuito de legitimar práticas, sancionadas pelo Judiciário, de internação de indivíduos considerados loucos (Arantes, 2004). A partir do século XX, a associação entre transtorno mental e crime passou a ser investigada de forma cada vez mais minuciosa e ponderada. Foi nesse contexto que foram 
desenvolvidos instrumentos de investigação de periculosidade, que era entendida como a inclinação de uma pessoa para emitir atos violentos (Abdalla-Filho, 2012).

Estudos subsequentes da Psiquiatria e da Psicologia Criminológica demonstraram que o conceito de periculosidade pouco contribuía para o entendimento da reincidência criminal, por partir do pressuposto de que características fixas e permanentes de um indivíduo, somadas a seus antecedentes, causavam o comportamento violento (Andrés-Pueyo \& Echeburúa, 2010). A classificação em níveis de risco, a partir da investigação de fatores de risco biopsicológicos e contextuais, bem como o uso do conceito de perigo como um risco iminente, vieram a substituir a concepção binária que classificava a pessoa, e não a situação, em periculosa ou não periculosa. A diferença proposta é que a classificação de risco considera uma grande complexidade de fatores, individuais e sociais de homens e de mulheres e pode admitir variações em um contínuo. Fatores de risco neste contexto são elementos individuais, sociais e contextuais que aumentam a probabilidade de ocorrer um ato violento (Herboso et al., 2012). O conceito de risco é mais abrangente e demonstra preocupação tanto com a investigação de elementos relacionados à violência, quanto com a gestão do risco em níveis ambientais e individuais, a curto, médio e longo prazo (Acosta, 2013).

$\mathrm{Na}$ atualidade, as avaliações de risco em casos de violência contra a mulher, junto com as avaliações de supostos psicopatas e pedófilos, destacam-se no campo de avaliação de risco à violência (Abdala-Filho, 2012). Diferentemente dos demais tipos de avaliação, a avaliação de risco de violência sofrida por mulheres nas relações de intimidade confere menor ênfase à questão da doença mental como fator de risco (Campbell, 2005). Contrário ao senso comum na cultura, ter uma doença mental não é um elemento central para cometer violência contra a parceira íntima (Abdala-Filho, 
2012). Nossa sociedade ainda é francamente marcada por relações hierárquicas entre homens e mulheres, pela defesa da honra masculina em função do comportamento feminino e pela banalização da violência. Os processos de socialização nessa cultura patriarcal, com seus elementos relacionados à desigualdade de gênero, são mais relevantes para o entendimento dos riscos. Tais fatores sociais e culturais favorecem a ocorrência da violência contra as mulheres nas relações afetivas (Bandeira, 2009). Existem, portanto, diferenças entre as violências sofridas por mulheres e aquelas vivenciadas por homens. As mulheres são mais vulneráveis a violências ocorridas em ambientes domésticos e cometidas por pessoas conhecidas, enquanto os homens são mais vulneráveis nos espaços públicos e vítimas da violência cometida por desconhecidos (Schraiber et al., 2005; Waiselfisz, 2012b).

A vulnerabilidade feminina à violência perpetrada pelo parceiro íntimo reforça a importância da ampliação do conhecimento sobre as experiências de vida de mulheres vítimas que buscam ajuda na rede de proteção às mulheres em situação de violência conjugal. Maria José Santos (2010, p. 49), pesquisadora de avaliação de risco em psicologia jurídica, defende que é

[...] necessário que após o reconhecimento da situação de violência, do perigo que comporta para os intervenientes e da existência de risco de agravamento, [que] se procurem fatores que possam ajudar a determinar o grau de gravidade dessa violência, bem como da probabilidade de que se mantenha ou se agrave.

É fundamental desenvolver estudos que indiquem os fatores efetivos na identificação do risco de reincidência de violências. Tais estudos serviriam de base para a construção de instrumentos e procedimentos que possam contribuir para a promoção da segurança de mulheres atendidas em instituições de Segurança Pública, de Saúde, de Justiça, de Assistência Social e da Educação. 


\section{Estratégias de avaliação de risco}

O campo de avaliação de risco nas relações de intimidade favorece a avaliação estruturada em contraste com a avaliação não estruturada (Acosta, 2013; Andrés-Pueyo \& Echeburúa, 2010; Grams \& Magalhães, 2011; Nicolls, Pritchard, Reeves \& Hilterman, 2013). Essa classificação segue a nomenclatura utilizada no campo da avaliação da violência potencial de homens e de mulheres que cometeram os diversos crimes da violência doméstica e familiar.

A avaliação clínica de caráter não estruturado é aquela que se baseia na adoção de procedimentos informais para a classificação de risco. O profissional utiliza sua intuição, seu julgamento, sua experiência profissional, sua observação e coleta de dados para a estimar a probabilidade de ocorrência da violência em cada caso individual (Acosta, 2013; Grams \& Magalhães, 2011; Litwack, 2001; Nicolls et al., 2013, Tavares, 2000a). Não há diretrizes, nem protocolos, nem formalização de processos ou de fatores de risco específicos para basear a avaliação (Acosta, 2013; Grams \& Magalhães, 2011; Nicolls et al., 2013; Singh, Grann, \& Fazel, 2011). Não existem instrumentos padronizados associados a esta forma de avaliação. Esse método é de pouca confiabilidade por ser facilmente enviesado pelas características do entrevistador relacionadas a sua subjetividade, como variáveis associadas a gênero e sua experiência na área (Singh et al., 2011; Grams \& Magalhães, 2011). A baixa confiabilidade desse tipo de entrevista a torna insuficiente para modelos de pesquisa e oferece pouco suporte para o desenvolvimento de modelos de prevenção da violência (Nicolls et al., 2013).

As abordagens de avaliação estruturada visam a majorar a precisão da estimativa da possibilidade de reincidência de violência por meio do aprimoramento de regras explícitas na articulação de fatores de risco (Nicolls et al., 2013). As estratégias 
estruturadas utilizam protocolos ou recursos padronizados que favorecem a cobertura ampla e completa dos quesitos relevantes na avaliação de risco. Entre seus procedimentos pode-se realizar a consulta aos registros criminais, médicos ou judiciários e requerer informações diretamente das vítimas e outros informantes, por meio de questionários, escalas, inventários ou entrevistas. Quando associada à entrevista, visa a oferecer uma descrição da história dos envolvidos e de seus comportamentos que têm relação com o que se pretende prever (Tavares, 2000b).

Existem vantagens importantes do uso de instrumentos e procedimentos de avaliação de risco pelas abordagens estruturadas, apesar de algumas críticas que lhes são atribuídas (Haggard-Grann, 2007; Williams \& Houghton, 2004; Singh et al., 2011). Por estes instrumentos envolverem algum tipo de padronização, seja na forma de escalas, questionários, inventários ou modelos de entrevistas, seus resultados apresentam mais consistência e fidedignidade do que as abordagens não estruturadas. Consequentemente, esta abordagem tende a produzir mais impacto e resolutividade dos atendimentos de casos nos serviços de proteção à mulher.

Esse tipo de avaliação pode utilizar um modelo estatístico para prever a probabilidade de reincidência de violência. Quando modelos estatísticos são utilizados, a previsão é feita a partir de itens preditores, pela quantidade de fatores de risco identificados e de pesos atribuídos a eles. Dados de pesquisas sobre fatores de riscos de reincidência são utilizados para a construção de fórmulas que oferecem a probabilidade de ocorrência de violências (Grams \& Magalhães, 2011; Nicolls et al., 2013). Dessa maneira, as avaliações são feitas com base em relação explicitada entre preditores mensuráveis e variáveis dependentes, oferecendo peso para escores (Campbell, 2005; Litwack, 2001). Este modelo requer o teste empírico da capacidade preditiva dos itens 
em situações reais, num processo de validação dos mesmos para a predição do comportamento violento em uma determinada cultura. $\mathrm{O}$ avaliador, ao usar instrumento padronizado, do tipo escala, questionário ou inventário deve, conforme apontam Nicolls e colaboradores (2013), indicar quais fatores de riscos estão presentes, ausentes ou são irrelevantes. Ao final dessa ação, aplica-se regras para a obtenção de um escore que deve levar a uma estimativa do risco envolvido.

A abordagem clínica estruturada é um tipo de avaliação desenhada em respostas às limitações da avaliação baseada exclusivamente em resultados obtidos a partir de estatísticas normativas (Nicolls et al., 2013). Idealmente, ela deve ser um guia ou protocolo que oferece orientações gerais sobre como conduzir a avaliação de risco, como comunicar os resultados e como gerenciar os riscos (Andrés-Pueyo \& Echeburúa, 2010; Campbell, 2005). A classificação de risco nesse tipo de avaliação é "uma decisão tomada sem regras fixas e explícitas, mas com base, pelo menos em parte, na consideração de informações padronizadas" (Kropp \& Hart, 2000, p. 102). É uma forma de avaliação que requer tanto a apreciação clínica do avaliador, quanto a análise de fatores de risco específicos descritos na literatura e que foram testados empiricamente (Grams \& Magalhães, 2011; Singh et al., 2011; Webster, Haque, Hucker, 2013). Estes fatores devem ser avaliados quanto à sua presença ou ausência, para que os riscos possam ser mais bem compreendidos (Acosta, 2013), mas a classificação em níveis de risco, como por exemplo, risco moderado, grave e extremo, não é baseada em um escore final. Ou seja, pode utilizar, mas não se limita, a informações ou instrumentos padronizados. Cabe ao avaliador fazer essa classificação final considerando a totalidade das informações investigadas pelos instrumentos bem como informações adicionais consideradas relevantes em cada caso específico (Nicolls et al., 2013). 
Diferentes instituições e serviços vinculados ao sistema de proteção têm características e necessidades particulares. Cada modelo de avaliação pode ser mais útil a depender da necessidade dos serviços, das características dos profissionais e do tipo de treinamento que eles possuem. A abordagem baseada exclusivamente em procedimentos estatísticos, por ser uma avaliação estruturada com base em procedimentos padronizados e operações fixas, pode ser mais facilmente utilizada por profissionais com pouco treinamento em técnicas de entrevista clínica. Alguns instrumentos podem ser preenchidos e contabilizados pela própria vítima. Por outro lado, a abordagem clínica estruturada, com o uso da entrevista, é um tipo de avaliação que investiga, além de aspectos objetivos e observáveis, aspectos pessoais e subjetivos e requer que uma apreciação clínica da situação seja realizada por um profissional suficientemente treinado. Estratégias intermediárias entre estes dois extremos podem ser desenvolvidas, pela associação de escalas padronizadas a diferentes tipos de entrevistas, realizadas por profissionais sem treinamento clínico - por exemplo, por um policial. Estas estratégias intermediárias podem atender necessidades específicas de diferentes instituições ou serviços no sistema de proteção.

\section{Principais Instrumentos de avaliação de Risco}

Os instrumentos estruturados mais frequentemente citados na literatura são: a Danger Assessment (DA), o Revised Domestic Violence Screening Instrument (DVSI-R), a Spousal Assault Risk Assessment (SARA), a Ontario Domestic Assault Risk Assessment (ODARA), o Brief Spousal Assault Form for the Evaluation of Risk (B-SAFER), e a Escala de Predicción del Riesgo de Violência Grave Contra la Pareja, Revisada (EPV-R). Apresentaremos os três primeiros entre estes instrumentos de avaliação de risco - a DA, o DVSI-R e a SARA. Eles foram selecionados por terem 
sido alvo de discussão de diversos estudos (Acosta, 2013; Almeida \& Soeiro, 2010; Andrés-Pueyo \& Echeburúa, 2010; Code \& La, 2009; Echeburúa, Amor, Loinaz, \& Coral, 2010; Grams \& Magalhães, 2011; Haggard-Grann, 2007; Nicolls et al., 2013). Estes três instrumentos têm sido utilizados por profissionais da rede de atendimento a pessoas em situação de violência nos Estados Unidos e no Canadá, e também passaram pelos devidos processos de tradução, adaptação cultural e padronização em países como Espanha e Portugal. Segue a descrição e discussão sobre cada instrumento.

\section{Danger Assessment (DA)}

Jaqueline Campbell publicou, em 1986, nos Estados Unidos, a primeira versão da escala Danger Assessment (DA), um instrumento padronizado para uso clínico e de pesquisa. A DA tem o objetivo de identificar o risco de homens e de mulheres sofrerem homicídio em relações íntimas heterossexuais (Campbell, 2005; Campbell, Webster \& Glass, 2009). Os itens foram construídos a partir da experiência da autora, da revisão da literatura sobre fatores de risco de violência grave e de homicídio nas relações de intimidade, bem como a partir da consulta a mulheres abrigadas e profissionais que trabalham em abrigos (Campbell, 2005; Campbell et al., 2009). Em 2003, a DA foi revisada em pesquisa realizada em onze cidades dos EUA, com uso da estratégia de caso controle (Campbell, Webster, Koziol-McLain \& Block et al., 2003).

Na primeira versão da DA, o escore era obtido por meio da soma do número de respostas do tipo "sim" e não havia nota de corte. Quanto maior o número de "sins", maior a presença de fatores de risco de homicídio ou de a mulher ser gravemente ferida. 
$\mathrm{Na}$ versão revisada, algoritmos ${ }^{1}$ com escores ponderados foram associados a quatro níveis de risco: perigo variável, com escore entre 0 a 7; perigo aumentado, com escore entre 9 a 13; perigo grave, com escore entre 14 a 17; e perigo extremo, com escore igual ou maior que 18 (Campbell et al., 2009).

A primeira parte da DA possibilita o acesso à frequência e à severidade da violência sofrida. Consiste em um calendário, no qual a vítima deve marcar em datas referentes ao último ano, a gravidade do incidente de violência física sofrida, conforme a seguinte escala: 1. Tapas, empurrões, sem ferimento e/ou dor presente; 2 . Perfurações, chutes, socos, cortes, e/ou dor presente; 3. "Surra", contusões graves, queimaduras, ossos quebrados; 4. Ameaça de uso de armas, ferimentos na cabeça, ferimentos internos, ferimentos permanentes; 5. Uso de armas, ferimento decorrente do uso de armas (Campbell, 2004; Campbell et al., 2009).

A segunda parte da DA é composta por itens que devem ser respondidos com “sim" ou "não". Neles, são descritos fatores de risco relacionados à vítima, ao agressor e à dinâmica da relação. Só depois de preencher o calendário é que a mulher responde a esses itens. Essa estratégia facilita a diminuição da minimização e da negação e favorece a reelaboração da mulher sobre o nível de risco (Campbell, 2001; Campbell et al., 2009; Webster et al., 2013). Após o preenchimento pela mulher, com ou sem a ajuda de um profissional, ela deve conversar sobre os resultados com um profissional capacitado (Webster et al., 2013). função de um algoritmo é explicitar um processo complexo de avaliação, julgamento e decisão para que ele possa ser realizado com fidelidade. 


\section{Revised Domestic Violence Screening Instrument (DVSI- R)}

O Revised Domestic Violence Screening Instrument (DVSI-R) é uma forma de avaliação padronizada que avalia o risco de reincidência e de agravamento de qualquer tipo de violência doméstica e não somente violência perpetrada por parceiro íntimo. Ele foi projetado para ser uma breve avaliação preenchida por profissionais da justiça, a partir das informações contidas na ficha criminal de autores de violência contra a parceira íntima (Webster et al., 2013). A versão original do DVSI-R foi desenvolvida no Colorado, Estados Unidos, pelo Colorado Departament of Probation Services com a participação de profissionais e de pesquisadores da área da violência doméstica (Campbell, 2005; Williams \& Houghton, 2004). Sua revisão ocorreu em 2000, resultando em um instrumento com onze itens que abordam a história de violência passada e atual contra a parceira e outros comportamentos do autor da violência (Williams \& Houghton, 2004).

Cada item deve ser classificado em uma escala com variações distintas, dependendo do tipo do item. Alguns têm por critério a frequência de ocorrência de eventos, outros têm por critério a temporalidade do evento (atual ou passado) ou a variação em alguma qualidade (por exemplo, status laboral ou severidade do abuso). Dos pesos e critérios aplicados aos onze itens resulta um escore final de risco pontuado entre 0 a 28 (Williams \& Grant, 2006). Quanto maior a pontuação, estima-se que é maior o risco de reincidência. Este escore fundamenta uma decisão final do profissional em dois quesitos, pontuados como risco "baixo", "moderado" ou "alto". Estes quesitos são: "iminente perigo de violência contra a vítima" e "iminente perigo de violência contra outros". Casos com descumprimento de ordem judicial ou outro tipo de 
supervisão durante o incidente da violência, presença de armas, crianças presentes durante a violência recebem maior categorização.

\section{Spousal Assault Risk Assessment (SARA)}

A Spousal Assault Risk Assessment (SARA) é uma forma de avaliação profissional estruturada desenvolvido na década de 1990 por Kropp, Hart, Webster, e Eves no Canadá (1994, 1995, 1998 citado por Kropp \& Gibas, 2010). Seu objetivo é avaliar o risco de reincidência e agravamento de violências perpetradas pelo parceiro íntimo, considerando qualquer relação afetiva sexual, mesmo aquelas nas quais os parceiros não têm vínculo formal. Pode ser aplicado tanto para relações heteroafetivas quanto para homoafetivas, independente do sexo da pessoa agressora. A SARA contém um protocolo ou guia com orientações sobre como proceder à avaliação do risco. Este guia é composto por: sugestões de treinamento para os avaliadores; informações que subsidiam a avaliação de risco; lista com vinte fatores de risco que devem ser considerados durante a avaliação; e orientações sobre como registrar e informar os resultados (Kropp \& Hart, 2000).

Três critérios foram utilizados para incluir um fator de risco na lista da SARA, Estes fatores devem: (1) ser capaz de discriminar casos nos quais houve intensa violência entre os parceiros íntimos; (2) estar relacionado à reincidência de violência entre parceiros íntimos; (3) ser um fator de risco recomendado em manuais de avaliação de risco de violência perpetrada pelo parceiro íntimo (Kropp \& Gibas, 2010). Os fatores presentes nesta lista da SARA podem ser divididos em dois grandes eixos. No primeiro, são abordados fatores de risco geral nas sessões sobre história criminal e ajustamento psicossocial. No segundo, estão os fatores de risco relacionados à violência perpetrada por parceiro íntimo, à história de violência contra a parceira e à ofensa mais recente. Há 
também uma sessão para o avaliador colocar fatores de risco presentes no caso particular que não são contemplados pela lista de fatores de risco da SARA.

A SARA foi pensada para ser usada no contexto da justiça, e pode ser aplicada por qualquer profissional com treinamento adequado. Os autores sugerem, todavia, que a avaliação deve englobar a participação de um profissional da saúde mental, por conter itens que requerem a identificação de transtorno mental. A avaliação é conduzida com informações obtidas em registros e por meio de entrevistas. As informações obtidas de registro incluem arquivos com os relatos das vítimas ou testemunhas, história de violência e antecedentes criminais. As entrevistas com a vítima, com o autor, com crianças ou com outras pessoas próximas devem ser conduzidas como forma de complementar as informações disponíveis nos registros (Kropp \& Hart, 2000; Nicolls et al., 2013; Santos, 2010).

A SARA não tem o seu resultado final baseado em um escore (Kropp \& Hart, 2000), embora a presença dos fatores de risco gere um escore. É a partir do julgamento do avaliador que o caso será classificado em risco baixo, moderado ou alto. Ou seja, o escore deverá ser considerado junto com outros elementos identificados pelo avaliador a partir de seu julgamento clínico. Aspectos relevantes da situação que não constam na lista de fatores de risco podem ser registrados e codificados em uma categoria chamada de itens críticos. Alguns exemplos desses itens sugeridos no manual da SARA são: crises emocionais sem sintomas psicóticos ou maníacos mas que necessitaram de intervenção psiquiátrica, comportamento sádico, perseguição (stalking), perda de suporte de rede social (Kropp, Hart, Webster \& Eaves, 1999). Há recomendação feita pelos autores de que alguns aspectos da situação devem ser classificados especificamente como alto risco, mesmo se o escore for baixo. Esses itens são: uso de 
facas e ciúme patológico (Nicolls et al., 2013). Esta observação é coerente com o conceito de validade clínica ao aplicar o julgamento profissional na avaliação visando a melhor contextualização e validade da decisão final (Tavares, 2004).

\section{Similaridades e diferenças entre os DA, DVSI-R e SARA}

O DVSI-R e a SARA são ferramentas elaboradas para serem preenchidas pelo profissional no contexto da justiça e abordam a possibilidade de reincidência com enfoque no agravamento da violência em seus diversos níveis. ADA foi construída para ser usada em qualquer atendimento da mulher em situação de violência pode ser preenchida pela vítima ou pelo profissional. Ela é o único entre estes instrumentos que pretende prever a possibilidade de femicídio. Nenhum desses instrumentos envolve, necessariamente, o contato entre profissional e vítima. No entanto, a DA deve ser preferencialmente preenchida pela vítima com assistência de um profissional, que tem a oportunidade de favorecer a conscientização do risco. A SARA pode ser preenchida somente a partir dos registros, embora a entrevista seja fortemente indicada para avaliar fatores clínicos e subjetivos. O DVSI-R não faz referências a entrevistas ou contato com a vítima e é geralmente preenchido diretamente a partir de registros. Apesar das diferenças entre estes instrumentos, eles são considerados de extrema utilidade para orientar decisões judiciais e policiais.

O DVSI-R e o DA são instrumentos cujos resultados da avaliação estão embasados prioritariamente em modelos estatísticos. Não há consenso na literatura sobre se esse método oferece resultados mais precisos e adequados do que as demais abordagens. Aqueles que criticam esse modelo destacam que, embora esse tipo de avaliação ofereça uma probabilidade estatística de recidiva, está centrada em fatores estáticos que dificilmente podem ser alterados (Grams \& Magalhães, 2011) e por isso 
não contribui para a elaboração de intervenções (Haggard-Grann, 2007). Outra limitação destacada por críticos é que as normas usadas nos cálculos estatísticos são para a população na qual os estudos foram realizados. Para sujeitos que não pertençam a tal grupo, os dados não devem ser usados sem avaliar o risco de, ao fazê-lo, tanto exagerar quanto subestimar o risco (Grams \& Magalhães, 2011).

A SARA é o único entre estes instrumentos que incluiu o julgamento clínico como elemento central. Esse tipo de avaliação, segundo Grams e Magalhães (2011), também recebeu críticas e apontamentos, por ter resultados piores quando comparados às avaliações centradas em cálculos estatísticos. Além disso, quando avaliadores diferentes repetem a avaliação de um mesmo caso, há maiores divergências nos resultados. Em parte, isso pode ser corrigido pelo treinamento, mas o resultado final ainda irá depender, em certa medida, das habilidades e da experiência do profissional que avalia.

É consenso na literatura e nosso entendimento que tanto o uso de instrumentos como DVSI-R e DA quanto o da SARA requerem algum nível de julgamento clínico. O DVSI-R, que é preenchido com base na ficha criminal, requer o julgamento durante a leitura dos registros. A DA, que pode ser preenchida pela mulher sozinha, requer que ela converse com o profissional que utiliza o julgamento clínico para ajudá-la a interpretar os resultados. A SARA requer o julgamento clínico na interpretação de registros e na realização de entrevistas.

A avaliação de risco feita por meio de instrumentos leva em conta tanto dados objetivos (estatísticos) quanto subjetivos (avaliação clínica feita por profissional treinado) (Williams \& Houghton, 2004). Algoritmos oferecem procedimentos e regras lógicas para avaliação e tomada de decisão relacionados às situações de alto e de baixo 
risco que devem ser investigados pelo clínico (Haggard-Grann, 2007), o que exige do profissional uma boa prática clínica (Litwack, 2001).

\section{Qual a Melhor Forma de Avaliar Riscos?}

Os instrumentos de avaliação de riscos DA, DVSI-R e SARA são referências importantes na avaliação de risco de reincidência de violência em relações íntimas. Não passaram, no entanto, por processo de adaptação e de validação para a cultura brasileira. Tais instrumentos tiveram seus itens formulados com base na identificação de fatores de risco presentes nas sociedades americana e canadense. Suas propriedades psicométricas foram investigadas em amostras da população dos seus países de origem. O uso desses instrumentos no Brasil requer que eles passem por procedimentos de tradução, adaptação cultural e validação.

No Brasil, a avaliação de risco ainda é predominantemente não estruturada. Os profissionais geralmente se orientam pela experiência com casos específicos e, com base nela, fazem predições em novos casos. Há, em nosso meio, uma ausência de estudos sobre avaliação de risco, o que resulta na escassez de estratégias e de orientações na forma de protocolos ou procedimentos padronizados, estabelecidos com base em pesquisa empíricas, a partir dos quais seja possível tomar decisões de modo adequado à população brasileira.

Tonia Nicolls e colaboradores (2013) destacam que a escolha do tipo de avaliação deve levar em conta o contexto, os recursos disponíveis e o treinamento do profissional. Cada avaliador deve escolher aquele método mais adequado ao contexto de trabalho e aos dados disponíveis (Grams \& Magalhães, 2011). Jay Singh e colaboradores (2011) também enfatizam que os avaliadores devem concentrar seus 
esforços em identificar medidas que possam predizer a violência em populações específicas. Quanto mais características demográficas a pessoa avaliada tiver em comum com a população testada, maior a contextualização sociocultural, e maior a probabilidade de acerto.

A escolha do método de avaliação de risco deve levar em conta que esta é uma tarefa que pode ser realizada por todos os profissionais que atendem mulheres em situação de violência perpetrada por parceiro íntimo (Campbell, 2001). Entretanto, cada um deve escolher uma estratégia adequada à sua formação e a sua área de atuação, ou buscar treinamento para o uso dos instrumentos necessários ao exercício de sua atividade. Instrumentos, como a DA ou o DVSI-R, podem ser utilizados por profissionais da rede especializada no atendimento a pessoas em situação de violência, entre os quais advogados, médicos, enfermeiros e psicólogos. Algumas avaliações, contudo, exigem conhecimento específico da área da saúde mental como, por exemplo, a SARA. Psicólogos e psiquiatras, com experiência na área de avaliação, são os mais aptos para usarem estratégias complementares, como entrevista clínica, exame do estado mental e testes psicológicos, para favorecer o entendimento desses aspectos.

Por outro lado, nem todos os psicólogos e psiquiatras estão habilitados para realizarem avaliações de risco de violência. É preciso oferecer treinamento e refinamento das estratégias utilizadas por estes profissionais, levando em consideração o conhecimento da legislação criminal e civil, de pesquisas baseadas em evidências e das teorias psicológicas relacionadas. Ao longo da prática profissional, devem também: buscar atualização constante; ressaltar as forças e as capacidades das vítimas; trabalhar em equipe; elaborar plano para situações de crise; buscar atuação organizacional para subsidiar ações individuais; estabelecer protocolos para troca de informações entre 
instituições sobre a vítima; detalhar e informar possíveis desfechos esperados (Webster, Haque \& Hucke, 2013).

Avaliações realizadas por diversos profissionais podem ter estrutura, complexidade e funções diferentes. Um mesmo profissional pode se deparar com a tarefa de realizar avaliações diferentes dependendo das demandas que geraram a avaliação. Maria Hermoso e colaboradores (2012) ressaltam que um psicólogo forense, ao ser chamado para fazer uma avaliação emergencial, dada a limitação de tempo, não terá condições de fazer uma análise exaustiva dos casos por meio de investigação de registro policiais, entrevistas com informantes significativos, aplicação de testes e outras técnicas clínicas que favoreçam a compreensão da dinâmica interacional. Neste contexto, muitas vezes, torna-se necessário focalizar fatores de risco relacionados à violência física iminente. Posteriormente, uma análise exaustiva do caso deve ser realizada.

\section{Considerações Finais}

Discutimos brevemente a importância e os tipos de avaliação para em seguida apresentar a necessidade e relevância da inclusão de modelos de avaliação de risco no contexto do atendimento a mulheres em situação de violência em relações íntimas. As estatísticas apontam a gravidade da situação, o aumento desse tipo de violência e o desfecho trágico que põe fim à vida de muitas mulheres. Apresentamos também alguns dos instrumentos que tem sido usados em contextos de violência em vários países do mundo. A intenção foi identificar e discutir estratégias de avaliação de risco de violência contra a mulher nas relações de intimidade, tendo em vista a vulnerabilidade feminina à violência nas relações íntimas. 
Este levantamento deixa claro uma mudança de paradigma no processo de avaliação de risco com a crescente valorização de abordagens estruturadas que se baseiam na investigação de fatores de risco identificados por meio de pesquisas científicas. A avaliação de risco é indicada como uma tarefa necessária que deve ser realizada nos serviços que compõem a rede especializada no atendimento a pessoas em situação de violência a fim de identificar os riscos e fazer o seu manejo.

O emprego de abordagens estruturadas, que podem ter os resultados da avaliação baseados em procedimentos estatísticos ou na combinação destes com o julgamento clínico de quem avalia, exige, além da capacitação profissional para a condução de avaliação de risco, o investimento em pesquisas empíricas sobre os fatores de risco e sua relação com a reincidência da violência. Somente assim seria possível o desenvolvimento de instrumentos de avaliação de risco adequados à cultura brasileira e o incremento dessa abordagem na prática de profissionais nos serviços de proteção em nosso meio. Estamos empenhados em desenvolver uma estratégia de avaliação de risco empiricamente construída para uso no Brasil a partir do análise desses instrumentos (DA, DVSI-R e SARA), e de uma avaliação contextualizada de fatores culturais e institucionais por meio da coleta de opinião junto a profissionais da rede de atendimento a pessoas em situação de violência no Distrito Federal.

No Brasil, é evidente a carência de pesquisa com o objetivo de desenvolver a área de avaliação de risco de violência contra a mulher perpetrada pelo parceiro íntimo. Este objetivo deve ser orientado para a identificação e manejo do risco de reincidência e agravamento de violências, com vistas a impedir que essa violência resulte em ferimentos graves ou letais. O reconhecimento das dificuldades cotidianas de profissionais que atuam nos serviços de assistência e proteção a pessoas em situação de 
violência deveria ser suficiente para mobilizar profissionais e acadêmicos para investir esforços nesta direção. O estudo das estratégias e instrumentos de avaliação de risco de reincidência de violência, a construção de uma checklist de avaliação de risco de violência contra mulher perpetrada pelo parceiro íntimo e a verificação da validade de seu conteúdo são primeiros passos nesta direção. A construção de um instrumento para este fim deverá ter em mente as particularidades do contexto brasileiro, sua cultura e as características de suas instituições e serviços. Nossa intenção, ao problematizarmos a importância da avaliação de risco e ao oferecermos parâmetros para seu desenvolvimento, é caminhar nessa direção.

\section{Referências}

Abdala-Filho, Elias (2012). Avaliação de Risco. In José G. V. Taborda, Elias Abdala-Filho \& Miguel Chalub (Orgs.), Psiquiatria Forense (pp. 183-204). Porto Alegre: Artmed.

Acosta, Miguel Lorente (2013). La valoración médico-forense del Riego en la violencia de género.

Predicción y prevención. Retirado de: http://www.poderjudicial.es/stfls/CGPJ/OBSERVATORIO\%20DE\%20VIOLENCIA\%20DOM\% C3\%89STICA/OTRAS\%20ACTIVIDADES\%20FORMATIVAS/FICHEROS/20130502\%20Lista do\%20de\%20Ponencias.pdf

Almeida, Isis \& Soeiro, Cristina (2010). Avaliação de risco de violência conjugal: versão para polícias (SARA: PV). Análise Psicológica, 1 (28), 179-192.

Andrés-Pueyo, Antonio \& Echeburúa, Enrique (2010). Valoración del riesgo de violência: instrumentos diponibles e indicaciones de aplicación. Psicothema, 22 (3), 403-409.

Arantes, Esther Maria de Magalhães (2004). Pensando a Psicologia aplicada à Justiça. In Hebe S Gonçalves. \& Eduardo P. Brandão (Orgs.), Psicologia Jurídica no Brasil (pp.15-50). Rio de Janeiro: Nau Ed.

Bandeira, Lourdes (2009). Três décadas de resistência feminista contra o sexismo e a violência feminina no Brasil: de 1976 a 2006. Sociedade e Estado, 24 (2), 401-438.

Bandeira, Lourdes \& Thurler, Ana Lieser (2009). A vulnerabilidade da mulher à violência doméstica: aspectos históricos e sociológicos. In Fausto Rodrigues de Lima \& Claudiene Santos (Orgs.), Violência doméstica: vulnerabilidades e desafios na intervenção criminal e multidisciplinar (pp. 159-167). Rio de Janeiro: Lumen Juris.

Brasil (2007). Presidência da República. Política Nacional de Enfrentamento à Violência contra as Mulheres. Brasília: Secretaria de Políticas para as Mulheres. 
Campbell, Jacquelyn (2001). Safety Planning Based on Lethality Assessment for Partners of Batterers in Intervention Programs. Journal of Agression, Maltreatment \& Trauma, 5 (2), 129-143.

Campbell, Jacquelyn (2004). Danger Assessment. Retirado de: http://www.dangerassessment.org/

Campbell, Jacquelyn (2005). Assessing dangerousness in domestic violence cases: history, challenges, and opportunities. Criminology \& Public Policy, 4(4), 653-672.

Campbell, Jacquelyn; Webster, Daniel W. \& Glass, Nancy (2009). The Danger Assessment: validations of a lethality risk assessment instrument for intimate partner femicide. Journal of Interpersonal Violence, 24 (4), 653-674.

Campbell, Jacquelyn; Webster, Daniel; Koziol-McLain, Jane; Block, Carolyn, et al. (2003). Risk factors for femicide in abuse relationships: results of a multisite case control study. American Journal of Public Health, 93 (7), 1089 - 1097.

Carneiro, Sueli (2003). Mulheres em movimento. Revista Estudos Avançados, 17 (49), 117-132.

Code, Ruth \& La, Lisa (2009). Inventory of Spousal Violence risk Assessment tools used in Canada. Canada: Department of Justice Canada.

Echeburúa, Enrique; Amor, Pedro Javier; Loinaz, Ismael; Coral, Paz de (2010). Escala de Predicción del Riesgo de Violencia Grave Contra la Pareja - Revisada (EPV-R). Psicothema, 22 (4), 1054-1060.

Garcia, Leila Posenato; Freitas, Rolim Santana de; Silva, Gabriela Drummond Marques da \& Höfelmann, Doroteia Aparecida (2013). Violência contra a mulher: feminicídios no Brasil. Disponível em: http://www.ipea.gov.br/portal/images/stories/PDFs/130925_sum_estudo_feminicidio_leilagarcia.p df

Grams, Ana Clara \& Magalhães, Teresa (2011). Violência nas relações de intimidade. Avaliação de Risco. Revista Portuguesa do Dano Corporal, 22, 75-98.

Griebler, Charlize Naiana \& Borges, Jeane Lessinger (2013). Violência contra mulher: perfil dos envolvidos em boletins de ocorrência da Lei Maria da Penha. Psico, PUCRS, 44 (2), 215-225.

Haggard-Grann, Ulrika (2007). Assessing violence risk: a review and clinical recommendations. Journal of Counseling and Development, 85 (3), 294-302.

Hermoso, María del Rocio Gómez; Vicente, José Manuel Muñoz; Mezquita, Blanca Gómez; Martins, Rebeca Gómes; De la Calle, Nuria Mateos (2012). Guía de buenas prácticas para la evaluación psicológica forense del riesgo de violencia contra la mujer en las relaciones de pareja (VCMP). Madrid: Colegio Oficial de Psicólogos de Madrid.

Kropp, P. Randall; Hart, Stephen D.; Webster, Christopher D. \& Eaves, Derek. (1999). Spousal Assault Risk Assessment Guide - user's manual. Toronto: Multi-Health Systems Inc. \& B. C. Institute Against Family Violence.

Kropp, P. Randall \& Hart, Stephen D (2000). The spousal assault risk assessment (SARA) guide: reliability and validity in adult male offenders. Law and Human Behavior, 24 (1), 101-118.

Kropp, P. Randall \& Gibas, Andre (2010). The Spousal Assault Risk Assessment Guide (SARA). In. Randy K. Otto \& Kevin Douglas (Orgs). Handbook of violence risk assessment (pp. 147-186). New York: Taylor \& Francis e-Library. 
Litwack, Thomas R. (2001). Actuarial versus clinical assessments of dangerousness. Psychology Public Policy and Law, 7 (2), 409-443.

Medeiros, Marcela Novais \& Puga, Vera. L. S. de (2007). Os Movimentos Feministas e de Mulheres no Entrelaçamento dos Fios da Rede de Apoio às Mulheres Vítimas de Violência Conjugal. Monografia de conclusão de Master Internacional não publicada, UFU, IUSM, UNIMOL, UCAM, PARIS V, Uberlândia.

Melo, Mônica de \& Teles, Maria Amélia de Azevedo (2003). O que é violência contra a mulher. São Paulo: Brasiliense.

Nicolls, Tonia L.; Pritchard, Michelle M.; Reeves, Kim A. \& Hilterman, Edward (2013). Risk assessment in intimate partner violence: a systematic review of contemporary approaches. Partner Abuse, v. 4 (1).

Tavares, Marcelo (2000a). A entrevista clínica. In: Jurema Alcides Cunha (Org.). Psicodiagnóstico V. 5ed., 45-56. Porto Alegre: Artes Médicas.

Tavares, Marcelo (2000b). A entrevista estruturada para o DSM-IV. In: Jurema Alcides Cunha (Org.). Psicodiagnóstico V. 5ed., 75-86. Porto Alegre: Artes Médicas.

Tavares, Marcelo (2004). Validade Clínica. Psico-USF, 8 (2), 125-136.

Santos, Maria José M. Lopes dos (2010). A perícia médico-legal nos casos de violência nas relações de intimidade - contributo para a qualidade. Dissertação de Mestrado, Universidade do Porto, Portugal.

Singh, Jay P., Grann, Martin \& Fazel, Seena (2011). A comparative study of violence risk assessment tolls: a systematic review and metaregression analysis of 68 studies involving 25, 986 participants. Clínical Psychology Review, 31, 499-513.

Schraiber, Lilia Blima; D’Oliveira, Ana Flávia Pires Lucas; Falcão, Maria Thereza Couto \& Figueiredo, Wagner dos Santos (2005). Violência dói e não é direito. A violência contra a mulher, a saúde e os direitos humanos. São Paulo: Editora UNESP.

Teixeira, Analba Brazão (2009). Nunca você sem mim: homicidas-suicidas nas relações afetivoconjugais. São Paulo: Annablume.

Waiselfisz, Julio Jacobo (2012a). Mapa da violência 2012 - Atualização: homicídio de mulheres no Brasil. Brasil: Centro Brasileiro de Estudos Latino Americano e Flacso Brasil.

Waiselfisz, Julio Jacobo (2012b). Mapa da violência 2012 - Caderno complementar 1: homicídio de mulheres no Brasil. São Paulo, Instituto Sangri.

Webster, Christopher D.; Haque, Quazi \& Hucker, Stephen J. (2013).Violence Risk-Assessment and Management: advances though structured professional judgment and sequential redirections (2 ed). UK: Wiley-Blackwel.

Williams, Kirk R. \& Grant, Stephen R. (2006). Empirically Examining the Risk of Intimate partner Violence: The Revised Domestic Instrument. Public Health Reports, 121, 400-408.

Williams, Kirk R. \& Houghton, Amy Barry (2004). Assessing the risk of domestic reoffending: a validation study. Law and Human Behavior, 28 (4), 437-455. 


\title{
Artigo 2 - Avaliação de risco: atuação
}

\section{profissional em casos de violência contra mulher}

\author{
na relação íntima
}

\section{Marcela Novais Medeiros}

Apresentado como parte integrante de tese de doutoramento do Programa de Pós-Graduação em Psicologia Clínica e Cultura do Departamento de Psicologia Clínica, Instituto de Psicologia, Universidade de Brasília.

\section{Resumo}

Este artigo relata resultados de estudo que buscou compreender como é feita a avaliação de risco de violência por profissionais que atuam em serviços que compõem a rede de atendimento a pessoas em situação de violência no Distrito Federal, com vistas à identificação de demandas e de dinâmicas relacionadas à avaliação de risco em casos de violência contra a mulher perpetrada pelo parceiro íntimo. Para tanto, foram realizadas entrevistas, sob a forma de grupo focal e entrevista individual, com vinte profissionais da rede de atendimento a pessoas em situação de violência do Distrito Federal. Os resultados demonstraram que é necessário o desenvolvimento de protocolos e diretrizes de avaliação de riscos adequados para a realidade brasileira, bem como a capacitação de profissionais para que os processos de identificação e de gestão de riscos sejam aprimorados.

Palavras-chave: Avaliação de Risco; Rede de Atendimento; Violência Perpetrada pelo Parceiro Íntimo.

A violência cometida por um homem contra uma mulher com quem tenha vínculo afetivo-sexual é denominada violência perpetrada por parceiro íntimo. A Organização Mundial de Saúde (Krug, Dahlberg, Mercy, Zwi, \& Lozano, 2002) 
conceitua esse tipo de violência como qualquer ação que provoque mal-estar físico, psicológico ou sexual, cometida no âmbito do namoro, do casamento formal ou informal, bem como entre ex-parceiros íntimos. Pode ocorrer sob a forma de violência física, psicológica, sexual e patrimonial.

A violência sofrida por mulheres em relações íntimas é um fenômeno que tem sido examinado por diversos ângulos, como, por exemplo, a relação entre violência e patriarcado (Bandeira \& Thurler, 2009; Zanotta, 2010), a magnitude da violência no Brasil (Barreto, 2012; Central de Atendimento à Mulher - Ligue 180/SPM, 2014), o femicídio (Garcia, Freitas, Silva \& Höfelmann, 2013; Segato, 2006; Zanotta, 1998) os impactos da violência na saúde física e mental (Medeiros, 2010; Minayo, 2006), a dinâmica conjugal violenta (Koller, \& Narvaz, 2004; Guimarães, 2009) e as estratégias de enfrentamento (Angelim, 2010; Ávila, Machado, Suxberger \& Távora, 2014; Ribeiro, José, et al., 2012). Nesse contexto, algumas questões ainda merecem ser estudadas e esclarecidas acerca dessa temática. A avaliação da periculosidade envolvida em uma situação de violência perpetrada por parceiro íntimo é tema que requer maior destaque no campo de estudos sobre a violência doméstica, a conjugal e a intrafamiliar.

A consciência da violência contra a mulher como crime exigiu que diversos países, entre eles o Brasil, alterassem sua legislação que trata de sanções penais (Campbell, 2005; Grams \& Magalhães, 2011; Williams \& Houghton, 2004), com vistas ao aprimoramento das estratégias para coibir a violência sofrida por mulheres nas suas relações afetivas. O Estado brasileiro, por exemplo, promulgou, em 2006, a Lei 11.340/2006, conhecida como Lei Maria da Penha - LMP, que representa uma legislação específica e de proteção integral a mulheres vítimas de violência doméstica. Além disso, criou as varas especializadas para julgar crimes de violência doméstica contra mulheres. 
Frente às alterações legislativas e institucionais, o Judiciário e outros participantes da rede de atendimento a mulheres em situação de violência foram impulsionados a refletir sobre estratégias para distinguir os casos que necessitam de intervenção urgente daqueles que não requeriam ação imediata. Também foram impelidos a pensar em estratégias que facilitassem a eleição do tipo de intervenção necessária para cada situação, de forma a separar quais requerem a prisão e quais exigem outras medidas menos drásticas como, por exemplo, afastamento do agressor do lar (Campbell, 2005; Grams \& Magalhães, 2011; Williams \& Houghton, 2004).

Embora todas as mulheres que buscam ajuda na rede de atendimento à mulher em situação de violência estejam em condição de perigo, ou seja, em risco potencial de danos, é preciso diferenciar a periculosidade de cada experiência, que é a presença efetiva de risco de danos ou de morte (Grams \& Magalhães, 2011; Santos, 2010). Uma mesma condição de perigo pode ter periculosidade diferente, dependendo das medidas de proteção adotadas (Santos, 2010). Assim, ter um homem violento como companheiro configura-se como condição de perigo. Caso a companheira de um homem violento peça a separação, ela está em condição de periculosidade e, se ele não for obrigado a entregar sua arma à polícia, a periculosidade é maior.

O tratamento de todos os casos de violência perpetrada pelo parceiro íntimo como situação de alto risco de periculosidade pode induzir a enganos e pode gerar relutância nas pessoas em buscarem intervenção do Judiciário para a solução de seus conflitos. Pode também provocar desnecessárias restrições de liberdade do agressor, bem como alterações na vida da vítima e de suas crianças que não seriam necessárias para garantir a seguranças dessas pessoas (Campbell, 2005). Além disso, não garante uma alocação adequada dos recursos no sistema criminal (Kropp \& Hart, 2000).

A avaliação de risco de violência contra a parceira íntima é conceituada na literatura como: “(...) processo de recolha de informação, acerca das pessoas envolvidas, 
para tomar decisões de acordo com o risco de reincidência da violência" (Almeida \& Soeiro, 2010, p. 180). É um processo de “determinação do valor qualitativo ou quantitativo do risco relatado numa situação concreta ou numa ameaça reconhecida" (Santos, 2010, p. 50) com finalidade de prevenir violências (Haggard-Grann, 2007), ao oferecer a profissionais, a vítimas e a ofensores informações sobre o nível de ameaça oferecida por um ofensor (Nicolls, Pritchard, Reeves \& Hilterman, 2013).

A avaliação de risco de violência é uma estratégia que permite a identificação dos casos mais graves, nos quais esteja ocorrendo o agravamento da violência, em contraste com aqueles menos graves (Almeida, \& Soeiro, 2010; Campbell, 2005; Campbell, Webster, Glass, 2009; Hucke, 2014; Santos, 2010). É, portanto, ação essencial para orientar intervenções no sistema de justiça e em outros setores (Nicholls et al., 2013).

Os resultados da avaliação de risco devem conduzir à gestão do risco observado. Gerir riscos significa usar um conjunto de estratégias para evitar a reincidência ou o aumento da gravidade da violência (Associação de Mulheres Contra a Violência et al., 2013, p. 13). Requer uma intervenção integrada entre os serviços da rede de atendimento e envolve a elaboração de plano de segurança pessoal e plano de intervenção institucional com enfoque na proteção da mulher, dos filhos e de outros familiares envolvidos na situação de risco (Associação de Mulheres Contra a Violência et al, 2013; Glass, Eden, Boom \& Perrin, 2010).

A avaliação e a gestão de riscos devem ser feitas por profissionais que atuam em serviços que compõem a rede de atendimento a pessoas em situação de violência. Essa rede de atendimento é formada por instituições governamentais e não governamentais que oferecem assistência jurídica, médica, psicológica, policial e assistencial as pessoas em situação de violência; é composta por serviços especializados e portas de entrada da Justiça, da Saúde, da Segurança Pública e da Assistência Social. 
Fazem parte dessa rede de atendimento, no Distrito Federal: Delegacia Especializada de Atendimento a Mulher (DEAM), Corpo de Bombeiros, Polícia Civil, Polícia Militar, Instituto de Medicina Legal (IML), Centro de Referência de Assistência Social (CRAS), Centro de Referência Especializado de Assistência Social (CREAS), Casa Abrigo, Juizados, Defensorias, Ministério Público, Hospitais, serviços de atendimento a vítimas de violência, serviços de saúde mental, Serviço de Atendimento Médico de Emergência (SAMU), postos de saúde.

O conhecimento da forma pela qual tem sido conduzida a avaliação de risco de violência e a identificação de problemas e alternativas existentes nesse processo é essencial para que essa prática seja aprimorada. Tais dinâmicas e demandas relacionadas à avaliação de risco feita pela rede de atendimento no Distrito Federal ainda não foram sistematizadas por meio de estudos científicos. Diante disso, justificase este estudo realizado, de caráter exploratório, que teve como objetivo geral: compreender como é feita a avaliação de risco de violência por profissionais que atuam em serviços que compõem a rede de atendimento a pessoas em situação de violência, com vistas à identificação de demandas e dinâmicas relacionadas à avaliação de risco em casos de violência contra a mulher perpetrada pelo parceiro íntimo.

\section{Método}

Foi realizado um encontro sob a forma de grupo focal com profissionais da rede de atendimento a pessoas em situação de violência do Distrito Federal. Entre eles, dois eram psicólogos que atuam em serviço psicossocial de assessoramento aos magistrados do Tribunal de Justiça do Distrito Federal e Territórios; dois eram estagiários de psicologia do Tribunal de Justiça do Distrito Federal e Territórios; duas eram psicólogas da Secretária de Saúde com atuação em serviço de proteção a vítimas de violência; uma era psicóloga da Secretaria de Saúde do Distrito Federal com atuação em Centro de 
Atenção Psicossocial (CAPS); uma era psicóloga do Centro de Referência da Assistência Social (CRAS); uma era psicóloga do Centro de Referência Especializado de Assistência Social (CREAS); três eram pesquisadores de grupos de estudos em gênero; uma era Promotora de Justiça.

Também foram realizadas entrevistas com dois juízes que atuam em Juizados Especializados em Violência Doméstica e Familiar contra as Mulheres, uma assistente social que atua em setor de análise psicossocial do Ministério Público do Distrito Federal e Territórios, uma psicóloga que atua em serviço psicossocial do Tribunal de Justiça do Distrito Federal e Territórios, um Promotor de Justiça, uma Delegada que atua em Delegacia Especializada no Atendimento a Mulher, um policial civil.

Os treze profissionais que participaram do grupo focal e um dos entrevistados individualmente foram identificados e convidados a participar do estudo durante reuniões mensais de profissionais que atendem mulheres em situação de violência. Os outros seis participantes entrevistados individualmente foram selecionados pela pesquisadora dentre colegas de trabalho ou indicados por eles.

As perguntas que orientaram o grupo focal e as entrevistas individuais foram: (1) O que constitui perigo nas situações de violência? (2) Como é feita a avaliação de risco durante o atendimento a mulheres em situação de violência no Distrito Federal? Tais perguntas facilitaram a promoção de um espaço de reflexão sobre crenças e comportamentos por parte dos participantes.

As entrevistas individuais e grupais sob a forma de grupo focal possuem suas vantagens e desvantagens, conforme aponta George Gaskell (2008). Uma das vantagens do grupo focal foi permitir a observação de processos de consenso e de divergências. A entrevista individual, por outro lado, permitiu a investigação em profundidade e contemplar pessoas que não puderam participar do grupo focal. 
Os dados foram analisados, a partir dos seguintes eixos de análise: (1) Como é feita avaliação de risco; (2) Quais são os executores da avaliação de risco; (3) Como se faz a gestão de riscos. Tais eixos de análise foram elencados a partir de revisão de literatura (Almeida \& Soeiro, 2010; Associação de Mulheres Contra a Violência AMCV et al., 2013; Bograd \& Mederos, 1990; Bracken, et al, 2010; Campbell, 2005; Cattaneo, Bell, Goodman, \& Dutton, 2007; Greene \& Bogo, 2002; Gondolf, 2002; Haggard-Grann, 2007;Kropp \& Hart, 2000; Nicholls et al., 2013; Webster, Haque \& Hucker, 2013; Santos, 2010;Williams \& Houghton, 2004). Estudos e pesquisas sobre avaliação de risco, ao discutirem o processo de avaliação de risco, fazem menção aos temas que originaram a construção dos eixos de análise.

\section{Resultados}

A análise das falas dos participantes forneceu evidências sobre a condução de avaliações de risco de violência em serviços porta de entrada e especializados no atendimento a mulheres em situação de violência. Os participantes teceram considerações sobre a forma pela qual profissionais da segurança pública, do Poder Judiciário, do Ministério Público, e do sistema de saúde e sistema socioassistencial realizam avaliação de risco.

\section{Segurança Pública}

Foi possível observar que a avaliação de risco realizada na DEAM, na maioria dos casos inseridos no sistema de justiça criminal, é a primeira avaliação de risco realizada. A análise das falas dos juízes, do Promotor de Justiça e da Delegada evidencia que a DEAM é a porta de entrada para a rede de atendimento a pessoas em situação de violência, por ser, frequentemente, o primeiro local procurado pela mulher. Na perspectiva desses participantes, a avaliação de risco realizada nessa instituição tem 
como finalidade identificar a necessidade de enviar ao Judiciário pedido de medidas protetivas de urgência - MPU para proteção da vítima, previstas na LMP.

A LMP prevê a possibilidade do deferimento de MPU, caso haja o requerimento da vítima ou do Ministério Público e o juiz avalie que elas são necessárias para protegêla. As medidas protetivas de urgência, previstas por essa lei são: suspensão do porte de armas do agressor, afastamento do agressor do lar, fixação de distância mínima entre agressor e a vítima, proibição de visita aos menores e pagamento provisório ou provisional de alimentos (Brasil, 2006).

De acordo com a Delegada, a avaliação de risco na DEAM é feita na ocasião da oitiva do depoimento da vítima. Há uma checklist com informações que devem ser investigadas durante o registro do Boletim de Ocorrência. Os profissionais investigam os seguintes aspectos: tempo de relacionamento, presença e idade de filhos, ocorrência de violências na presença de filhos, ocorrência de outras violências cometidas pelo autor contra a vítima com ousem notificação às autoridades, motivos para não ter registrado Boletim de Ocorrência policial anteriormente, uso de álcool e drogas por parte do autor, posse de arma pelo autor, relato do fato.

Outra preocupação apontada foi com relação a informações que devem ser anexadas ao pedido de medidas protetivas de urgência, a saber: fotos tiradas pelos agentes policiais das lesões apresentadas pela vítima e de mensagens de ameaças enviadas pelo autor para o celular da vítima; cópia do prontuário civil e de antecedentes penais de ambos.

A experiência de avaliação de risco na DEAM difere da experiência de delegacias não especializadas, nas quais não é utilizada a referida checklist durante a oitiva da vítima. Conforme destacou o policial participante da pesquisa, na Delegacia em que atua e já atuou, o registro do Boletim de Ocorrência contém somente os seguintes elementos: oitiva da vítima e descrição do autor, das testemunhas e do fato. 
Há uma divergência entre os participantes sobre a avaliação realizada na DEAM. Alguns psicólogos jurídicos e da saúde consideram que é uma avaliação muito simples e demonstraram não saber quais são os elementos investigados nessa avaliação. Outros participantes, entre eles juiz, Promotor de Justiça, Delegada e psicólogos, consideram que a avalição de risco realizada na DEAM aborda aspectos possíveis e importantes para aquele contexto.

\section{Poder Judiciário e Ministério Público}

A avaliação de risco realizada no âmbito do Poder Judiciário e do Ministério Público é feita pelo Promotor de Justiça, pelo juiz e por psicólogos e assistentes sociais dos serviços psicossociais de assessoramento aos magistrados e setor de análise psicossocial do Ministério Público do Distrito Federal e Territórios. Um dos promotores de Justiça informou que cabe ao Ministério Público avaliar riscos na ocasião da chegada dos autos da MPU ou outra comunicação relacionada ao fato. Essa avaliação feita por promotores de Justiça, com informações dos autos ou oitiva da vítima, leva em consideração a experiência e o conhecimento acerca de fatores de risco.

Em algumas promotorias, conforme destacaram os promotores de Justiça e assistente social, o Promotor de Justiça faz uso de checklist de identificação de violências produzido para uso do setor de análise psicossocial e que investigam os seguintes aspectos: comportamento controlador e impulsivo, não aceitação da separação, acesso a arma de fogo, uso de utensílios domésticos na agressão, determinadas agressões físicas (bater, empurrar, chutar), agressão a filhos ou enteados, ameaças, agressões com lesões.

Os profissionais do setor de análise psicossocial utilizam o referido instrumental para avaliar riscos. De acordo com assistente social e com promotores de Justiça, a avaliação de risco só é feita em determinados casos, podendo haver diferenças entre 
promotorias. Por exemplo, em algumas são selecionados os casos nos quais as medidas protetivas foram indeferidas, há relatos de ameaça sem outras agressões, sem histórico de ocorrências anteriores.

Juízes e psicólogos do serviço psicossocial de assessoramento aos magistrados do Tribunal de Justiça do Distrito Federal e Territórios destacaram que cabe ao juiz fazer uma prévia análise de risco quando recebe autos de MPU. Segundo um dos juízes, para deferir ou indeferir pedido de MPU, bem como decidir sobre necessidade de reforço de medida deferidas em virtude do descumprimento, ele deve analisar qual o risco de a mulher ser agredida novamente, não havendo normas na legislação ou na jurisprudência para embasar essa avaliação.

Um dos juízes relatou que, em sua avaliação, focaliza comportamentos já emitidos pelo autor, por considerar que são mais graves do que aqueles que denotam uma futura ação. Alertou que valoriza a percepção da vítima, mas que sabe que ela pode subestimar os fatos, em virtude dos sentimentos de raiva ou subestimar os fatos por estar envolvida na dinâmica de violência que dificulta sua real percepção dos fatos.

Outro juiz acrescentou que, particularmente, faz essa avaliação de risco a partir de três pontos: (1) da identificação de fatores de risco de ocorrência de violências descritos na literatura, (2) da análise da história criminal com foco na reincidência em crimes de violência doméstica e (3) da presunção do risco.

Após o deferimento ou indeferimento das MPU pelo juiz, a equipe psicossocial de assessoramento aos magistrados pode ser acionada para conduzir sua avaliação de risco. De acordo com juízes e psicólogos dessa equipe, fica a cargo do juiz decidir quando será requerida essa avaliação. Em alguns Juizados, por exemplo, os casos envolvendo lesão corporal e indeferimento de medidas protetivas são os escolhidos. 
De acordo com os juízes e psicólogos do setor de assessoramento aos magistrados, os profissionais dessa equipe psicossocial elaboram um relatório, a partir de elementos identificados durante atendimento individual agendado para realização de estudo psicossocial ou durante o atendimento multidisciplinar a mulheres e homem envolvidos em situação de violência doméstica. Nesse documento, são descritas a possibilidade de reincidência de violências e a existência ou não de risco de morte.

Alguns psicólogos desse serviço psicossocial relataram o uso de checklist construído em seus locais de trabalho, com base em fatores de risco e em fatores de proteção de ocorrência de violência descritos na literatura e que ajudam a identificar os tipos de violência ocorridos, a gravidade da situação. Há também a preocupação com a identificação de fatores que podem proteger a mulher, como ter pessoas com quem possa contar e a independência financeira feminina.

\section{Sistema de Saúde e Sistema Socioassistencial}

Os serviços de saúde e socioassistencial fazem parte do Executivo da rede de atendimento multidisciplinar a pessoas em situação de violência. A partir da análise das falas dos participantes que atuam nesses locais, pode-se perceber falta sistematização nos processos de avaliação de risco. No CAPS, quando se identifica que a mulher está em situação de violência, faz-se o encaminhamento para atendimento em algum serviço especializado. Riscos são identificados durante seus atendimentos no CRAS, no CREAS e no serviço de saúde especializado. Contudo, os psicólogos não têm um momento determinado para avaliar riscos, como, por exemplo, nos primeiros atendimentos. Não há também a prática de monitorar os riscos por meios de novas avaliações.

Os profissionais consideram que o atendimento a mulher em situação de violência deve englobar a identificação dos tipos de violências sofridas e avaliação da 
rede social das mulheres. Esses elementos permitem acessar informações sobre o risco de a mulher ser morta ou gravemente ferida.

Sobre os tipos de violência, os profissionais destacaram que importa saber especialmente se está ocorrendo o escalonamento da violência física. Psicólogos acrescentaram que acham importante entender também se houve violência psicológica e que costumam usar exemplos dos tipos de violências para favorecer a fala da mulher. Também levam em consideração a percepção da mulher, que é, na maioria dos casos, a principal fonte de informações.

Sobre a rede social, os psicólogos afirmaram que não basta saber se ela tem rede social ou se está isolada. Destacaram que importa saber como amigos, familiares e igreja reagem a essa violência. Consideram que a rede social pode tanto ajudar na proteção da mulher, quanto colocá-la em situação de maior risco de reincidência de violências, caso compartilhem ideias relacionadas a papéis de gênero excessivamente tradicionais e rígidos.

\section{Gestão de Riscos}

A gestão de riscos com vistas à proteção da mulher na Segurança Pública, no Poder Judiciário e no Ministério Público está centrada no pedido e deferimento de MPU. Outras ações de gestão de risco apontadas foram o encaminhamento para atendimento feito pela equipe psicossocial e para outros órgãos, considerando que os atendimentos psicossocial, de saúde e socioassistencial podem ajudar a reduzir riscos.

Por sua vez, as principais medidas de gestão de risco nos serviços de saúde e socioassistencial são o encaminhamento para delegacias e casas-abrigo. Frequentemente, somente face à ambivalência que muitas mulheres apresentam quanto ao abrigamento é que outras medidas são buscadas. 
Todos os participantes da pesquisa destacaram o papel da casa-abrigo na proteção de mulheres. As casas-abrigo são iniciativas do movimento feminista. Esse local é definido pela Política Nacional de Enfrentamento da Violência contra Mulheres (Brasil, 2007, p.15) como: “(...) locais seguros que oferecem moradia protegida e atendimento integral a mulheres em risco de vida iminente em razão da violência doméstica”. A permanência nessas casas deve ser sigilosa e temporária, por, no máximo, 90 dias. Além da garantia da integridade física e psíquica, objetiva auxiliar a mulher a retomar seus projetos de vida.

Conforme a análise dos dados mostrou, no Distrito Federal, quem encaminha a vítima para casa-abrigo é a DEAM e esse encaminhamento está centrado no pedido da mulher. Esse encaminhamento é oferecido para todas as mulheres. Também não há critérios estabelecidos para orientar psicólogos na discussão com suas pacientes quanto ao encaminhamento para DEAM para que sejam conduzidas para casa-abrigo. Isso contribui para que seja transferida para a mulher a decisão de ir para o abrigo, não havendo critérios para orientá-la nesse pedido.

Os participantes da pesquisa refletiram sobre falhas na proteção da mulher após a identificação de riscos. Profissionais do Judiciário e do Ministério Público afirmaram que dificuldades na gestão de riscos pelo Judiciário decorrem da necessidade de ampliar o monitoramento das MPU. Elencaram como de extrema importância a instalação no Distrito Federal de mecanismo de teleassistência, já utilizados em outros países e em alguns estados brasileiros. No Brasil, tais aparelhos são conhecidos como "botão do pânico" ou "botão de emergência", e consistem em dispositivos eletrônicos que permitem que a polícia seja acionada pela vítima em situações de risco.

Psicólogos do Judiciário, do Ministério Público e do Executivo indicaram a ausência da percepção dos riscos pelas mulheres como fator que dificulta a gestão de riscos. A não percepção acarreta a recusa das ações de gestão de risco. 


\section{Convergências, Divergências e Desafios}

Todos os participantes da pesquisa relataram ser importante conhecer a periculosidade da situação de violência. Consideram que é elemento essencial para proteger a mulher que corre risco de ser gravemente ferida ou morta pelo parceiro ou ex-parceiro íntimo. Todavia, nem todos os participantes compreendem que checklist de avaliação é um instrumental que favorece e oferece suporte para que questões pertinentes sejam investigadas em todos os casos, sem que outras perguntas e intervenções sejam feitas.

Nem todos os participantes citaram a existência de protocolos ou diretrizes institucionais de avaliação de risco. Mas há um consenso de que a classificação em alto grau de periculosidade é feita com base na sua intuição, na experiência e no julgamento clínico. Não há uma normatização psicométrica para quantificação dos resultados das checklists que foram mencionadas.

Todos os participantes da pesquisa concordam que seria importante ter orientações específicas sobre como conduzir uma avaliação de risco. A ausência de parâmetros gera dúvidas e angústia nos profissionais. Faltam parâmetros para orientar a análise dos dados obtidos nas entrevistas com as mulheres em situação de violência.

Alguns participantes da pesquisa consideram viável a existência de diretrizes únicas sobre avaliação de risco que possam ser usadas por todos os profissionais da rede ou por todos os psicólogos que atuam nos serviços psicossociais, de serviços de saúde e socioassistencial. A avaliação, na opinião deles, pode ser a mesma, havendo diferença na forma pela qual será planejada a intervenção pelos profissionais dos diversos serviços de atendimento.

Profissionais demonstraram dúvidas sobre a necessidade de todos os serviços realizarem avaliação de risco e como isso poderia ser realizado. Uma das preocupações 
apresentadas relacionou-se ao fato de que a avaliação repetida diversas vezes pudesse ser prejudicial para a mulher em situação de violência.

\section{Discussão}

A análise das falas dos participantes demonstrou a necessidade de capacitação dos profissionais da rede de atendimento para que ampliem sua compreensão sobre o papel de cada ator dessa rede na realização da avaliação de risco. É preciso ampliar a compreensão do papel de cada serviço e superar desentendimentos sobre quem deve fazer a avaliação de risco, pois avaliar riscos não é tarefa que compete somente aos profissionais da Segurança Pública, do Judiciário e do Ministério Público. Avaliar riscos

é importante para orientar a ação institucional, bem como para promover a conscientização da mulher sobre o perigo vivenciado por ela. Por isso, deve ser uma tarefa continuada e sistematizada.

A valorização do sistema de justiça como local essencialmente avaliativo demonstrada na análise dos dados pode ter relação com a história de avaliação de risco nas relações de intimidade. A literatura aponta que a avaliação de risco é tipicamente conduzida por profissionais da saúde mental que atuam no sistema de justiça (Nicolls et al., 2013) e foi nesse campo que instrumentos de avaliação foram gestados (AbdalaFilho, 2012).

Contudo, a avaliação de risco, na atualidade, conforme alerta Jaquelyn Campbell (2001), compete a todos os profissionais que atendem mulheres em situação de violência perpetrada por parceiro íntimo. Em qualquer atendimento dispensado a esse público, questões de segurança devem ser identificadas e, quando necessário, elaborada uma estratégia de proteção para a mulher e familiares (Bograd \& Mederos, 1999; Haddock, 2002; Greene \& Boro, 2002; Walker, 2009, 1999). 
Profissionais da saúde mental não são os únicos que devem conduzir avaliações de risco. Policiais, enfermeiros, advogados e assistentes sociais que atuam na atenção direta a pessoas em situação de violência, em virtude do alto custo de manutenção de um profissional da saúde mental, têm participado da avaliação de risco, após terem sido treinados para isso (Nicolls et al., 2013). Jaquelyn Campbell (2005) destaca que, em alguns sistemas, aqueles que têm o contato imediato com a vítima são os que fazem a avaliação de risco. Já em outros sistemas, advogados e profissionais especializados recebem a tarefa de investigar riscos por meio de uma avaliação aprofundada.

Ao contrário do que afirmaram alguns participantes da pesquisa, estudos demonstram que a atividade de avaliar riscos não deve ser a mesma em todos os serviços da rede de atendimento, embora todos os profissionais que atendem tais devam avaliar risco. A avaliação de risco deve ser contextualizada. Tonia Nicolls e colaboradores (2013) destacam que o tipo de informação investigada dependerá do contexto, dos recursos disponíveis e da natureza da avaliação de risco. Campbell (2005) alerta que diferentes contextos irão gerar gestão de riscos diferentes. Por exemplo, no contexto da Justiça, o avaliador não poderá manter sigilo do resultado da avaliação de risco e isso deve ser informado previamente para a vítima.

A complexidade da avaliação de risco também deve variar de acordo com o tipo de serviço no qual é realizada e do profissional que a conduz. Campbell (2001) oferece exemplos de avaliações com complexidade diferentes. Em uma publicação, a autora (Campbell, 2001) sugere que a avaliação de risco de femicídio com menor nível de complexidade deve avaliar, no mínimo, os seguintes elementos: (1) ameaças de letalidade; (2) ameaças com armas ou uso de armas; (3) a presença de uma arma em casa; (3) ciúme obsessivo. A mesma autora, por sua vez, apresenta em outra publicação (Campbell, 2005) o instrumento Danger Assessment (DA), que é um instrumento de 
avaliação de risco composto por vinte itens que deve ser usado por enfermeiros, advogados, psicólogos, entre outros.

É possível encontrar na literatura outros instrumentos de avaliação de risco que também demonstram essa diferença de complexidade entre as avaliações realizadas em contextos diversos. Exemplo disso são os instrumentos Spousal Assault Risk Assessment (SARA) e Brief Spousal Assault Form for the Evaluation of Risk (B-SAFER), também conhecido como Spousal Assault Risk Assessment: Police version (SARA: PV). A SARA é uma checklist de vinte itens criado por Randall Kropp, Stephen Hart, Cristopher Webster e Derek (1994). Ela deve ser preenchido preferencialmente por um profissional da saúde mental ou com sua assessoria, pois requer a compreensão da saúde mental do agressor.

Para que esse instrumento pudesse ser aplicado por policiais durante o atendimento de ocorrências de violência doméstica, Randall Kropp, Stephen Hart e Henrik Belfrage (2005) desenvolveram uma versão reduzida e simplificada dele com apenas 10 itens, denominando-a de Brief Spousal Assault Form for the Evaluation of Risk (B-SAFER). Tais itens enfatizam a presença atual ou passada de: (1) grave violência física/sexual com ou sem armas; (2) ameaças ou pensamentos violentos contra outras pessoas; (3) aumento da intensidade e da frequência da violência; (4) violação de ordens judiciais; (5) atitudes de culpar a vítima e não se responsabilizar ou crenças que contribuem para a violência; (6) outros crimes não relacionados a violência conjugal; (7) separação ou aumento dos conflitos conjugais; (8) Instabilidade no emprego ou desemprego; (9) abuso de substâncias; (10) problemas de saúde mental. O tema violência na família de origem foi excluído. Sintomas maníacos, ideação suicida ou desordens de personalidade foram tratados em um único tema chamado de saúde mental. Esta pode ser provisoriamente avaliada sem uma avaliação por profissional da saúde mental ou investigação em registros médicos. 
Determinadas avaliações de risco exigem conhecimentos e habilidades específicas, por isso requerem qualificação em determinada área. Tonia Nicolls e colaboradores (2013) destacam que nem todo profissional da saúde mental está apto para conduzir uma avaliação de risco do tipo clínica/profissional estruturada que é um tipo de avaliação que leva em conta fatores de risco e o julgamento clínico. Esse tipo de avaliação requer treinamento e conhecimento oriundo de diversas áreas do conhecimento, como Psicologia, Psiquiatria, Serviço Social, Enfermagem e Direito.

Psicólogos da rede de atendimento especializada no atendimento a pessoas em situação de violência devem, para serem habilitados a realizar avaliações de risco, levar em consideração as sugestões de Cristopher Webster, Quazi Haque e Stephen Hucke (2014). Tais autores defendem que o profissional da saúde mental deve refinar constantemente suas estratégias levando em consideração: conhecimento da legislação criminal e civil, conhecimento de pesquisas baseadas em evidências, conhecimento das teorias psicológicas. Ao longo de sua prática profissional, devem também: buscar treinamento constante; ressaltar as forças e as capacidades do paciente; trabalhar em equipe; elaborar plano para situações de crise; buscar atuação organizacional para subsidiar ações individuais; estabelecer protocolos para troca de informações entre instituições sobre o paciente; detalhar e informar possíveis desfechos esperados.

A valorização da percepção da mulher sobre a letalidade de sua situação demonstrada pelos participantes da pesquisa pode contribuir para o aprimoramento das avaliações, mas pode prejudicar o entendimento da periculosidade, caso outras estratégias não sejam utilizadas. Embora as mulheres, frequentemente, possuam mais informações sobre características da relação e do agressor do que os instrumentos de avaliação de risco avaliam, podem não pensar sobre o grau de risco presente em sua relação para evitar a ansiedade (Campbell, 2001, 2005) e tendem a subestimar o risco de 
femicídio (Campbell, Webster \& Glass, 2009). Por isso nem sempre têm a real dimensão de periculosidade e de letalidade.

Profissionais da rede de atendimento, conforme sugerem Nicholls e colaboradores (2013), devem incluir outras fontes de informação além das mulheres, de acordo com os recursos disponíveis e a natureza do contexto no qual a avaliação é realizada. Podem ser usados: entrevistas com vítimas, ofensores, familiares; registros médicos; registros de testagem psicológica; registros criminais.

Para que a percepção da mulher contribua adequadamente com o processo de avaliação de riscos, os profissionais devem também levar em consideração a saúde mental da paciente. Lauren Cataneo e colaboradores (2007) alertam que mulheres com sintomas de Transtorno de Estresse Pós-Traumático tendem a superestimarem seu risco, enquanto mulheres que fazem uso abusivo de álcool tendem a subestimá-lo.

É importante destacar que as avaliações de risco realizadas pelos psicólogos participantes da pesquisa crescem em importância, à medida que incluem resultados de pesquisas anteriores (Angelim, 2009; Diniz \& Angelim, 2003; Diniz \& Poondag, 2006; Guimarães, 2009; Medeiros, 2010; Ravazzola, 2005) acerca da forma de investigar a violência. Mulheres podem ter dificuldade de nomear suas experiências como violência. Por isso, necessitam de exemplos sobre os tipos de violência.

Outro ponto forte dessas avaliações é o uso de fatores de risco para conduzir suas avaliações. Para aumentar a validade das avaliações, sugere-se a inclusão de outros fatores de risco identificados, a partir de pesquisa empíricas sobre violências graves e femicídios no Distrito Federal.

O uso da experiência e da intuição para avaliar risco, conforme demonstrou a análise dos dados, decorre da ausência de normas e de protocolos a serem seguidos por psicólogos que atuam em diversos órgãos da rede de atendimento a mulheres em 
situação de violência. A falta de normatização institucional narrada pelos participantes da pesquisa não é realidade exclusiva do Distrito Federal. É possível encontrar na literatura internacional checklists, escalas e outros instrumentos de avaliação de risco elaborados, a partir de pesquisas empíricas. Mas, na literatura brasileira, verificam-se poucas publicações sobre o tema e ausência de instrumentos padronizados que possam ser utilizados pelos diversos profissionais que atuam nos serviços que compõem a rede de atendimento.

Segundo Laís Silva (2011), alguns serviços no Brasil, utilizam checklists elaboradas por seus profissionais e que levam em consideração a presença de fatores de risco relacionados ao agressor, tais como: uso de armas brancas ou de fogo; história criminal; comportamento abusivo diante de animais domésticos; agressões prévias a conhecidos, estranhos e/ou policiais; presença de ideação ou tentativas suicidas recentes; descumprimento de medidas protetivas de urgência; histórico de agressão aos filhos; ser autor de abuso sexual infantil; fazer uso abusivo de álcool ou drogas; minimização de forma extrema ou negação da história de violência doméstica e familiar.

Exemplo de uma checklist elaborada com base na identificação de fatores de riscos está descrito por Barbára Soares (2005) em sua publicação "Enfrentando a Violência contra Mulher: orientações práticas para profissionais e voluntários (as)”. A pesquisadora alerta que sua sugestão de checklist não se configura como um teste infalível e que devem ser levados em conta o bom senso do profissional e o da mulher. Ela oferece perguntas relacionadas à mulher, ao agressor e à dinâmica da relação. Para cada pergunta, são listadas possíveis respostas que estão associadas a um risco médio, alto e extremo. Por exemplo, se o agressor não tem arma, é considerado situação de risco médio; se ele tem e já a utilizou para ameaçar a vítima, a situação é de risco extremo. Nessa avaliação, segue-se a tendência internacional (Campbell, 2001, 2005; 
Kropp \& Hart, 2000; Nicholls et al., 2013;Williams \& Houghton, 2004) de considerar que toda situação de violência envolve algum risco, por isso não há a possibilidade de classificar em risco ausente.

A análise dos dados indica a necessidade de que a gestão de riscos realizada nos serviços da rede de atendimento seja aprimorada com vistas à adequação aos princípios da gestão de riscos. A literatura mostra que a gestão de riscos deve englobar a elaboração de um plano de segurança e a realização de encaminhamentos a partir de plano de intervenção institucional (Associação de Mulheres Contra a Violência et al., 2013). A análise dos dados demonstrou que a elaboração sistematizada de um plano de segurança com a vítima não é prática presente nos serviços da rede de atendimento no Distrito Federal.

Os profissionais da rede de atendimento devem considerar, conforme ressalta Mary Dutton (2004), que a construção de um plano de segurança deve ser adaptada às condições de cada mulher quanto aos riscos de novas violências, sua capacidade de se proteger e as características de sua rede social. Uma complexidade de fatores comunitários e individuais, tais como guarda das crianças, suporte social, acesso a casaabrigo, sentimentos pelo companheiro, devem ser considerados.

De maneira geral, o plano de segurança deve perpassar o oferecimento de informações sobre a situação de risco e sobre a rede de atendimento, incluindo as leis de proteção, os abrigos e os grupos de apoio disponíveis (Associação de Mulheres Contra a Violência et al, 2013). Além disso, deve ajudar a mulher a identificar ações pessoais que favorecem sua segurança. É preciso identificar com a mulher, conforme sugerido por Jeel Davies e Eleanor Lyon (1998): com quem ela poderia deixar as crianças, caso preciso; se ela possui dinheiro disponível; com que amigo ou familiar ela pode falar, caso precise de ajuda. Caso a mulher não tenha tais recursos, seu plano de segurança 
deverá envolver recursos de serviços da rede de atendimento, tais como abrigo e grupo de apoio.

É preciso explorar as opções e suas consequências, para que se antecipem possíveis situações de perigo (Davies \& Lyon, 1998). Nesse contexto, deve-se planejar como será a fuga para local seguro, caso haja riscos. Isso deve ser pensado passo a passo, como, por exemplo, ter chaves extras, deixar roupas e documentos com pessoas de confiança, encontrar lugar seguro para permanência (Walker, 2009; 1999).

Cada instituição deve traçar seu plano de intervenção institucional, a partir das características do tipo de serviço que presta, conforme demonstrou a descrição de gestão de riscos narrada pelos participantes da pesquisa. Todavia, para que sejam eficazes, é preciso haver maior articulação entre os órgãos da rede de atendimento e atuação efetiva de todos os serviços nesse processo de gestão de risco. A MPU, por exemplo, só será efetiva, se houver fiscalização pela polícia.

A condução da mulher para casa-abrigo é uma importante ação de gestão de riscos desenvolvida pela rede de atendimento no Distrito Federal, mas alternativas, além dessa devem ser implementadas. A casa-abrigo não é indicada para todas as mulheres. Mulheres que não correm risco de morte ou que não podem ir, por não poderem afastarse do trabalho, requererem outros encaminhamentos durante a gestão de risco.

De acordo com as Diretrizes Nacionais para Abrigamento de Mulheres em Situação de Violência (Brasil, 2011), o acolhimento de mulheres em situação de violência com vistas à proteção de sua integridade física e psíquica não se restringe ao acolhimento nas casas-abrigo. É possível fazer o encaminhamento para casas de acolhimento provisório de curta duração que acolhem mulheres em situação de violência doméstica ou outro tipo de violência de gênero por, no máximo, quinze dias. Outra medida possível é a concessão de benefício eventual, nos casos em que se identifique vulnerabilidade temporária de mulheres em situação de risco. 


\section{Considerações finais}

Como elemento central para garantia da integridade física e psíquica de mulheres e da preservação da vida, a avaliação de risco de violência precisa ser fortalecida no Distrito Federal. A compreensão dos riscos envolvidos em uma situação de violência pelos profissionais da rede de atendimento é essencial para a eleição de estratégias de gestão de riscos adequadas ao nível de risco identificado.

Os resultados obtidos indicam que o incentivo à condução de avaliação e gestão de risco, bem como a capacitação continuada de profissionais dos serviços especializados da rede de atendimento devem ser alvo das políticas públicas de enfrentamento à violência sofrida por mulheres. É urgente a normatização da avaliação de risco na Segurança Pública, no Poder Judiciário, no Ministério Público e nos serviços da rede de atendimento a pessoas em situação de violência, do Executivo.

\section{Referências}

Abdala-Filho, Elias. (2012). Avaliação de Risco. In José G. V Taborda, Elias Abdala-Filho, Miguel Chalub (Orgs.). Psiquiatria Forense (pp. 183-204). Porto Alegre: Artmed.

Almeida, Isis \& Soeiro, Cristina. (2010). Avaliação de risco de violência conjugal: versão para polícias (SARA: PV). Análise Psicológica, 1 (28), 179-192.

Angelim, Fábio Pereira. (2010). Mulheres vítimas de violência doméstica: dilemas entre a busca da intervenção do estado e a tomada de consciência. Tese de doutorado, Universidade de Brasília, Distrito Federal.

Angelim, Fábio Pereira. (2009). A importância da intervenção multidisciplinar face à complexidade da violência doméstica. In Fausto Rodrigues de Lima \& Claudiene Santos (Orgs.), Violência doméstica: vulnerabilidades e desafios na intervenção criminal e multidisciplinar (pp. 125-136). Rio de Janeiro: Lumen Juris.

Associação de Mulheres Contra a Violência - AMCV, et al.. (2013). Avaliação e Gestão em rede manual para profissionais - para uma proteção efectiva das sobreviventes de violências nas relações de intimidade. Associação de Mulheres Contra a Violência: Portugal.

Ávila, Thiago André Pierobom de, Machado, Bruno Amaral, Suxberger, Antonio Henrique Graciano \& Távora, Mariana Fernandes (Orgs.). (2014). Modelos europeus de enfrentamento à violência de gênero. Experiências e representações sociais. Brasília: ESMPU. 
Bandeira, Lourdes, \& Thurler, Ana Lieser. (2009). A vulnerabilidade da mulher à violência doméstica: aspectos históricos e sociológicos. In Fausto Rodrigues de Lima \& Claudiene Santos (Orgs.), Violência doméstica: vulnerabilidades e desafios na intervenção criminal e multidisciplinar (pp. 159-167). Rio de Janeiro: Lumen Juris

Barreto, Fabiana Oliveira. (2012). Redução de casos de violência doméstica e familiar contra a mulher na circunscrição judiciária do Paranoá, Distrito Federal: números, princípios e razões. Brasília: Paper.

Brasil (2006). Lei nº 11.340 - Lei Maria da Penha, de 7 agosto de 2006. Código Penal. Diário Oficial da União 8 set 2006; 151: 56. Acessado em 28 de agosto, 2008, de http://www.planalto.gov.br/ccivil/_ato2004-2006/2006/lei/111340.htm

Brasil. (2007). Presidência da República. Política Nacional de Enfrentamento à Violência contra as Mulheres. Brasília: Secretaria de Políticas para as Mulheres.

Brasil. (2011). Presidência da Republica. Secretária Especial de Políticas para as Mulheres. Diretrizes Nacionais para Abrigamento de Mulheres em Situação de Violência. Brasília: Secretaria de Políticas para as Mulheres.

Bracken, Michele Irene, Messing, Jill Theresa, Campbell, Jacquelyn C., La Flair, Lareina N., Kub, Joan. (2010). Intimate partner violence and abuse among female nurses and nursing personnel: prevalence and risk factors. Mental Health Nursing, 31, 137-148.

Bograd, Michele \& Mederos, Fernando. (1990). Battering and couple therapy: universal screening and selections of treatment modality. Journal of marital and family therapy, 25 (3), 291-312.

Campbell, Jacquelyn. (2001). Safety Planning Based on Lethality Assessment for Partners of Batterers in Intervention Programs. Journal of Aggression, Maltreatment \& Trauma, 5 (2), 129-143.

Campbell, Jacquelyn C. (2005). Assessing dangerousness in domestic violence cases: history, challenges, and opportunities. Criminology \& Public Policy. Columbus, 4(4), 653-672.

Campbell, J., Webster, D. W. \& Glass, Nancy. (2009). The Danger Assessment: validations of a lethality risk assessment instrument for intimate partner femicide. Journal of Interpersonal Violence, 24 (4), 653-674.

Campbell, Jacquelyn; Webster, Daniel; Koziol-McLain, Jane; Block, Carolyn, et al. (2003). Risk factors for femicide in abuse relationships: results of a multisite case control study. American Journal of Public Health, 93 (7), 1089 - 1097.

Cattaneo, Lauren Bennett, Bell, Margret E., Goodman, Lisa A. \& Dutton, Mary Ann. (2007). Intimate partner violence victims' accuracy in assessing their risk of re-abuse. Journal of Family Violence, $22,429-440$.

Central de Atendimento à Mulher - Ligue 180/SPM, 2014. Disponível em: http://www.spm.gov.br/noticias/ultimas_noticias/2014/04/24-04-ligue-180-agora-e-disque-balancoanual-mostra-que-subiu-para-70-percentual-de-municipios-atendidos

Davies, Jeel \& Lyon, Eleanor. (1998). Safety planning with battered women: complex lives/difficult choices. Thousand Oaks, CA: Sage. 
Dutton, Mary Ann. A. (2004). Complexity of women's response to Violence. Journal of Interpersonal Violence, 19 (1277-1282).

Diniz, Gláucia Ribeiro Starling, \& Angelim, Fábio. (2003). Violência doméstica: porque é tão difícil lidar com ela? Revista de Psicologia da UNESP, 2 (1), 20-35.

Diniz, Gláucia Ribeiro Starling, \& Pondaag, Miriam Cássia Mendonça. (2006). A face oculta da violência contra a mulher: o silêncio como estratégia de sobrevivência. In Angela Maria de Oliveira Almeida, Maria de Fátima de Souza Santos, Gláucia Ribeiro Starling Diniz \& Zeidi Araújo Trindade (Org.). Violência, exclusão e desenvolvimento humano. Estudos em representações sociais (pp. 233-259). Brasília: Editora UNB.

Diniz, Normélia Maria Freire, Lopes, Regina Lúcia Mendonça, Rodrigues, Adriana Diniz, \&Freitas, Daniela Santos de. Mulheres queimadas pelos maridos ou companheiros. (2007). Acta Paul Enferm, 20(3), 321-325.

Garcia, Leila Posenato; Freitas, Rolim Santana de; Silva, Gabriela Drummond Marques da \& Höfelmann, Doroteia Aparecida (2013). Violência contra a mulher: feminicídios no Brasil. Disponível em: http://www.ipea.gov.br/portal/images/stories/PDFs/130925_sum_estudo_feminicidio_leilagarcia.p df

Gaskell, George. (2008). Entrevistas individuais e grupais. In. Martin W. Bauer \& George Gaskell (Orgs.). Pesquisa qualitativa com texto, imagem e som (pp. 64-89). Petrópolis: Vozes.

Glass, Nancy; Eden, Karen B.; Bloom, Tina; \& Perrin, Nancy. (2010). Computerized aid improves safety decision process for survivors of intimate partner violence. Journal of Interpersonal Violence, 25 (11), 1947-1967.

Grams, Ana Clara \& Magalhães, Teresa. (2011). Violência nas relações de intimidade. Avaliação de Risco. Revista Portuguesa do Dano Corporal, 22, 75-98.

Gondolf, Edward W. (2002). Batterer intervention systems: issues, outcomes and recommendation. USA: Sage Publications.

Greene, Kell \& Bogo, Marion. (2002). The different faces of intimate partner violence: implications for assessment and treatment. Journal of Marital and Family Therapy, 28 (4), 455-466.

Guimarães, Fabrício. (2009). “Mas ele diz que me ama...": impacto da história de uma vítima na vivência de violência conjugal de outras mulheres. Dissertação de mestrado, Universidade de Brasília, Distrito Federal.

Haddock, Shelley A. (2002). Training family therapists to assess for and intervene in partner abuse: a curriculum for graduate courses, professional workshops, and self-study. Journal of Marital and Family Therapy, 28(2), 193-202.

Haggard-Grann, Ulrika. (2007). Assessing violence risk: a review and clinical recommendations. Journal of Counseling and Development, 85 (3), 294-302.

Koller, Silvia Helena, \& Narvaz, Martha Giudice. (2004). Famílias, Gêneros e violências: Desvelando as tramas da transmissão transgeracional da violência de gênero. In Mariana P. R. de Azambuja, Fernanda P. Jaeger \& Marlene N. Strey (Orgs.). Violência, Gênero e Políticas Públicas (pp. 149176). Porto Alegre: Editora da PUCRS. 
Kropp, P. Randall \& Hart, Stephen D. (2000). The spousal assault risk assessment (SARA) guide: reliability and validity in adult male offenders. Law and Human Behavior, 24 (1), 101-118.

Kropp, P. Randall, Hart, Stephen D, Webster, Christopher. D.\& Eaves, Derek. (1994). Manual for spousal assault risk assessment guide. Vancouver: British Columbia Institute on Family Violence.

Kropp, P. Randall, Hart, Stephen D. \& Belfrage, Henrik. (2005). Brief spousal assault form for the evaluation of risk (B-SAFER): user manual. Vancouver: Proactive Resolutions.

Krug, Etienne. G., Dahlberg, Linda L; Mercy, James A., Zwi, Anthony B. \& Lozano, Rafael. (2002). World Report on violence and health. Genebra: WHO, 2002.

Nicholls, Tonia L., Pritchard, Michelle M., Reeves, Kim A. \& Hilterman, Edward. (2013). Risk assessment in intimate partner violence: a systematic review of contemporary approaches. Partner Abuse, 4 (1), 76-168.

Medeiros, Marcela. (2010). Violência conjugal: repercussões na saúde mental de mulheres e de suas/seus filhas/os. Dissertação de mestrado, Universidade de Brasília, Distrito Federal.

Minayo, Maria Cecília de Souza. (2006). Violência e Saúde. Rio de Janeiro: Editora Fiocruz.

Ravazzola, María Cristina. (2005). Historias infames: los maltratos em las relaciones. Buenos Aires: Paidós.

Ribeiro, José, et al. (2012). Impacto da audiência interprofissional sobre as mulheres em processo de violência doméstica. In Marília Lobão, Elizangela Caldas Barroco Roque, Eliane Cristina Martins de R. Andrade, Valéria Brito (Orgs), Conexões: teoria e prática do trabalho e redes na Secretária Psicossocial Judiciária do TJDFT (pp. 211-234) . Brasília: Lumen Juris

Santos, Maria José M. Lopes dos (2010). A perícia medico-legal nos casos de violência nas relações de intimidade - contributo para a qualidade. Dissertação de Mestrado, Universidade do Porto, Portugal.

Segato, Rita Laura. (2013). Que es um feminicidio. Notas para um debate emergente. Serie Antropologica, 401, 2-11.

Silva, Taís Cerqueira. (2011). Diretrizes Nacional para o Abrigamento de Mulheres em Situação de Risco e Violência. Brasília: Secretária Nacional de Enfrentamento à Violência contra as Mulheres, Secretaria Especial de Políticas para as Mulheres, Presidência da Republica, 46 p.

Soares, Barbára Sumeci. (2005). Enfrentando a Violência contra Mulher: orientações práticas para profissionais e voluntários (as). Brasília: Secretaria Especial de Políticas para as Mulheres, Presidência da Republica, 63 p.

Walker, Leonore E. A. (1999). The Battered woman syndrome (2. ed.). United States of America: Spring Publishing Company.

Walker Leonore E. A. (2009). The Battered woman syndrome (3. ed.). United States of America: Spring Publishing Company.

Webster, Cristopher. D., Haque, Quazi, Hucker, Stephen. J. (2014). Violence Risk-Assessment and Management: advances though structured professional judgment and sequential redirections (2 ed.). UK: Wiley-Blackwel. 
Williams, Kirk R. \& Houghton, Amy Barry. (2004). Assessing the risk of domestic reoffending: a validation study. Law and Human Behavior, 28 (4), 437-455.

Zanotta, Lia Machado. (2010). Feminismo em movimento. São Paulo: Francis

Zanotta, Lia Machado. (1998). Matar e morrer no feminino e no masculino. In Dijaci David de Oliveira, Ellen Cristina Geraldes, Ricardo Barbosa de Lima (Orgs.). Primavera já partiu: retrato dos homicídios femininos no Brasil (pp.96-121). Brasília: MNDH. 


\section{Artigo 3 - Dimensões da avaliação de risco de}

\section{violência contra mulher na relação íntima}

\section{Marcela Novais Medeiros}

Apresentado como parte integrante de tese de doutoramento do Programa de Pós-Graduação em Psicologia Clínica e Cultura do Departamento de Psicologia Clínica, Instituto de Psicologia, Universidade de Brasília.

\section{Resumo}

O objetivo deste estudo foi identificar variáveis que devem compor uma checklist de avaliação de risco, a partir da análise de fatores de risco presentes nos instrumentos Danger Assessment (DA), Revised Domestic Violence Screening Instrument (DVSI-R) e Spousal Assault Risk Assessment (SARA). A estratégia metodológica envolveu análise da literatura e a coleta de opinião junto a quatorze profissionais da rede de atendimento a pessoas em situação de violência do Distrito Federal. Foi possível identificar sugestões de formulação de itens e de fatores de risco relacionados à vítima, ao autor da violência e sua relação com o sistema de Justiça e à dinâmica relacional que são relevantes para a avaliação de risco.

Palavras-chave: Avaliação de Risco, Fatores de Risco, Violência Perpetrada pelo parceiro íntimo.

Avaliar risco é uma tarefa difícil. Não se pode saber com precisão se uma pessoa apresentará intencionalmente comportamento violento no futuro (Hermoso, Vicente, Mezquita, Martin \& De la Calle, 2012). É possível, no entanto, prever quais grupos possuem maior propensão para cometer determinados atos violentos. Nessa perspectiva, a avaliação de risco é uma tarefa que tem como finalidade prevenir violências 
(Haggard-Grann, 2007) por meio de um prognóstico de reiteração de comportamentos violentos (Hermoso et al., 2012). Configura-se como uma estratégia para avaliar os casos que necessitam de intervenção urgente, de forma a favorecer a gestão adequada de recursos públicos (Campbell, 2005; Grams \& Magalhães, 2011; Williams \& Houghton, 2004).

Desde a década de 1980, diversos instrumentos de avaliação de risco de violência contra a mulher cometida pelo parceiro íntimo foram construídos com objetivo de permitir a identificação de níveis de risco (Acosta, 2013; Echeburúa, Amor, Loinaz \& Coral, 2010). Exemplos desses instrumentos são: Danger Assessment (DA) (Campbell, Webster \& Glass, 2009), Revised Domestic Violence Screening Instrument (DVSI-R) (Williams \& Houghton, 2004), Ontario Domestic Assault Risk Assessment (ODARA) (Hilton et al., 2004), Spousal Assault Risk Assessment (SARA) (Kropp, Hart, Webster \& Eves, 1999), Escala de Predicción del Riesgo de Violência Grave Contra la Pareja-revisada (EPV-R) (Echeburúa et al, 2010).

Os Estados Unidos e o Canadá foram pioneiros no desenvolvimento desse tipo de instrumento. O primeiro instrumento de avaliação de risco, por exemplo, foi o Danger Assessment (DA), desenvolvido nos Estados Unidos. O Brasil, ao contrário desses países e de países europeus, ainda não desenvolveu um instrumento de avaliação de risco cujo valor preditivo tenha sido estudado por meio de pesquisa científica.

Entre os instrumentos de avaliação de risco disponíveis na literatura internacional destacam-se: a Danger Assessment (DA), a Spousal Assault Risk Assessment (SARA), o Revised Domestic Violence Screening Instrument (DVSI-R). Tais instrumentos, construídos em Língua Inglesa e com propriedade adequada à cultura de seu país de origem são citados em diversos estudos de línguas inglesa, portuguesa e 
espanhola. Além disso, foram utilizados por profissionais da rede de atendimento a pessoas em situação de violência nos Estados Unidos e Canadá e em países como Espanha e Portugal, após os devidos processos de tradução e adaptação.

A Danger Assessment (DA) foi elaborada pela americana Jaqueline Campbell, com o intuito de avaliar o risco de mulheres sofrerem homicídio em relações íntimas heterossexuais (Campbell, 2005; Campbell et al., 2009). É um instrumento que pode ser usado em qualquer órgão da rede de atendimento a vítimas de violência, sendo composto de vinte itens que devem ser respondidos com "sim ou não". Nesses itens são descritos fatores de risco relacionados à vítima, ao agressor e à dinâmica da relação. Também compõe o instrumento um calendário no qual a vítima deve marcar em cada data a gravidade do incidente ocorrido de acordo com a seguinte escala: 1. Tapas, empurrões, sem ferimento e/ou dor presente; 2. Perfurações, chutes, socos, cortes, e/ou dor presente; 3. "Surra", contusões graves, queimaduras, ossos quebrados; 4. Ameaça de uso de armas, ferimentos na cabeça, ferimentos internos, ferimentos permanentes; 5. Uso de armas, ferimento decorrente do uso de armas (Campbell, 2004a).

O Revised Domestic Violence Screening Instrument (DVSI-R) é um instrumento americano de avaliação do risco de reincidência e agravamento de violência doméstica preenchido por profissionais da Justiça, a partir das informações contidas na ficha criminal de autores de violência contra a parceira íntima (Webster, Haque \& Hucke, 2013). É composto por onze itens que abordam a dinâmica da relação, aspectos relacionados à vítima e à história do agressor (Williams \& Houghton, 2004).

A Spousal Assault Risk Assessment Guide (SARA) é uma forma canadense de avaliação de risco que objetiva avaliar o risco de reincidência e agravamento de violência contra mulher perpetrada pelo parceiro íntimo. Foi construída para ser 
aplicada no contexto da Justiça preferencialmente por profissional da saúde mental, a partir de informações obtidas em entrevistas, em registros criminais, em prontuários (Kropp \& Hart, 2000; Nicolls, Pritchard, Reeves \& Hilterman, 2013; Santos, 2010). É composta por vinte itens que abordam história criminal, o ajustamento psicossocial, a história de violência passada e recente e outros fatores de risco identificados no caso particular.

Os instrumentos de avaliação de risco acima citados tiveram seus itens formulados a partir da identificação de fatores de risco e demonstram preocupação com estatísticas de validade. Os fatores de risco são elementos individuais, sociais e contextuais que aumentam a probabilidade de ocorrer um ato violento (Hermoso et al., 2012). Não são necessariamente causas diretas da violência. São elementos que potencializam o acontecimento da violência e, nesse sentido, quanto mais fatores de risco ocorrerem juntos, maior o risco de reincidência de violência e de possibilidade de ela ser letal (Santos, 2010).

Os fatores de risco de violência perpetrada por parceiro íntimo podem ser estáticos ou dinâmicos, sendo divididos quanto a sua probabilidade de modificação e influência no nível de risco (Acosta, 2013; Almeida \& Soeiro, 2010; Haggard-Grann, 2007; Heckert \& Gondolf, 2005). Os fatores estáticos são aqueles que têm maior estabilidade ao longo do tempo e se relacionam com a história de vida e características pessoais (Haggard-Grann, 2007). Tais fatores são mais difíceis de serem alterados. São fatores estáticos, por exemplo, comportamento violento prévio.

Os fatores dinâmicos são aqueles que têm maior propensão para sofrer alterações ao longo do tempo, com ou sem intervenção profissional. São fatores dinâmicos, as variáveis sociais, situacionais e psicológicas (Almeida \& Soeiro, 2010). Ter pouca 
idade, estar desempregado, ter acesso a arma (Haggard-Grann, 2007), ter acesso à vítima e à participação em programas de intervenção (Heckert \& Gondolf, 2005). Alguns fatores de riscos dinâmicos sofrem mudança mais rapidamente por meio da intervenção clínica. Ter pouca idade, por exemplo, é um fator relacionado a pouca maturidade que pode ser apressada por meio de um tratamento que favoreça o amadurecimento (Haggard-Grann, 2007).

Estratégias de avaliação de risco devem incluir tanto fatores estáticos quanto dinâmicos. Especial consideração deve ser dada aos elementos dinâmicos, que requerem uma avaliação continuada, à medida que podem alterar a situação de risco a qualquer momento (Almeida \& Soeiro, 2010). Nessa perspectiva, a atenção a tais variáveis possibilita o manejo do caso e a previsão em longo prazo do risco (Heckert \& Gondolf, 2005).

É possível encontrar na literatura diversos fatores de risco de reincidência de violência perpetrada por parceiro íntimo e de homicídio que devem ser considerados durante uma avaliação de risco. Tais fatores de risco podem relacionar-se com a vítima, com o agressor, com a dinâmica da relação do casal, com o ambiente familiar no qual a relação ocorre e com o ambiente sociocultural (Santos, 2010).

Autores (Campbell et al., 2003; Campbell et al., 2009) que pesquisam especificamente o homicídio conjugal feminino destacam a importância de distinguir os fatores de risco relativos à reincidência de violência dos fatores relacionados ao femicídio. Esses fatores de risco podem sobrepor-se, mas não exatamente os mesmos (Campbell, 2004b; Campbell et al, 2009). O conceito de reincidência é diferente do conceito de risco de femicídio. Nesse último caso, é preciso, conforme apontam 
Avaliação de risco de violência contra a mulher

Campbell e colaboradores (2009), demarcar a real intenção de matar. No quadro 1, foi realizada a sistematização de tais fatores de riscos. 
Quadro 1. Fatores de risco de reincidência e de femicídio.

Risco de Reincidência

Femicídio

\begin{tabular}{|c|c|c|c|}
\hline \multirow[b]{2}{*}{ Mulher } & $\begin{array}{l}\text { Características } \\
\text { Psicológicas }\end{array}$ & $\begin{array}{l}\text { Dificuldades de tomar decisões e baixa autoestima; ser } \\
\text { dependente emocionalmente do parceiro (Soares, 2005; } \\
\text { Santos, 2010). }\end{array}$ & $\begin{array}{l}\text { Ser jovem (idade entre } 14 \text { a } 44 \text { anos); perceber-se em perigo } \\
\text { (Campbell et al., 2003; Campbell, et al., 2009); ter transtornos } \\
\text { psiquiátricos (Walker, 1999). }\end{array}$ \\
\hline & $\begin{array}{l}\text { Características } \\
\text { Socioambientai } \\
\text { s e Econômicas }\end{array}$ & $\begin{array}{l}\text { Dependência financeira do companheiro; falta de acesso } \\
\text { a serviços de proteção e tratamento e de suporte social } \\
\text { (Haggard-Grann, 2007; Santos, 2010); condições de } \\
\text { pobreza extrema (Santos 2010). }\end{array}$ & $\begin{array}{l}\text { Isolamento de amigos e familiares junto com seu companheiro } \\
\text { (Walker, 1999). }\end{array}$ \\
\hline \multirow[t]{2}{*}{ Homem } & $\begin{array}{l}\text { Características } \\
\text { Psicológicas }\end{array}$ & $\begin{array}{l}\text { Ter personalidade impulsiva e baixo autocontrole; ser } \\
\text { intolerante; ter baixa capacidade de reflexão de seus } \\
\text { atos; não reconhecer o abuso cometido (Santos, 2010; } \\
\text { Bograd \& Mederos, 1999); ter história criminal } \\
\text { (Almeida \& Soeiro, 2010; Bograd \& Mederos, 1999); } \\
\text { fazer uso abusivo de substâncias (Santos, 2010; Bograd } \\
\text { \& Mederos, 1999). }\end{array}$ & $\begin{array}{l}\text { Ter idade muito maior que a vítima (Campbell et al., 2009; } \\
\text { Campbell, et al., 2003); ser excessivamente ciumento e } \\
\text { controlador (Soares, 2005; Santos, 2010); ter necessidade de } \\
\text { controlar as crianças; usar violência e coerção para resolver } \\
\text { conflitos (Walker, 1999);ter tentado suicídio (Campbell et al., } \\
\text { 2003); ter história criminal prévia; ter aumentado consumo de } \\
\text { álcool e outras drogas (Walker, 1999); ter ameaçado cometer } \\
\text { homicídio seguido de suicídio; falta de senso de consequência } \\
\text { (Soares, 2005);ter transtornos psiquiátricos; ter comportamento } \\
\text { de destruir objetos (Walker, 1999). }\end{array}$ \\
\hline & $\begin{array}{l}\text { Condições } \\
\text { socioambientais } \\
\text { e Econômicas }\end{array}$ & $\begin{array}{l}\text { Baixo nível econômico e sociocultural; desempregado } \\
\text { (Santos, 2010). }\end{array}$ & $\begin{array}{l}\text { Estar desempregado (Campbell et al., 2009; Campbell, et al., } \\
\text { 2003); ter acesso a armas brancas e de fogo (Bograd \& } \\
\text { Mederos, 1999; Santos, 2010). }\end{array}$ \\
\hline $\begin{array}{l}\text { Violências } \\
\text { e } \\
\text { dinâmica } \\
\text { relacional }\end{array}$ & & $\begin{array}{l}\text { Ocorrência de violências bizarras entre o casal; } \\
\text { stalking (Bograd \& Mederos, 1999); ameaças de } \\
\text { morte; crises do ciclo de vida familiar (divórcio, } \\
\text { separação, morte); migração; famílias com muitos } \\
\text { filhos e famílias recasadas; gravidez indesejada (Santos } \\
\text { 2010); coabitação (Hilton, Harris, Rice, Houghton \& } \\
\text { Eke, 2011). }\end{array}$ & $\begin{array}{l}\text { Episódio de violência prévia na relação íntima; presença de } \\
\text { filhos de outra relação; coabitação sem casamento formal; } \\
\text { tentativa de separação após coabitação (Campbell et al., 2003; } \\
\text { Campbell et al., 2009); agressão durante a gravidez; violência } \\
\text { sexual; stalking; estrangulamento; escalonamento da violência } \\
\text { física; abuso contra criança (Campbell et al., 2003); } \\
\text { escalonamento da violência; sexo forçado; novos } \\
\text { relacionamentos amorosos; (Walker, 1999); agressão após a } \\
\text { separação; uso de arma (Soares, 2005). }\end{array}$ \\
\hline
\end{tabular}


Diante da importância da avaliação de risco e da necessidade de que haja uma ferramenta de avaliação de risco seja adequada à cultura brasileira, justifica-se a realização da presente pesquisa cujo objetivo geral é: a identificação de variáveis que devem compor uma checklist de avaliação de risco, a partir da identificação e análise de fatores de risco presentes nos instrumentos Danger Assessment (DA), Revised Domestic Violence Screening Instrument (DVSI- R), Spousal Assault Risk Assessment (SARA).

\section{Método}

A estratégia metodologia envolveu análise da literatura e a coleta de opinião junto a profissionais da rede de atendimento. Em primeiro lugar, a pesquisadora analisou os itens da $D A$, do $D V S I-R$ e da $S A R A$, à luz da teoria sobre fatores de risco. Nesse processo, foram elencadas as dimensões e variáveis de cada instrumento, com vistas ao entendimento de diferenças e similaridades.

Posteriormente, a pesquisadora traduziu para o português itens do DVSI-R e da SARA (Anexos 1 e 2). Esse material, junto com uma versão em português da $D A$ (Anexo 3) disponibilizada pela autora do instrumento em seu site (http://www.dangerassessment.com) foi distribuído durante entrevista sob a forma de grupo focal e entrevista individual. Após a leitura desse material por profissionais da rede de atendimento, foi realizada discussão orientada pelas seguintes perguntas: (1) Os instrumentos de avaliação de risco são adequados para sua realidade de trabalho? (2) Quais itens dos instrumentos, em sua opinião, tratam de fatores de risco que devem compor uma avaliação de risco? 
Os participantes foram identificados e convidados a participar do estudo durante reuniões mensais de profissionais que atendem mulheres em situação de violência. Participaram das entrevistas sob a forma de grupo focal treze profissionais da rede de atendimento a pessoas em situação de violência. Entre eles; dois eram psicólogos que atuam em serviço psicossocial de assessoramento aos magistrados do Tribunal de Justiça do Distrito Federal e Territórios; dois eram estagiários de Psicologia do Tribunal de Justiça do Distrito Federal e Territórios; duas eram psicólogas da Secretária de Saúde com atuação em serviço de proteção a vítimas de violência; uma era psicóloga da Secretaria de Saúde do Distrito Federal com atuação em Centro de Atenção Psicossocial (CAPS); uma era psicóloga do Centro de Referência da Assistência Social (CRAS); uma era psicóloga do Centro de Referência Especializado de Assistência Social (CREAS); três eram pesquisadores de grupo de estudos em gênero; uma era Promotora de Justiça. Também foi realizada uma entrevista individual com o Juiz que atua em Juizado Especializado em Violência Doméstica e Familiar contra as Mulheres.

\section{Resultados e Discussão}

\section{Avaliação dos Itens dos Instrumentos}

A análise dos dados obtidos demonstrou que, na perspectiva dos participantes da pesquisa, nenhum dos instrumentos, na íntegra, é adequado para medir o tema proposto no Distrito Federal. Todavia, seus itens tratam de fatores de fatores de risco de reincidência e de femicídio que são relevantes, sendo importantes para a construção de checklist de avaliação de risco.

Foi possível identificar, também, que os instrumentos avaliados abordam as seguintes dimensões: (1) perfil do autor da violência e perfil da vítima; (2) conflitos 
interpessoais; (3) violência contra a parceira na presença de outros; (4) uso de álcool e/ou drogas; (5) escalada da violência; (6) intervenção para pessoas em situação de violência; (7) meio de agressão; (8) percepção sobre a violência; (9) experiências de violência na família de origem; (10) filhos de outra relação íntima; (11) história criminal; (12) separação/divórcio; (13) outras violências; (14) situação ocupacional; (15) saúde mental; (16) percepção sobre o risco; (17) história de violência contra a parceira; (18) rede social. Cada uma dessas dimensões possui pelo menos uma variável.

A seguir, é descrito com que instrumento cada uma dessas dimensões é tratada e a forma pela qual são abordadas. Também são apresentadas as percepções dos profissionais acerca de cada uma dessas dimensões e de suas variáveis.

\section{(1) Perfil do autor da violência e perfil da vítima}

Conhecer o perfil do autor da violência é uma dimensão importante da avaliação de risco. Os instrumentos avaliam aspectos temperamentais e comportamentais. A DA aborda o comportamento ciumento e o comportamento controlador excessivo. $\mathrm{Na}$ perspectiva dos profissionais participantes da pesquisa, esses itens são considerados extremamente relevantes. Esse tipo de comportamento estaria relacionado à socialização de gênero, à concepção de amor como posse e à baixa autoestima do homem.

O controle é fator de riscos de violência grave (Santos, 2010; Soares, 2005) que, conforme aponta Soares (2005), envolve o monitoramento das atividades da mulher e o seu isolamento de familiares, de amigos e de colegas. Esse fator pode ser agravado, se o homem tiver algum recurso especial contra a mulher, como por exemplo, ser policial ou ter amigo policial. 
São abordadas pela SARA a impulsividade e o baixo controle da raiva, que sinalizam que o autor da violência tem pouca ou nenhuma latência temporal diante de um estímulo que provoque emoção negativa ou positiva. No julgamento de dois participantes, Promotora e Psicólogo Jurídico, a imprevisibilidade da violência está associada a tais características de personalidade.

Cabe ressaltar que nenhum dos instrumentos avalia se faz parte do perfil do homem resolver conflitos de forma violenta. Walker (1999) alerta que o padrão de comportamento violento para resolver conflitos interpessoais é um indicador de riscos de femicídio. Nessa perspectiva, compreender se o parceiro usa arma ou ameaça agredir fisicamente pessoas para intimidar é outro elemento importante para ser investigado quanto à personalidade do agressor.

Nenhum dos instrumentos avalia o perfil da mulher e, para os participantes da pesquisa, é preciso avaliar a personalidade dela também. Em consonância com Soares (2005), alertam que a dependência emocional é um fator de deixa a mulher vulnerável às violências cometidas pelo parceiro.

Quadro 2. Itens e variáveis sobre o perfil do autor da violência.

\begin{tabular}{|c|c|c|}
\hline Instrumento & Item & Variável \\
\hline DA & $\begin{array}{l}13 \text { - Ele tenta controlar a maioria ou todas as suas atividades diárias? } \\
\text { Por exemplo: ele te diz com quem pode ser seu amigo, quando você } \\
\text { pode ver sua família, quanto dinheiro você pode gastar, ou quando } \\
\text { você pode pegar o carro? }\end{array}$ & $\begin{array}{l}\text { Comportamento } \\
\text { controlador }\end{array}$ \\
\hline DA & $\begin{array}{l}14 \text { - "Ele é violento e tem ciúmes, constantemente, de você"? Por } \\
\text { exemplo, ele diz: "Se eu não posso tê-la, ninguém pode". }\end{array}$ & $\begin{array}{l}\text { Ciúme } \\
\text { excessivo }\end{array}$ \\
\hline SARA & $\begin{array}{l}10 \text { - Desordens de personalidade com raiva, impulsividade ou } \\
\text { comportamento instável. }\end{array}$ & $\begin{array}{l}\text { Impulsividade e } \\
\text { baixo controle }\end{array}$ \\
\hline
\end{tabular}

\section{(2) Conflitos interpessoais}

Os profissionais participantes da pesquisa consideram que o tema conflitos no relacionamento adotado pela SARA é importante para compreender risco. Conforme mostram Kropp e Gibas (2010), o item que questiona a ocorrência de problemas de 
relacionamento recente, quer saber se houve separação do parceiro íntimo ou conflitos intensos no último ano.

Quadro 3. Item e variável sobre conflitos interpessoais.

\begin{tabular}{llll}
\hline Instrumento & Item & Variável \\
\hline SARA & $\begin{array}{l}4-\text { Problemas de relacionamento } \\
\text { recente. }\end{array}$ & $\begin{array}{l}\text { Separação da parceira íntima ou conflitos } \\
\text { intensos }\end{array}$ \\
\hline
\end{tabular}

\section{(3) Violência contra a parceira na presença de}

\section{outros}

O DVSI-R inclui a seguinte pergunta: "Crianças estavam presentes durante o incidente de violência familiar?”. A violência na presença de outras pessoas como familiares, amigos ou desconhecidos, que é indicio de que a presença de terceiros não inibe o comportamento violento, não é abordada por nenhum dos instrumentos analisados nesta pesquisa.

Profissionais da rede de atendimento não consideraram a presença de crianças, tratada por um item do DVSI-R, como fator que ajuda a identificar os casos de risco extremo, pois seria frequente em grande parte dos casos. A literatura, contudo, afirma que esse é um fator de reincidência de violências (Santos, 2010).

A psicóloga da Assistência Social apontou que quando crianças estão presentes, por serem vítimas indiretas das violências, seja por ouvir ou por assistir às violências sofridas pela mãe, fica mais fácil acompanhar o caso, pois podem notificar autoridades competentes da existência de violência contra criança. Nesse contexto, as mulheres vítimas sentem-se pressionadas a aceitar a intervenção.

Quadro 4. Item e variável sobre Violência contra a parceira na presença de outros.

\begin{tabular}{lll}
\hline Instrumento & Item & Variável \\
\hline \multirow{2}{*}{ DVSI $-\mathbf{R}$} & $\begin{array}{l}7 \text { - Crianças estavam presentes durante o incidente de } \\
\text { violência familiar? }\end{array}$ & $\begin{array}{l}\text { Crianças } \\
\text { indiretas das violências. }\end{array}$ \\
\hline
\end{tabular}




\section{(4) Uso de álcool e/ou drogas}

O tema uso de álcool e/ou drogas aparece nos três instrumentos. A DA divide em dois itens a investigação de álcool e de drogas. Separa o uso eventual do uso abusivo. O DVSI-R coloca de forma geral o uso de substâncias, sem especificar se é abusivo, no intuito de investigar se houve o uso durante a violência. A SARA questiona a dependência física ou psicológica dessas substâncias.

Para os participantes da pesquisa, o uso de álcool é muito frequente, sendo sua dependência mais relevante para saber se há risco de agravar. Na perspectiva desses participantes, os itens 12 da DA e 7 da SARA seriam os mais importantes para compreender o risco de femicídio, por ressaltarem não apenas o uso, mas a dependência de álcool e de outras substâncias.

O uso de álcool, abusivo ou não, pode aumentar a possibilidade de ocorrência de violência, pois diminui as inibições e a capacidade de julgamento, bem como altera a habilidade de interpretar os sinais (Krug, Dahlberg, Mercy, Zwi, \& Lozano, 2002). Outras substâncias psicoativas além do álcool e consideradas ilícitas também alteram o estado de consciência, da cognição e do humor (Abdalla-Filho \& Oliveira, 2002). Por isso, o uso de álcool e de outras substâncias pode contribuir para o comportamento violento e estimular a violência perpetrada pelo parceiro íntimo. Contudo, nem todos os que fazem uso de álcool ou de outras substâncias demonstram comportamento violento e agridem fisicamente suas parceiras. Nessa perspectiva, é importante compreender se o parceiro íntimo apresenta comportamento violento com a parceira quando sob efeito dessas substâncias e se elas potencializam a violência.

O uso de drogas é um fator de risco de reincidência, enquanto o uso abusivo é sinalizado como fator indicativo de risco extremo de violência (Bograd \& Medeiros, 
1999; Santos, 2010; Soares, 2005). O abuso de drogas parece relacionado ao femicídio como indicador indireto, à medida que é fator de risco para violências físicas que, por sua vez, são fatores de risco diretos para femicídio (Campbell et al., 2003).

Quadro 5. Itens e variáveis sobre uso de álcool e/ou drogas.

\begin{tabular}{|c|c|c|}
\hline Instrumento & Item & Variável \\
\hline DA & $\begin{array}{l}11 \text { - Ele usa alguma droga ilegal? Por drogas entenda: } \\
\text { "estimulante ou anfetaminas, heroína, crack, drogas de } \\
\text { rua ou misturas". }\end{array}$ & Drogas ilegais \\
\hline DA & 12 - Ele é alcoólatra ou tem problemas com bebidas? & Álcool \\
\hline DVSI - R & $\begin{array}{l}5 \text { - Evidência de uso de substância durante o incidente de } \\
\text { violência familiar? }\end{array}$ & Qualquer substância \\
\hline SARA & 7- Recente abuso/dependência de substâncias. & $\begin{array}{ll}\text { Dependência } & \text { de } \\
\text { Qualquer substância } & \\
\end{array}$ \\
\hline
\end{tabular}

\section{(5) Escalada da violência}

Os instrumentos DA, DVSI-R e SARA abordam a escalada da violência. A DA quer saber se a violência física aumentou no último ano. O DVSI-R divide em duas perguntas o questionamento sobre o aumento da intensidade e da frequência da violência familiar nos últimos seis meses. A SARA em um único item pergunta sobre o aumento da frequência e da intensidade, sem fazer delimitação temporal.

A escalada da violência é uma dimensão fundamental. Foi consenso entre os profissionais a relevância do item 1 da DA para compreender o risco de femicídio. Tais percepções estão em consonância com a literatura. A violência física aumentada é uma variável apontada como fator de risco de homicídio (Campbell et al., 2003). O escalonamento da violência, independente do tipo, é fator de risco para femicídio (Walker, 1999).

Os profissionais indicaram a necessidade de investigar o aumento da violência psicológica e a transformação desse tipo de violência em violência física para o entendimento do agravamento da situação. Segundo uma das participantes, é relevante 
ter dois itens sobre esse tema: um sobre violência física e um sobre violência psicológica.

Quadro 6. Itens e variáveis sobre a escalada da violência.

\begin{tabular}{lll}
\hline Instrumento & Item & Variável \\
\hline DA & $\begin{array}{l}\text { 1 - A violência física aumentou de severidade ou de } \\
\text { frequência no último ano? }\end{array}$ & Escalada da violência física \\
\hline DVSI - R & $\begin{array}{l}\text { 10- Qual foi a frequência de violência familiar nos } \\
\text { últimos } 6 \text { meses? }\end{array}$ & $\begin{array}{l}\text { Frequência da violência } \\
\text { familiar }\end{array}$ \\
\hline DVSI - R & $\begin{array}{l}\text { 11 - O padrão de violência familiar escalou nos } \\
\text { últimos } 6 \text { meses? }\end{array}$ & $\begin{array}{l}\text { Aumento da intensidade da } \\
\text { violência familiar }\end{array}$ \\
\hline SARA & $\begin{array}{l}14 \text { - Recente escalonamento na frequência ou } \\
\text { severidade da violência. }\end{array}$ & $\begin{array}{l}\text { Aumento da frequência e da } \\
\text { intensidade }\end{array}$ \\
\hline
\end{tabular}

\section{(6) Intervenção para pessoas em situação de violência}

Somente o DVSI-R pergunta se o autor da violência já fez tratamento para pessoas em situação de violência. Na perspectiva de profissionais, esse item não é relevante.

Ter participado de atendimento para homens em situação de violência e ainda continuar agredindo a parceira íntima pode ser um indício de que o homem considera natural o uso da violência e que não se sente coagido pela rede de atendimento a pessoas em situação de violência. Não ter aceitado participar desse tipo de atendimento pode sinalizar que o agressor não se responsabiliza pela violência.

Quadro 7. Item e variável sobre intervenção para pessoas em situação de violência.

\begin{tabular}{lll}
\hline Instrumento & Item & Subtema \\
\hline DVSI-R & $\begin{array}{l}3 \text { - Prévio tratamento/intervenção para pessoas em } \\
\text { situação de violência? }\end{array}$ & $\begin{array}{l}\text { Atendimento para homens } \\
\text { autores de violência } \\
\text { doméstica }\end{array}$ \\
\hline
\end{tabular}

\section{(7) Meio de agressão}

O tema meio de agressão aparece no instrumentos DA, DVSI-R e SARA. Eles usam as palavras arma, arma letal, revólver e faca. O acesso a armas é apontado como fator de risco de ocorrência de violências (Santos 2010; Bograd \& Mederos, 1999). O 
uso dessas armas durante a violência é fator de risco extremo de violência (Soares, 2005).

A DA tem três itens sobre esse tema. Questiona se o agressor tem arma, se já usou arma letal contra companheiro, se a arma era revólver. Não tem pergunta específica sobre uso de faca, embora inclua faca quando pergunta se o autor já usou arma letal. Não pergunta sobre outras armas de fogo além do revólver, tais como, espingarda, metralhadora, cartucheira.

Por sua vez, o DVSI-R e a SARA perguntam somente sobre o uso de faca, que é uma arma branca. Outros instrumentos que poderiam causar o mesmo tipo de lesão que a faca não foram mencionados. O uso de arma de fogo também não foi aludido.

DA, DVSI-R e SARA valorizam somente os instrumentos perfurocontantes do tipo faca e o perfurocontundente do tipo arma de fogo. Os instrumentos contundentes, como pedaço de pau, cassetete, barra de ferro, deveriam ser considerados, mas não o são.

Na perspectiva dos profissionais participantes da pesquisa, identificar se houve o uso de arma é extremamente relevante para entender o risco de femicídio. Tanto o uso de arma durante as agressões, quanto o acesso a elas são apontados como fatores de risco.

A necessidade de especificar do tipo de arma, se era revólver ou faca, realizada no item 2 da DA, não foi consensual entre os profissionais. Alguns profissionais consideram que faca e arma de fogo têm o mesmo grau de risco, enquanto outros consideram que o uso de arma é mais grave. 
Quadro 8. Itens e variáveis sobre meios de agressão.

\begin{tabular}{lll}
\hline Instrumento & Item & Variável \\
\hline DA & 2 - Ele possui arma? & Arma \\
\hline DA & $\begin{array}{l}\text { 5 - Ele já usou uma arma contra você ou ameaçou você com uma } \\
\text { arma letal? Se sim, a arma era revólver? }\end{array}$ & $\begin{array}{l}\text { Ameaça/uso } \\
\text { de arma letal }\end{array}$ \\
\hline DVSI - R & $\begin{array}{l}\text { 6 - Qualquer evidência de uso de faca durante prévio ou atual crime } \\
\text { de violência familiar? }\end{array}$ & Faca \\
\hline SARA & 13 - Uso de facas ou de ameaças consistentes de morte. & $\begin{array}{l}\text { Uso/ameaça } \\
\text { com faca }\end{array}$ \\
\hline SARA & 19 - Uso de facas ou ameaças de morte (último ano). & $\begin{array}{l}\text { Uso/ameaça } \\
\text { com faca }\end{array}$ \\
\hline
\end{tabular}

\section{(8) Percepção sobre a violência}

Somente a SARA investiga se a vítima e o autor da violência não reconhecem a situação de violência. Em um item a SARA pergunta se a vítima tem atitudes no sentido de suportar ou de perdoar a violência. Em outro item, questiona se o agressor minimiza ou nega a violência. Essa minimização, descrita no item 16 da SARA, segundo (Kropp \& Gibas, 2010), tem relação com um padrão de não reconhecer comportamentos criminosos, ou com o não reconhecimento somente da violência contra mulher. O não reconhecimento da gravidade da violência, expresso nos itens 16 e 17 da SARA, é fator de risco de reincidência (Bograd \& Mederos, 1999; Santos, 2010; Soares, 2005), avaliado como importante para uma avaliação de risco pelo juiz, pelo psicólogo jurídico, pela psicóloga da saúde e pela psicóloga da assistência social. Uma das profissionais sugeriu que o item 16 da DA fosse alterado para: "Desconsidera totalmente os atos dele contra ela" (psicóloga da assistência social).

Quadro 9. Itens e variáveis sobre percepção da violência.

\begin{tabular}{lll}
\hline Instrumento & Item & Variável \\
\hline SARA & 16 - Extrema negação ou minimização da violência. & Diminuir \\
\hline SARA & 17 - Atitudes de suportar ou perdoar a violência. & Perdoar \\
\hline
\end{tabular}




\section{(9) Experiências de violência na família de origem}

Na SARA consta uma pergunta sobre o fato de o agressor ter sido vítima ou testemunha de violência doméstica. Esse item faz referência a situações disfuncionais vivenciadas na família de origem e que podem contribuir para o comportamento violento (Kropp \& Gibas, 2010). A transgeracionalidade da violência é um fator de risco de reincidência apontado pela literatura (Santos, 2010), porque a exposição a tais vivências naturaliza a situação de dominação das mulheres pelos homens e a submissão feminina (Koller \& Narvaz, 2004).

Quadro 10. Item e variável sobre experiências de violência na família de origem.

\begin{tabular}{lll}
\hline Instrumento & Item & Variável \\
\hline SARA & 6 - Foi vítima ou testemunha de violência doméstica. & Vítima de violência doméstica. \\
\hline
\end{tabular}

\section{(10) Filhos de outra relação íntima}

Na DA há uma pergunta sobre a vítima ter filhos com outro parceiro que não é o agressor, que a literatura aponta como fator de risco de femicídio (Campbell et al., 2003; Campbell, et al., 2009). Na perspectiva de profissionais, esse questionamento é relevante para avaliar riscos.

Quadro 11. Item e variável sobre filhos de outra relação íntima.

\begin{tabular}{lll}
\hline Instrumento & Item & Variável \\
\hline DA & 8 - Você tem uma criança que não é filha dele? & Filhos que não são do agressor. \\
\hline
\end{tabular}

\section{(11) História Criminal}

A história criminal, investigada pelos instrumentos tem as seguintes variáveis: prisão por violência contra não familiares, prisão por violência doméstica e violação de ordem judicial. Tais elementos são classificados na literatura como fatores de risco de 
reincidência (Almeida \& Soeiro, 2010; Bograd \& Mederos, 1999) e de femicídio (Walker, 1999).

O DVSI-R e a SARA buscam entender a forma pela qual o agressor se relaciona com o sistema de Justiça. O DVSI-R investiga se há história criminal não relacionada à violência doméstica e violação de medida judicial relacionada a qualquer crime. $\mathrm{O}$ SARA investiga a violação de ordens judiciais e exemplifica vários tipos de violações. Se tais violações ocorrem concomitantes a um episódio de violência contra a parceira, não serão fatores de risco a serem considerados.

A DA não focaliza a prisão em si, mas se o agressor já tentou não ser preso por violência. A autora desse instrumento em publicação compartilhada com outros autores (Campbell et al., 2003) destaca que ser preso por outros crimes não diferencia aquele que comete homicídio contra a parceira íntima daquele que é autor de outras violências contra a mulher. Prisão anterior por violência doméstica também não é considerado um fator de risco para femicídio. Tal prisão, ao contrário, pode ser protetiva já que pode impedir que ocorra tentativas de homicídio.

Os textos dos itens que abordam a história criminal foram os que mais geraram sugestões de mudança. Na percepção de Promotora e do Juiz, o item 4 do DVSI deveria ser unido com os itens 3, 15 e 20 da SARA e item 7 da DA. Nas palavras de um deles: "Descumpriu medida restritiva, violação prévia de liberdade condicional de supervisão comunitária. Esses dois itens é coisa lá dos americanos" (Promotora). Essa participante considera que essa medida de liberdade condicional comunitária não se aplica ao Judiciário brasileiro. Outro participante recomenda que seria interessante especificar "medida protetiva" em vez de usar o termo medida restritiva, conforme escrito no item 4 
do DVSI-R, pois é a nomenclatura utilizada na Lei 11.340/2006, conhecida como Maria da Penha, para se referir às medidas protetivas de urgência.

O descumprimento de medidas protetivas de urgência foi objeto de reflexão. Os profissionais destacaram que é importante entender se o agressor demonstra não ter medo da Justiça. Isso deveria ser verificado em duas situações: quando a mulher deixa-o aproximar-se dela, quando ela não quer a aproximação e mesmo assim ele se aproxima.

O item 1 do DVSI-R foi considerado relevante pelos profissionais da rede, mas um dos participantes sugeriu alteração. Considera que é necessário especificar quais os tipos de crimes cometidos pelo agressor.

O item 7 da DA é avaliado como relevante para avaliação de risco. Um dos participantes esclareceu que a principal manobra para não ser preso é tentar impedir que a mulher busque ajuda na Delegacia.

Quadro 12. Itens e variáveis sobre história criminal.

\begin{tabular}{lll}
\hline Instrumento & Item & Variável \\
\hline DVSI-R & $\begin{array}{l}1-\text { Evidencia de assaltos, prisões ou condenação } \\
\text { criminais não relacionados à violência familiar? }\end{array}$ & $\begin{array}{l}\text { Prisão por Violência contra } \\
\text { não familiares }\end{array}$ \\
\hline DVSI - R & $\begin{array}{l}4-\text { História de violação de medidas restritivas ou } \\
\text { supervisão da corte? }\end{array}$ & Violação de ordem judicial \\
\hline SARA & $\begin{array}{l}3-\text { Violação passada de liberdade condicional ou } \\
\text { supervisão comunitária. }\end{array}$ & Violação de ordem judicial \\
\hline SARA & 15 - Violações passadas de ordens de não contato. & Violação de ordem judicial \\
\hline SARA & 20 - Violações de ordens de não contato (último ano). & Violação de ordem judicial \\
\hline DA & 7 - Ele já tentou não ser preso por violência doméstica? & Violação de ordem judicial \\
\hline
\end{tabular}

\section{(12) Separação/divórcio}

Somente a DA tem um item sobre separação/divórcio, tendo como foco a investigação de tentativa de separação. Esse fator é apontado como elemento de risco extremo de violências (Campbell et al., 2003), especialmente, se, após a tentativa de separação, o agressor foi atrás da companheira e a agrediu ou foi violento com pessoas que a ajudavam (Soares, 2005). 
$\mathrm{Na}$ perspectiva de profissionais, especialmente dos psicólogos e do juiz, é interessante avaliar o comportamento do agressor após a separação, no intuito de saber se ele a nega. É necessário também entender por que a mulher não se separou. Um dos motivos pode ser o medo do agressor, conforme apontaram os psicólogos.

Quadro 13. Item e variável sobre separação/divórcio.

\begin{tabular}{lll}
\hline Instrumento & Item & Variável \\
\hline DA & $\begin{array}{l}3 \text { - Você o deixou depois de viverem juntos no último } \\
\text { ano? Se você nunca o deixou marque aqui }\end{array}$ & Tentativa de separação \\
\hline
\end{tabular}

\section{(13) Outras violências}

Enquanto a DA focaliza o comportamento violento com crianças, a SARA investiga a violência contra estranhos ou desconhecidos e a violência doméstica além daquela contra a parceira íntima. De acordo com Kropp e Gibas (2010), o item que investiga se o autor da violência já cometeu violência doméstica, diz respeito à violência contra membros da família de origem dele ou da parceira, ou contra os filhos e filhas dele ou dela. $\mathrm{O}$ item que investiga a violência passada contra estranhos ou desconhecidos, diz respeito à violência contra pessoas com quem não tem nenhum vínculo familiar, nem biológico, nem jurídico.

A violência contra crianças é avaliada por apenas um dos profissionais da rede como um elemento muito importante para entender se a violência se está agravando. Campbell e colaboradores (2003) destacam que, se o agressor ameaça machucar as crianças ou as agride, é fator de risco extremo.

Soares (2005) e Walker (2009) alertam que a crueldade com animais e outros abusos intra ou extrafamiliares também são fatores de risco para violências. Nessa perspectiva, além da violência contra desconhecidos, crianças e outros familiares, é importante avaliar também a violência contra animais domésticos e a violência contra 
outras parceiras para que se compreenda se o comportamento violento está associado à naturalização da violência no ambiente doméstico.

Quadro 14. Itens e variáveis sobre outras violências.

\begin{tabular}{llll}
\hline Instrumento & Item & Variável & \\
\hline SARA & 2 - Violência passada contra estranhos ou desconhecidos. & $\begin{array}{l}\text { Violência contra não } \\
\text { familiares }\end{array}$ \\
\hline SARA & $\begin{array}{l}\text { 1- Violência passada contra membros da família (Não } \\
\text { inclui violência contra parceiro íntimo). }\end{array}$ & $\begin{array}{l}\text { Violência } \\
\text { exceto contra a parceira } \\
\text { íntima. }\end{array}$ \\
\hline DA & 17 - Ele ameaça machucar seus filhos? & $\begin{array}{l}\text { Violência doméstica contra } \\
\text { criança }\end{array}$ \\
\hline
\end{tabular}

\section{(14) Situação ocupacional}

DA e DVSI-R têm cada um apenas um item no qual é abordado o status ocupacional. A SARA aborda essa questão associada a problemas de relacionamento no emprego, definindo-a como desemprego ou instabilidade quanto ao status.

A literatura mostra que o desemprego pode ser tanto fator de risco de reincidência (Santos, 2010), quanto de femicídio (Campbell et al., 2003; Campbell, et al., 2009). Para profissionais da rede de atendimento, esse não é fator que ajuda a separar riscos, pois é elemento presente em quase todos os casos. Isso pode ter relação com o perfil da população que busca atendimento em órgãos governamentais, nos quais atuam os participantes da pesquisa, ou com vieses e mitos relacionados à violência.

Quadro 15. Itens e variáveis sobre situação ocupacional.

\begin{tabular}{lll}
\hline Instrumento & Item & Variável \\
\hline DA & 4 - Ele está desempregado? & Desemprego \\
\hline DVSI - R & 8 - Atual status ocupacional? & Desempregado/empregado \\
\hline SARA & 5 - Recente problema no emprego. & $\begin{array}{l}\text { Desemprego } \\
\text { instabilidade quanto ao } \\
\text { status. }\end{array}$ \\
\hline
\end{tabular}




\section{(15) Saúde mental}

Ao abordar a saúde mental, os seguintes elementos são investigados pelo DA e SARA: ameaça de suicídio seguido ou não de intenção homicida e presença de transtorno mental. DA e SARA abordam o suicídio. Em um item, a DA questiona se o companheiro já ameaçou ou tentou suicídio. Em outro item pergunta o mesmo com relação à vítima. Já a SARA pergunta em um mesmo item se o autor já demonstrou intenção suicida ou homicida. Somente a SARA pergunta sobre sintomas maníacos e psicóticos apresentados pelo agressor.

Na perspectiva dos psicólogos e do juiz, participantes da pesquisa, sobre a saúde mental, é mais relevante o entendimento da ideação suicida do autor e da vítima. Um dos participantes da pesquisa destaca que saber se há ideação suicida acompanhada de intenção suicida é extremamente relevante por demonstrar que o agressor está disposto a ir às últimas consequências. Essa percepção está em consonância com a literatura que destaca como fatores de risco de femicídio tanto a ideação suicida (Campbell et al., 2003), quanto o desejo de morte seguido de envolvimento da mulher nesse processo como "ele fez roleta russa e me forçou a fazer também" (Soares, 2005, p.61).

Sobre os sintomas maníacos e psicóticos, é importante destacar que, embora não haja uma associação direta entre transtorno mental e violência, o adoecimento mental é uma das variáveis que devem ser investigadas, conforme alerta Abdalla-Filho (2012). Indivíduos com sintomas psicóticos, acompanhados ou não de sintomas maníacos, podem apresentar comportamentos violentos, sendo suas vítimas, especialmente, pessoas conhecidas (Telles, Day \& Zoratto, 2012).

Um homem que comete violência contra sua parceira, legitimado pela desigualdade de gênero e pela naturalização da violência contra a mulher, pode tornar- 
se mais violento caso passe a apresentar sintomas psicóticos com ou sem mania. Soares (2005, p. 61) alerta que é importante saber se a mulher acha que ele "parece maluco", focalizando mudanças de comportamento e perda do senso de consequência. Caso ache que o agressor mereça ser contido, a mulher está em risco extremo.

Walker (1999) e Santos (2010) alertam que a saúde mental da mulher também deve ser avaliada. A identificação de transtornos psiquiátricos na mulher e o uso abusivo de remédios psicotrópicos são elementos que devem ser identificados como fatores de risco de femicídio e de outras violências. Resultados de estudo (Cattaneo et al., 2007) mostram que mulheres com sintomas de Transtorno de Estresse PósTraumático tendem a superestimarem o risco, enquanto aquelas que fazem uso abusivo de álcool subestimam o risco. Portanto, faz-se necessário avaliar a ocorrência desses comprometimentos da saúde.

Walker (2009) demonstra que sintomas da Síndrome da Mulher Maltratada, adoecimento típico de mulheres reiteradamente agredidas, prejudica a capacidade de a mulher prever quais ações serão efetivas para se proteger. A mulher fica mais pessimista e com a sensação de que nada pode ser feito para mudar sua situação. Os sintomas dessa síndrome, considerada uma subcategoria do Transtorno de Estresse Pós-Traumático, são: disfunção na relação do casal, marcada pelo isolamento da mulher e controle e poder por parte do agressor, cujos comportamentos são imprevisíveis e manipuladores; distorção da imagem corporal; queixas físicas ou somáticas e ligadas à intimidade sexual; entorpecimento emocional e evitação comportamental da situação, por meio de minimização, de repressão, de negação e de depressão. 
Quadro 16. Itens e variáveis sobre saúde mental.

\begin{tabular}{lll}
\hline Instrumento & Item & Variável \\
\hline DA & 16 - Ele já ameaçou ou tentou cometer suicídio? & $\begin{array}{l}\text { Ameaça de suicídio pelo } \\
\text { autor da violência }\end{array}$ \\
\hline DA & 20- Você já ameaçou ou tentou cometer o suicídio? & $\begin{array}{l}\text { Ameaça de suicídio pela } \\
\text { vítima }\end{array}$ \\
\hline SARA & 8 - Recente intenção/ideação suicida ou homicida. & Suicídio/homicídio \\
\hline SARA & 9 - Recentes sintomas maníacos ou psicóticos. & Transtorno mental \\
\hline
\end{tabular}

\section{(16) Percepção sobre o risco}

Somente a DA incluiu um item para saber qual é a percepção da mulher sobre a letalidade de sua situação. A avaliação positiva da mulher sobre a intenção e capacidade do agressor de matá-la é fator de risco de femicídio, conforme destaca Campbell e colaboradores (2003).

Essa percepção da mulher é valorizada por todos os profissionais da rede de atendimento. Para eles, é essencial conhecer o que ela pensa. Essa percepção cresce em importância diante de ameaças, mesmo sem aumento da intensidade ou frequência da violência física.

Quadro 17. Item e variável sobre percepção do risco.

\begin{tabular}{lll}
\hline Instrumento & Item & Variável \\
\hline DA & 18 - Você acredita que ele é capaz de matá-la? & Capacidade de matar \\
\hline
\end{tabular}

\section{(17) História de violência contra a parceira}

A história de violência passada e atual é avaliada a partir das seguintes variáveis: violência física, violência sexual, estrangulamento, ameaça de morte, violência psicológica, perseguição. A SARA aborda somente a violência sexual atual e passada. O DVSI - R questiona somente a ocorrência de violência psicológica. A DA investiga formas de violência sexual, ameaça, perseguição e violência física grave. 
A violência sexual é considerada fator de risco tanto de reincidência (Soares, 2005), quanto de femicídio (Campbell et al., 2003). Soares (2005) sugere que o comportamento extremamente violento durante o sexo e o sexo forçado são indicativos de alto risco. Persistir para fazer sexo, mesmo quando a companheira não deseja é sugestivo de médio risco.

A ameaça, descrita no item 6 , é considerada por todos os profissionais da rede de atendimento como elemento relevante na avaliação de risco. É um elemento que ajuda a entender a gravidade do caso, mesmo quando a violência física não é intensa ou frequente.

O item 15 da DA que aborda o fator de risco de femicídio (Campbell et al., 2003) violência durante a gestação, é avaliado por operadores do Direito como pouco relevante, porque não acontece com muita frequência. Já os demais participantes, consideram esse item relevante.

O item 9 do DVSI que aborda a violência psicológica é considerado extremamente importante por todos os profissionais, mas deveria ser alterado para uso no Brasil. O foco, na perspectiva deles, deve ser a compreensão do escalonamento da violência psicológica para física. De acordo com a literatura, esse tipo de escalonamento é fator de risco de violências que pode resultar em violências mais graves (Walker, 1999). 
Quadro 18. Itens e variáveis sobre história de violência.

\begin{tabular}{|c|c|c|}
\hline Instrumento & Item & Variável \\
\hline SARA & 11 - Violência física passada. & Violência física \\
\hline SARA & 12 - Violência sexual passada. & Violência sexual \\
\hline SARA & 18 - Violência sexual (último ano). & Violência sexual \\
\hline DA & $\begin{array}{l}15 \text { - Você já foi agredida por ele quando estava } \\
\text { grávida? Se você nunca ficou grávida dele, marque } \\
\text { aqui: }\end{array}$ & Gravidez \\
\hline DA & $\begin{array}{l}9 \text { - Ele já forçou você a fazer sexo sem que você } \\
\text { desejasse fazê-lo? }\end{array}$ & Violência sexual \\
\hline DA & 10 - Ele já tentou estrangular você? & Estrangulamento \\
\hline DA & 6- Ele ameaça matá-la? & Ameaça de morte \\
\hline DA & $\begin{array}{l}19 \text { - Ele já seguiu ou espionou você, deixou bilhetes ou } \\
\text { mensagens na secretária eletrônica, destruiu sua } \\
\text { propriedade ou te ligou quando você não queria? }\end{array}$ & Perseguição \\
\hline DVSI - R & $\begin{array}{l}9 \text { - Evidencia de prévio ou atual abuso verbal ou } \\
\text { emocional? }\end{array}$ & Violência psicológica \\
\hline
\end{tabular}

\section{(18) Rede social}

DA, DVSI-R e SARA não apresentam a dimensão rede social, que pode ser compreendida como "conjunto de seres com quem interagimos de maneira regular, com quem conversamos, com quem trocamos sinais que nos corporizam, que nos tornam reais" (Sluzki, 1997, p.15). Contudo, psicólogos participantes da pesquisa, consideram que é importante entender se a mulher tem rede social e como é essa rede, especialmente família. Alertam, conforme já destacado na literatura (Ravazzola, 2005; Medeiros, 2010; Guimarães, 2009; Angelim, 2009; Diniz \& Angelim, 2003; Diniz \& Pondaag, 2006) que o isolamento contribui para a não percepção da gravidade. E que a naturalização da violência e a valorização da manutenção do casamento contribuem para que a mulher não busque ajuda na rede de atendimento e permaneça correndo riscos. 


\section{Considerações finais}

A escolha da estratégia metodológica envolvendo busca e análise de literatura e a coleta de opinião junto a profissionais da rede de atendimento a pessoas em situação de violência possibilitou identificar que nenhum dos instrumentos avaliados, se utilizado sozinho, contemplaria todas as dimensões relevantes para a avaliação de risco. A DA, o DVSI-E e a SARA tratam de fatores de risco importantes, mas a linguagem e o tipo de itens desses instrumentos precisam ser adequados ao contexto sociocultural brasileiro. Além disso, existem fatores de risco que não são tratados por esses instrumentos e que são importantes para a avaliação de risco no Brasil.

Nesse contexto, cresce em importância o desenvolvimento de uma checklist de avaliação de risco que contemple a análise de fatores de risco relacionados a: características de personalidade do autor e da vítima; conflitos interpessoais; violência contra a parceira na presença de outros; uso de álcool e/ou de drogas; escalada da violência; participação em intervenção para pessoas em situação de violência; meios de agressão; percepção sobre a gravidade da violência; experiências de violência na família de origem; filhos de outra relação íntima; história criminal; separação/divórcio; outras violências; situação ocupacional; saúde mental; percepção sobre o risco; história de violência contra a parceira e rede social. Tais elementos estão relacionados à vítima, ao autor da violência e sua relação com o sistema de Justiça, à dinâmica relacional do casal.

Com relação à vítima é importante que a checklist englobe as seguintes variáveis: dependência emocional; ideação suicida; minimização da violência; depressão; transtorno de estresse pós-traumático e uso abusivo de álcool. Cabe investigar também o isolamento social; dependência emocional e se sua rede social tem 
crenças que naturalizam as violências e valorizam a manutenção do casamento mesmo frente às violências.

Com relação ao agressor, é relevante investigar se ele apresenta comportamento controlador e ciumento, impulsividade e baixo controle da raiva. É preciso identificar sua situação ocupacional e se ele cresceu em ambiente violento. Sobre sua saúde mental, deve-se averiguar se ele manifesta ideação suicida seguida ou não de ameaça de homicídio, bem como sintomas maníacos ou psicóticos. É preciso entender também se é dependente de álcool e de outras drogas; se é violento quando está sobre efeito de álcool e se essas substâncias potencializam a violência; se já foi atendido em programa específico para autores de violência; se nega ou minimiza os atos dele contra a parceira; se apresenta outras atitudes de justificam as violências; se utiliza comportamento intimidatório para resolver conflitos; se tem algum recurso especial para encontrar sua mulher em caso de fuga; se ele já cometeu violência contra crianças, familiares, animais domésticos e outras parceiras.

A relação do autor da violência com o sistema de Justiça deve ser avaliada. É preciso examinar a história criminal tendo como foco tanto os crimes contra desconhecidos, quanto conhecidos. Ao investigar crimes não relacionados à violência doméstica, deve-se pesquisar os crimes envolvendo pessoas. Precisa-se compreender também se o agressor respeita as ordens judiciais. Deve ser investigado separadamente se o agressor descumpriu medida restritiva e se o descumprimento de medida de afastamento ocorreu e a mulher aceitou a aproximação.

A avaliação da dinâmica relacional requer a identificação da história de violência passada e atual com atenção para os seguintes eventos: perseguição; ameaça com ou sem violência física; comportamento violento durante o sexo; sexo forçado; aumento da intensidade e frequência da violência psicológica e da violência física; 
violência durante a gestação; presença de testemunhas durante as violências; tentativa de separação com negativa dessa possibilidade por parte do agressor; ausência de tentativa de separação por medo da reação do agressor; agressão com instrumentos perfurocontante; agressão com instrumentos perfurocontundentes e contundentes.

\section{Referências}

Abdala-Filho, Elias. (2012). Avaliação de Risco. In Taborda, José G. V., Abdala-Filho, Elias, Chalub, Miguel (Orgs.). Psiquiatria Forense (pp. 183-204). Porto Alegre: Artmed.

Abdalla-Filho, Elias \& Oliveira, Everardo Furtado de. (2002). Transtornos por uso de substâncias psicoativas. In Taborda, José G. V., Abdala-Filho, Elias, Chalub, Miguel (Orgs.). Psiquiatria Forense (pp. 338-354). Porto Alegre: Artmed.

Acosta, Miguel Lorente. (2013). La valoración médico-forense del Riego em la violência de género. Predicción y prevención. Retirado de: http://www.poderjudicial.es/stfls/CGPJ/OBSERVATORIO\%20DE\%20VIOLENCIA\%20DO M\%C3\%89STICA/OTRAS\%20ACTIVIDADES\%20FORMATIVAS/FICHEROS/20130502 \%20Listado\%20de\%20Ponencias.pdf

Almeida, Isis \& Soeiro, Cristina. (2010). Avaliação de risco de violência conjugal: versão para polícias (SARA: PV). Análise Psicológica, 1 (28), 179-192.

Angelim, Fábio Pereira. (2009). A importância da intervenção multidisciplinar face à complexidade da violência doméstica. In Fausto Rodrigues de Lima \& Claudiene Santos (Orgs.), Violência doméstica: vulnerabilidades e desafios na intervenção criminal e multidisciplinar (pp. 125-136). Rio de Janeiro: Lumen Juris.

Bograd, Michele \& Mederos, Fernando. (1990). Battering and couple therapy: universal screening and selections of treatment modality. Journal of marital and family therapy, 25 (3), 291-312.

Campbell, Jacquelyn. (2004a). Danger Assessment. Retirado de: http://www.dangerassessment.org/

Campbell, Jacquelyn C. (2004b). Helping Women understand their risk in situations of intimate partner violence. Journal of Interpersonal Violence, 19 (12), 1464-1477.

Campbell, Jacquelyn C. (2005). Assessing dangerousness in domestic violence cases: history, challenges, and opportunities. Criminology \& Public Policy, 4(4), 653-672.

Campbell, Jacquelyn; Webster, Daniel; Koziol-McLain, Jane; Block, Carolyn, et al. (2003). Risk factors for femicide in abuse relationships: results of a multisite case control study. American Journal of Public Health, 93 (7), 1089 - 1097. 
Campbell, J., Webster. W. \& Glass, N. (2009). The Danger Assessment: validations of a lethality risk assessment instrument for intimate partner femicide. Journal of Interpersonal Violence, 24 (4), 653-674.

Cattaneo, Lauren Bennett, Bell, Margret E., Goodman, Lisa A. \& Dutton, Mary Ann. (2007). Intimate partner violence victims' accuracy in assessing their risk of re-abuse. Journal of Family Violence, 22, 429-440.

Diniz, Gláucia Ribeiro Starling, \& Angelim, Fábio. (2003). Violência doméstica: porque é tão difícil lidar com ela? Revista de Psicologia da UNESP, 2 (1), 20-35.

Diniz, Gláucia Ribeiro Starling, \& Pondaag, Miriam Cássia Mendonça. (2006). A face oculta da violência contra a mulher: o silêncio como estratégia de sobrevivência. In Ângela Maria de Oliveira Almeida, Maria de Fátima de Souza Santos, Gláucia Ribeiro Starling Diniz, Zeidi Araújo Trindade (Org). Violência, exclusão e desenvolvimento humano. Estudos em representações sociais (pp. 233-259). Brasília: Editora UNB.

Echeburúa, Enrique, Amor, Pedro Javier, Loinaz, Ismael, Coral, Paz de. (2010). Escala de Predicción del Riesgo de Violencia Grave Contra la Pareja - Revisada (EPV-R). Psicothema, 22 (4), 1054-1960.

Grams, Ana Clara \& Magalhães, Teresa. (2011). Violência nas relações de intimidade. Avaliação de Risco. Revista Portuguesa do Dano Corporal, 22, 75-98.

Guimarães, Fabrício. (2009). “Mas ele diz que me ama...”: impacto da história de uma vítima na vivência de violência conjugal de outras mulheres. Dissertação de mestrado, Universidade de Brasília, Distrito Federal.

Haggard-Grann, Ulrika. (2007). Assessing violence risk: a review and clinical recommendations. Journal of Counseling and Development, 85 (3), 294-302.

Heckert, D. Alex \& Gondolf, Edward W. (2005). Do multiples outcomes and conditional factors improve predictions of batterer reassault? Violence and victims, 20 (1), 3-24.

Hermoso, María del Rocio Gómez, Vicente, José Manuel Muñoz, Mezquita, Blanca Gómez, De la Calle, Nuria Mateos. (2012). Guía de buenas prácticas para la evaluación psicológica forense del riesgo de violência contra la mujer em las relaciones de pareja (VCMP). Madrid: Colegio Oficial de Psicólogos de Madrid.

Hilton, N. Zoe, Harris, Grant T., Rice, Marbie E., Houghton, Ruth E. \& Eke, Angela W. (2011). Intimate partner homicide: risk assessment and prospects for predictions. Journal of Family Violence, 26 (3), 211-216.

Hilton, N. Z. Harris, G. T., Rice, M. E., Lang, C. Cormier, C. A., Lines, K. J. ( 2004). A brief actuarial assessment for the prediction of wife assault recidivism: The Ontario domestic assault risk assessment. Psychological Assessment, 16, 267-275.

Koller, Silvia Helena, \& Narvaz, Martha Giudice. (2004). Famílias, Gêneros e violências: Desvelando as tramas da transmissão transgeracional da violência de gênero. In M. P. R. de Azambuja, F. P. 
Jaeger \& M. N. Strey (Orgs.). Violência, Gênero e Políticas Públicas (pp. 149-176). Porto Alegre: Editora da PUCRS.

Kropp, P. Randall, Hart, Stephen D. Webster, C. \& Eves. D. (1999). Spousal Risk Asssessment Guide User's Manual. Canada: Multi-Health Systems and BC Institute Against Family Violence.

Kropp, P. Randall \& Hart, Stephen D. (2000). The spousal assault risk assessment (SARA) guide: reliability and validity in adult male offenders. Law and Human Behavior, 24 (1), 101-118.

Kropp, P. Randall \& Gibas, Andre. (2010). The Spousal Assault Risk Assessment Guide (SARA). In. Randy K Otto \& Kevin Douglas (Orgs).Handbook of violence risk assessment (pp. 147-186). New York: Taylor \& Francis e-Library.

Krug, E. G., Dalberg, L. L., Mercy, J. A, Zwi, A. B. \& Lozano, R. (2002). Relatório mundial sobre violência e saúde. Geneva: Organização Mundial de Saúde.

Medeiros, Marcela. (2010). Violência conjugal: repercussões na saúde mental de mulheres e de suas/seus filhas/os. Dissertação de mestrado, Universidade de Brasília, Distrito Federal.

Nicholls, Tonia L., Pritchard, Michelle M., Reeves, Kim A. \& Hilterman, Edward. (2013). Risk assessment in intimate partner violence: a systematic review of contemporary approaches. Partner Abuse, 4 (1), 76-168.

Ravazzola, María Cristina. (2005). Historias infames: los maltratos em las relaciones. Buenos Aires: Paidós.

Santos, Maria José M. Lopes dos (2010). A perícia medico-legal nos casos de violência nas relações de intimidade - contributo para a qualidade. Dissertação de Mestrado, Universidade do Porto, Portugal.

Sluzki, Carlos. (1997). A rede social na prática sistêmica: alternativas terapêuticas. São Paulo: Casa do Psicólogo.

Soares, Barbára Sumeci. (2005). Enfrentando a Violência contra Mulher: orientações práticas para profissionais e voluntários (as). Brasília: Secretaria Especial de Políticas para as Mulheres, Presidência da Republica, 63 p.

Walker, Leonore E. A. (1999). The Battered woman syndrome (2. ed.). United States of America: Spring Publishing Company.

Walker Leonore E. A. (2009). The Battered woman syndrome (3. ed.). United States of America: Spring Publishing Company.

Webster, Christopher D., Haque, Quazi \& Hucker, Stephen J. (2013).Violence Risk-Assessment and Management: advances though structured professional judgment and sequential redirections (2 ed). UK: Wiley-Blackwel.

Williams, Kirk R. \& Houghton, Amy Barry. (2004). Assessing the risk of domestic reoffending: a validation study. Law and Human Behavior, 28 (4), 437-455. 


\title{
Artigo 4 - Construção e validação de
}

\section{conteúdo de checklist de avaliação de risco de}

\author{
violência contra parceira íntima.
}

\section{Marcela Novais Medeiros}

Apresentado como parte integrante de tese de doutoramento do Programa de Pós-Graduação em Psicologia Clínica e Cultura do Departamento de Psicologia Clínica, Instituto de Psicologia, Universidade de Brasília.

\section{Resumo}

O presente artigo descreve o processo de validação de conteúdo de checklist de avaliação de risco de violência contra parceira íntima. Foi utilizada a metodologia $\mathrm{Q}$, com uso da técnica $Q$ sort para avaliar as percepções e concordância de 34 participantes da pesquisa acerca dos itens que compõem a Checklist. Os dados foram analisados por meio de estatística descritiva, cuja análise permitiu a classificação dos itens em três categorias: risco extremo, risco grave e risco moderado. Foi possível observar a tendência de avaliar o item como representando maior o risco quando o seu texto apresentava temas mais comportamentais ou objetivos. A maioria dos itens do grupo de risco grave é referente ao ofensor. Questões de saúde mental, perfil da vítima e abuso e dependência de álcool e drogas foram predominantemente avaliados como fatores com menor potencial de causar danos do que outros itens.

Palavras-chave: Avaliação de Risco; Checklist; Validade de Conteúdo.

A violência contra a mulher perpetrada por parceiro íntimo é qualquer ação que provoque mal-estar físico, psicológico ou sexual, cometida no âmbito do namoro, do casamento formal ou informal, bem como entre ex-parceiros íntimos, podendo ocorrer 
sob a forma de violência física, psicológica, sexual e patrimonial (Krug, Dahlberg, Mercy, Zwi \& Lozano, 2002). Esse tipo de violência pode provocar danos à saúde mental e física de mulheres (Medeiros, 2010; Minayo, 2006), bem como resultar na morte de um ou de ambos os parceiros, sob a forma de homicídios seguidos de suicídios (Grams \& Magalhães, 2011; Teixeira, 2009).

Frente ao perigo e à possibilidade de danos relacionados às situações de violência nas relações íntimas, cresce em importância a realização de previsões relacionadas aos riscos envolvidos. Embora todas as mulheres vitimadas estejam em condição de perigo, ou seja, em risco potencial de danos, é preciso diferenciar a periculosidade de cada experiência, ou seja, a presença de risco de danos externos ou de morte (Grams \& Magalhães, 2011; Santos, 2010) e o risco de adoecimento em virtude da experiência subjetiva de sofrimento ou de estresse.

A identificação da periculosidade envolvida em cada caso pode ser obtida por meio de avaliações de risco. Avaliar riscos consiste na "determinação do valor qualitativo ou quantitativo do risco relatado numa situação concreta ou numa ameaça reconhecida" (Santos, 2010, p. 50). Envolve a realização de um prognóstico de reiteração de comportamentos violentos (Hermoso et al., 2012) com objetivo de oferecer a profissionais, a vítimas e a agressores informações sobre o nível de ameaça oferecida por um ofensor (Nicolls, Pritchard, Reeves \& Hilterman, 2013). Esse tipo de informação é útil para subsidiar a escolha do tipo de intervenção adequada para evitar ou extinguir o risco (Andrés-Pueyo \& Echeburúa, 2010; Santos, 2010) e, dessa forma, prevenir violências e garantir a segurança e a integridade física e psíquica de mulheres, bem como a responsabilização adequada do ofensor. 
Diversas são as estratégias de avaliação de risco utilizadas por profissionais e por pesquisadores interessados no tema da violência contra mulher. Algumas das estratégias adotadas são checklist, entrevistas clínicas, instrumentos padronizados, nível de experiência e de intuição do avaliador (Santos, 2010), que podem ter como fonte de informação as vítimas, os autores da violência, as testemunhas, os registros criminais ou os prontuários (Almeida \& Soeiro, 2010; Andrés-Pueyo \& Echeburúa, 2010).

A avaliação de risco feita no contexto clínico começou a receber atenção a partir da década de 1970 (Haggard-Grann, 2007). Críticas quanto à baixa validade das avaliações e à pouca eficiência no processo de decisão e de manejo frente aos riscos, impulsionaram o desenvolvimento de estudos com vistas à construção de estratégias de avaliação de risco empiricamente validadas.

Desses estudos sugiram nas décadas de 1980 e 2000, diversas estratégias de avaliação de risco elaboradas à luz das culturas norte-americana, canadense e europeia, tais como: Danger Assessment (DA) (Campbell, Webster \& Glass, 2009), Revised Domestic Violence Risk Guide (DVSI-R) (Williams \& Houghton, 2004), Ontario Domestic Assault Risk Assessment (ODARA) (Hilton et al., 2004), Spousal Assault Risk Assessment (SARA) (Kropp, Hart, Webster \&Eves, 1999), Escala de Predicción del Riesgo de Violência Grave Contra la Pareja - revisada (EPV-R) (Echeburúa et al., 2010).

Tais instrumentos de avaliação de risco foram construídos em ambientes socioculturais diferentes do brasileiro e não passaram por processo de tradução e de adaptação cultural para uso no Brasil. Pode-se dizer que o Brasil, ainda hoje, carece instrumentos de avaliação de risco e de estudos sobre modelos e métodos de avaliação de risco. Esse contexto deixa os profissionais da área abandonados aos seus próprios 
vieses e tendo como recurso apenas a própria experiência. O desenvolvimento de modelos e de métodos validados para a avaliação do risco no campo da atenção às mulheres em situação de violência é absolutamente necessário para a adequada proteção dessas mulheres, sem exageros e sem deixá-las expostas a riscos importantes.

Com vistas à construção de uma checklist de avaliação de risco, em estudo anterior (artigo 3) dimensões da avaliação de risco foram identificadas. Para tanto, foi executada análise dos instrumentos Danger Assessment (DA), Revised Domestic Violence Risk Guide (DVSI- R) e Spousal Assault Risk Assessment (SARA) à luz da literatura. Também foi realizada coleta de opinião junto a profissionais da rede de atendimento acerca de fatores de risco relevantes para a avaliação de risco no Distrito Federal e da aplicabilidade do referidos instrumentos nesse contexto específico. A partir disso, foram identificadas dimensões e variáveis de cada instrumento, com vistas ao entendimento de diferenças e similaridades e da adequação de cada dimensão ao contexto sociocultural brasileiro.

A partir dos resultados obtidos nesse estudo, 100 itens foram formulados para compor uma checklist de avaliação de risco (Anexo 4). Tais itens foram construídos respeitando-se as orientações presentes na literatura (Pasquali, 1998) acerca dos cuidados com a construção de enunciados de itens: apresentar apenas uma ideia em cada item (pois múltiplos conceitos em um único enunciado podem gerar confusão no respondente); ter relevância quanto ao conceito subjacente ao item; e ser facilmente compreensível por qualquer pessoa, independente no nível socioeducacional.

Não se trata, portanto, de uma adaptação cultural da DA, do DVSI-R ou da SARA. Esses instrumentos serviram apenas como inspiração para o desenvolvimento dos itens da checklist que é foco deste estudo. A livre tradução desses instrumentos foi 
utilizada apenas para análise de modelos de avaliação de risco disponíveis na literatura em busca de suas convergências e divergências. Além disso, tais traduções foram úteis para fomentar a discussão e a reflexão crítica junto aos profissionais acerca de dimensões de avalição de risco adequadas ao contexto brasileiro.

Para que a validade dessa checklist de avaliação de risco possa ser estimada, é necessário que ela seja submetida a procedimentos de validação. Quando se busca a validade de um instrumento, deseja-se saber se o instrumento possibilita a aferição correta daquilo que se pretende medir. "A validade se refere ao grau em que um instrumento realmente mede a variável que pretende medir" (Martins, 2006, p. 5) e pode ser obtida por meio do exame da validade de conteúdo, validade de aparência, validade de critério e validade de constructo (Martins, 2006).

A validação de conteúdo é uma importante fase no desenvolvimento inicial de um instrumento, que permite avaliar “(...) se o conteúdo de um instrumento de medida explora, de maneira efetiva, os quesitos para mensuração de um determinado fenômeno a ser investigado" (Bellucci Junior \& Matsudan, 2013, p. 752). Realizar a validação de conteúdo "consiste em verificar se o teste constitui uma amostra representativa de um universo finito de comportamentos (domínio)” (Pasquali, 2009, p. 998). Diante do exposto e com vistas à compreensão da validade da checklist de avaliação de risco, o presente estudo objetivou descrever o processo de validação de conteúdo da referida checklist de avaliação de risco. 


\section{Método}

\section{$Q$-sort}

A validação de conteúdo é obtida por meio do julgamento. Lúcia Beccaria, Renée Amorim, Sirley Pacheco, Simone Vacondino e Petronilha Fechio (2008) sugerem que um grupo de peritos julgue o instrumento de forma a analisar se os itens são adequados para medir o tema proposto. Participaram desse processo, 34 pessoas, sendo seis representantes da sociedade civil e 28 profissionais que atuam em serviços especializados no atendimento a mulheres em situação de violência.

Treze dos participantes foram selecionadas pela pesquisadora dentre sua rede social composta por colegas trabalho, amigos e membros do Núcleo de Estudos de Gênero e Psicologia Clínica (NEGENPSIC) do Laboratório de Estudos em Saúde Mental e Cultura do Instituto de Psicologia da Universidade de Brasília e coordenado pela professora Gláucia Diniz. Vinte e um participantes foram identificados e convidados a participar do estudo pela pesquisadora durante reuniões intersetoriais coordenadas pelo Núcleo de Gênero Pró-Mulher do Ministério Público do Distrito Federal e Territórios, cujo objetivo era a construção de um projeto de proteção integral à mulher em situação de violência doméstica com diretrizes de avaliação de risco.

Foi utilizada a metodologia $\mathrm{Q}$, com uso da técnica $Q$-sort (distribuição-Q) para avaliar as percepções e concordâncias entre os participantes da pesquisa acerca dos itens que compõem a Checklist. Normalmente, os itens são avaliados independentemente em escalas do tipo Likert (método R), permitindo vieses do tipo atribuição de valores centrais ou extremos à maioria dos itens, o que tende a diminuir a variabilidade e dificulta a distinção entre os itens. Como os itens neste estudo foram escolhidos por 
representarem risco com variações entre risco moderado e extremo, empregou-se o método $Q$-sort, que requer que cada item seja avaliado em relação a todos, comparativamente, forçando o posicionamento de cada item em um continuum de variabilidade, neste caso, o grau de risco atribuídos ao item, segundo uma distribuição normal predefinida, como é frequentemente realizado em $Q$-sorts.

Ao pedir que os sujeitos classifiquem as variáveis em categorias subjetivas que variam de valoração, esse método permite que a subjetividade dos participantes seja acessada com menor influência do pesquisador (Bigras \& Dessen, 2002). Além disso, força-os a avaliar o problema como um todo, ao terem que ordenar as questões e não somente avaliar individualmente questão por questão (Santos \& Amaral, 2004). A avaliação de cada item em relação ao outro é realizada com auxílio de cartões que contêm impressos os elementos avaliados e que devem ser ordenados em pilhas horizontais em material de apoio sobreposto em uma mesa.

A coleta de dados ocorreu de formal presencial. Cada participante recebeu o conjunto de 100 itens, cada um impresso em um pequeno cartão. Foi pedido que eles classificassem cada cartão em três categorias, a saber, pouca ou menor periculosidade, média periculosidade, muita ou maior periculosidade. $\mathrm{O}$ uso dessa terminologia gerou confusão entre os primeiros participantes que alegaram se sentirem desconfortáveis em classificar como de pouco risco, pois nenhuma situação de violência envolveria ausência de risco. Diante disso, percebeu-se que era necessário oferecer explicação adicional acerca dessas categorias. Foi oferecido a eles e aos demais participantes a explicação de que a categoria pouco ou menor risco poderia ser compreendida como risco moderado, a categoria média periculosidade correspondia a situações de risco grave, a categoria muita ou maior periculosidade corresponderia a risco extremo. 
Após a classificação nesses três níveis de risco, com uso de um banner com nove colunas impressas (Anexo 5), foi pedido que classificassem cada item em uma escala de 1 a 9, considerando que, quanto mais próximo de 1 , menor o risco de ocorrerem violências graves ou letais e, quanto mais próximo de 9, maior a periculosidade envolvida. Para cada um desses graus havia um número limitado de cartas a serem selecionadas, tendo sido escolhido o número de cada coluna em conformidade com a curval normal, variando de 5 cartões nas extremidades a 18 cartões na categoria central (Anexo 6).

Após a realização dessa classificação, os participantes responderam a um questionário que investigou as seguintes dimensões: sexo, idade, formação acadêmica, formação específica em técnica de intervenção para pessoas em situação de violência, atuação profissional da rede de enfrentamento a violência, experiência ao realizar essa tarefa, percepção sobre os itens.

\section{Classificação dos itens quanto à subjetividade}

Com o objetivo de estimar o grau de objetividade ou de subjetividade do conteúdo expresso no item, cada um deles foi avaliado de modo a verificar se haveria uma tendência a classificar na direção de risco extremo itens que envolvem comportamentos do agressor e se itens mais subjetivos seriam interpretados na direção de itens de risco moderado. Os 100 itens da checklist foram classificados pela pesquisadora e por dois colaboradores com formação em Direito e outro em Educação em duas categorias: "Item Predominantemente Comportamental" e "Item Predominantemente Subjetivo". Após essa classificação, as divergências forma discutidas em busca do consenso. 
Itens Predominantemente Comportamentais descrevem uma ação efetivada pelo ofensor ou pela vítima, um comportamento observável de ambos. Outro critério foi que a resposta do item exigisse pouco juízo de valor do respondente da pergunta para dizer se o comportamento ocorreu ou não por terem sua definição clara e compartilhada socialmente. Exemplo de itens desse tipo são: "Seu (ex-) parceiro, no último ano, deu tapas ou empurrou você?” e "Seu (ex-) parceiro já foi preso por cometer crimes violentos contra não familiares?”.

Itens Predominantemente Subjetivos envolvem processos psíquicos ou comportamentos que dependem muito de juízo de valor do respondente da pergunta para serem identificados. Exemplos desses itens são: "Você não consegue imaginar sua vida sem seu (ex-) parceiro?", Você acredita que seu (ex-) parceiro tem a intenção de matá-la?”.

\section{Análise dos dados}

Os dados obtidos por meio da avaliação dos participantes e da classificação dos tipos dos itens foram tabulados com auxílio do programa Microsoft Excell@ 2010. Para o tratamento dos dados, foi utilizado o software aplicativo SPSS por meio do qual foi realizada estatística descritiva, com uso da soma, média e porcentagem. Foi realizado o teste T de Student para identificação de igualdade de médias e o teste de Levene para análise de igualdade de variações. 


\section{Resultados}

\section{Dados demográficos}

O grupo de participantes da pesquisa foi predominantemente composto por 27 mulheres (79\%) e sete homens (21\%). A idade média grupo foi de 36,41 anos, variando entre 27 a 60 anos. Somente 8,8 \% ( $n=3)$ eram separados, enquanto 44,1\% (n=15) eram solteiros e $47 \%(n=16)$ eram casados. Todos os participantes da pesquisa tinham Curso Superior e fizeram algum curso de pós-graduação. As principais áreas do conhecimento eram Psicologia $(41,2 \%, n=14)$, Serviço Social $(11,8 \% n=4)$, Direito $(38,3 \% \mathrm{n}=13)$. Grande parte deles $(73,5 \%, \mathrm{n}=25)$ tiveram capacitação em serviço na temática violência contra mulher.

Do total de participantes da pesquisa, $82,4 \%(\mathrm{n}=28)$ atuavam na rede de atendimento a pessoas em situação de violência e $17 \%(n=6)$ são representantes da sociedade civil e sem experiência profissional na temática violência.

Entre o grupo de profissionais, 39,2\% $(\mathrm{n}=11)$ dos participantes eram profissionais do campo jurídico ou da segurança pública, que exerciam uma dessas atividades: Juiz de Direito, Promotor de Justiça, Delegado de Polícia, Advogado, Policial Civil ou Policial Militar. Os outros 60,8\% $(n=17)$ compuseram o grupo psicossocial, por englobar pessoas que atuavam como psicólogos ou assistentes sociais em serviços multidisciplinares de atendimentos a pessoas em situação de violência. Nos dois grupos, havia representantes de serviços do âmbito do Poder Judiciário, do Ministério Público e do Executivo da rede de atendimento a pessoas em situação de violência. 


\section{Distribuição de Periculosidade}

Trinta e três itens foram classificados como risco extremo, 34 como risco grave e 33 como risco moderado levando-se em consideração as médias de periculosidade. $\mathrm{O}$ grupo risco extremo teve média de 6,61 ( $\mathrm{DP}=0,67)$, com mínimo de 5,64 e máximo de 8,02. O grupo risco grave teve média de 5,00 ( $\mathrm{DP}=0,32)$, com mínimo de 4,44 e máximo de 5,61. O grupo risco moderado teve média de 3,37 (DP = 0,72), com mínimo de 2,00 e máximo de 4,41. As curvas de distribuição dos itens de acordo com a referida classificação de risco apresentadas são nas figuras 1, 2 e 3 . Houve uma correlação positiva $(\mathrm{r}=0,00 ; \mathrm{p}<0,05)$ entre o tipo do item e sua periculosidade, indicando a tendência de avaliar o item como representando maior o risco quando o seu texto apresentava temas mais comportamentais ou objetivos.

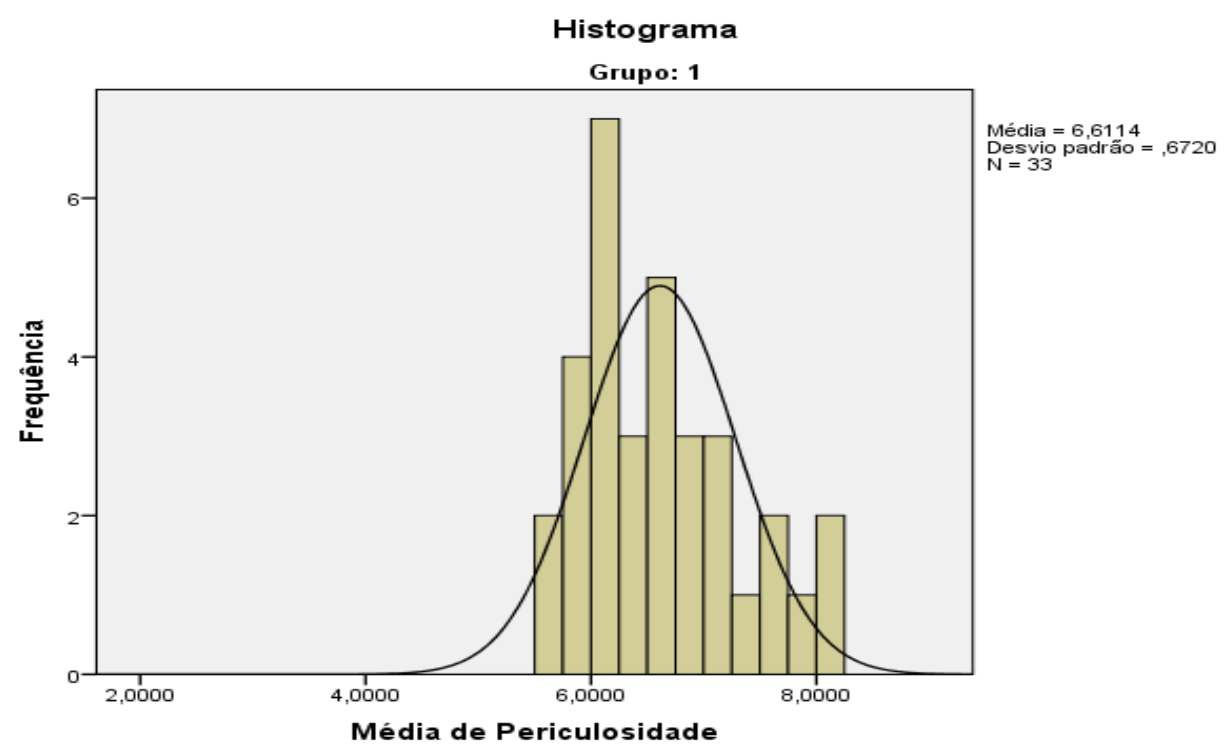

Figura 1. Curva de distribuição de itens que representam risco extremo. 


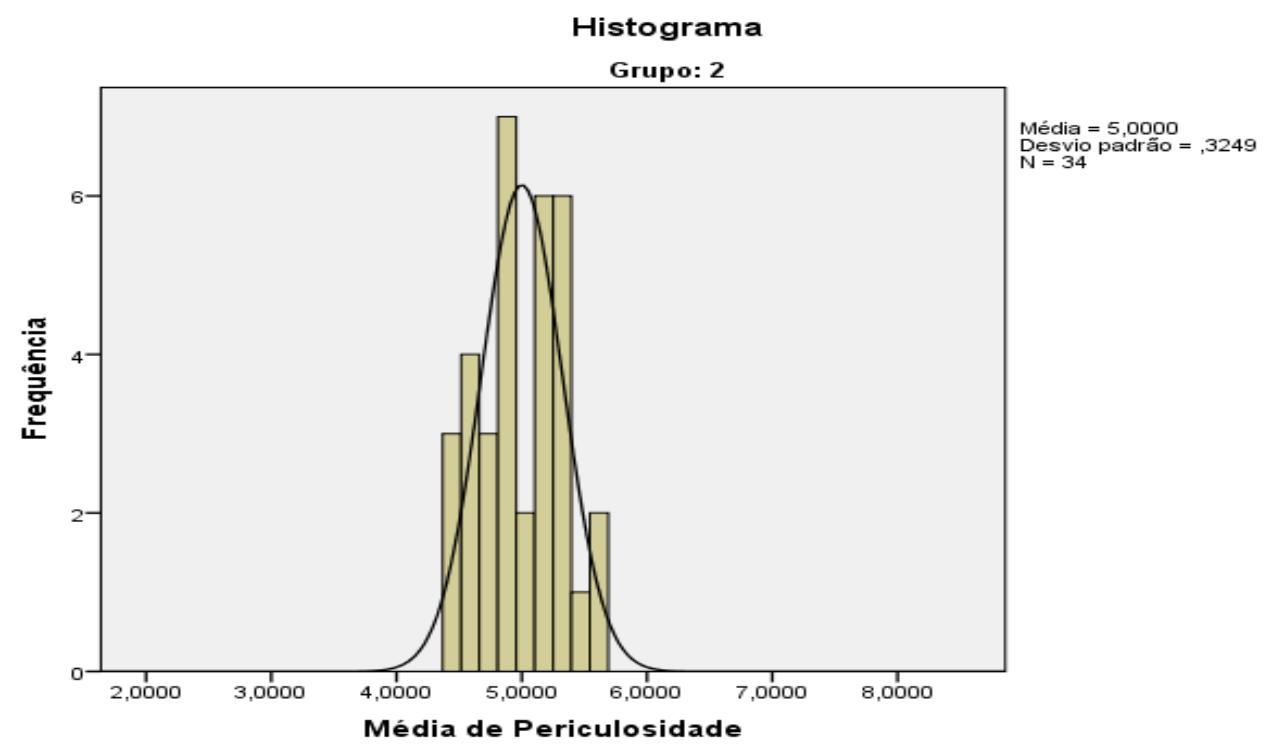

Figura 2. Curva de distribuição de itens que representam risco grave.

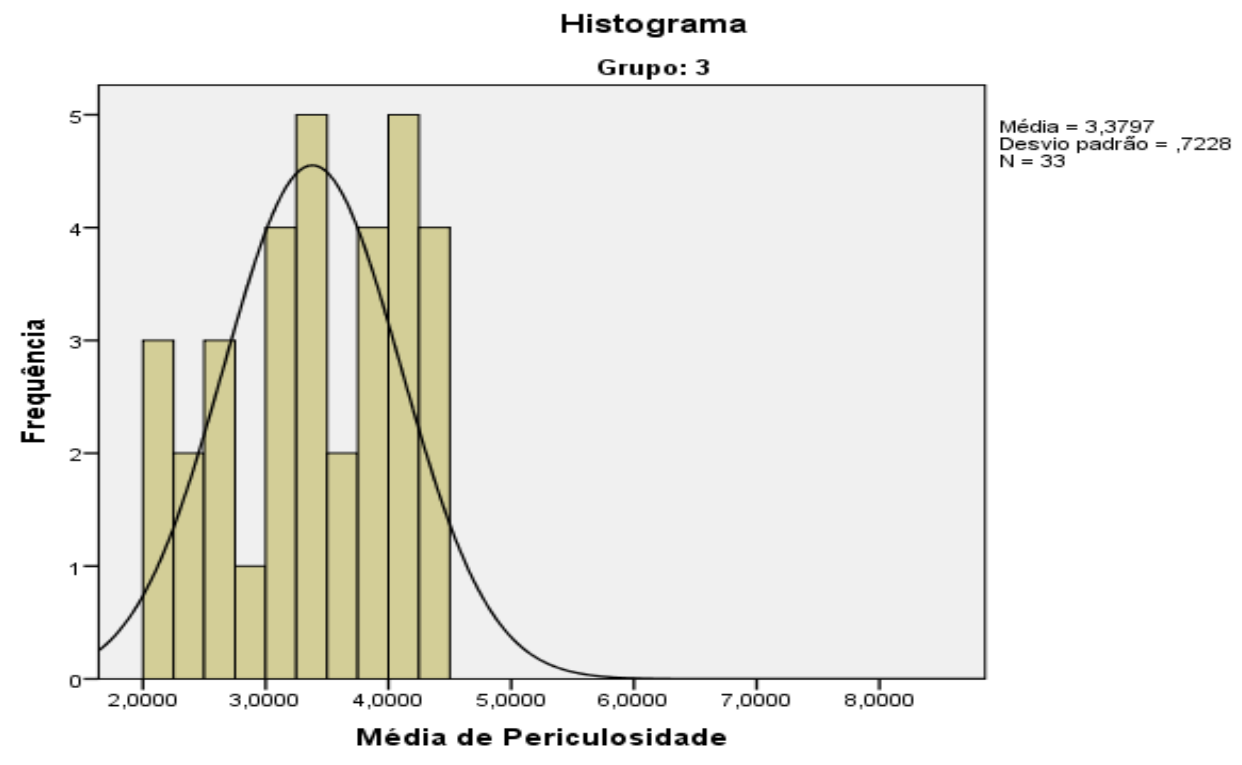

Figura 3. Curva de distribuição de itens que representam risco moderado.

\section{Risco extremo}

Os itens que tiveram as maiores médias de periculosidade, classificados como risco extremo, referem-se aos seguintes temas: envenenamento (I.69); uso de arma de 
fogo, pedaço de pau, cassetete, barra de ferro ou faca durante a violência contra a parceira (I.78; I.79; I.80); agressão sob a forma de chutes ou socos (I.75); violência sexual (I.79); estrangulamento (I.68); vigilância e perseguição constantes (I.67); agressão com ferimentos (ossos quebrados, contusões, ferimentos internos ou externos) (I.77); agressão na gestação (I.62); agressão à mulher ou às pessoas que a ajudavam após a separação (I.89); ausência de tentativa de separação por ameaças (I.91); agressão ou perseguição à mulher ou outra parceira íntima (I.88; I.61); ameaça de homicídio seguido de suicídio (I.35); ameaça de homicídio (I.63); ameaça de que ninguém mais a terá como companheira (I.64); crescimento da intensidade e da frequência da violência (I.83); descumprimento de medida protetiva (I.27; I.26); percepção da mulher sobre o risco (I.72; I.94; I.93; I.95); violência na presença de familiares, amigos ou desconhecidos (I.85; I.86); violência contra crianças (I.57); fácil acesso a arma de fogo (I.81); posse de arma de fogo e uso para intimidar pessoas (I.07); desconsideração e minimização da violência pelo ofensor (I.22); prisão por crimes violentos (I.28).

A Tabela 1 apresenta as médias, o desvio padrão, o máximo e o mínimo dos itens classificados como risco extremo (a tabela completa com todos os itens pode ser consultada no Anexo 7). 
Tabela 1.

Estatística descritiva dos itens classificados como risco extremo.

\begin{tabular}{|c|c|c|c|c|c|}
\hline & Item & Texto & Tipo & Risco & Desvio Padrão \\
\hline I.69 & & $\begin{array}{l}\text { Seu (ex) parceiro já tentou } \\
\text { envenenar você? }\end{array}$ & Comportamental & 8,03 & 1,27 \\
\hline I.68 & & $\begin{array}{l}\text { Seu (ex) parceiro já tentou } \\
\text { estrangular você?? }\end{array}$ & Comportamental & 7,79 & 1,20 \\
\hline I.79 & & $\begin{array}{l}\text { Seu (ex) parceiro usou pedaço } \\
\text { de pau, cassetete, barra de ferro } \\
\text { durante episódio de violência } \\
\text { contra você? }\end{array}$ & Comportamental & 7,65 & 1,35 \\
\hline I.76 & & $\begin{array}{l}\text { Seu (ex) parceiro, no último } \\
\text { ano, surrou, quebrou osso, } \\
\text { queimou ou provocou } \\
\text { contusões em você? }\end{array}$ & Comportamental & 7,50 & 1,52 \\
\hline I.78 & & $\begin{array}{l}\text { Seu (ex) parceiro já usou faca } \\
\text { durante episódio de violência } \\
\text { contra você? }\end{array}$ & Comportamental & 7,38 & 1,76 \\
\hline I.62 & & $\begin{array}{l}\text { Seu (ex) parceiro agrediu você } \\
\text { quando estava grávida? }\end{array}$ & Comportamental & 7,03 & 1,49 \\
\hline I.77 & & $\begin{array}{l}\text { Seu (ex) parceiro, no último } \\
\text { ano, provocou ferimentos } \\
\text { internos ou externos em você? }\end{array}$ & Comportamental & 7,03 & 1,66 \\
\hline I.07 & & $\begin{array}{l}\text { Seu (ex) parceiro possui arma } \\
\text { de fogo e a utiliza para } \\
\text { intimidar pessoas conhecidas } \\
\text { ou desconhecidas? }\end{array}$ & Comportamental & 7,00 & 1,63 \\
\hline I.72 & & $\begin{array}{l}\text { Seu (ex) parceiro a agrediu de } \\
\text { forma que a fez pensar que ele } \\
\text { tinha a intenção de matá-la? }\end{array}$ & Subjetivo & 6,91 & 1,66 \\
\hline I.88 & & $\begin{array}{l}\text { Seu (ex) parceiro após } \\
\text { tentativa de separação foi atrás } \\
\text { de você e a agrediu } \\
\text { fortemente? }\end{array}$ & Comportamental & 6,91 & 1,24 \\
\hline I.35 & & Seu (ex) parceiro já ameaçou & Comportamental & 6,85 & 1,52 \\
\hline
\end{tabular}




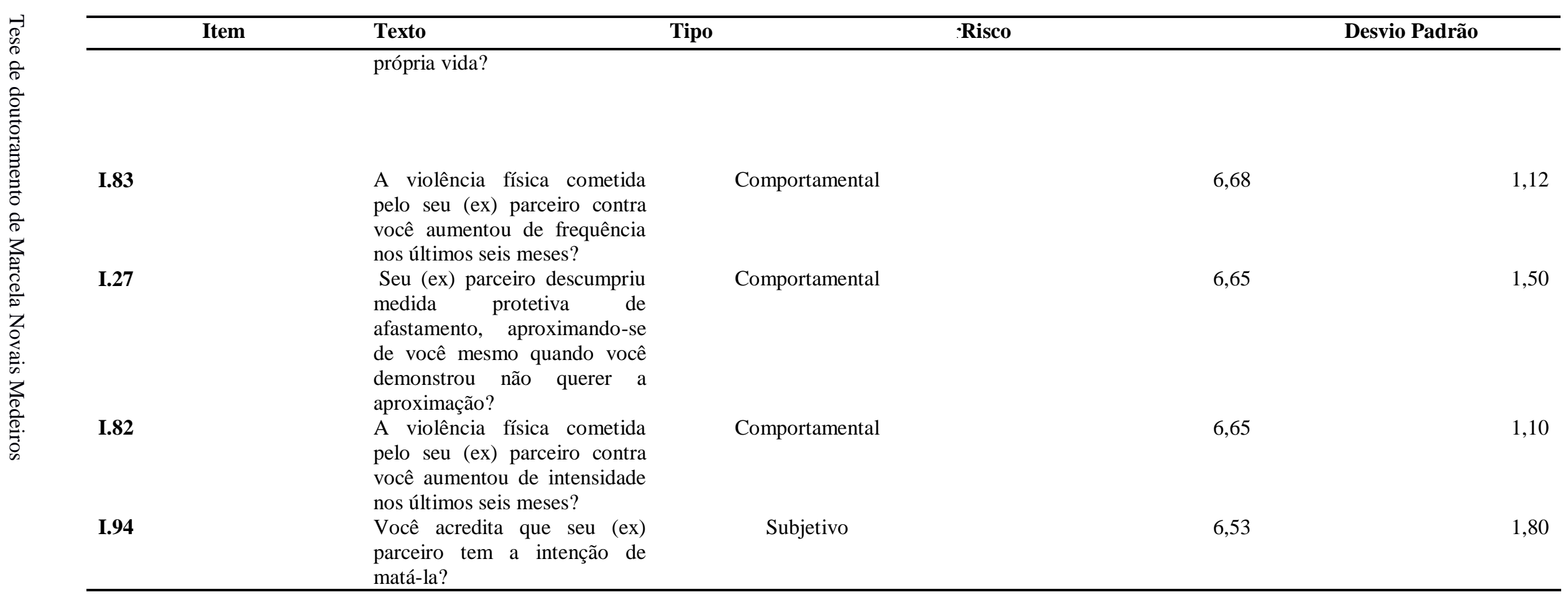




\begin{tabular}{|c|c|c|c|c|}
\hline & Texto & & Desv & o Padrão \\
\hline Item & Texto & Tipo & ;co & Desvio Padrão \\
\hline I.64 & $\begin{array}{l}\text { Seu (ex) parceiro já ameaçou você dizendo algo parecido com a frase "se eu não posso ter você, } \\
\text { ninguém mais pode"? }\end{array}$ & Comportamental & 6,35 & 1,65 \\
\hline I.93 & Você acredita que seu (ex) parceiro é capaz de matá-la? & Subjetivo & 6,26 & 1,56 \\
\hline I.89 & Seu (ex) parceiro, após tentativa de separação, foi atrás de você e agrediu pessoas que a ajudavam? & Comportamental & 6,21 & 1,37 \\
\hline I.95 & $\begin{array}{l}\text { Você acredita que seu (ex) parceiro continuará te agredindo, podendo causar graves ferimentos em } \\
\text { você ou em seus filhos? }\end{array}$ & Subjetivo & 6,21 & 1,41 \\
\hline I.26 & Seu (ex) parceiro descumpriu medida protetiva prevista na Lei Maria da Penha? & Comportamental & 6,18 & 1,47 \\
\hline I.85 & Seu (ex) parceiro já agrediu você na presença de familiares ou de amigos? & Comportamental & 6,18 & 1,22 \\
\hline I.57 & Seu (ex) parceiro é violento com as crianças? & Comportamental & 6,09 & 1,50 \\
\hline I.81 & Seu (ex) parceiro tem fácil acesso a arma de fogo? & Subjetivo & 6,03 & 1,95 \\
\hline I.70 & Seu (ex) parceiro já forçou você a fazer sexo sem que você desejasse fazê-lo? & Comportamental & 5,97 & 2,04 \\
\hline I.91 & Você não se separou porque seu parceiro a ameaça caso tente deixá-lo? & Subjetivo & 5,91 & 1,14 \\
\hline I.67 & Seu (ex) parceiro vigia e persegue você constantemente? & Comportamental & 5,82 & 1,73 \\
\hline I.86 & Seu (ex) parceiro já agrediu você na presença de desconhecidos? & Comportamental & 5,82 & 1,42 \\
\hline I.22 & $\begin{array}{l}\text { Seu (ex) parceiro minimiza a importância ou desconsidera totalmente os atos de violência dele contra } \\
\text { você? }\end{array}$ & Subjetivo & 5,65 & 1,41 \\
\hline I.61 & Seu (ex) parceiro agrediu ou apresentou comportamento persecutório com outra parceira íntima? & Comportamental & 5,65 & 1,57 \\
\hline
\end{tabular}


A título de ilustração, veja a curva de destruição do item I.68 cujo texto era "seu parceiro já tentou estrangular você?”, a média desse item foi de 7,79, com desvio padrão de 1,20, mínimo de 4 e máximo de 9.

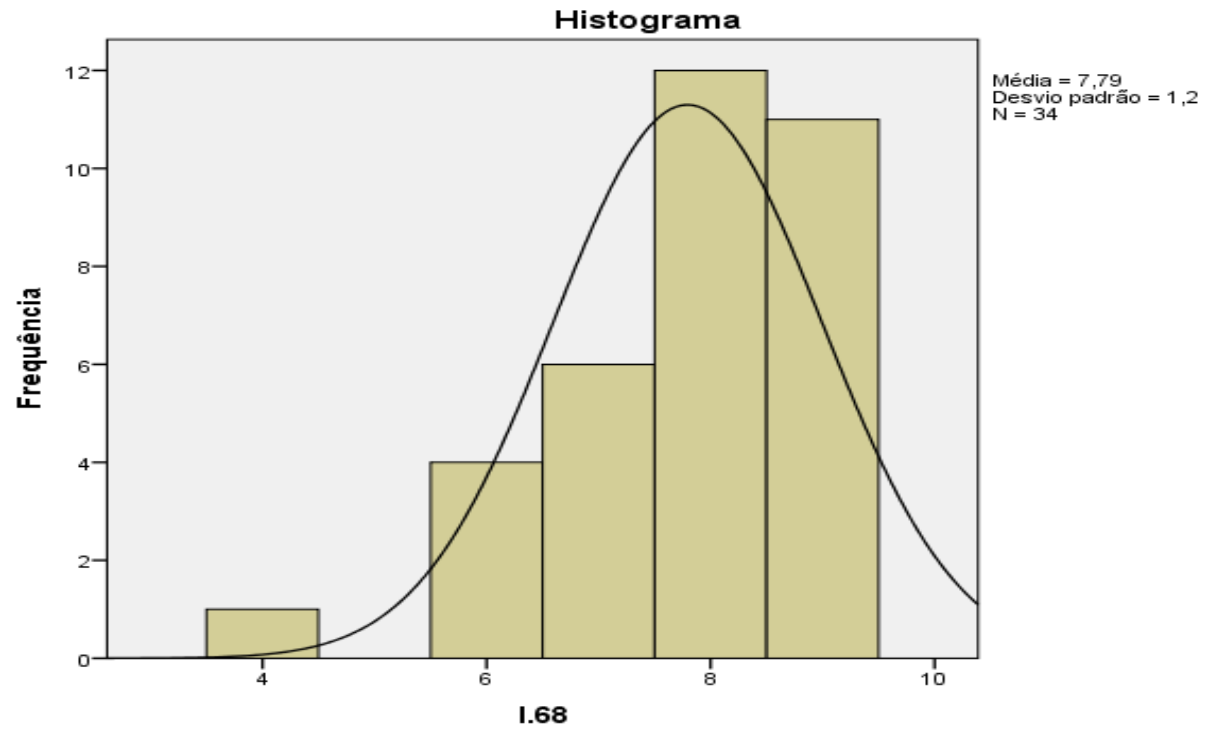

Figura 4. Curva de distribuição do item I.68.

Somente sete dos 33 itens desse grupo são do tipo subjetivo. Isso mostra que há preferência por itens comportamentais, nos quais são descritas ações efetivadas pelo ofensor ou pela vítima, que podem ser percebidas por um observador externo e que exigem pouco juízo de valor para sua classificação. Tais comportamentos descritos nos itens são todos referentes ao ofensor. Somente dois itens tratam da percepção e comportamento feminino. Tais itens são: I.91 - "Você não se separou porque seu parceiro a ameaça caso tente deixá-lo?" e I.93 - "Você acredita que seu (ex-) parceiro é capaz de matá-la?”.

Para os participantes da pesquisa, a respeito da saúde mental do ofensor, só representa risco extremo a ameaça de suicídio precedida de homicídio. Nenhum item 
sobre saúde mental da mulher ou rede social e suas características foi considerado como fator de risco extremo pelos participantes da pesquisa.

\section{Risco grave}

Não há grande predominância de tipos de itens classificados como risco grave. São do tipo comportamental dezoito itens, enquanto dezesseis itens são subjetivos. Os comportamentais são: violência contra familiares, amigos, desconhecidos, animais domésticos (I.59; I.58; I.60); comportamento violento associado ao ciúme (I.03); presença de crianças nos episódios de violência (I.84); controle de atividades diárias (I.01); violência sob a forma de tapas ou empurrão (I.74); ameaça de suicido do ofensor (I.34); uso da força para resolver conflitos (I.08); recusa em participar de atendimento para autores de violência (I.21); comportamento violento durante o sexo (I.71); tentativa de evitar prisão por violência doméstica (I.30); stalking (I.65; I.66); experiência de violência na família de origem (I.25).

Os itens do tipo subjetivo são: abuso e dependência de álcool e drogas (I.10); minimização da violência pela mulher (I.23); ciúmes obsessivos em relação a mulher (I.02); recurso especial para encontrar a mulher (I.92); sintomas psicóticos apresentados pelo ofensor (I.38; I.42); uso de álcool ou de drogas associado às violências (I.14; I.15; I.11); comportamento impulsivo e instável associado à raiva (I.04); violência auto infligida (I.45); ideação suicida (I.46); problemas de saúde do ofensor em decorrência do uso de álcool ou de drogas (I.12); sintomas de transtorno de estresse pós-traumático apresentados pela mulher (I.53; I.51); perdão (I.24); isolamento social da mulher (I.99); rede social com crenças de manutenção do casamento (I.96); medo da separação (I.90). 
Assim como no grupo de fatores de risco extremo, a maioria dos itens classificados no grupo de risco grave é referente ao ofensor. Somente quatro itens são referentes à mulher. Tais itens que são todos do tipo subjetivos são: I.46 - "Você tem pensado em fazer alguma coisa contra você mesma?"; I.90 - "Você não se separou porque teme a reação do seu parceiro?"; I.24 - "Você perdoou nos últimos seis meses algum incidente de violência depois de achar que não perdoaria?"; I.96 - "Seus amigos, familiares e conhecidos consideram que a mulher deve permanecer casada, mesmo se estiver sofrendo violência?"; I.51 - "Você tem tido imagens, pensamentos ou lembranças dolorosas relacionadas às agressões que parecem invadir sua cabeça?”.

A respeito da saúde mental do ofensor, para os participantes da pesquisa, só representou risco grave o item que aborda vários sintomas psicóticos e o que avalia delírio de perseguição. Os demais itens, nos quais é destrinchado cada um dos sintomas psicóticos não foram classificados nessa categoria.

A título de exemplo, observa-se a curva de distribuição do item I.03. Esse item cujo texto era "Seu (ex-) parceiro torna-se violento quando enciumado?", apresentou média de 5,59, desvio padrão de 1,282, mínimo de 3 e máximo de 8 . 


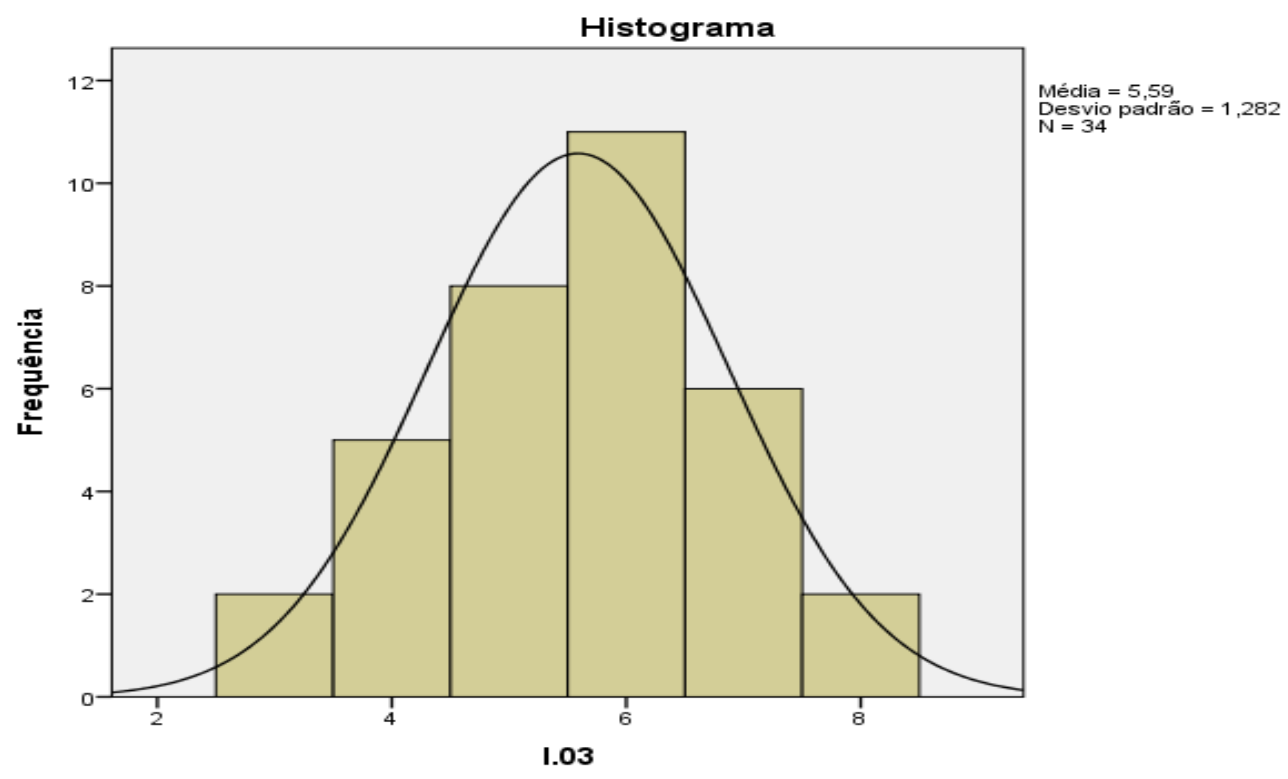

Figura 5.Curva de distribuição do item I.03.

\section{Risco moderado}

A grande maioria itens com risco moderado (23 entre 33) são do tipo subjetivo. A título de exemplo, observa-se a curva de distribuição do item I.50, cujo texto é "Você tem apresentado dificuldades para se concentrar?", que teve média de 2,24, desvio padrão de 1,18, mínimo de 1 e máximo de 6 . 


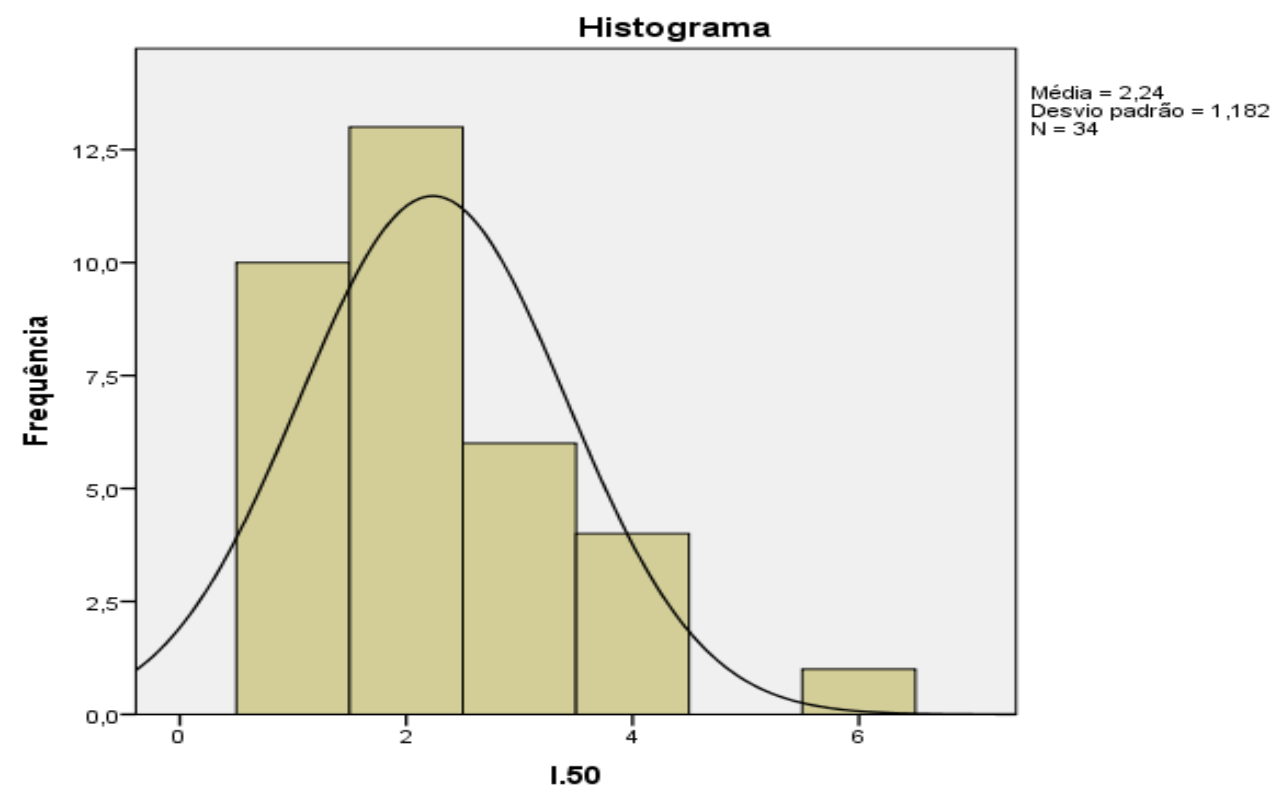

Figura 6. Curva de distribuição do item I.50.

A análise desses itens mostra que questões de saúde mental, perfil da vítima e abuso e dependência de álcool e drogas foram predominantemente avaliados como fatores com menor potencial de causar danos do que outros itens. Foram classificadas nesse todas as perguntas sobre abuso e dependência de drogas pela mulher (I.16; I.17; I.18; I,19), dependência emocional da mulher em relação ao parceiro (I.05; I.06) e situação ocupacional (I.31; I.32; I.33), a maior parte dos itens sobre saúde mental da mulher (I.46; I.47; I.48; I.49; I.50; I.52; I.54; I.55) e do ofensor (I.36; I.37; I.39; I.40; I.41; I.43; I.44).Os únicos itens que investigavam ocorrência de conflitos intensos (I.09), ter participado de intervenção para homens autores de violência (I.20), separação efetivada (I.87), mulher ter filhos de relação anterior (I.56) e ofensor ter dito coisas de natureza sexual ofensivas (I.73), foram classificados como risco moderado.

Somente um item sobre uso de álcool ou de drogas pelo ofensor (I.13) foi classificado no grupo de risco moderado. Todos os itens sobre uso de álcool ou de 
drogas pela mulher foram classificados nesse grupo. Deles, quatro eram do tipo subjetivo (I.13; I.16; I.18; I.19) e um era do tipo comportamental (I.17).

Do total de cinco itens sobre rede somente um era comportamental (.I.100) e ele foi classificado no grupo de risco moderado. Dois itens subjetivos (I.97 e I.98) também foram classificados em risco moderado, enquanto os outros dois itens subjetivos sobre esse tema foram classificados como risco grave.

Pela avaliação qualitativa dos comentários dos participantes durante a classificação dos itens e nos questionários respondidos, observou-se que, na perspectiva de alguns profissionais jurídicos e da segurança, perguntas muito específicas sobre uso de álcool e de drogas e saúde mental não deveriam compor uma checklist de avaliação de risco que poderia ser utilizada por eles. Profissionais psicossociais também fizerem observações sobre os itens. A maioria $(\mathrm{n}=14)$ mencionou que havia muitos itens sobre saúde mental e que, em uma checklist para uso deles, seria desnecessário ter todas elas.

Sobre a rede social, a maioria dos profissionais mencionou que classificaram como risco alto somente os itens que representavam ausência extrema de rede social ou ter uma rede com crenças que contribuem para a permanência na conjugalidade violenta. Os demais itens representavam risco moderado.

O ofensor ter dito "coisas de natureza sexual que ofenderam" (I.73) na perspectiva de dez profissionais participantes era um item muito amplo e causou dificuldade de entendimento. Cinco desses profissionais ressaltaram que não fariam tal pergunta, pois o que pode ser ofensivo sobre sexo depende da cultura e da religião. 


\section{Diferenças de gênero}

Com objetivo de gerar hipóteses a respeito das diferenças de gênero na avaliação de riscos, mesmo frente ao número reduzido de homens $(n=7)$, foi realizada a comparação estatística entre os grupos de mulheres e de homens. A análise desses dados demostrou que houve diferenças significativas $(\mathrm{p}<0,05)$ de gênero entre as médias em apenas seis itens (I.09; I.38; I.42; I,57; I.62; I.73) (as tabelas completas com a análise de todos os itens podem ser consultadas no Anexo 8). Tais itens tratam de discordâncias e conflitos intensos entre o (ex-) casal (I.38), sintomas psicóticos (I.42; I.57), agressão na gravidez (I.62), ofensas de natureza sexual (I.73).

\section{Tabela 2:}

Estatística descritiva de grupo por gênero

\begin{tabular}{|c|c|c|c|c|}
\hline \multirow{2}{*}{$\frac{\text { Item }}{\text { I.09 }}$} & \multirow{2}{*}{$\begin{array}{l}\text { Texto } \\
\begin{array}{lll}\text { Você e seu (ex-) } \\
\text { parceiro } & \text { têm }\end{array}\end{array}$} & \multirow{2}{*}{$\begin{array}{c}\text { Média (Desvio } \\
\text { Padrão) }\end{array}$} & \multicolumn{2}{|c|}{ Teste t de Student* } \\
\hline & & & Masculino $(n=7)$ & \\
\hline I.09 & $\begin{array}{l}\text { Você e seu (ex-) } \\
\text { parceiro } \\
\text { apresentado } \\
\text { discordâncias } \\
\text { conflitos intensos } \\
\text { no último ano? }\end{array}$ & $3,30(1,17)$ & $2,29(0,76)$ & 0,039 \\
\hline I. 38 & $\begin{array}{l}\text { Seu (ex-) parceiro já } \\
\text { apresentou } \\
\text { recentemente } \\
\text { sintomas psicóticos, } \\
\text { como ouvir vozes, } \\
\text { ver coisas, falar } \\
\text { coisas ou fazer } \\
\text { coisas estranhas ou } \\
\text { bizarras, difíceis de } \\
\text { compreender? }\end{array}$ & $4,89(1,502)$ & $6,43(2,573)$ & 0,047 \\
\hline I.42 & $\begin{array}{l}\text { Seu (ex-) parceiro } \\
\text { sente-se perseguido } \\
\text { constantemente, } \\
\text { achando que } \\
\text { pessoas o seguem, o } \\
\text { observam na rua, } \\
\text { riem dele? }\end{array}$ & $4,11(1,553)$ & $5,86(1,215)$ & 0,010 \\
\hline I. 57 & $\begin{array}{l}\text { Seu (ex-) parceiro é } \\
\text { violento com as } \\
\text { crianças? }\end{array}$ & $6,37(1,523)$ & $5,00(0,816)$ & 0,029 \\
\hline
\end{tabular}




\begin{tabular}{|c|c|c|c|c|}
\hline \multirow[b]{2}{*}{ Item } & \multirow[b]{2}{*}{ Texto } & $\begin{array}{c}\text { Média (Desvio } \\
\text { Padrão) }\end{array}$ & \multicolumn{2}{|c|}{ Teste $\mathrm{t}$ de Student* } \\
\hline & & Feminino $(n=27)$ & Masculino $(n=7)$ & \\
\hline I.62 & $\begin{array}{lr}\text { Seu (ex-) } & \text { parceiro } \\
\text { agrediu } & \text { você } \\
\text { quando } & \text { estava } \\
\text { grávida? } & \end{array}$ & $7,30(1,382)$ & $6,00(1,528)$ & 0,038 \\
\hline $\mathrm{I} .73$ & $\begin{array}{l}\text { Seu (ex-) parceiro } \\
\text { disse coisas de } \\
\text { natureza sexual que } \\
\text { a ofenderam }\end{array}$ & $3,56(1,368)$ & $2,29(1,254)$ & 0,033 \\
\hline
\end{tabular}

Nos itens I.09, I.62, I.73, apesar das diferenças significativas de média, houve a concordância entre os grupos a respeito do grupo de risco do item (moderado, grave ou extremo). Em apenas três itens (I.38; I.42; I.57), a médias de periculosidade de homens e de mulheres geraram uma classificação final diferente quanto ao risco. O item I.57, que trata de violência contra criança, teve classificação de risco extremo no grupo de mulheres e de risco grave no grupo de homens. Os dois outros itens tratam de sintomas psicóticos e tiveram uma classificação de risco extremo no grupo de homens, enquanto as mulheres os classificaram no grupo risco grave (I.42) e moderado (I.38).

Em alguns itens, observa-se menor ou maior consenso entre homens e mulheres. Por exemplo, os itens I.09 e I.57, que tratam respectivamente de conflitos intensos entre o casal e violência contra crianças, os homens responderam de maneira mais coesa (menor desvio padrão), e observou-se maior variação nas respostas do grupo de mulheres. Já o item I.38 encontra maior dispersão de avaliação entre os homens. Esse fenômeno pode ter ampliado a significância da diferença das médias entre os grupos de mulheres e de homens.

Pode-se perceber que, quando comparado cada grupo com a amostra toda, houve pouca diferença na classificação final dos itens nos grupos risco moderado, grave e extremo. Nessa comparação com o grupo de mulheres, somente um item foi alterado 
(I.42 e I.98). Com o grupo de homens, somente nove itens (I.62; I.57; I.61; I.38 I.11; I.66; I.42; I.41; I.44) (as tabelas completas dessas comparações podem ser consultadas no Anexo 9), o que era esperado, considerando a menor proporção de homens na amostra.

Frente ao número reduzido de itens com pouca variabilidade entre os grupos, das características de dispersão intragrupos, e do fato de que a classificação final dos itens nos grupos risco moderado, alto e extremo pouco se altera, quando comparado cada grupo com a amostra toda, pode-se considerar que o grupo de mulheres e o grupo de homens apresentaram comportamento semelhante em relação à grande maioria dos itens. A diferença significativa de média que ocorreu em $6 \%$ dos itens quando comparado o grupo de mulheres e a amostra geral e em $10 \%$ dos itens na comparação do grupo de homem com amostra toda foi considerada como erro relacionado ao acaso, próximo a 5\% que é postulado para 100 itens.

\section{Diferenças entre profissionais e sociedade civil}

Apesar de haver poucos representantes da sociedade civil $(n=6)$, optou-se por avaliar possíveis diferenças entre as avaliações desse grupo e dos profissionais (as tabelas completas com a análise de todos os itens podem ser consultadas no Anexo 10). A análise estatística demostrou houve diferença significativa de média $(p<0,05)$ em quatorze itens (I.01; I.10; I.11; I.18; I.27; I;29; I.45; I.55; I;59; I.62; I.79; I.80; I.87; I.96) as avaliações de profissionais diferiram das dos representantes da sociedade civil. Tais itens abordam controle e vigilância de atividades diária (I.10); uso abusivo e dependência de álcool e drogas pelo parceiro (I.10; I.11) e pela mulher (I.18); descumprimento de medida protetiva (I.27); medo da Justiça (I.29); tentativa de suicídio 
pela mulher (I.45); internação psiquiátrica da mulher (I.55); violência contra outros (I.59); agressão na gravidez (I.62); agressão com pedaço de pau, cassetete ou barra de ferro (I.79); uso de arma de fogo na violência contra a companheira (I.80); separação (I.87); crenças da rede social (I.96). Em apenas sete desses itens (I.01; I.27;I.59; I.62; I.79; I.80; I.87) a classificação de risco em moderado, grave, extremo foi diferentes nos dois grupos.

Tabela 3.

Estatística descritiva dos grupos sociedade civil e profissionais.

\begin{tabular}{|c|c|c|c|c|}
\hline \multirow[b]{2}{*}{ Item } & \multirow[b]{2}{*}{ Texto } & \multirow{2}{*}{$\begin{array}{l}\text { Média (Desvio } \\
\text { Padrão) } \\
\begin{array}{l}\text { Sociedade civil } \\
(\mathrm{n}=6)\end{array}\end{array}$} & \multicolumn{2}{|c|}{ Teste $\mathrm{t}$ de Student* } \\
\hline & & & $\begin{array}{l}\text { Profissionais } \\
\quad(\mathrm{n}=28)\end{array}$ & \\
\hline I.01 & $\begin{array}{l}\text { Seu (ex-) parceiro } \\
\text { tenta controlar sua } \\
\text { vida e vigia a } \\
\text { maioria de suas } \\
\text { atividades diárias? } \\
\text { Por exemplo: ele te } \\
\text { diz quem pode ser } \\
\text { seu amigo, quando } \\
\text { você pode ver sua } \\
\text { família, quanto } \\
\text { dinheiro você pode } \\
\text { gastar ou onde você } \\
\text { pode ir? }\end{array}$ & $\begin{array}{c}3,83 \\
(1,602)\end{array}$ & $\begin{array}{c}5,68 \\
(1,416)\end{array}$ & 0,008 \\
\hline I. 10 & $\begin{array}{l}\text { Seu (ex-) parceiro } \\
\text { faz uso abusivo ou é } \\
\text { dependente de } \\
\text { alguma droga ou de } \\
\text { álcool? }\end{array}$ & $\begin{array}{c}6,83 \\
(1,329)\end{array}$ & $\begin{array}{c}4,64 \\
(1,283)\end{array}$ & 0,001 \\
\hline I. 11 & $\begin{array}{l}\text { Seu (ex-) parceiro } \\
\text { usa diariamente ou } \\
\text { quase todo dia } \\
\text { álcool ou drogas? }\end{array}$ & $\begin{array}{c}6,00 \\
(0,623)\end{array}$ & $\begin{array}{c}4,46 \\
(1,710)\end{array}$ & 0,040 \\
\hline I. 18 & $\begin{array}{lr}\text { Você } & \text { tem } \\
\text { apresentado com } \\
\text { frequência } \\
\text { problemas de saúde, } \\
\text { com a Justiça ou } \\
\text { com pessoas do seu } \\
\text { convívio r em } \\
\text { decorrência do } \\
\text { consumo de álcool } \\
\text { ou de drogas? }\end{array}$ & $\begin{array}{c}2,67 \\
(0,816)\end{array}$ & $\begin{array}{c}4,04 \\
(1,319)\end{array}$ & 0,021 \\
\hline
\end{tabular}




\begin{tabular}{|c|c|c|c|c|}
\hline \multirow[b]{2}{*}{ Item } & \multirow[b]{2}{*}{ Texto } & \multirow{2}{*}{$\begin{array}{l}\text { Média (Desvio } \\
\text { Padrão) }\end{array}$} & \multicolumn{2}{|c|}{ Teste $\mathrm{t}$ de Student* } \\
\hline & & & $\begin{array}{l}\text { Profissionais } \\
\quad(\mathrm{n}=28)\end{array}$ & \\
\hline $\mathrm{I} .27$ & $\begin{array}{l}\text { Seu (ex-) parceiro } \\
\text { descumpriu medida } \\
\text { protetiva } \\
\text { afastamento, } \\
\text { aproximando-se de } \\
\text { você mesmo quando } \\
\text { você demonstrou } \\
\text { não querer a } \\
\text { aproximação? }\end{array}$ & $\begin{array}{c}5,50 \\
(1,517)\end{array}$ & $\begin{array}{c}6,89 \\
(1,397)\end{array}$ & 0,036 \\
\hline I. 29 & $\begin{array}{l}\text { Seu (ex-) parceiro } \\
\text { tem medo da polícia } \\
\text { ou da Justiça? }\end{array}$ & $\begin{array}{c}4,67 \\
(1,633)\end{array}$ & $\begin{array}{c}2,29 \\
(1,740)\end{array}$ & 0,004 \\
\hline I.45 & $\begin{array}{l}\text { Você já se } \\
\text { machucou de } \\
\text { propósito, ameaçou } \\
\text { se matar ou tentou } \\
\text { cometer suicídio? }\end{array}$ & $\begin{array}{c}3,50 \\
(1,049)\end{array}$ & $\begin{array}{c}5,46 \\
(2,269)\end{array}$ & 0,048 \\
\hline I.55 & $\begin{array}{lr}\text { Você já } & \text { foi } \\
\text { submetida } & \text { a } \\
\text { internação } & \\
\text { psiquiátrica? } & \end{array}$ & $\begin{array}{c}2,67 \\
(1,366)\end{array}$ & $\begin{array}{c}3,11 \\
(1,729)\end{array}$ & 0,036 \\
\hline I.62 & $\begin{array}{lr}\text { Seu (ex-) } & \text { parceiro } \\
\text { agrediu } & \text { você } \\
\text { quando } & \text { estava } \\
\text { grávida? } & \end{array}$ & $\begin{array}{c}8,17 \\
(0,983)\end{array}$ & $\begin{array}{c}6,79 \\
(1,475)\end{array}$ & 0,037 \\
\hline I.79 & $\begin{array}{lr}\text { Seu (ex-) parceiro já } \\
\text { usou faca } & \text { durante } \\
\text { episódio } & \text { de } \\
\text { violência } & \text { contra } \\
\text { você? } & \end{array}$ & $\begin{array}{c}6,33 \\
(2,338)\end{array}$ & $\begin{array}{c}7,93 \\
(0,858)\end{array}$ & 0,006 \\
\hline I. 80 & $\begin{array}{l}\text { Seu (ex-) parceiro } \\
\text { usou ou ameaçou } \\
\text { usar arma de fogo } \\
\text { durante episódio de } \\
\text { violência contra } \\
\text { você? }\end{array}$ & $\begin{array}{c}7,00 \\
(2,280)\end{array}$ & $\begin{array}{c}8,25 \\
(1,005)\end{array}$ & 0,039 \\
\hline I.87 & $\begin{array}{l}\text { Vocês se separaram } \\
\text { recentemente depois } \\
\text { de viverem juntos? }\end{array}$ & $\begin{array}{c}1,33 \\
(0,516)\end{array}$ & $\begin{array}{c}2,82 \\
(1,389)\end{array}$ & 0,015 \\
\hline I.96 & $\begin{array}{l}\text { Seus } \\
\text { familiares } \\
\text { conhecidos } \\
\text { consideram que a } \\
\text { mulher deve } \\
\text { permanecer casada, } \\
\text { mesmo se estiver } \\
\text { sofrendo violência? }\end{array}$ & $\begin{array}{c}6,17 \\
(1,941)\end{array}$ & $\begin{array}{c}4,25 \\
(1,898)\end{array}$ & 0,032 \\
\hline
\end{tabular}

$* \mathrm{p}<0,05$ para todas as diferenças de médias 
Diferenças significativas de médias apresentadas por profissionais e por representantes da sociedade civil podem ter relação com o desconhecimento de representantes da sociedade civil sobre teorias e conceitos sobre a violência e a crenças em mitos relacionados a esse fenômeno. O item I.01, por exemplo, que trata do controle das atividades diária pelo (ex-) parceiro, foi classificado com média mais alta pelos profissionais do que pelos representantes da sociedade civil. Essa diferença pode ter relação com a naturalização do controle e da vigilância nas relações íntimas e não entendimento desses como violência por aqueles que não têm formação e atuação na área de violência. Por outro lado essas diferenças nos fazem levantar a hipótese da possibilidade de que as próprias mulheres vítimas tenham opiniões diferentes acerca do que constitui violência e risco, o que sugere a importância de replicar este levantamento com estas mulheres.

Outros itens que cuja classificação pode estar relacionada com a permanência de mitos na opinião da sociedade civil são os itens I.11 e I.18. O uso abusivo e dependência de álcool pelo ofensor teve uma maior classificação de risco pelos representantes da sociedade civil, enquanto o uso abusivo e dependência de álcool pela mulher recebeu maior avaliação pelos profissionais. Essas diferenças de classificação podem estar relacionadas ao mito de que o uso de álcool pelo homem é fator causal de violência contra a mulher, bem como à desconsideração da relação entre violência e uso abusivo de álcool pela mulher.

A falta de conhecimento de conceitos e de teorias também pode ter provocado a diferença de avaliação no item I.96, que aborda a percepção da rede social da mulher acerca da manutenção do casamento. Para profissionais, foi risco grave e para os representantes da sociedade civil, risco moderado. A sociedade civil parece não 
perceber que crenças de familiares e amigos colocam em risco mulheres em situação de violência.

Pode-se inferir a influência de conhecimento de conceitos e teorias também nos itens I.27 e I.29. A diferença entre os grupo acerca do item (I.27) que trata do medo da Justiça e medidas protetivas (I.29) pode ter relação com o não entendimento do texto dos itens, já que quatro representantes da sociedade civil questionaram o que significava medidas protetivas e que era a "Justiça" e o que isso tinha a ver com medo.

Diferenças internas nos grupos também podem ter contribuído para o grau de significância das diferenças de média. O item I.45, sobre tentativa de suicídio, apresentou amplo desvio padrão no grupo de profissionais, sinalizando dispersão de opiniões acerca do risco neste item, mais do que para membros da sociedade civil. $\mathrm{O}$ item I.80 sobre uso de arma de fogo apresentou grande variância no grupo de representantes da sociedade civil.

Apesar de terem diferenças significativas na percepção de risco de representantes da sociedade civil e de profissionais da rede, com a inclusão da opinião do grupo de pessoas sem experiência na área, a classificação dos itens que representam risco extremo não sofre alteração. Somente em cinco itens (I.01; I.25; I.96; I.41; I.98) mudaram sua classificação final ao comparar a classificação dos itens nos grupos moderado, grave e extremo risco com e sem a média dos representantes da sociedade civil. Essa diferença em apenas 5\% foi considerada como erro relacionado ao acaso (a tabela completa dessa comparação pode ser consultada no Anexo 11). Por isso, optou-se por realizar a análise com a amostra inteira sem diferenciar profissionais e representantes da sociedade civil. 
A forma pela qual representantes da sociedade civil e profissionais vivenciaram a distribuição dos cartões foi diferente. Os representantes da sociedade civil requereram com mais frequência a explicação sobre conceitos e significados relacionados aos itens. Em sua maioria, consideraram que a experiência era fácil, embora entendessem que alguns itens não tinham nenhuma relação com risco de violência contra mulher.

Para os profissionais, a experiência foi difícil, pois o número limitado de escolhas em cada coluna impedia que fosse escolhido o número desejado de fatores de risco extremo, o que era ótimo do ponto de vista metodológico, por forçar a distinção entre os itens. Todos os profissionais ressaltaram que alguns itens eram muito parecidos. Alguns mencionaram que uma das estratégias utilizadas para classificar os itens de em risco moderado, grave e extremo foi selecionar entre os que tinham fatores de risco sobre um mesmo tema, como, por exemplo, aqueles que tinham a melhor linguagem e representatividade do tema de forma geral e colocá-lo em risco grave ou extremo. Os demais itens eram colocados na categoria restante. Nessa perspectiva, muitos itens classificados como risco moderado, foram colocados nesse grupo, por não terem a melhor linguagem ou representatividade do tema.

\section{Diferenças entre profissionais psicossociais e}

\section{profissionais jurídicos e da segurança}

Também foi realizado o contraste entre o grupo de profissionais que trabalham na assistência, entre eles psicólogos e assistentes sociais, comparando suas respostas às de profissionais que trabalham no sistema jurídico ou de segurança (as tabelas completas com a análise de todos os itens podem ser consultadas no Anexo 12). Somente em dois itens (I.43; I.64) houve diferenças significativas de média $(p<0,05)$ 
dos profissionais psicossociais e dos profissionais jurídicos e da segurança. Tais itens são: I.43 “Seu (ex-) parceiro já foi submetido a internação psiquiátrica?” e I.64 "Se parceiro já ameaçou você dizendo algo parecido com a frase 'se eu não posso ter você, ninguém mais pode'?". Os dois itens se referem a aspectos relacionados ao ofensor. O item I.43 teve maior média no grupo dos profissionais jurídicos e da segurança e o item I.64 teve maior média no grupo de profissionais psicossociais quando comparado ao outro grupo.

\section{Tabela 4.}

Estatística descritiva dos grupos de profissionais.

\begin{tabular}{|c|c|c|c|c|}
\hline \multirow[b]{2}{*}{ Item } & \multirow[b]{2}{*}{ Texto } & $\begin{array}{l}\text { Média (Desvio } \\
\text { Padrão) }\end{array}$ & \multicolumn{2}{|c|}{ Teste t de Student* } \\
\hline & & $\begin{array}{c}\text { Profissionais } \\
\text { Jurídicos e da } \\
\text { segurança }(\mathrm{n}=11)\end{array}$ & $\begin{array}{l}\text { Profissionais } \\
\text { Psicossociais } \\
\quad(n=17)\end{array}$ & \\
\hline $\mathrm{I} .43$ & $\begin{array}{l}\text { Seu (ex-) parceiro } \\
\text { tenta controlar sua } \\
\text { vida e vigia a } \\
\text { maioria de suas } \\
\text { atividades diárias? } \\
\text { Por exemplo: ele te } \\
\text { diz quem pode ser } \\
\text { seu amigo, quando } \\
\text { você pode ver sua } \\
\text { família, quanto } \\
\text { dinheiro você pode } \\
\text { gastar ou onde você } \\
\text { pode ir? }\end{array}$ & $\begin{array}{c}4,91 \\
(1,973)\end{array}$ & $\begin{array}{c}3,59 \\
(1,176)\end{array}$ & 0,035 \\
\hline I.64 & $\begin{array}{l}\text { Seu (ex-) parceiro } \\
\text { faz uso abusivo ou é } \\
\text { dependente de } \\
\text { alguma droga ou de } \\
\text { álcool? }\end{array}$ & $\begin{array}{c}5,64 \\
(1,206)\end{array}$ & $\begin{array}{c}6,88 \\
(1,764)\end{array}$ & 0,035 \\
\hline
\end{tabular}

* $\mathrm{p}<0,05$ para todas as diferenças de médias

O item I.43 no grupo de profissionais jurídicos e da segurança, teve média de 4,91 (DP 1.97) sendo enquadrado em risco grave. Para os profissionais psicossociais, a média foi de 3,59 (DP 1.17), que significou risco moderado. Essa diferença pode ter relação com o fato de que, durante a realização das atividades, profissionais 
psicossociais referiram que não é frequente nos casos que atendem que o ofensor tenha transtorno mental. Alguns demonstraram desconsiderar a relação entre violência e transtorno mental apontada pela literatura (Abdalla-Filho, 2012; Day et al., 2003). Um homem que comete violência contra sua parceira legitimado pela desigualdade de gênero e pela naturalização da violência contra a mulher pode tornar-se mais violento caso passe a apresentar sintomas psicóticos com ou sem mania (Soares, 2005).

O item I.64 que pergunta se o homem já ameaçou com a frase "se eu não posso ter você, ninguém mais pode", apresentou tanto diferenças significativas de médias quanto de concentração dos dados. Houve maior concordância no grupo de profissionais jurídicos e da segurança, em que o item foi classificado como risco grave e com de 5.64 (DP 1.20). No grupo psicossocial, o item foi classificado como risco extremo com média de 6.88 (DP 1.76).

Ao comparar a classificação dos itens do grupo de profissionais psicossociais em risco moderado, grave e extremo com a classificação da amostra geral, houve diferenças em apenas nove itens (I.45; I.01; I.22; I.98; I.05; I.32; I.66; I.42; I.11). A mesma comparação feita com o grupo de profissionais jurídicos e da segurança, resultou em diferença em apenas onze itens (I.84; I.14; I.03; I.61; I.86; I.41; I.43; I.40; I.90; I.25; I.96). Essa diferença foi considerada como erro relacionado ao acaso (as tabelas completas dessas comparações podem ser consultadas no Anexo 13).

É possível apontar diferenças na experiência dos participantes de classificar os itens em grupos dois grupos. Os profissionais jurídicos e da segurança relataram ter tido dificuldade em avaliar itens relacionados à saúde mental ou considerar que tais itens seriam mais bem avaliados em uma avaliação de risco realizada por profissionais psicossociais. 
Tais apontamentos não foram frequentes no grupo psicossocial. Pelo contrário, as dificuldades apresentadas, de acordo com alguns participantes, decorreram da impossibilidade de colocar todos os fatores em risco extremo ou grave. Essa limitação ressaltada por tais participantes decorre da escolha metodológica orientada pela necessidade de forçar os participantes a analisar cada item em relação a outro em variações contínuas de risco e a evitar vieses do tipo atribuição de valores centrais ou extremos à maioria dos itens.

Profissionais jurídicos e da segurança, ao responderem ao questionário com indagações sobre a experiência de distribuição do itens, demonstraram ter expectativas diferentes frente a uma checklist de avaliação de risco. Para a maioria dos profissionais psicossociais, quase todos os itens poderiam fazer parte de uma checklist de avaliação de risco. Foi consenso que retirariam algumas perguntas que eram muito semelhantes. Por outro lado, entre o grupo de profissionais jurídicos e da segurança, foi unanimidade que uma checklist de 100 itens seria inapropriada para o contexto em que atuam. Na perspectiva deles, deveria ser mais concisa, para que pudesse ser aplicada por promotores e por delegados.

Alguns profissionais jurídicos e da segurança destacaram que a avaliação realizada em emergências policiais necessitaria de ser ainda mais reduzida, pois, nesses contextos, não seria possível realizar uma quantidade grande de determinadas perguntas. Sugeriram que, em uma ocorrência policial, seria possível investigar apenas os itens sobre: descumprimento de medidas protetivas (I.26), arma de fogo (I.80; I.81), ameaça de matar (I.63), aumento da intensidade e frequência das violências (I.82; I.83). Todos esses itens foram classificados como representativos de risco extremo. 


\section{Discussão e considerações finais}

A análise dos dados permitiu identificar consensos acerca da classificação dos itens nos grupos risco moderado, grave e extremo. Também permitiu identificar que profissionais jurídicos e da segurança têm expectativa diferente acerca de uma checklist de avaliação de risco daquela apresentada por profissionais psicossociais. Os primeiros consideram que a checklist para seu uso deve ser mais objetiva e concisa do que a utilizada por psicossociais. Os profissionais psicossociais concordaram que podem fazer uma avaliação mais extensa e que teriam mais condições de avaliar itens com temas sobre saúde mental.

Essa diferença de expectativa está em consonância com a literatura, que afirma que a complexidade da avaliação de risco também deve variar de acordo com o tipo de serviço onde é realizada e tipo de profissional que a conduz (Campbell, 2001; Hermoso et al., 2012). Determinadas investigações exigem formação específica, como a investigação de questões de saúde (Hermoso et al., 2012; Nicolls et al., 2013).

O uso da checklist para fins de pesquisa ou de intervenção irá requerer capacitação e experiência na temática violência, especialmente acerca da avaliação de riscos. Embora a análise dos dados tenha mostrado poucas diferenças entre sociedade civil e profissionais que atuam na rede de atendimento a pessoas em situação de violência, a falta de experiência e de formação na temática violência dos leigos pode ter contribuído para as diferenças existentes e para que houvesse dificuldade de entendimentos dos itens.

Durante o processo de construção e de validação da checklist, não foi desconsiderado que uma checklist de avaliação de risco com 100 itens é extensa e pode ser inapropriada para alguns contextos. Todavia, a construção de um instrumento deve 
iniciar-se com a formulação de itens de forma a cobrir a totalidade ou a maior parte das dimensões daquilo que se pretende medir. $\mathrm{O}$ número final de itens só poderá ser decidido depois de terem passado por análise estatística do valor preditivo do risco que pode indicar quais são os melhores itens.

Espera-se que esta pesquisa contribua para o desenvolvimento de método válido de avaliação risco. A validação de conteúdo realizada é o primeiro passo para construção de uma checklist válida. Outros estudos de padronização e determinação da validade de critério serão absolutamente necessários no futuro. Estudos correlacionais prospectivos são necessários para determinar a capacidade preditiva do risco real desse conjunto de itens. Tais estudos devem envolver a avaliação de mulheres realizada por profissionais utilizando a checklist, seguido de acompanhamento longitudinal das avaliadas, (de seis meses a dois anos) para verificar informações acerca da reincidência de violência e sobre sua natureza e os tipo de danos sofridos. Isto permitiria estimar a probabilidade de risco de violência, danos ou morte.

\section{Referências}

Abdala-Filho, Elias. (2012). Avaliação de Risco. In José G. V Taborda, Elias Abdala-Filho \& Miguel Chalub (Orgs.), Psiquiatria Forense (pp. 183-204). Porto Alegre: Artmed.

Acosta, Miguel Lorente. (2013). La valoración médico-forense del Riego em la violência de género. Predicción y prevención. In. Encuentro-taller sobre conclusiones extraidas de los últimos informes elaborados por el ovdyg. Buenas prácticas judiciales. Disponível em: http://www.poderjudicial.es/stfls/CGPJ/OBSERVATORIO\%20DE\%20VIOLENCIA\%20DOM\% C3\%89STICA/OTRAS\%20ACTIVIDADES\%20FORMATIVAS/FICHEROS/20130502\%20Lista do\%20de\%20Ponencias.pdf

Almeida, Isis \& Soeiro, Cristina. (2010). Avaliação de risco de violência conjugal: versão para polícias (SARA: PV). Análise Psicológica, 1 (28), 179-192.

Andrés-Pueyo, Antonio \& Echeburúa, Enrique. (2010). Valoración del riesgo de violência: instrumentos diponibles e indicaciones de aplicación. Psicothema, 22 (3), 403-409. 
Bigras, Marc \& Dessen, Maria Auxiliadora. (2002). O método Q na avaliação psicológica: utilizando a família como ilustração. Avaliação Psicológica. 2, 119-131.

Beccaria, Corrêa Lúcia M.; Amorim, Renée C.; Pacheco, Sirley S.; Vacondino, Simone; Fechio, Petronilha B. (2008). Coleta de dados de enfermagem em unidade coronária: validação de instrumento. Arq Ciênc Saúde, 15 (2), 751-757.

Bellucci Junior, Jose Aparecido Bellucci \& Matsudan, Laura Misue. (2012). Construção e validação de instrumento para avaliação do acolhimento com classificação de risco. Revista Brasileira de Enfermagem, 65(5), 751-757.

Campbell, Jacquelyn C. (2005). Assessing dangerousness in domestic violence cases: history, challenges, and opportunities. Criminology \& Public Policy. Columbus, 4(4), 653-672.

Campbell, J., Webster, D. W. \& Glass, Nancy. (2009). The Danger Assessment: validations of a lethality risk assessment instrument for intimate partner femicide. Journal of Interpersonal Violence, 24 (4), 653-674.

Day, Vivian P.; Telles, Lisiex E. de B.; Zoratto, Pedro Henrique; Azambuja, Maria Regina Fay de; Machado, Denise A.; Silveira, Marisa B.; Debiaggi, Moema; Reis, Maria da Graça; Cardoso, Rógerio; Blank, Paulo. (2003). Violência doméstica e suas diferentes manifestações. Revista de Psiquiatria, 25 (1), 9-21.

Grams, Ana Clara \& Magalhães, Teresa. (2011). Violência nas relações de intimidade. Avaliação de Risco. Revista Portuguesa do Dano Corporal, 22, 75-98.

Haggard-Grann, Ulrika. (2007). Assessing violence risk: a review and clinical recommendations. Journal of Counseling and Development, 85 (3), 294-302.

Krug, E. G., Dalberg, L. L., Mercy, J. A, Zwi, A. B. \& Lozano, R. (2002). Relatório mundial sobre violência e saúde. Geneva: Organização Mundial de Saúde.

Martins, Gilberto de Andrade Martins. Sobre confiabilidade e validade. Rev. Bras. Ges. Neg., 8 (20), 112.

Pasquali, L. (1998). Princípios de elaboração de escalas psicológicas. Rev. Psiq. Clin., 25 (5),Edição Especial, 206-213.

Pasquali, L. (2009). Psicometria. Rev. Esc. Enfermagem, 43 (Esp.), 992-999.

Santos, Leonel Duarte dos \& Amaral, Luis Alfredo Martins do. (2004). Estudos Delphi com Q-Sort sobre a web - A sua utilização em Sistema. Retirado de: https://repositorium.sdum.uminho.pt/bitstream/1822/2280/1/ArtigoCAPSI2004Delphi.pdf

Williams, Kirk R. \& Houghton, Amy Barry. (2004). Assessing the risk of domestic reoffending: a validation study. Law and Human Behavior, 28 (4), 437-455. 


\section{Considerações Finais}

Conhecer formas de avaliação de risco descritas na literatura possibilitou tecer considerações acerca da condução de avaliações de risco em outros países e no Brasil, especialmente, no Distrito Federal. A avaliação de risco tem-se tornado cada vez mais frequente em diversos países e pesquisadores têm-se interessado por instrumentos com evidência empírica que possam ser utilizados nesse contexto. Apesar de coexistirem diferentes abordagens - não estruturada e estruturadas -, percebe-se mudança de paradigma no processo de avaliação de risco com crescente valorização da combinação do uso de instrumentos e do julgamento clínico.

A avaliação de risco no Distrito Federal mostrou-se como predominantemente não estruturada. Profissionais valorizam a investigação de fatores de risco de violências e utilizam sua experiência acadêmica e profissional para identificar situações de perigo. Todavia, a ausência de normas e de diretrizes institucionais contribui para que essa experiência seja diversificada e dependente de motivações pessoais. Tais resultados ressaltam a urgência da normatização da avaliação de risco na Segurança Pública, no Poder Judiciário, no Ministério Público e nos serviços do Executivo da rede de atendimento a pessoas em situação de violência.

Tem-se como desafio a tarefa de capacitar profissionais para o uso de instrumentos visando normatizar os processos avaliação e gerar ações de proteção às vítimas e responsabilização dos autores de violências. O processo de avaliação de risco, conduzido por profissional capacitado, pode permitir que a mulher amplie sua consciência sobre sua situação e discuta possíveis estratégias pessoais e institucionais para auxiliá-la na sua proteção. Assim, favorece a saída da minimização dos perigos 
envolvidos, bem como coloca a mulher como corresponsável na condução da elaboração das ações a serem tomadas para garantir sua segurança. A avaliação formal feita nos serviços é, portanto, um importante momento para ajudá-las a ter uma noção mais realista de suas situações e decidir o que é mais adequado para elas.

Espera-se que as reflexões apresentadas nesse estudo, ainda que iniciais, ofereçam contribuições teórico-práticas para a atuação de psicólogos clínicos e outros profissionais que atuam no atendimento às famílias em situação de violência conjugal. A avaliação de risco, quando conduzida por profissional capacitado, também é útil para orientar as ações de profissionais da rede de atendimento às mulheres. A utilização de estratégias sistemáticas de avaliação de risco favorece a padronização da linguagem utilizada pelos profissionais dos diversos serviços que compõem a rede de atendimento. Além disso, possibilita que as práticas de avaliação e risco sejam embasadas em evidências.

Prever uma conduta humana é uma tarefa extremamente difícil. Não existe um número fixo de fatores de risco que estejam associados a um risco de violência grave ou letal, nem uma regra infalível acerca do peso de cada fator de risco. No entanto, estudos empíricos sobre fatores de risco, como este, podem oferecer um suporte que, somado à experiência, à formação e ao uso de multimétodos favoreça a realização de avaliações de risco mais acertadas.

Os itens de avaliação de risco elaborados neste estudo resultaram da análise dos instrumentos Danger Assessment - DA, Revised Domestic Violence Screening Instrument - DVSI- R e Spousal Assault Risk Assessment - SARA, à luz da literatura e da coleta de opinião e da avaliação de profissionais da rede de atendimento. A escolha 
dessa metodologia possibilitou o entendimento das dimensões da avaliação de risco e permitiu que a construção dos itens fosse realizada em parceria com profissionais da rede de atendimento a pessoas em situação de violência.

Espera-se que este esse estudo contribua para o desenvolvimento de método válido de avaliação risco, à medida que a análise dos dados possibilitou que fossem construídos e identificados itens que podem compor uma checklist de avaliação de risco. Para que a capacidade preditiva da checklist e de seus itens seja conhecida, é necessário o desenvolvimento de estudos correlacionais prospectivos, nos quais a checklist seja aplicada e que as mulheres avaliadas sejam acompanhadas longitudinalmente para avaliar a recorrência de atos de violência.

Qualquer checklist deve ser compreendida como um guia, no sentido de que seus itens orientam o profissional acerca das áreas que devem ser exploradas durante sua avaliação. A forma pela qual será conduzida a interação com a vítima, a escolha de métodos adicionais de investigação e a tomada de decisão acerca dos resultados dependerão, em última instância, da formação e da experiência de cada profissional.

O uso da checklist deve ter como fim último o embasamento de estratégias de gestão de risco. Todos os casos avaliados requerem medidas de gestão, mesmo aqueles que não oferecem elementos de risco extremo. Além disso, para que sejam eficazes, é preciso haver maior articulação entre os órgãos da rede de atendimento e atuação efetiva de todos os serviços nesse processo de gestão de risco. 
Anexo 1 - Livre tradução para fins de estudo do

instrumento Revised Domestic Violence Screening InstrumentDVSI-R 


\section{Revised Domestic Violence Screening Instrument - DVSI}

\begin{tabular}{|c|c|c|c|c|}
\hline & 0 & 1 & 2 & 3 \\
\hline $\begin{array}{l}\text { 1. Evidencia de assaltos, prisões ou } \\
\text { condenação criminal não relacionados à } \\
\text { violência familiar? }\end{array}$ & $\begin{array}{c}\text { Sem } \\
\text { evidencia }\end{array}$ & $\begin{array}{c}1 \text { ou } 2 \\
\text { incidentes }\end{array}$ & 3 ou mais & \\
\hline $\begin{array}{l}\text { 2. Evidencia de prévia de golpes, ameaça } \\
\text { ou prisão relacionada à violência familiar? }\end{array}$ & $\begin{array}{c}\text { Sem } \\
\text { evidencia }\end{array}$ & $\begin{array}{c}1 \text { ou } 2 \\
\text { incidentes }\end{array}$ & 3 ou mais & \\
\hline $\begin{array}{l}\text { 3. Prévio tratamento/intervenção para } \\
\text { pessoas em situação de violência? }\end{array}$ & $\begin{array}{c}\text { Sem } \\
\text { evidencia }\end{array}$ & $\begin{array}{c}1 \text { ou } 2 \\
\text { incidentes }\end{array}$ & 3 ou mais & \\
\hline $\begin{array}{l}\text { 4. História de violação de medidas } \\
\text { protetivas ou supervisão da corte? }\end{array}$ & $\begin{array}{c}\text { Sem } \\
\text { evidencia }\end{array}$ & Prévio & Atual & $\begin{array}{c}\text { Prévio e } \\
\text { atual }\end{array}$ \\
\hline $\begin{array}{l}\text { 5. Evidência de abuso de substâncias na } \\
\text { ocasião do incidente de violência familiar? }\end{array}$ & $\begin{array}{c}\text { Sem } \\
\text { evidencia }\end{array}$ & Prévio & Atual & $\begin{array}{c}\text { Prévio e } \\
\text { atual }\end{array}$ \\
\hline $\begin{array}{l}\text { 6. Qualquer evidência de uso de faca } \\
\text { durante prévia ou atual crime de violência } \\
\text { familiar crime? }\end{array}$ & $\begin{array}{c}\text { Sem } \\
\text { evidencia }\end{array}$ & Prévio & Atual & $\begin{array}{c}\text { Prévio e } \\
\text { atual }\end{array}$ \\
\hline $\begin{array}{l}\text { 7. Crianças estavam presentes durante o } \\
\text { incidente de violência familiar? }\end{array}$ & $\begin{array}{c}\text { Sem } \\
\text { evidencia }\end{array}$ & Prévio & Atual & $\begin{array}{c}\text { Prévio e } \\
\text { atual }\end{array}$ \\
\hline 8. Atual status ocupacional? & Empregado & $\begin{array}{l}\text { Incerto/tempo } \\
\text { parcial }\end{array}$ & Desempregado & \\
\hline $\begin{array}{l}\text { 9. Evidencia de prévio ou atual abuso } \\
\text { verbal ou emocional? }\end{array}$ & $\begin{array}{c}\text { Sem } \\
\text { evidencia }\end{array}$ & Alto/moderado & Severo & \\
\hline $\begin{array}{l}\text { 10. Qual foi a frequência de violência } \\
\text { familiar nos últimos } 6 \text { meses? }\end{array}$ & $\begin{array}{c}\text { Sem } \\
\text { evidencia }\end{array}$ & 1 incidente & 2 incidentes & $\begin{array}{l}3 \text { ou } \\
\text { mais }\end{array}$ \\
\hline $\begin{array}{l}\text { 11. O padrão de violência familiar escalou } \\
\text { nos últimos } 6 \text { meses? }\end{array}$ & $\begin{array}{c}\text { Sem } \\
\text { evidencia }\end{array}$ & & & Sim \\
\hline
\end{tabular}


Anexo 2 - Livre tradução para fins de estudo do

instrumento Spousal Assault Risk Assessment - SARA 
SARA

SPOUSAL ASSAULT RISK ASSESSMENT

Ofensor:

Avaliador:

Assinatura:

Data:

PROCEDIMENTOS DE CLASSIFICAÇÃO

O SARA é um checklist para auxiliar na determinação do risco de violência que ocorre no contexto de violência perpetrada pelo parceiro íntimo. É importante que o avaliador não use somente a taxa individual para avaliar risco. Um ofensor pode ter poucos itens classificados como " 2 "e ainda ser alto risco de violência. Instruções gerais para codificação são apresentadas abaixo; veja o manual do SARA para instruções específicas sobre a codificação de itens individuais.

\section{HISTÓRIA CRIMINAL}

\begin{tabular}{|l|l|l|l|}
\hline & Ausente & $\begin{array}{l}\text { Parcialmente } \\
\text { possível }\end{array}$ & Presente \\
\hline $\begin{array}{l}\text { 1. Violência passada contra membros da família } \\
\text { (Não inclui violência contra parceiro íntimo). }\end{array}$ & & & \\
\hline $\begin{array}{l}\text { 2. Violência passada contra estranhos ou } \\
\text { desconhecidos. }\end{array}$ & & & \\
\hline $\begin{array}{l}\text { 3. Violação passada de liberdade condicional ou } \\
\text { supervisão comunitária. }\end{array}$ & & & \\
\hline
\end{tabular}

AJUSTAMENTO PSICOSSOCIAL

\begin{tabular}{|l|l|l|l|}
\hline & Ausente & $\begin{array}{l}\text { Parcialmente } \\
\text { possível }\end{array}$ & Presente \\
\hline 4. Problemas de relacionamento recente. & & & \\
\hline 5. Recente problema no emprego. & & & \\
\hline $\begin{array}{l}\text { 6. Foi vítima ou testemunha de violência } \\
\text { doméstica. }\end{array}$ & & & \\
\hline 7. Recente abuso/dependência de substâncias. & & & \\
\hline $\begin{array}{l}\text { 8. Recente intenção/ideação suicida ou } \\
\text { homicida. }\end{array}$ & & & \\
\hline 9. Recentes sintomas maníacos ou psicóticos. & & & \\
\hline $\begin{array}{l}\text { 10. Desordens de personalidade com raiva, } \\
\text { impulsividade ou comportamento instável. }\end{array}$ & & & \\
\hline
\end{tabular}

HISTÓRIA DE VIOLÊNCIA CONTRAA PARCEIRA

\begin{tabular}{|l|l|l|l|}
\hline & Ausente & $\begin{array}{l}\text { Parcialmente } \\
\text { possível }\end{array}$ & Presente \\
\hline 11. Violência física passada. & & & \\
\hline 12. Violência sexual passada. & & & \\
\hline $\begin{array}{l}\text { 13. Uso de facas ou de ameaças consistentes de } \\
\text { morte. }\end{array}$ & & & \\
\hline
\end{tabular}




\begin{tabular}{|l|l|l|l|}
\hline $\begin{array}{l}\text { 14. Recente escalonamento na frequência ou } \\
\text { severidade da violência. }\end{array}$ & & & \\
\hline 15. Violação passada de ordens de não contato. & & & \\
\hline $\begin{array}{l}\text { 16. Extrema negação ou minimização da } \\
\text { violência. }\end{array}$ & & & \\
\hline 17. Atitudes de suportar ou perdoar a violência. & & & \\
\hline
\end{tabular}

\section{RECENTE/ OFENSA MAIS ATUAL}

Complete essa sessão se alguma ofensa atual envolve violência contra a parceira íntima ou se o ofensor cometeu violência contra parceira íntima no último ano na comunidade.

\begin{tabular}{|l|l|l|l|}
\hline & Ausente & $\begin{array}{l}\text { Parcialmente } \\
\text { possível }\end{array}$ & Presente \\
\hline 18. Violência sexual. & & & \\
\hline 19. Uso de facas ou ameaças de morte. & & & \\
\hline 20. Violação de ordens de não contato. & & & \\
\hline
\end{tabular}

\section{OUTRAS CONSIDERAÇÕES}

Qualquer fator de risco específico não relatado anteriormente.

\begin{tabular}{|l|l|l|l|}
\hline & Ausente & $\begin{array}{l}\text { Parcialmente } \\
\text { possível }\end{array}$ & Presente \\
\hline & & & \\
\hline & & & \\
\hline & & & \\
\hline
\end{tabular}

\section{RISCO DE VIOLÊNCIA PERPETRADA POR PARCEIRO ÍNTIMO}

\begin{tabular}{|l|l|l|l|}
\hline & BAIXO & MODERADO & ALTO \\
\hline $\begin{array}{l}\text { Risco de } \\
\text { violência contra } \\
\text { parceiro ou ex- } \\
\text { parceiro }\end{array}$ & & \\
\hline $\begin{array}{l}\text { Risco de } \\
\text { violência contra } \\
\text { outros }\end{array}$ & & \\
\hline $\begin{array}{l}\text { Inclui violência } \\
\text { contra alvos } \\
\text { relacionados ä } \\
\text { relação intima } \\
\text { (crianças, nova } \\
\text { parceira íntima, }\end{array}$ & & & \\
\hline
\end{tabular}


Avaliação de risco de violência contra a mulher

\begin{tabular}{|l|l|l|l|l|}
\hline $\begin{array}{l}\text { parente da } \\
\text { parceira íntima). }\end{array}$ & & \multicolumn{2}{|l|}{} \\
\hline $\begin{array}{l}\text { Alvo (s) } \\
\text { específico (s): }\end{array}$ & & & & \\
& & & & \\
\hline
\end{tabular}


Anexo 3 - Versão em português do instrumento Danger Assessment- DA-R 


\section{AVALIAÇÃO DE RISCO}

Jacquelyn C. Campbell, Ph.D., R.N.

Copyright 2003; www.dangerassessment.com

Vários fatores de risco têm sido associados ao aumento de risco para homicídios (assassinato) de mulheres e homens em um relacionamento violento. Nós não podemos predizer o que pode acontecer em seu caso, mas gostaríamos que você tivesse consciência do perigo de homicídio em uma situação de abuso e que você veja quantos fatores de risco aplicam-se á sua situação. Usando o calendário, por favor marque a data aproximada durante o último ano na qual você foi agredida por seu parceiro ou ex-parceiro. Escreva nesta data a gravidade do incidente ocorrido seguindo a seguinte escala:

1. Tapas, empurrões, sem ferimento e/ou dor presente.

2. Perfurações, chutes, socos, cortes, e/ou dor presente.

3. "Surra", contusões graves, queimaduras, ossos quebrados.

4. Ameaça de uso de armas, ferimentos na cabeça, ferimentos internos, ferimentos permanentes.

5. Uso de armas, ferimento decorrente do uso de armas.

(Escolha o número maior se alguma dessas descrições se aplicarem ao número mais alto.)

Marque SIM ou NÃO para cada uma das afirmações ("ele" refere-se a seu marido, parceiro, exmarido,

ex-parceiro, ou qualquer um, que no momento, estiver a agredindo fisicamente).

1. A violência física aumentou de severidade ou freqüência no último ano?

2. Ele possui uma arma?

3. Você o deixou depois de viverem juntos no último ano?

3a. Se você nunca o deixou, marque aqui

4. Ele está desempregado?

5. Ele já usou uma arma contra você ou ameaçou você com uma arma letal?

(Se sim, a arma era um revolver?

6. Ele ameaça matá-la?

7. Ele já tentou não ser preso por violência doméstica?

8. Você tem uma criança que não é filha dele?

9. Ele já forçou você a fazer sexo sem que você desejasse fazê-lo?

10. Ele já tentou estrangular você?

11. Ele usa alguma droga ilegal? Por drogas entenda: "estimulante"ou anfetaminas, heroína, crack, drogas de rua ou misturas.

12. Ele é alcoólatra ou tem problemas com bebidas?

13 Ele tenta controlar a maioria ou todas as suas atividades diárias? Por exemplo: ele te diz quem pode ser seu amigo, quando você pode ver sua família, quanto dinheiro você pode gastar, ou quando você pode pegar o carro? (Se ele tenta controlar, mas você não o deixa, marque aqui:

14. Ele é violento e tem ciúmes, constantemente, de você? (Por exemplo, ele diz: "Se eu não posso tê-la, ninguém pode")

15. Você já foi agredida por ele quando estava grávida? (Se você nunca ficou grávida dele, marque aqui:

16. Ele já ameaçou ou tentou cometer o suicídio?

17 Ele ameaça machucar seus filhos?

18. Você acredita que ele é capaz de matá-la?

19. Ele já seguiu ou espionou você, deixou bilhetes ou mensagens na secretária eletrônica, destruiu sua propriedade ou te ligou quando você não queria?

20. Você já ameaçou ou tentou cometer o suicídio?

Total de respostas "SIM". 
Avaliação de risco de violência contra a mulher

Anexo 4 - Checklist de avaliação de risco 


\section{Checklist de Avaliação de Risco}

\section{Perfil do autor da violência e perfil da vítima:}

\begin{tabular}{|l|l|l|}
\hline $\begin{array}{l}\text { I.01 - Seu (ex-) parceiro tenta controlar sua vida e vigia a } \\
\text { maioria de suas atividades diárias? Por exemplo: ele te diz quem } \\
\text { pode ser seu amigo, quando você pode ver sua família, quanto } \\
\text { dinheiro você pode gastar ou onde você pode ir? }\end{array}$ & & \\
\hline I.02 - Seu (ex-) parceiro tem ciúmes obsessivos de você? & & \\
\hline I.03 - Seu (ex-) parceiro torna-se violento quando enciumado? & & \\
\hline $\begin{array}{l}\text { I.04 - Seu (ex-) parceiro apresenta comportamento impulsivo e } \\
\text { instável quando com raiva? }\end{array}$ & \\
\hline $\begin{array}{l}\text { I.05 - Você considera que ninguém irá amá-la e aceitá-la como } \\
\text { seu (ex-) parceiro? }\end{array}$ & \\
\hline $\begin{array}{l}\text { I.06 - Você não consegue imaginar sua vida sem seu (ex-) } \\
\text { parceiro? }\end{array}$ & & \\
\hline $\begin{array}{l}\text { I.07 - Seu (ex-) parceiro possui arma de fogo e a utiliza para } \\
\text { intimidar pessoas conhecidas ou desconhecidas? }\end{array}$ & \\
\hline $\begin{array}{l}\text { I.08 - Seu (ex-) parceiro ameaça usar sua força física para } \\
\text { intimidar pessoas? }\end{array}$ & & \\
\hline
\end{tabular}

\section{Conflitos interpessoais:}

\begin{tabular}{|l|l|l|}
\hline & Sim & Não \\
\hline $\begin{array}{l}\text { I.09 - Você e seu (ex-) parceiro têm apresentado discordâncias e } \\
\text { conflitos intensos no último ano? }\end{array}$ & & \\
\hline
\end{tabular}

Uso de álcool e/ou de drogas:

\begin{tabular}{|l|l|l|}
\hline & Sim & Não \\
\hline $\begin{array}{l}\text { I.10 - Seu (ex-) parceiro faz uso abusivo ou é dependente de } \\
\text { alguma droga ou de álcool? }\end{array}$ & & \\
\hline $\begin{array}{l}\text { I.11 - Seu (ex-) parceiro usa diariamente ou quase todo dia álcool } \\
\text { ou drogas? }\end{array}$ & & \\
\hline $\begin{array}{l}\text { I.12 - Seu (ex-) parceiro tem apresentado com frequência } \\
\text { problemas de saúde, com a Justiça ou com pessoas do convívio } \\
\text { dele em decorrência do consumo de álcool ou de drogas? }\end{array}$ & & \\
\hline $\begin{array}{l}\text { I.13 - Seu (ex-) parceiro com frequência tem deixado de fazer } \\
\text { coisas que eram normais para ele porque havia consumido álcool } \\
\text { ou drogas em excesso? }\end{array}$ & & \\
\hline $\begin{array}{l}\text { I.14 - Seu (ex-) parceiro estava sobre efeito de álcool ou de } \\
\text { drogas durante os últimos incidentes de violência familiar? }\end{array}$ & & \\
\hline $\begin{array}{l}\text { I.15 - Seu (ex-) parceiro é mais violento quando está sob o efeito } \\
\text { de álcool ou de drogas? }\end{array}$ & & \\
\hline $\begin{array}{l}\text { I.16 - Você faz uso abusivo ou é dependente de alguma droga ou } \\
\text { de álcool? }\end{array}$ & & \\
\hline I.17 - Você usa diariamente ou quase todo dia álcool ou drogas? & & \\
\hline $\begin{array}{l}\text { I.18 - Você tem apresentado com frequência problemas de saúde, } \\
\text { com a Justiça ou com pessoas do seu convívio em decorrência do } \\
\text { consumo de álcool ou de drogas? }\end{array}$ & & \\
\hline
\end{tabular}


I.19 - Você frequentemente tem deixado de fazer coisas que eram normais para você porque havia consumido álcool ou drogas em excesso?

Intervenção para pessoas em situação de violência:

\begin{tabular}{|l|l|l|}
\hline $\begin{array}{l}\text { I.20 - Seu (ex-) parceiro participou recentemente de alguma } \\
\text { forma de intervenção terapêutica, em grupo ou individual, para } \\
\text { homens autores de violência? }\end{array}$ & & \\
\hline $\begin{array}{l}\text { I.21 - Seu (ex-) parceiro foi encaminhado para alguma forma de } \\
\text { intervenção terapêutica, em grupo ou individual, para homens } \\
\text { autores de violência, mas não participou? }\end{array}$ & & \\
\hline
\end{tabular}

\section{Percepção sobre a violência:}

\begin{tabular}{|l|l|l|}
\hline $\begin{array}{l}\text { I.22 - Seu (ex-) parceiro minimiza a importância ou desconsidera } \\
\text { totalmente os atos de violência dele contra você? }\end{array}$ & & Não \\
\hline $\begin{array}{l}\text { I.23 - Você ouviu recentemente de amigos, profissionais ou } \\
\text { familiares que não estava reconhecendo a gravidade da violência } \\
\text { que sofre? }\end{array}$ & & \\
\hline $\begin{array}{l}\text { I.24 - Você perdoou nos últimos seis meses algum incidente de } \\
\text { violência depois de achar que não perdoaria? }\end{array}$ & & \\
\hline
\end{tabular}

Experiências de violência na família de origem:

\begin{tabular}{|l|l|l|}
\hline & Sim & Não \\
\hline $\begin{array}{l}\text { I.25 - Seu (ex-) parceiro já presenciou ou esteve envolvido em } \\
\text { outras cenas de violência em sua família de origem? }\end{array}$ & & \\
\hline
\end{tabular}

\section{História Criminal:}

\begin{tabular}{|l|l|l|}
\hline & Sim & Não \\
\hline $\begin{array}{l}\text { I.26 - Seu (ex-) parceiro descumpriu medida protetiva prevista na } \\
\text { Lei Maria da Penha? }\end{array}$ & & \\
\hline $\begin{array}{l}\text { I.27 - Seu (ex-) parceiro descumpriu medida protetiva de } \\
\text { afastamento, aproximando-se de você mesmo quando você } \\
\text { demonstrou não querer a aproximação? }\end{array}$ & & \\
\hline $\begin{array}{l}\text { I.28 - Seu (ex-) parceiro já foi preso por cometer crimes } \\
\text { violentos contra não familiares? }\end{array}$ & & \\
\hline I.29 - Seu (ex-) parceiro tem medo da polícia ou da Justiça? & & \\
\hline $\begin{array}{l}\text { I.30 - Seu (ex-) parceiro já tentou não ser preso por violência } \\
\text { doméstica? Por exemplo: Fugiu, escondeu-se ou impediu você } \\
\text { de ir à delegacia. }\end{array}$ & & \\
\hline
\end{tabular}

\section{Situação ocupacional:}

\begin{tabular}{|l|l|l|}
\hline & Sim & Não \\
\hline I.31 - Seu (ex-) parceiro está atualmente desempregado? & & \\
\hline $\begin{array}{l}\text { I.32 - Cenas de violência eram mais frequentes durante períodos } \\
\text { que seu (ex-) parceiro estava desempregado? }\end{array}$ & & \\
\hline I.33 - Seu (ex-) parceiro muda frequentemente de emprego ou & & \\
\hline
\end{tabular}


tem dificuldades de se manter em um mesmo emprego por

períodos maiores que seis meses?

Saúde mental do (ex-) parceiro:

\begin{tabular}{|l|l|l|}
\hline & Sim & Não \\
\hline I.34 - Seu (ex-) parceiro já ameaçou ou tentou cometer suicídio? & & \\
\hline $\begin{array}{l}\text { I.35 - Seu (ex-) parceiro já ameaçou matar você e depois tirar a } \\
\text { própria vida? }\end{array}$ & & \\
\hline $\begin{array}{l}\text { I.36 - Seu (ex-) parceiro já apresentou recentemente sintomas } \\
\text { maníacos como agitação, falar demais ou de modo acelerado, } \\
\text { querer fazer muitas coisas ao mesmo tempo? }\end{array}$ & & \\
\hline $\begin{array}{l}\text { I.37 - Seu (ex-) parceiro apresenta com frequência euforia } \\
\text { desproporcional às situações? }\end{array}$ & & \\
\hline $\begin{array}{l}\text { I.38 - Seu (ex-) parceiro já apresentou recentemente sintomas } \\
\text { psicóticos, como ouvir vozes, ver coisas, falar coisas ou fazer } \\
\text { coisas estranhas ou bizarras, difíceis de compreender? }\end{array}$ & & \\
\hline $\begin{array}{l}\text { I.39 - Seu (ex-) parceiro já chamou recentemente sua atenção por } \\
\text { apresentar reaçôes emocionais inapropriadas ou indiferentes aos } \\
\text { assuntos durante diálogos? }\end{array}$ & & \\
\hline I.40 - Seu (ex-) parceiro ouve ou vê coisas que só ele as percebe? & & \\
\hline $\begin{array}{l}\text { I.41 - Seu (ex-) parceiro sente que não controla os pensamentos } \\
\text { dele, considerando que outras pessoas os ouvem ou podem } \\
\text { interferir neles? }\end{array}$ & & \\
\hline $\begin{array}{l}\text { I.42 - Seu (ex-) parceiro sente-se perseguido constantemente, } \\
\text { achando que pessoas o seguem, o observam na rua, riem dele? }\end{array}$ & & \\
\hline $\begin{array}{l}\text { I.43 - Seu (ex-) parceiro já foi submetido a internação } \\
\text { psiquiátrica? }\end{array}$ & & \\
\hline $\begin{array}{l}\text { I.44 - Seu (ex-) parceiro apresenta comportamento bizarro ou } \\
\text { parece maluco? }\end{array}$ & & \\
\hline
\end{tabular}

Saúde mental da mulher:

\begin{tabular}{|l|l|l|}
\hline $\begin{array}{l}\text { I.45 - Você já se machucou de propósito, ameaçou se matar ou } \\
\text { tentou cometer suicídio? }\end{array}$ & Não \\
\hline $\begin{array}{l}\text { I.46 - Você tem pensado em fazer alguma coisa contra você } \\
\text { mesma? }\end{array}$ & & \\
\hline $\begin{array}{l}\text { I.47 - Você tem apresentado alteração no apetite, com aumento } \\
\text { ou redução da vontade de comer? }\end{array}$ & & \\
\hline $\begin{array}{l}\text { I.48 - Você tem acordado no meio da noite ou despertado mais } \\
\text { cedo do que o habitual? }\end{array}$ & \\
\hline $\begin{array}{l}\text { I.49 - Você se sente triste na maior parte do tempo e sem prazer } \\
\text { em fazer coisas que antes eram prazerosas? }\end{array}$ & \\
\hline I.50 - Você tem apresentado dificuldades para se concentrar? & \\
\hline $\begin{array}{l}\text { I.51 - Você tem tido imagens, pensamentos ou lembranças } \\
\text { dolorosas relacionadas às agressões que parecem invadir sua } \\
\text { cabeça? }\end{array}$ & \\
\hline $\begin{array}{l}\text { I.52 - Você experiência algum sintoma físico quando se recorda } \\
\text { das violências, como tremor, palpitação, sudorese, náusea, falta }\end{array}$ & & \\
\hline
\end{tabular}




\begin{tabular}{|c|c|}
\hline de ar ou diarreia? & \\
\hline $\begin{array}{l}\text { I.53 - Você já sentiu que estava revivendo a violência, mesmo } \\
\text { quando não estava ocorrendo nenhum episódio de violência? }\end{array}$ & \\
\hline $\begin{array}{l}\text { I.54 - Você tem-se sentido com frequência sobressaltada ou } \\
\text { assustada? }\end{array}$ & \\
\hline I.55 - Você já foi submetida a internação psiquiátrica? & \\
\hline
\end{tabular}

\section{Filhos de outra relação íntima:}

\begin{tabular}{|l|l|l|}
\hline & Sim & Não \\
\hline I.56 - Você tem algum filho ou filha de relação íntima anterior? & & \\
\hline
\end{tabular}

\section{Outras violências:}

\begin{tabular}{|l|l|l|}
\hline & Sim & Não \\
\hline I.57 - Seu (ex-) parceiro é violento com as crianças? & & \\
\hline $\begin{array}{l}\text { I.58 - Seu (ex-) parceiro é violento com outros membros da } \\
\text { família? }\end{array}$ & & \\
\hline $\begin{array}{l}\text { I.59 - Seu (ex-) parceiro é violento com pessoas desconhecidas, } \\
\text { amigos ou colegas de trabalho? }\end{array}$ & & \\
\hline I.60 - Seu (ex-) parceiro é violento com animais domésticos? & & \\
\hline $\begin{array}{l}\text { I.61 - Seu (ex-) parceiro agrediu ou apresentou comportamento } \\
\text { persecutório com outra parceira íntima? }\end{array}$ & & \\
\hline
\end{tabular}

História de violência contra a parceira:

\begin{tabular}{|l|l|l|}
\hline I.62 - Seu (ex-) parceiro agrediu você quando estava grávida? & Sim & Não \\
\hline I.63 - Seu (ex-) parceiro já ameaçou matá-la? & & \\
\hline $\begin{array}{l}\text { I.64 - Seu (ex-) parceiro já ameaçou você dizendo algo parecido } \\
\text { com a frase "se eu não posso ter você, ninguém mais pode"? }\end{array}$ & & \\
\hline $\begin{array}{l}\text { I.65 - Seu (ex-) parceiro já te telefonou, enviou mensagens pelo } \\
\text { celular ou e-mails obsessivos a você? }\end{array}$ & & \\
\hline $\begin{array}{l}\text { I.66 - Seu (ex-) parceiro já fez visitas não solicitadas a sua casa } \\
\text { ou ao local de trabalho com frequência? }\end{array}$ & & \\
\hline I.67 - Seu (ex-) parceiro vigia e persegue você constantemente? & & \\
\hline I.68 - Seu (ex-) parceiro já tentou estrangular você? & & \\
\hline I.69 - Seu (ex-) parceiro já tentou envenenar você? & \\
\hline $\begin{array}{l}\text { I.70 - Seu (ex-) parceiro já forçou você a fazer sexo sem que } \\
\text { você desejasse fazê-lo? }\end{array}$ & \\
\hline $\begin{array}{l}\text { I.71 - Seu (ex-) parceiro já apresentou comportamento violento } \\
\text { durante o sexo? }\end{array}$ & \\
\hline $\begin{array}{l}\text { I.72 - Seu (ex-) parceiro a agrediu de forma que a fez pensar que } \\
\text { ele tinha a intenção de matá-la? }\end{array}$ & \\
\hline $\begin{array}{l}\text { I.73 - Seu (ex-) parceiro disse coisas de natureza sexual que a } \\
\text { ofenderam? }\end{array}$ & \\
\hline $\begin{array}{l}\text { I.74 - Seu (ex-) parceiro, no último ano, deu tapas ou empurrou } \\
\text { você? }\end{array}$ & & \\
\hline $\begin{array}{l}\text { I.75 - Seu (ex-) parceiro, no último ano, chutou ou deu socos em } \\
\text { você? }\end{array}$ & & \\
\hline I.76 - Seu (ex-) parceiro, no último ano, surrou, quebrou osso, & & \\
\hline
\end{tabular}


queimou ou provocou contusões em você?

I.77 - Seu (ex-) parceiro, no último ano, provocou ferimentos

internos ou externos em você?

\section{Meio de Agressão}

\begin{tabular}{|l|l|l|}
\hline $\begin{array}{l}\text { I.78 - Seu (ex-) parceiro já usou faca durante episódio de } \\
\text { violência contra você? }\end{array}$ & & Não \\
\hline $\begin{array}{l}\text { I.79 - Seu (ex-) parceiro usou pedaço de pau, cassetete, barra de } \\
\text { ferro durante episódio de violência contra você? }\end{array}$ & & \\
\hline $\begin{array}{l}\text { I.80 - Seu (ex-) parceiro usou ou ameaçou usar arma de fogo } \\
\text { durante episódio de violência contra você? }\end{array}$ & & \\
\hline I.81 - Seu (ex-) parceiro tem fácil acesso a arma de fogo? & & \\
\hline
\end{tabular}

\section{Escalada da Violência}

\begin{tabular}{|l|l|l|}
\hline $\begin{array}{l}\text { I.82 - A violência física cometida pelo seu (ex-) parceiro contra } \\
\text { você aumentou de intensidade nos últimos seis meses? }\end{array}$ & & Não \\
\hline $\begin{array}{l}\text { I.83 - A violência física cometida pelo seu (ex-) parceiro contra } \\
\text { você aumentou de frequência nos últimos seis meses? }\end{array}$ & & \\
\hline
\end{tabular}

\section{Violência contra a parceira na presença de outros}

\begin{tabular}{|l|l|l|}
\hline & Sim & Não \\
\hline I.84 - Seu (ex-) parceiro já agrediu você na presença de crianças? & & \\
\hline $\begin{array}{l}\text { I.85 - Seu (ex-) parceiro já agrediu você na presença de } \\
\text { familiares ou de amigos? }\end{array}$ & & \\
\hline $\begin{array}{l}\text { I.86 - Seu (ex-) parceiro já agrediu você na presença de } \\
\text { desconhecidos? }\end{array}$ & & \\
\hline
\end{tabular}

\section{Separação/divórcio:}

\begin{tabular}{|l|l|l|}
\hline $\begin{array}{l}\text { I.87 - Vocês se separaram recentemente depois de viverem } \\
\text { juntos? }\end{array}$ & Não \\
\hline $\begin{array}{l}\text { I.88 - Seu (ex-) parceiro, após tentativa de separação, foi atrás de } \\
\text { você e a agrediu fortemente? }\end{array}$ & & \\
\hline $\begin{array}{l}\text { I.89 - Seu (ex-) parceiro, após tentativa de separação, foi atrás de } \\
\text { você e agrediu pessoas que a ajudavam? }\end{array}$ & & \\
\hline $\begin{array}{l}\text { I.90 - Você não se separou porque teme a reação do seu } \\
\text { parceiro? }\end{array}$ & & \\
\hline $\begin{array}{l}\text { I.91 - Você não se separou porque seu parceiro a ameaça caso } \\
\text { tente deixá-lo? }\end{array}$ & & \\
\hline $\begin{array}{l}\text { I.92 - Seu (ex-) parceiro possui algum poder, meio ou ajuda } \\
\text { especial para encontrá-la caso você tente deixá-lo? }\end{array}$ & \\
\hline
\end{tabular}

\section{Percepção sobre o risco:}

\begin{tabular}{|l|l|l|}
\hline & Sim & Não \\
\hline I.93 - Você acredita que seu (ex-) parceiro é capaz de matá-la? & & \\
\hline I.94 - Você acredita que seu (ex-) parceiro tem a intenção de & & \\
\hline
\end{tabular}




\begin{tabular}{|c|}
\hline matá-la? \\
\hline $\begin{array}{l}\text { I.95 - Você acredita que seu (ex-) parceiro continuará te } \\
\text { agredindo, podendo causar graves ferimentos em você ou em } \\
\text { seus filhos? }\end{array}$ \\
\hline
\end{tabular}

\section{Rede social:}

\begin{tabular}{|l|l|l|}
\hline $\begin{array}{l}\text { I.96 - Seus amigos, familiares e conhecidos consideram que a } \\
\text { mulher deve permanecer casada, mesmo se estiver sofrendo } \\
\text { violência? }\end{array}$ & & Não \\
\hline $\begin{array}{l}\text { I.97 - Você possui pessoas com quem pode contar nos momentos } \\
\text { difíceis? }\end{array}$ & & \\
\hline $\begin{array}{l}\text { I.98 - Você gostaria de ter contato com amigos ou familiares, } \\
\text { mas se sente impedida pelo seu (ex-) parceiro? }\end{array}$ & & \\
\hline $\begin{array}{l}\text { I.99 - Seu (ex-) parceiro tenta evitar que você veja médicos, } \\
\text { psicólogos ou outros profissionais de saúde? }\end{array}$ & & \\
\hline $\begin{array}{l}\text { I. - Seu (ex-) parceiro tenta evitar que você frequente igreja ou } \\
\text { participe de outros grupos da comunidade? }\end{array}$ & & \\
\hline
\end{tabular}


Avaliação de risco de violência contra a mulher

Anexo 5 - Fotos de material de apoio usado no $Q$-sort 

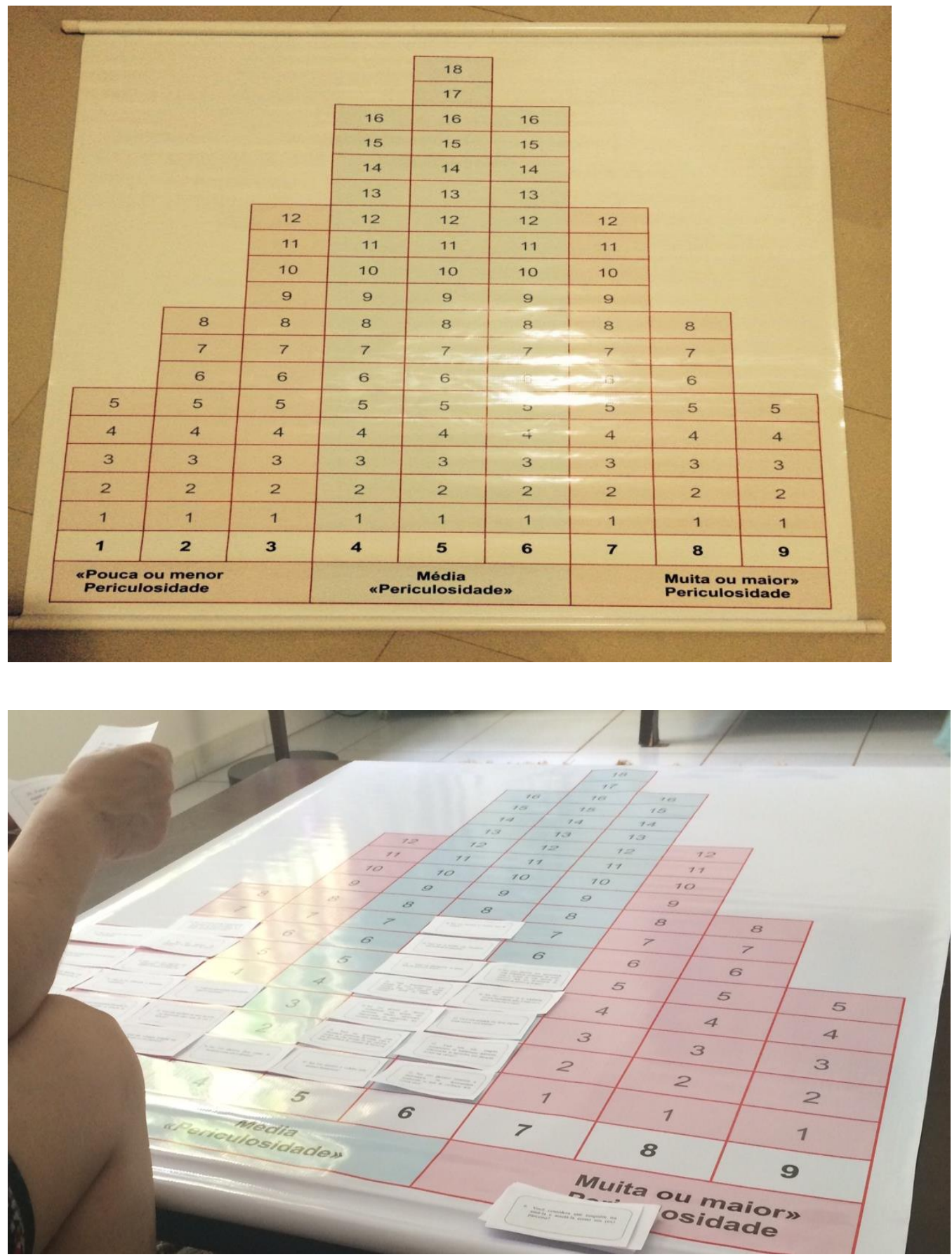
Anexo 6 - Distribuição dos itens em conformidade com curva normal 


\begin{tabular}{|c|c|c|c|c|c|c|c|c|c|c|}
\hline \multicolumn{11}{|c|}{ CalculatingStanines } \\
\hline Result Ranking & $4 \%$ & $7 \%$ & $12 \%$ & $17 \%$ & $20 \%$ & $17 \%$ & $12 \%$ & $7 \%$ & $4 \%$ & Totais \\
\hline Stanine & 1 & 2 & 3 & 4 & 5 & 6 & 7 & 8 & 9 & \\
\hline $\begin{array}{l}\text { Percentis } \\
\text { ascendentes }\end{array}$ & 4 & 11 & 23 & 40 & 60 & 77 & 89 & 96 & 100 & 100 \\
\hline $\begin{array}{l}\text { Percentis } \\
\text { descendentes }\end{array}$ & 100 & 96 & 89 & 77 & 60 & 40 & 23 & 11 & 4 & 100 \\
\hline $\begin{array}{l}\text { Distribuição } \\
\text { percentual de } \\
109 \text { casos }\end{array}$ & 4,36 & 7,63 & 13,08 & 18,53 & 21,8 & 18,53 & 13,08 & 7,63 & 4,36 & 109 \\
\hline $\begin{array}{l}\text { Arredondamento } \\
\text { automárico } \\
\text { aproximando } \\
109 \text { casos }\end{array}$ & 4 & 8 & 13 & 19 & 22 & 19 & 13 & 8 & 4 & 110 \\
\hline Diferença & 0 & 1 & 1 & 2 & 2 & 2 & 1 & 1 & 0 & 10 \\
\hline $\begin{array}{l}\text { Distribuição } \\
\text { final de } 109 \\
\text { casos }\end{array}$ & 5 & 8 & 13 & 18 & 21 & 18 & 13 & 8 & 5 & 109 \\
\hline $\begin{array}{l}\text { Diferença } \\
\text { absoluta de } \\
\text { casos por } \\
\text { stanine }\end{array}$ & 1 & 1 & 1 & 1 & 1 & 1 & 1 & 1 & 1 & 9 \\
\hline $\begin{array}{l}\text { Difference } \\
\text { percentual de } \\
\text { casos por } \\
\text { stanine }\end{array}$ & 0,64 & 0,37 & $-0,08$ & $-0,53$ & $-0,8$ & $-0,53$ & $-0,08$ & 0,37 & 0,64 & $\begin{array}{c}-5,33 \mathrm{E}- \\
15\end{array}$ \\
\hline
\end{tabular}


Avaliação de risco de violência contra a mulher

\begin{tabular}{|c|c|c|c|c|c|c|c|c|}
\hline & & & & 21 & & & & \\
\hline & & & & 20 & & & & \\
\hline & & & & 19 & & & & \\
\hline & & & 18 & 18 & 18 & & & \\
\hline & & & 17 & 17 & 17 & & & \\
\hline & & & 16 & 16 & 16 & & & \\
\hline & & & 15 & 15 & 15 & & & \\
\hline & & & 14 & 14 & 14 & & & \\
\hline & & 13 & 13 & 13 & 13 & 13 & & \\
\hline & & 12 & 12 & 12 & 12 & 12 & & \\
\hline & & 11 & 11 & 11 & 11 & 11 & & \\
\hline & & 10 & 10 & 10 & 10 & 10 & & \\
\hline & & 9 & 9 & 9 & 9 & 9 & & \\
\hline & 8 & 8 & 8 & 8 & 8 & 8 & 8 & \\
\hline & 7 & 7 & 7 & 7 & 7 & 7 & 7 & \\
\hline & 6 & 6 & 6 & 6 & 6 & 6 & 6 & \\
\hline 5 & 5 & 5 & 5 & 5 & 5 & 5 & 5 & 5 \\
\hline 4 & 4 & 4 & 4 & 4 & 4 & 4 & 4 & 4 \\
\hline 3 & 3 & 3 & 3 & 3 & 3 & 3 & 3 & 3 \\
\hline 2 & 2 & 2 & 2 & 2 & 2 & 2 & 2 & 2 \\
\hline 1 & 1 & 1 & 1 & 1 & 1 & 1 & 1 & 1 \\
\hline 1 & 2 & 3 & 4 & 5 & 6 & 7 & 8 & 9 \\
\hline $\begin{array}{r}\ll \text { Pouca } \\
\text { pericu }\end{array}$ & & & & $\begin{array}{c}\text { Média } \\
\ll<\text { periculosidade } \gg>\end{array}$ & & & & $\begin{array}{r}\text { Muita ou maior } \gg> \\
\text { periculosidade }\end{array}$ \\
\hline
\end{tabular}


Anexo 7 - Tabela com média de periculosidade dos itens 


\begin{tabular}{|c|c|c|c|c|c|}
\hline \multicolumn{3}{|c|}{$\begin{array}{r}\text { Classificação dos itens conforme média de } \\
\text { periculosidade }\end{array}$} & \multirow[b]{2}{*}{ Média de Periculosidade } & \multirow[b]{2}{*}{$\begin{array}{c}\text { Desvio } \\
\text { Padrão }\end{array}$} & \multirow[b]{2}{*}{ Grupo de risco } \\
\hline Item & Texto & Tipo & & & \\
\hline I.69 & Seu (ex) parceiro já tentou envenenar você? & Comportamental & 8,03 & 1,27 & Extremo \\
\hline I.80 & $\begin{array}{l}\text { Seu (ex) parceiro usou ou ameaçou usar arma de fogo } \\
\text { durante episódio de violência contra você? }\end{array}$ & Comportamental & 8,03 & 1,36 & Extremo \\
\hline I.68 & Seu (ex) parceiro já tentou estrangular você? & Comportamental & 7,79 & 1,20 & Extremo \\
\hline I.79 & $\begin{array}{l}\text { Seu (ex) parceiro usou pedaço de pau, cassetete, barra de } \\
\text { ferro durante episódio de violência contra você? }\end{array}$ & Comportamental & 7,65 & 1,35 & Extremo \\
\hline I.76 & $\begin{array}{l}\text { Seu (ex) parceiro, no último ano, surrou, quebrou osso, } \\
\text { queimou ou provocou contusões em você? }\end{array}$ & Comportamental & 7,50 & 1,52 & Extremo \\
\hline I.78 & $\begin{array}{l}\text { Seu (ex) parceiro já usou faca durante episódio de } \\
\text { violência contra você? }\end{array}$ & Comportamental & 7,38 & 1,76 & Extremo \\
\hline I.62 & Seu (ex) parceiro agrediu você quando estava grávida? & Comportamental & 7,03 & 1,49 & Extremo \\
\hline I.77 & $\begin{array}{l}\text { Seu (ex) parceiro, no último ano, provocou ferimentos } \\
\text { internos ou externos em você? }\end{array}$ & Comportamental & 7,03 & 1,66 & Extremo \\
\hline I.07 & $\begin{array}{l}\text { Seu (ex) parceiro possui arma de fogo e a utiliza para } \\
\text { intimidar pessoas conhecidas ou desconhecidas? }\end{array}$ & Comportamental & 7,00 & 1,63 & Extremo \\
\hline I.72 & $\begin{array}{l}\text { Seu (ex) parceiro a agrediu de forma que a fez pensar que } \\
\text { ele tinha a intenção de matá-la? }\end{array}$ & Subjetivo & 6,91 & 1,66 & Extremo \\
\hline I.88 & $\begin{array}{l}\text { Seu (ex) parceiro após tentativa de separação foi atrás de } \\
\text { você e a agrediu fortemente? }\end{array}$ & Comportamental & 6,91 & 1,24 & Extremo \\
\hline I.35 & $\begin{array}{l}\text { Seu (ex) parceiro já ameaçou matar você e depois tirar a } \\
\text { própria vida? }\end{array}$ & Comportamental & 6,85 & 1,52 & Extremo \\
\hline I.63 & Seu (ex) parceiro já ameaçou matá-la? & Comportamental & 6,74 & 1,42 & Extremo \\
\hline $\mathbf{I . 8 3}$ & $\begin{array}{l}\text { A violência física cometida pelo seu (ex) parceiro contra } \\
\text { você aumentou de frequência nos últimos seis meses? }\end{array}$ & Comportamental & 6,68 & 1,12 & Extremo \\
\hline I.27 & $\begin{array}{l}\text { Seu (ex) parceiro descumpriu medida protetiva de } \\
\text { afastamento, aproximando-se de você mesmo quando } \\
\text { você demonstrou não querer a aproximação? }\end{array}$ & Comportamental & 6,65 & 1,50 & Extremo \\
\hline
\end{tabular}




I.82 A violência física cometida pelo seu (ex) parceiro contra
você aumentou de intensidade nos últimos seis meses?
I.94 Você acredita que seu (ex) parceiro tem a intenção de

matá-la?

I.75 Seu (ex) parceiro, no último ano, chutou ou deu socos em você?

I.64 Seu (ex) parceiro já ameaçou você dizendo algo parecido com a frase "se eu não posso ter você, ninguém mais pode"?

I.93 Você acredita que seu (ex) parceiro é capaz de matá-la?

I.89 Seu (ex) parceiro após tentativa de separação foi atrás de você e agrediu pessoas que a ajudavam?

I.95 Você acredita que seu (ex) parceiro continuará te agredindo, podendo causar graves ferimentos em você ou em seus filhos?

I.26 Seu (ex) parceiro descumpriu medida protetiva prevista na Lei Maria da Penha?

I.85 Seu (ex) parceiro já agrediu você na presença de familiares ou de amigos?

I.28 Seu (ex) parceiro já foi preso por cometer crimes violentos contra não familiares?

I.57 Seu (ex) parceiro é violento com as crianças?

I.81 Seu (ex) parceiro tem fácil acesso à arma de fogo?

I.70 Seu (ex) parceiro já forçou você a fazer sexo sem que você desejasse fazê-lo?

I.91 Você não se separou porque seu parceiro a ameaça caso tente deixá-lo?

I.67 Seu (ex) parceiro vigia e persegue você constantemente?

I.86 Seu (ex) parceiro já agrediu você na presença de desconhecidos?

I.22 Seu (ex) parceiro minimiza a importância ou desconsidera totalmente os atos de violência dele contra você?

\begin{tabular}{|c|c|c|c|}
\hline Comportamental & 6,65 & 1,10 & Extremo \\
\hline Subjetivo & 6,53 & 1,80 & Extremo \\
\hline Comportamental & 6,38 & 1,74 & Extremo \\
\hline Comportamental & 6,35 & 1,65 & Extremo \\
\hline Subjetivo & 6,26 & 1,56 & Extremo \\
\hline Comportamental & 6,21 & 1,37 & Extremo \\
\hline Subjetivo & 6,21 & 1,41 & Extremo \\
\hline Comportamental & 6,18 & 1,47 & Extremo \\
\hline Comportamental & 6,18 & 1,22 & Extremo \\
\hline Comportamental & 6,12 & 1,59 & Extremo \\
\hline Comportamental & 6,09 & 1,50 & Extremo \\
\hline Subjetivo & 6,03 & 1,95 & Extremo \\
\hline Comportamental & 5,97 & 2,04 & Extremo \\
\hline Subjetivo & 5,91 & 1,14 & Extremo \\
\hline Comportamental & 5,82 & 1,73 & Extremo \\
\hline Comportamental & 5,82 & 1,42 & Extremo \\
\hline Subjetivo & 5,65 & 1,41 & Extremo \\
\hline
\end{tabular}




\section{I.61 Seu (ex) parceiro agrediu ou apresentou comportamento persecutório com outra parceira íntima?}

I.59 Seu (ex) parceiro é violento com pessoas desconhecidas, amigos ou colegas de trabalho?

I.03 Seu (ex) parceiro torna-se violento quando enciumado?

I.23 Você ouviu recentemente de amigos, profissionais ou familiares que não estava reconhecendo a gravidade da violência que sofre?

I.84 Seu (ex) parceiro já agrediu você na presença de crianças?

I.01 Seu (ex) parceiro tenta controlar sua vida e vigia a maioria de suas atividades diárias? Por exemplo: ele te diz quem pode ser seu amigo, quando você pode ver sua família, quanto dinheiro você pode gastar ou onde você pode ir?

I.14 Seu (ex) parceiro estava sobre efeito de álcool ou de drogas durante os últimos incidentes de violência familiar?

I.74 Seu (ex) parceiro, no último ano, deu tapas ou empurrou você?

I.34 Seu (ex) parceiro já ameaçou ou tentou cometer suicídio?

I.92 Seu (ex) parceiro possui algum poder, meio ou ajuda especial para encontrá-la caso você tente deixá-lo?

I.38 Seu (ex) parceiro já apresentou recentemente sintomas psicóticos, como ouvir vozes, ver coisas, falar coisas ou fazer coisas estranhas ou bizarras, difíceis de compreender?

I.02 Seu (ex) parceiro tem ciúmes obsessivos de você?

I.58 Seu (ex) parceiro é violento com outros membros da família?

I.15 Seu (ex) parceiro é mais violento quando está sob o efeito de álcool ou de drogas?

\begin{tabular}{|c|c|c|c|}
\hline Comportamental & 5,65 & 1,57 & Extremo \\
\hline Comportamental & 5,62 & 1,28 & Grave \\
\hline Comportamental & 5,59 & 1,28 & Grave \\
\hline Subjetivo & 5,44 & 1,56 & Grave \\
\hline Comportamental & 5,38 & 1,23 & Grave \\
\hline Comportamental & 5,35 & 1,59 & Grave \\
\hline Comportamental & 5,32 & 1,53 & Grave \\
\hline Comportamental & 5,32 & 1,09 & Grave \\
\hline Comportamental & 5,29 & 2,07 & Grave \\
\hline Subjetivo & 5,26 & 1,88 & Grave \\
\hline Subjetivo & 5,21 & 1,84 & Grave \\
\hline Subjetivo & 5,18 & 1,88 & Grave \\
\hline Comportamental & 5,18 & 1,11 & Grave \\
\hline Subjetivo & 5,15 & 1,48 & Grave \\
\hline
\end{tabular}


I.04 Seu (ex) parceiro apresenta comportamento impulsivo e instável quando com raiva?

I.45 Você já se machucou de propósito, ameaçou se matar ou tentou cometer suicídio?

I.08 Seu (ex) parceiro ameaça usar sua força física para
intimidar pessoas?

I.10 Seu (ex) parceiro faz uso abusivo ou é dependente de alguma droga ou álcool?

I.21 Seu (ex) parceiro foi encaminhado para alguma forma de intervenção terapêutica, em grupo ou individual, para homens autores de violência, mas não participou?

I.71 Seu (ex) parceiro já apresentou comportamento violento durante o sexo?

I.30 Seu (ex) parceiro já tentou não ser preso por violência doméstica? Por exemplo: Fugiu, escondeu-se ou impediu você de ir à delegacia.

I.46 Você tem pensado em fazer alguma coisa contra você mesma?

I.90 Você não se separou porque teme a reação do seu parceiro?

I.60 Seu (ex) parceiro é violento com animais domésticos?

I.65 Seu (ex) parceiro já te telefonou, enviou mensagens pelo celular ou e-mails obsessivos a você?

I.12 Seu (ex) parceiro tem apresentado com frequência problemas de saúde, com a Justiça ou com pessoas do convívio dele em decorrência do consumo de álcool ou de drogas?

I.53 Você já sentiu que estava revivendo a violência, mesmo quando não estava ocorrendo nenhum episódio de violência?

I.11 Seu (ex) parceiro usa diariamente ou quase todo dia álcool ou drogas?

I.24 Você perdoou nos últimos seis meses algum incidente de violência depois de achar que não perdoaria?

\section{Subjetivo}

Comportamental

5,12

1,39

Grave

5,12

2,23

Grave

Comportamental

5,09

1,16

Grave

Subjetivo

Comportamental

1,53

Grave

Comportamental

Comportamental

1,37

Grave

,67

Grave

1,44

Grave

Subjetivo

4,88

1,89

Grave

Subjetivo

Comportamental

Comportamental

1,72

Grave

1,67

Grave

1,46

Grave

Subjetivo

Grave

Subjetivo

4,76

1,37

Grave

Comportamental

4,74

1,68

Grave

Subjetivo 
I.99 Seu (ex) parceiro tenta evitar que você veja médicos, psicólogos ou outros profissionais de saúde?

I.96 Seus amigos, familiares e conhecidos consideram que a mulher deve permanecer casada mesmo se estiver

sofrendo violência?

I.66 Seu (ex) parceiro já fez visitas não solicitadas a sua casa ou local de trabalho com frequência?

I.25 Seu (ex) parceiro já presenciou ou esteve envolvido em outras cenas de violência em sua família de origem?

I.42 Seu (ex) parceiro sente-se perseguido constantemente, achando que pessoas o seguem, o observam na rua, riem dele?

I.51 Você tem tido imagens, pensamentos ou lembranças dolorosas relacionadas às agressões que parecem invadir sua cabeça?

I.41 Seu (ex) parceiro sente que não controla os pensamentos dele, considerando que outras pessoas os ouvem ou podem interferir neles?

I.44 Seu (ex) parceiro apresenta comportamento bizarro ou parece maluco?

I.43 Seu (ex) parceiro já foi submetido a internação psiquiátrica?

I.98 Você gostaria de ter contato com amigos ou familiares, mas se sente impedida pelo seu (ex) parceiro?

I.32 Cenas de violência eram mais frequentes durante períodos que seu (ex) parceiro estava desempregado?

I.36 Seu (ex) parceiro já apresentou recentemente sintomas maníacos como agitação, falar demais ou de modo acelerado, querer fazer muitas coisas ao mesmo tempo?

I.40 Seu (ex) parceiro ouve ou vê coisas que só ele as percebe?

I.52 Você experiência algum sintoma físico quando se recorda das violências, como tremor, palpitação, sudorese, náusea, falta de ar ou diarreia?

I.05 Você considera que ninguém irá amá-la e aceitá-la como seu (ex) parceiro?

Subjetivo

4,62

Subjetivo

4,56

4,47

4,47

Subjetivo

4,47

$1,37 \quad$ Grave

Subjetivo

Grave

Comportamental

Subjetivo

Comportamental

Subjetivo

Subjetivo

Moderado

Subjetivo

Subjetivo

4,12 

coisas que eram normais para ele porque havia consumido coisas que eram normais para
ácool ou drogas em excesso?

I.18 Você tem apresentado com frequência problemas de

Subjetivo

Moderado saúde, com a justiça ou com pessoas do seu convívio em decorrência do consumo de álcool ou de drogas?

I.39 Seu (ex) parceiro já chamou recentemente sua atenção por apresentar reações emocionais inapropriadas ou indiferentes aos assuntos durante diálogos?

I.100 Seu (ex) parceiro tenta evitar que você frequente igreja ou participe de outros grupos da comunidade?

I.16 Você faz uso abusivo ou é dependente de alguma droga ou álcool?

I.37 Seu (ex) parceiro apresenta com frequência euforia
desproporcional às situações?

I.54 Você tem-se sentido com frequência sobressaltada ou assustada?

I.06 Você não consegue imaginar sua vida sem seu (ex) parceiro?

I.19 Você frequentemente tem deixado de fazer coisas que eram normais para você porque havia consumido álcool ou drogas em excesso?

I.73 Seu (ex) parceiro disse coisas de natureza sexual que a ofenderam?

I.17 Você usa diariamente ou quase todo dia álcool ou drogas?

I.20 Seu (ex) parceiro participou recentemente de alguma forma de intervenção terapêutica, em grupo ou individual, para homens autores de violência?

I.09 Você e seu (ex) parceiro têm apresentado discordâncias e conflitos intensos no último ano?

I.49 Você se sente triste na maior parte do tempo e sem prazer em fazer coisas que antes eram prazerosas?

I.55 Você já foi submetida a internação psiquiátrica?

Subjetivo

1,18

Moderado

Comportamental

3,76

1,54

Moderado

Subjetivo

3,68

1,41 Moderado

Subjetivo

3,53

1,31

Moderado

Subjetivo

Moderado

Subjetivo

Subjetivo

1,64 Moderado

1,20 Moderado

Subjetivo

3,29

Moderado

Comportamental

1,16

Moderado

Comportamental

Moderado

Subjetivo

1,16

Moderado

Subjetivo

3,03

1,55 Moderado

Comportamental 
I.47 Você tem apresentado alteração no apetite, com aumento

I.87 Vocês se separaram recentemente depois de viverem

Comportamental

Moderado

I.33 Seu (ex) parceiro muda frequentemente de emprego ou tem dificuldades de se manter em um mesmo emprego por períodos maiores do que seis meses?

I.48 Você tem acordado no meio da noite ou despertado mais

Moderado

Comportamental

Moderado

I.31 Seu (ex) parceiro está atualmente desempregado?

\section{Subjetivo}


Avaliação de risco de violência contra a mulher

Anexo 8 - Comparação entre grupo de mulheres e grupo

de homens 
Comparação entre grupos para cada item

\begin{tabular}{|c|c|c|c|c|c|}
\hline & Grupo & $\mathrm{N}$ & Média & Desvio padrão & $\begin{array}{c}\text { Erro padrão da } \\
\text { média }\end{array}$ \\
\hline \multirow{2}{*}{ I.01 } & Feminino & 27 & 5,41 & 1,693 & ,326 \\
\hline & Masculino & 7 & 5,14 & 1,215 & ,459 \\
\hline \multirow{2}{*}{ I.02 } & Feminino & 27 & 5,19 & 2,039 & ,392 \\
\hline & Masculino & 7 & 5,14 & 1,215 & ,459 \\
\hline \multirow{2}{*}{ I.03 } & Feminino & 27 & 5,67 & 1,330 &, 256 \\
\hline & Masculino & 7 & 5,29 & 1,113 & 421 \\
\hline \multirow{2}{*}{ I.04 } & Feminino & 27 & 5,26 & 1,375 & ,265 \\
\hline & Masculino & 7 & 4,57 & 1,397 &, 528 \\
\hline \multirow{2}{*}{ I.05 } & Feminino & 27 & 4,26 & 1,953 &, 376 \\
\hline & Masculino & 7 & 3,57 & 1,902 &, 719 \\
\hline \multirow{2}{*}{ I.06 } & Feminino & 27 & 3,37 & 1,597 & ,307 \\
\hline & Masculino & 7 & 3,57 & 1,902 &, 719 \\
\hline \multirow{2}{*}{ I.07 } & Feminino & 27 & 6,85 & 1,703 &, 328 \\
\hline & Masculino & 7 & 7,57 & 1,272 & ,481 \\
\hline \multirow{2}{*}{ I.08 } & Feminino & 27 & 5,22 & 1,086 & ,209 \\
\hline & Masculino & 7 & 4,57 & 1,397 &, 528 \\
\hline \multirow{2}{*}{ I.09 } & Feminino & 27 & 3,30 & 1,171 &, 225 \\
\hline & Masculino & 7 & 2,29 & ,756 & ,286 \\
\hline \multirow{2}{*}{ I. 10} & Feminino & 27 & 4,93 & 1,591 & ,306 \\
\hline & Masculino & 7 & 5,43 & 1,272 & ,481 \\
\hline \multirow{2}{*}{ I.11 } & Feminino & 27 & 4,48 & 1,649 &, 317 \\
\hline & Masculino & 7 & 5,71 & 1,496 &, 565 \\
\hline \multirow{2}{*}{ I.12 } & Feminino & 27 & 4,67 & 1,569 & ,302 \\
\hline & Masculino & 7 & 5,29 & 1,604 & ,606 \\
\hline \multirow{2}{*}{ I. 13} & Feminino & 27 & 3,96 & 1,400 & ,269 \\
\hline & Masculino & 7 & 3,43 & 1,813 & ,685 \\
\hline \multirow{2}{*}{ I. 14} & Feminino & 27 & 5,26 & 1,559 & ,300 \\
\hline & Masculino & 7 & 5,57 & 1,512 &, 571 \\
\hline \multirow{2}{*}{ I. 15} & Feminino & 27 & 5,22 & 1,577 & ,304 \\
\hline & Masculino & 7 & 4,86 & 1,069 & ,404 \\
\hline \multirow{2}{*}{ I. 16} & Feminino & 27 & 3,56 & 1,251 & ,241 \\
\hline & Masculino & 7 & 4,14 & 1,952 & ,738 \\
\hline \multirow{2}{*}{ I. 17} & Feminino & 27 & 3,07 & 1,174 & ,226 \\
\hline & Masculino & 7 & 4,00 &, 816 & ,309 \\
\hline \multirow{2}{*}{ I. 18} & Feminino & 27 & 3,70 & 1,203 & ,232 \\
\hline & Masculino & 7 & 4,14 & 1,864 &, 705 \\
\hline \multirow{2}{*}{ I. 19} & Feminino & 27 & 3,22 & 1,251 & ,241 \\
\hline & Masculino & 7 & 3,86 & ,900 & 340 \\
\hline \multirow{2}{*}{ I. 20} & Feminino & 27 & 2,93 & 1,542 & ,297 \\
\hline & Masculino & 7 & 3,86 & 1,574 &, 595 \\
\hline \multirow{2}{*}{ I. 21} & Feminino & 27 & 4,85 & 1,406 & ,271 \\
\hline & Masculino & 7 & 5,29 & 1,254 & ,474 \\
\hline \multirow{2}{*}{ I. 22} & Feminino & 27 & 5,78 & 1,476 & ,284 \\
\hline & Masculino & 7 & 5,14 & 1,069 &, 404 \\
\hline 223 & Feminino & 27 & 5,52 & 1,695 & ,326 \\
\hline 1.23 & Masculino & 7 & 5,14 & ,900 & 340 \\
\hline I. 24 & Feminino & 27 & 4,63 & 1,471 & ,283 \\
\hline
\end{tabular}


Avaliação de risco de violência contra a mulher

\begin{tabular}{|c|c|c|c|c|c|}
\hline & Masculino & 7 & 4,71 & 1,254 & ,474 \\
\hline \multirow{2}{*}{ I. 25} & Feminino & 27 & 4,59 & 1,118 & ,215 \\
\hline & Masculino & 7 & 4,00 & 1,155 & ,436 \\
\hline \multirow{2}{*}{ I. 26} & Feminino & 27 & 6,00 & 1,441 & ,277 \\
\hline & Masculino & 7 & 6,86 & 1,464 & ,553 \\
\hline \multirow{2}{*}{ I. 27} & Feminino & 27 & 6,44 & 1,577 & ,304 \\
\hline & Masculino & 7 & 7,43 &, 787 & ,297 \\
\hline \multirow{2}{*}{ I. 28} & Feminino & 27 & 6,00 & 1,664 &, 320 \\
\hline & Masculino & 7 & 6,57 & 1,272 & ,481 \\
\hline \multirow{2}{*}{ I. 29} & Feminino & 27 & 2,56 & 1,928 &, 371 \\
\hline & Masculino & 7 & 3,29 & 1,976 & ,747 \\
\hline \multirow{2}{*}{ I.30 } & Feminino & 27 & 4,81 & 1,388 & ,267 \\
\hline & Masculino & 7 & 5,29 & 1,704 & ,644 \\
\hline \multirow{2}{*}{ I. 31} & Feminino & 27 & 2,56 & 1,188 & ,229 \\
\hline & Masculino & 7 & 1,71 & ,951 & ,360 \\
\hline \multirow{2}{*}{ I. 32} & Feminino & 27 & 4,26 & 1,375 & ,265 \\
\hline & Masculino & 7 & 4,14 & 1,069 & ,404 \\
\hline \multirow{2}{*}{ I.33 } & Feminino & 27 & 2,67 & 1,387 & ,267 \\
\hline & Masculino & 7 & 2,00 & 1,000 & ,378 \\
\hline \multirow{2}{*}{ I. 34} & Feminino & 27 & 5,11 & 1,888 &, 363 \\
\hline & Masculino & 7 & 6,00 & 2,708 & 1,024 \\
\hline \multirow{2}{*}{ I. 35} & Feminino & 27 & 6,93 & 1,542 & ,297 \\
\hline & Masculino & 7 & 6,57 & 1,512 &, 571 \\
\hline \multirow{2}{*}{ I. 36} & Feminino & 27 & 4,22 & 1,423 & ,274 \\
\hline & Masculino & 7 & 4,14 & 1,345 & ,508 \\
\hline \multirow{2}{*}{ I. 37} & Feminino & 27 & 3,56 & 1,340 & ,258 \\
\hline & Masculino & 7 & 3,43 & 1,272 & ,481 \\
\hline \multirow{2}{*}{ I. 38} & Feminino & 27 & 4,89 & 1,502 & ,289 \\
\hline & Masculino & 7 & 6,43 & 2,573 & ,972 \\
\hline \multirow{2}{*}{ I.39 } & Feminino & 27 & 3,70 & 1,171 & ,225 \\
\hline & Masculino & 7 & 4,00 & 1,291 & , 488 \\
\hline \multirow{2}{*}{ I. 40} & Feminino & 27 & 4,00 & 1,387 & ,267 \\
\hline & Masculino & 7 & 5,00 & 1,291 & , 488 \\
\hline \multirow{2}{*}{ I.41 } & Feminino & 27 & 4,11 & 1,761 & ,339 \\
\hline & Masculino & 7 & 5,57 & 2,573 & ,972 \\
\hline \multirow{2}{*}{ I. 42} & Feminino & 27 & 4,11 & 1,553 & ,299 \\
\hline & Masculino & 7 & 5,86 & 1,215 & , 459 \\
\hline \multirow{2}{*}{ I. 43} & Feminino & 27 & 4,00 & 1,544 & ,297 \\
\hline & Masculino & 7 & 5,29 & 2,138 & ,808 \\
\hline \multirow{2}{*}{ I. 44} & Feminino & 27 & 4,26 & 1,196 &, 230 \\
\hline & Masculino & 7 & 4,57 & 2,699 & 1,020 \\
\hline I 45 & Feminino & 27 & 4,93 & 2,252 &, 433 \\
\hline 1.45 & Masculino & 7 & 5,86 & 2,116 & ,800 \\
\hline I 46 & Feminino & 27 & 4,74 & 1,723 & ,332 \\
\hline 1.40 & Masculino & 7 & 5,43 & 2,507 & ,948 \\
\hline I 47 & Feminino & 27 & 2,70 & 1,409 & ,271 \\
\hline 1.41 & Masculino & 7 & 3,00 & 1,414 &, 535 \\
\hline I 48 & Feminino & 27 & 2,33 & 1,301 &, 250 \\
\hline 1.40 & Masculino & 7 & 3,00 & 1,155 & ,436 \\
\hline I 40 & Feminino & 27 & 3,11 & 1,649 &, 317 \\
\hline 1.47 & Masculino & 7 & 2,71 & 1,113 &, 421 \\
\hline I. 50 & Feminino & 27 & 2,22 & 1,219 & ,235 \\
\hline
\end{tabular}


Avaliação de risco de violência contra a mulher

\begin{tabular}{|c|c|c|c|c|c|}
\hline & Masculino & 7 & 2,29 & 1,113 & ,421 \\
\hline \multirow{2}{*}{ I. 51} & Feminino & 27 & 4,41 & 1,474 & ,284 \\
\hline & Masculino & 7 & 4,57 & ,976 & ,369 \\
\hline \multirow{2}{*}{ I.52 } & Feminino & 27 & 4,30 & 1,514 & ,291 \\
\hline & Masculino & 7 & 3,86 & 1,574 & ,595 \\
\hline \multirow{2}{*}{ I.53 } & Feminino & 27 & 4,74 & 1,347 & ,259 \\
\hline & Masculino & 7 & 4,86 & 1,574 &, 595 \\
\hline \multirow{2}{*}{ I. .54} & Feminino & 27 & 3,70 & 1,683 &, 324 \\
\hline & Masculino & 7 & 2,57 &, 787 & ,297 \\
\hline \multirow{2}{*}{ I. 55} & Feminino & 27 & 2,81 & 1,618 &, 311 \\
\hline & Masculino & 7 & 3,86 & 1,676 & ,634 \\
\hline \multirow{2}{*}{ I. 56} & Feminino & 27 & 2,19 & 1,331 & ,256 \\
\hline & Masculino & 7 & 2,29 & ,951 & ,360 \\
\hline \multirow{2}{*}{ I. 57} & Feminino & 27 & 6,37 & 1,523 & ,293 \\
\hline & Masculino & 7 & 5,00 &, 816 & ,309 \\
\hline \multirow{2}{*}{ I.58 } & Feminino & 27 & 5,26 & 1,163 & ,224 \\
\hline & Masculino & 7 & 4,86 & ,900 &, 340 \\
\hline \multirow{2}{*}{ I.59 } & Feminino & 27 & 5,74 & 1,228 & ,236 \\
\hline & Masculino & 7 & 5,14 & 1,464 &, 553 \\
\hline \multirow{2}{*}{ I.60 } & Feminino & 27 & 4,89 & 1,805 & ,347 \\
\hline & Masculino & 7 & 4,71 & 1,113 &, 421 \\
\hline \multirow{2}{*}{ I.61 } & Feminino & 27 & 5,81 & 1,469 & ,283 \\
\hline & Masculino & 7 & 5,00 & 1,915 & ,724 \\
\hline \multirow{2}{*}{ I.62 } & Feminino & 27 & 7,30 & 1,382 & ,266 \\
\hline & Masculino & 7 & 6,00 & 1,528 & ,577 \\
\hline \multirow{2}{*}{ I.63 } & Feminino & 27 & 6,96 & 1,315 & ,253 \\
\hline & Masculino & 7 & 5,86 & 1,574 &, 595 \\
\hline \multirow{2}{*}{ I.64 } & Feminino & 27 & 6,48 & 1,695 & ,326 \\
\hline & Masculino & 7 & 5,86 & 1,464 & ,553 \\
\hline \multirow{2}{*}{ I. 65} & Feminino & 27 & 5,04 & 1,400 & ,269 \\
\hline & Masculino & 7 & 4,14 & 1,574 & ,595 \\
\hline \multirow{2}{*}{ I.66 } & Feminino & 27 & 4,67 & 1,441 & ,277 \\
\hline & Masculino & 7 & 4,14 & 1,464 &, 553 \\
\hline \multirow{2}{*}{ I.67 } & Feminino & 27 & 5,81 & 1,882 & ,362 \\
\hline & Masculino & 7 & 5,86 & 1,069 & ,404 \\
\hline \multirow{2}{*}{ I.68 } & Feminino & 27 & 7,70 & 1,203 & ,232 \\
\hline & Masculino & 7 & 8,14 & 1,215 & , 459 \\
\hline \multirow{2}{*}{ I.69 } & Feminino & 27 & 7,85 & 1,350 & ,260 \\
\hline & Masculino & 7 & 8,71 &, 488 & , 184 \\
\hline \multirow{2}{*}{ I.70 } & Feminino & 27 & 5,93 & 2,093 & ,403 \\
\hline & Masculino & 7 & 6,14 & 1,952 & ,738 \\
\hline 71 & Feminino & 27 & 5,11 & 1,761 & ,339 \\
\hline $1 . / 1$ & Masculino & 7 & 4,29 & 1,113 &, 421 \\
\hline I 7 & Feminino & 27 & 6,96 & 1,315 &, 253 \\
\hline $1 . / 2$ & Masculino & 7 & 6,71 & 2,752 & 1,040 \\
\hline I 73 & Feminino & 27 & 3,56 & 1,368 &, 263 \\
\hline 1.13 & Masculino & 7 & 2,29 & 1,254 & , 474 \\
\hline I 74 & Feminino & 27 & 5,37 & 1,043 & ,201 \\
\hline 1.14 & Masculino & 7 & 5,14 & 1,345 & ,508 \\
\hline J 75 & Feminino & 27 & 6,44 & 1,649 &, 317 \\
\hline 1.73 & Masculino & 7 & 6,14 & 2,193 & ,829 \\
\hline I.76 & Feminino & 27 & 7,59 & 1,185 & ,228 \\
\hline
\end{tabular}


Avaliação de risco de violência contra a mulher

\begin{tabular}{|c|c|c|c|c|c|}
\hline & Masculino & 7 & 7,14 & 2,545 & ,962 \\
\hline \multirow{2}{*}{ I.77 } & Feminino & 27 & 7,26 & 1,196 &, 230 \\
\hline & Masculino & 7 & 6,14 & 2,795 & 1,056 \\
\hline \multirow{2}{*}{ I.78 } & Feminino & 27 & 7,22 & 1,908 &, 367 \\
\hline & Masculino & 7 & 8,00 &, 816 &, 309 \\
\hline \multirow{2}{*}{ I.79 } & Feminino & 27 & 7,56 & 1,450 &, 279 \\
\hline & Masculino & 7 & 8,00 &, 816 & ,309 \\
\hline \multirow{2}{*}{ I. 80} & Feminino & 27 & 8,04 & 1,480 & ,285 \\
\hline & Masculino & 7 & 8,00 &, 816 & ,309 \\
\hline \multirow{2}{*}{ I. 81} & Feminino & 27 & 5,89 & 2,044 &, 393 \\
\hline & Masculino & 7 & 6,57 & 1,512 &, 571 \\
\hline \multirow{2}{*}{ I. 82} & Feminino & 27 & 6,67 & 1,074 & ,207 \\
\hline & Masculino & 7 & 6,57 & 1,272 & ,481 \\
\hline \multirow{2}{*}{ I. 83} & Feminino & 27 & 6,67 & 1,240 &, 239 \\
\hline & Masculino & 7 & 6,71 & ,488 & , 184 \\
\hline \multirow{2}{*}{ I. 84} & Feminino & 27 & 5,52 & 1,122 &, 216 \\
\hline & Masculino & 7 & 4,86 & 1,574 &, 595 \\
\hline \multirow{2}{*}{ I. 85} & Feminino & 27 & 6,33 & 1,177 & ,226 \\
\hline & Masculino & 7 & 5,57 & 1,272 &, 481 \\
\hline \multirow{2}{*}{ I.86 } & Feminino & 27 & 6,00 & 1,359 &, 261 \\
\hline & Masculino & 7 & 5,14 & 1,574 &, 595 \\
\hline \multirow{2}{*}{ I. 87} & Feminino & 27 & 2,44 & 1,340 &, 258 \\
\hline & Masculino & 7 & 3,00 & 1,633 & ,617 \\
\hline \multirow{2}{*}{ I. 88} & Feminino & 27 & 6,85 & 1,231 &, 237 \\
\hline & Masculino & 7 & 7,14 & 1,345 &, 508 \\
\hline \multirow{2}{*}{ I.89 } & Feminino & 27 & 6,07 & 1,357 &, 261 \\
\hline & Masculino & 7 & 6,71 & 1,380 &, 522 \\
\hline \multirow{2}{*}{ I.90 } & Feminino & 27 & 4,96 & 1,720 &, 331 \\
\hline & Masculino & 7 & 4,57 & 1,813 & ,685 \\
\hline \multirow{2}{*}{ I.91 } & Feminino & 27 & 5,81 & 1,145 &, 220 \\
\hline & Masculino & 7 & 6,29 & 1,113 &, 421 \\
\hline \multirow{2}{*}{ I.92 } & Feminino & 27 & 5,26 & 2,011 &, 387 \\
\hline & Masculino & 7 & 5,29 & 1,380 &, 522 \\
\hline \multirow{2}{*}{ I.93 } & Feminino & 27 & 6,37 & 1,497 & ,288 \\
\hline & Masculino & 7 & 5,86 & 1,864 & ,705 \\
\hline \multirow{2}{*}{ I.94 } & Feminino & 27 & 6,74 & 1,583 &, 305 \\
\hline & Masculino & 7 & 5,71 & 2,430 & ,918 \\
\hline \multirow{2}{*}{ I.95 } & Feminino & 27 & 6,30 & 1,409 &, 271 \\
\hline & Masculino & 7 & 5,86 & 1,464 &, 553 \\
\hline \multirow{2}{*}{ I.96 } & Feminino & 27 & 4,67 & 1,961 &, 377 \\
\hline & Masculino & 7 & 4,29 & 2,360 &, 892 \\
\hline \multirow{2}{*}{ I.97 } & Feminino & 27 & 1,93 & 1,141 &, 220 \\
\hline & Masculino & 7 & 2,29 & 1,496 &, 565 \\
\hline \multirow{2}{*}{ I.98 } & Feminino & 27 & 4,48 & 1,929 &, 371 \\
\hline & Masculino & 7 & 3,43 & 1,512 &, 571 \\
\hline I 99 & Feminino & 27 & 4,59 & 1,394 &, 268 \\
\hline 1.99 & Masculino & 7 & 4,71 & 1,380 &, 522 \\
\hline 100 & Feminino & 27 & 3,89 & 1,502 &, 289 \\
\hline 1.100 & Masculino & 7 & 3,29 & 1,704 & 644 \\
\hline
\end{tabular}


Teste de amostras independentes

\begin{tabular}{|c|c|c|c|c|c|c|c|c|c|c|}
\hline & $\begin{array}{c}\text { Teste de Levene } \\
\text { para igualdade de }\end{array}$ & \multicolumn{9}{|c|}{ teste t para Igualdade de Médias } \\
\hline & $\mathrm{F}$ & \multirow[t]{2}{*}{ Sig. } & \multirow[t]{2}{*}{$\mathrm{t}$} & \multirow[t]{2}{*}{ df } & \multirow[t]{2}{*}{ Significância } & \multirow[t]{2}{*}{ Diferença média } & \multirow{2}{*}{$\begin{array}{l}\text { Erro padrão de } \\
\text { diferença }\end{array}$} & \multicolumn{3}{|c|}{ 95\% Intervalo de confiança da diferença } \\
\hline & & & & & & & & Inferior & Supe & \\
\hline I.01 & $\begin{array}{l}\text { Variações iguais } \\
\text { assumidas }\end{array}$ & 2,022 &, 165 &, 386 & 32 & ,702 & 265 & 685 & $-1,130$ & 1,659 \\
\hline I.03 & $\begin{array}{l}\text { Variações iguais } \\
\text { assumidas }\end{array}$ &, 275 & 604 & 695 & 32 & ,492 &, 381 &, 548 &,- 735 & 1,497 \\
\hline I.04 & $\begin{array}{l}\text { Variações iguais } \\
\text { assumidas }\end{array}$ & ,004 & ,949 & 1,176 & 32 & 248 & ,688 &, 585 &,- 504 & 1,880 \\
\hline I.05 & $\begin{array}{l}\text { Variações iguais } \\
\text { assumidas }\end{array}$ & ,019 & 891 &, 834 & 32 &, 410 & ,688 &, 824 &,- 991 & 2,367 \\
\hline I.06 & $\begin{array}{l}\text { Variações iguais } \\
\text { assumidas }\end{array}$ & 829 &, 369 &,- 286 & 32 &, 777 &,- 201 &, 703 & $-1,634$ & 1,232 \\
\hline I.08 & $\begin{array}{l}\text { Variações iguais } \\
\text { assumidas }\end{array}$ & 1,996 &, 167 & 1,333 & 32 &, 192 & 651 & ,488 &,- 343 & 1,645 \\
\hline I.09 & $\begin{array}{l}\text { Variações iguais } \\
\text { assumidas }\end{array}$ & 2,711 & ,109 & 2,157 & 32 & ,039 & 1,011 & ,469 & ,056 & 1,965 \\
\hline I. 10 & $\begin{array}{l}\text { Variações iguais } \\
\text { assumidas }\end{array}$ & , 175 & 679 &,- 771 & 32 & ,446 &,- 503 & ,652 & $-1,830$ & ,825 \\
\hline I.11 & $\begin{array}{l}\text { Variações iguais } \\
\text { assumidas }\end{array}$ &, 345 &, 561 & $-1,792$ & 32 & 083 & $-1,233$ & ,688 & $-2,634$ & , 168 \\
\hline I. 12 & $\begin{array}{l}\text { Variações iguais } \\
\text { assumidas }\end{array}$ & , 156 & ,695 &,- 926 & 32 &, 361 &,- 619 & 668 & $-1,980$ & ,742 \\
\hline I. 13 & $\begin{array}{l}\text { Variações iguais } \\
\text { assumidas }\end{array}$ & 1,639 & ,210 & ,848 & 32 & ,403 &, 534 & ,630 &,- 750 & 1,818 \\
\hline I. 14 & $\begin{array}{l}\text { Variações iguais } \\
\text { assumidas }\end{array}$ & ,005 & ,943 &,- 475 & 32 & ,638 &,- 312 & ,657 & $-1,651$ & 1,027 \\
\hline I. 15 & $\begin{array}{l}\text { Variações iguais } \\
\text { assumidas }\end{array}$ & 1,799 & 189 & ,576 & 32 &, 569 & ,365 & ,634 &,- 927 & 1,657 \\
\hline
\end{tabular}




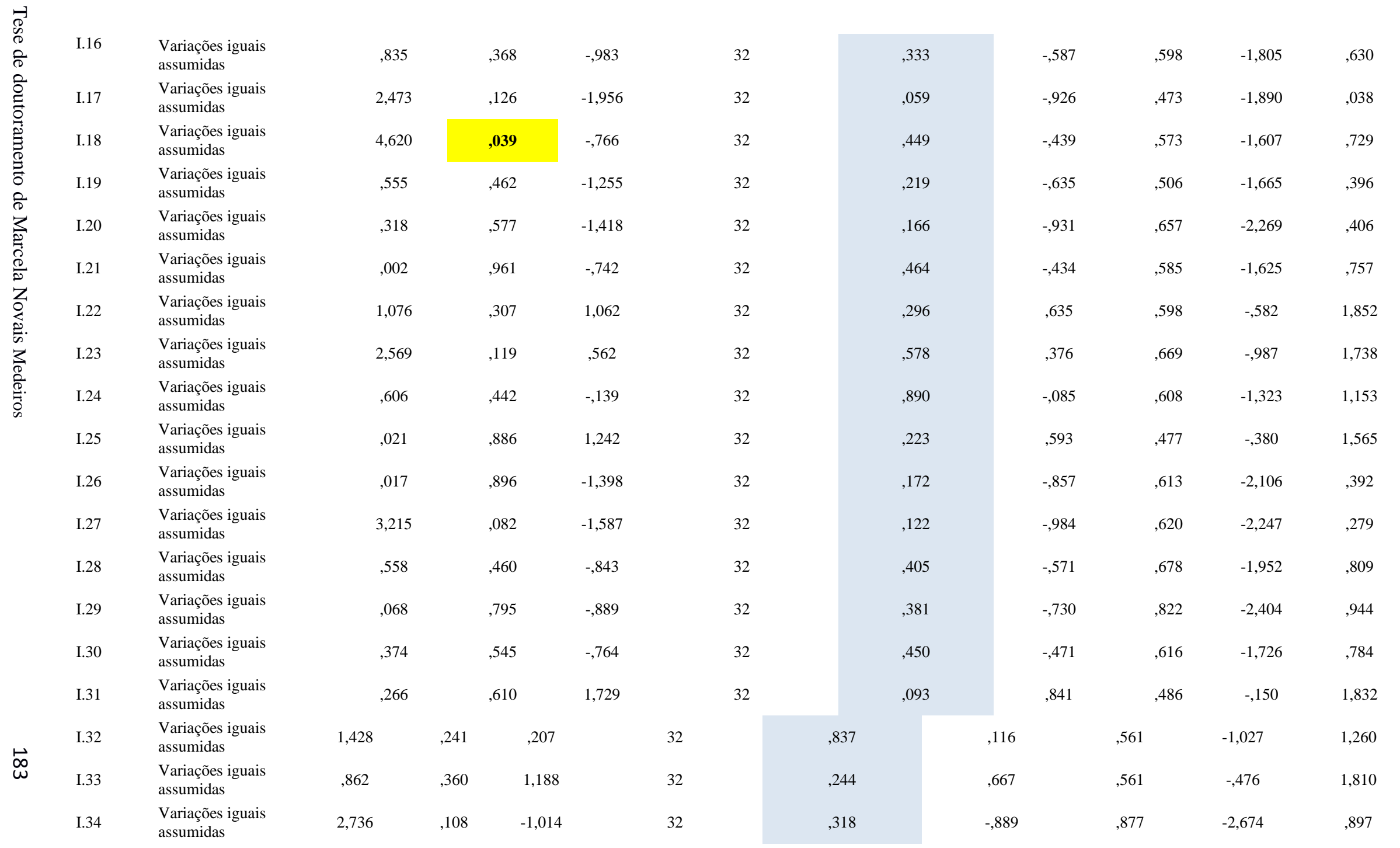




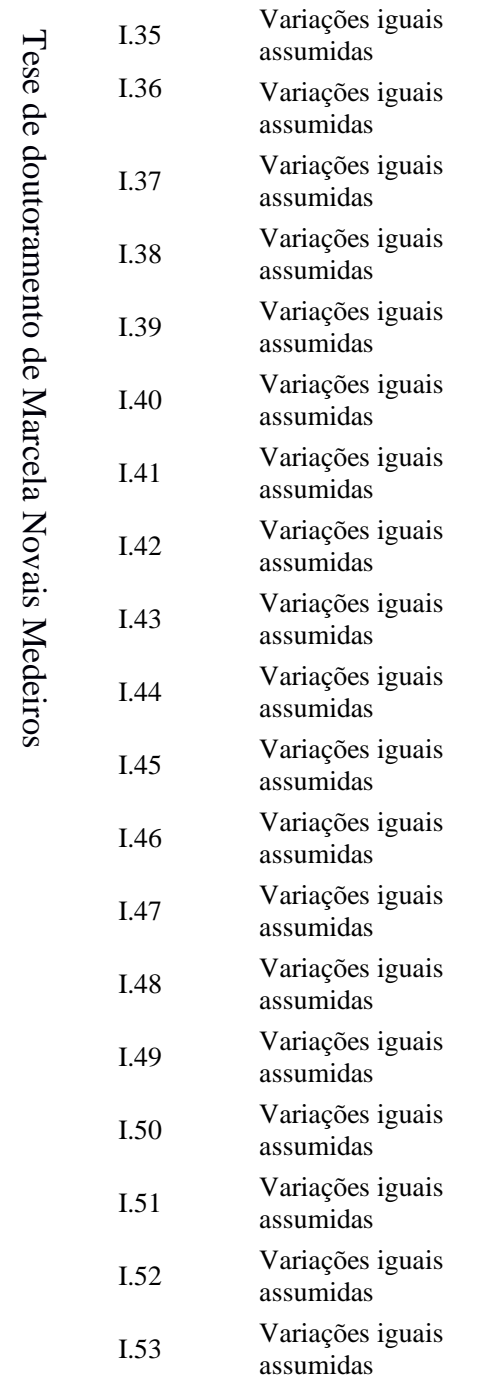

\begin{tabular}{|c|c|c|c|}
\hline , 128 & ,723 & ,544 & \\
\hline ,111 &, 742 &, 133 & \\
\hline ,012 & ,912 & ,226 & \\
\hline 4,763 & ,037 & $-2,070$ & \\
\hline 163 & 689, &,- 585 & \\
\hline ,533 & ,471 & $-1,722$ & \\
\hline 3,474 &, 072 & $-1,775$ & \\
\hline ,353 & ,556 & $-2,754$ & \\
\hline 2,362 & ,134 & $-1,813$ & \\
\hline 19,780 &, 000 &,- 463 & \\
\hline ,033 &, 858 &,- 986 & \\
\hline 1,389 & ,247 &,- 856 & \\
\hline ,001 & ,977 &,- 495 & \\
\hline 848 & ,364 & $-1,233$ & \\
\hline 1,379 & ,249 & ,599 & \\
\hline \multicolumn{2}{|c|}{,001 } & 982 &,- 125 \\
\hline \multicolumn{2}{|c|}{1,588} & ,217 &,- 277 \\
\hline \multicolumn{2}{|c|}{061} & 806 & 679 \\
\hline \multicolumn{2}{|c|}{,030 } & ,865 &,- 197 \\
\hline
\end{tabular}

\begin{tabular}{|c|c|c|c|c|}
\hline & 590, & & ,354 & \\
\hline & 895, & & 079, & \\
\hline & ,823 & & 127 & \\
\hline & ,047 & & $-1,540$ & \\
\hline & 563, & & -296 & \\
\hline & 095, & & $-1,000$ & \\
\hline & 085, & & $-1,460$ & \\
\hline & ,010 & & $-1,746$ & \\
\hline & 079, & & $-1,286$ & \\
\hline & 647, & &,- 312 & \\
\hline & ,332 & &,- 931 & \\
\hline & 398, & & -688 & \\
\hline & 624, & & -296 & \\
\hline & 227, & & -667 & \\
\hline & 553, & & ,397, & \\
\hline 32 & & 902 & &,- 063 \\
\hline 32 & & 783, & &,- 164 \\
\hline 32 & & 502 & & ,439 \\
\hline 32 & & ,845 & &,- 116 \\
\hline
\end{tabular}

\begin{tabular}{|c|c|c|}
\hline ,652 &,- 973 & 1,682 \\
\hline ,598 & $-1,138$ & 1,297 \\
\hline ,563 & $-1,020$ & 1,274 \\
\hline ,744 & $-3,055$ &,- 025 \\
\hline ,506 & $-1,328$ & ,735 \\
\hline ,581 & $-2,183$ & ,183 \\
\hline ,823 & $-3,136$ & ,215 \\
\hline ,634 & $-3,038$ &,- 454 \\
\hline 709 & $-2,730$ & ,159 \\
\hline 674 & $-1,686$ & 1,062 \\
\hline ,945 & $-2,855$ & ,993 \\
\hline ,804 & $-2,325$ & ,949 \\
\hline ,598 & $-1,515$ & ,922 \\
\hline ,541 & $-1,768$ & ,435 \\
\hline 663 &,- 953 & 1,746 \\
\hline ,509 & $-1,100$ & ,973 \\
\hline ,591 & $-1,369$ & 1,041 \\
\hline 647 &,- 879 & 1,757 \\
\hline ,591 & $-1,319$ & 1,087 \\
\hline
\end{tabular}




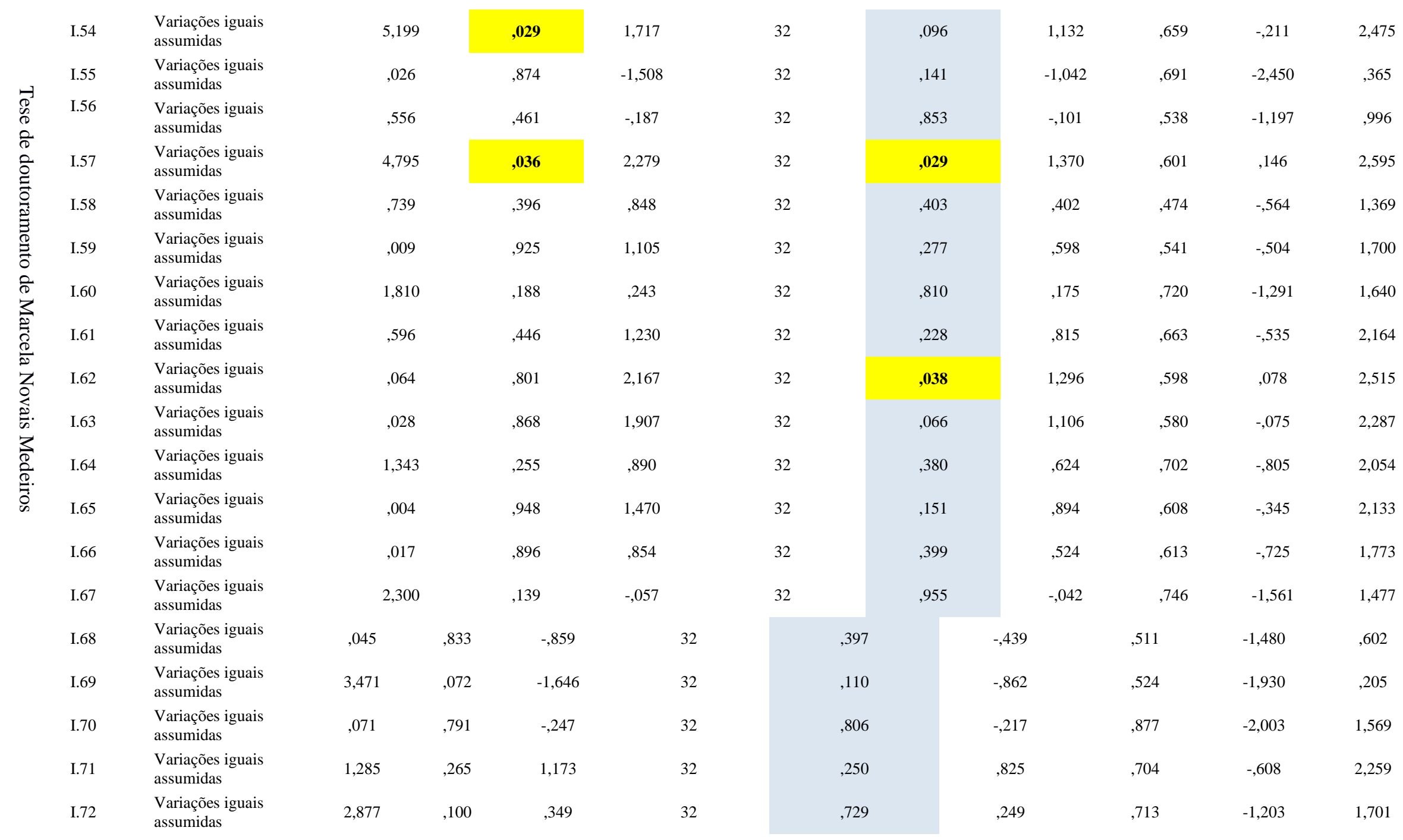




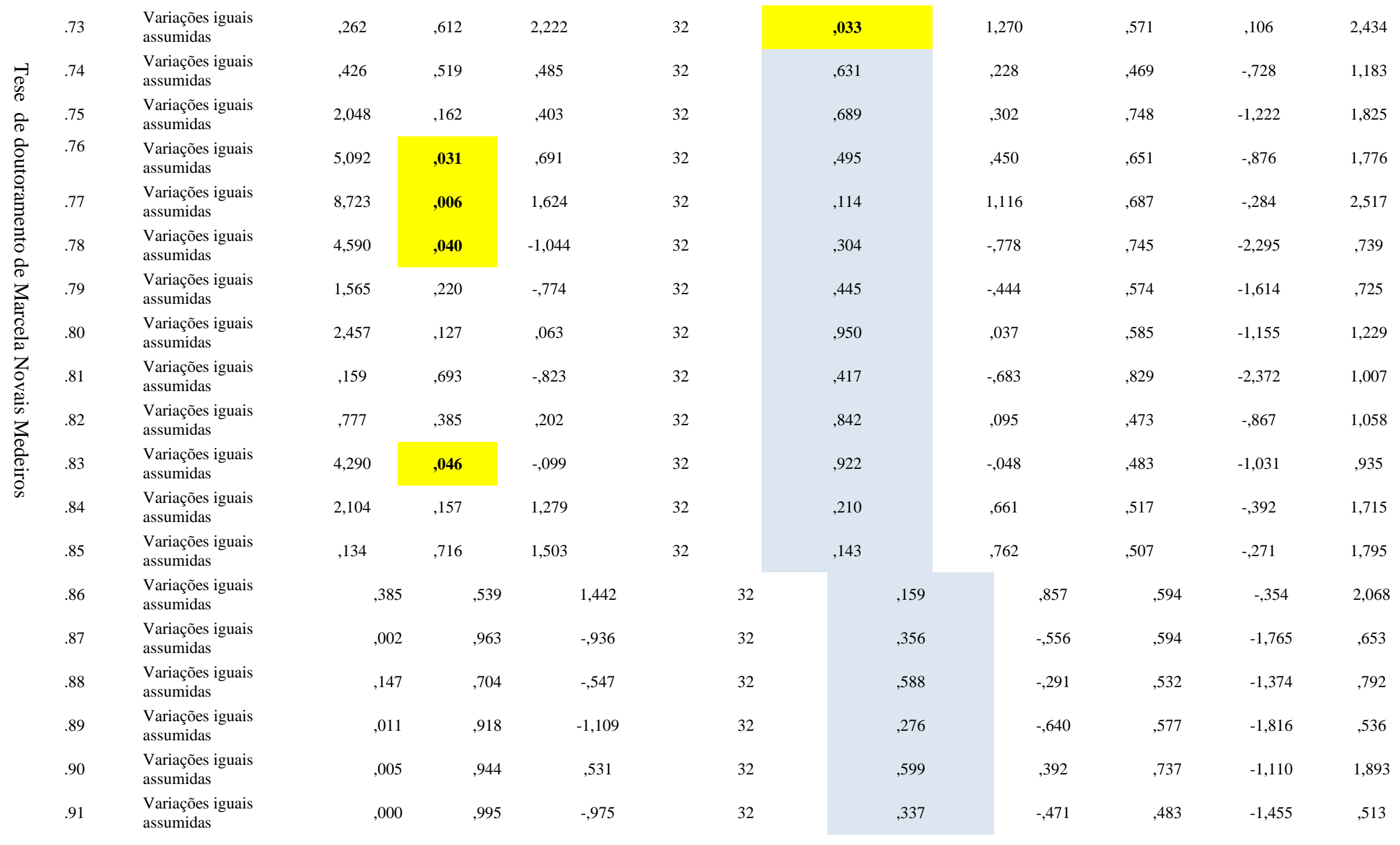




\begin{tabular}{|c|c|c|c|c|c|c|c|c|c|c|}
\hline I.92 & $\begin{array}{l}\text { Variações iguais } \\
\text { assumidas }\end{array}$ & 2,283 & ,141 &,- 033 & 32 & ,974 &,- 026 & ,810 & $-1,676$ & 1,623 \\
\hline I.93 & $\begin{array}{l}\text { Variações iguais } \\
\text { assumidas }\end{array}$ & ,019 & ,893 & ,769 & 32 & ,447 & ,513 & 667 &,- 846 & 1,872 \\
\hline I.94 & $\begin{array}{l}\text { Variações iguais } \\
\text { assumidas }\end{array}$ & ,992 &, 327 & 1,365 & 32 & , 182 & 1,026 & ,752 &,- 505 & 2,558 \\
\hline I.95 & $\begin{array}{l}\text { Variações iguais } \\
\text { assumidas }\end{array}$ & ,005 & ,946 & ,729 & 32 & ,471 & 439 & 602 &,- 787 & 1,666 \\
\hline I.96 & $\begin{array}{l}\text { Variações iguais } \\
\text { assumidas }\end{array}$ & , 165 & 687 & ,440 & 32 & 663 & ,381 & ,866 & $-1,383$ & 2,145 \\
\hline I.97 & $\begin{array}{l}\text { Variações iguais } \\
\text { assumidas }\end{array}$ & ,706 & ,407 &,- 698 & 32 & ,490 &,- 360 & ,516 & $-1,410$ & 690 \\
\hline I.98 & $\begin{array}{l}\text { Variações iguais } \\
\text { assumidas }\end{array}$ & ,156 & 695 & 1,336 & 32 & ,191 & 1,053 & ,788 &,- 552 & 2,658 \\
\hline I.99 & $\begin{array}{l}\text { Variações iguais } \\
\text { assumidas }\end{array}$ & ,090 & ,767 &,- 206 & 32 &, 838 &,- 122 & ,590 & $-1,324$ & 1,080 \\
\hline I. 100 & $\begin{array}{l}\text { Variações iguais } \\
\text { assumidas }\end{array}$ & ,314 & ,579 & ,922 & 32 & ,363 & 603 & ,654 &,- 729 & 1,935 \\
\hline
\end{tabular}


Anexo 9 - Comparação entre grupo de mulheres e grupo

de homens com a amostra total 
Avaliação de risco de violência contra mulher

\begin{tabular}{|c|c|c|c|c|c|c|}
\hline \multicolumn{2}{|l|}{ Todos } & \multicolumn{5}{|c|}{ Só Mulheres } \\
\hline Pergunta & $\begin{array}{l}\text { Tipo de } \\
\text { item }\end{array}$ & $\begin{array}{c}\text { Média de } \\
\text { Periculosidade }\end{array}$ & & Pergunta & $\begin{array}{l}\text { Tipo de } \\
\text { item }\end{array}$ & $\begin{array}{c}\text { Média de } \\
\text { Periculosidade }\end{array}$ \\
\hline I.69 & 1 & 8,03 & & I. 81 & 0 & 8,89 \\
\hline I. 80 & 1 & 8,03 & & I. 80 & 1 & 8,04 \\
\hline I.68 & 1 & 7,79 & & I.69 & 1 & 7,85 \\
\hline I.79 & 1 & 7,65 & & I.68 & 1 & 7,70 \\
\hline I.76 & 1 & 7,50 & & I.79 & 1 & 7,56 \\
\hline I.78 & 1 & 7,38 & & I.76 & 1 & 7,59 \\
\hline I.62 & 1 & 7,03 & & I.78 & 1 & 7,22 \\
\hline I.77 & 1 & 7,03 & & I.62 & 1 & 7,30 \\
\hline I.07 & 1 & 7,00 & & I.77 & 1 & 7,26 \\
\hline I.72 & 0 & 6,91 & & I.35 & 1 & 6,93 \\
\hline I. 88 & 1 & 6,91 & Risco severo & I.63 & 1 & 6,93 \\
\hline I.35 & 1 & 6,85 & & I.07 & 1 & 6,85 \\
\hline I.63 & 1 & 6,74 & & I. 88 & 1 & 6,85 \\
\hline I.83 & 1 & 6,68 & & I.72 & 0 & 6,60 \\
\hline I. 27 & 1 & 6,65 & & I.83 & 1 & 6,67 \\
\hline I. 82 & 1 & 6,65 & & I. 27 & 1 & 6,44 \\
\hline I.94 & 0 & 6,53 & & I. 82 & 1 & 6,67 \\
\hline I.75 & 1 & 6,38 & & I.94 & 0 & 6,74 \\
\hline I.64 & 1 & 6,35 & & I.64 & 1 & 6,48 \\
\hline I.93 & 0 & 6,26 & & I.75 & 1 & 6,44 \\
\hline I. 89 & 1 & 6,21 & & I. 57 & 1 & 6,37 \\
\hline I.95 & 0 & 6,21 & & I.93 & 0 & 6,37 \\
\hline I. 26 & 1 & 6,18 & & I.95 & 0 & 6,30 \\
\hline I.85 & 1 & 6,18 & & I. 85 & 1 & 6,33 \\
\hline I. 28 & 1 & 6,12 & & I. 89 & 1 & 6,07 \\
\hline I.57 & 1 & 6,09 & & I. 26 & 1 & 6,00 \\
\hline I.81 & 0 & 6,03 & & I. 28 & 1 & 6,00 \\
\hline I.70 & 1 & 5,97 & & I.86 & 1 & 6,00 \\
\hline I.91 & 0 & 5,91 & & I.70 & 1 & 5,93 \\
\hline I.67 & 1 & 5,82 & & I.91 & 0 & 5,81 \\
\hline I.86 & 1 & 5,82 & & I.67 & 1 & 5,81 \\
\hline I. 22 & 0 & 5,65 & & I.61 & 1 & 5,81 \\
\hline I.61 & 1 & 5,65 & & I. 22 & 0 & 5,78 \\
\hline I.59 & 1 & 5,62 & & I.59 & 1 & 5,74 \\
\hline I.03 & 1 & 5,59 & & I.03 & 1 & 5,67 \\
\hline I. 23 & 0 & 5,44 & & I. 23 & 0 & 5,52 \\
\hline I. 84 & 1 & 5,38 & & I. 84 & 1 & 5,52 \\
\hline I.01 & 1 & 5,35 & & I.01 & 1 & 5,41 \\
\hline I.14 & 1 & 5,32 & & I. 14 & 1 & 5,26 \\
\hline I.74 & 1 & 5,32 & & I.74 & 1 & 5,37 \\
\hline I.34 & 1 & 5,29 & & I.34 & 1 & 5,11 \\
\hline I.92 & 0 & 5,26 & & I.92 & 0 & 5,26 \\
\hline
\end{tabular}


Avaliação de risco de violência contra mulher

\begin{tabular}{|c|c|c|c|c|c|c|}
\hline I.38 & 0 & 5,21 & \multirow{25}{*}{ Risco grave } & I.02 & 0 & 5,19 \\
\hline I.02 & 0 & 5,18 & & I. 58 & 1 & 5,26 \\
\hline I.58 & 1 & 5,18 & & I. 15 & 0 & 5,22 \\
\hline I. 15 & 0 & 5,15 & & I.04 & 0 & 5,26 \\
\hline I.04 & 0 & 5,12 & & I. 65 & 1 & 5,04 \\
\hline I. 45 & 1 & 5,12 & & I. 45 & 1 & 4,93 \\
\hline I.08 & 1 & 5,09 & & I.08 & 1 & 5,22 \\
\hline I.10 & 0 & 5,03 & & I. 10 & 0 & 4,93 \\
\hline I. 21 & 1 & 4,94 & & I. 21 & 1 & 4,85 \\
\hline I.71 & 1 & 4,94 & & I. 71 & 1 & 5,11 \\
\hline I.30 & 1 & 4,91 & & I. 30 & 1 & 4,81 \\
\hline I.46 & 0 & 4,88 & & I. 46 & 0 & 4,74 \\
\hline I.90 & 0 & 4,88 & & I. 90 & 0 & 4,96 \\
\hline I.60 & 1 & 4,85 & & I. 38 & 0 & 4,89 \\
\hline I.65 & 1 & 4,85 & & I.60 & 1 & 4,89 \\
\hline I.12 & 0 & 4,79 & & I. .53 & 0 & 4,74 \\
\hline I.53 & 0 & 4,76 & & I. 96 & 0 & 4,67 \\
\hline I.11 & 1 & 4,74 & & I. 12 & 0 & 4,67 \\
\hline I. 24 & 0 & 4,65 & & I.66 & 1 & 4,67 \\
\hline I.99 & 0 & 4,62 & & I. 24 & 0 & 4,63 \\
\hline I.96 & 0 & 4,59 & & I.99 & 0 & 4,59 \\
\hline I.66 & 1 & 4,56 & & I. 25 & 1 & 4,59 \\
\hline I. 25 & 1 & 4,47 & & I. 11 & 1 & 4,48 \\
\hline I. 42 & 0 & 4,47 & & I.98 & 0 & 4,48 \\
\hline I.51 & 0 & 4,44 & & I.51 & 0 & 4,41 \\
\hline I.41 & 0 & 4,41 & \multirow{20}{*}{$\begin{array}{c}\text { Risco } \\
\text { Moderado }\end{array}$} & I. .52 & 0 & 4,30 \\
\hline I. 44 & 0 & 4,32 & & I. 44 & 0 & 4,26 \\
\hline I.43 & 1 & 4,26 & & I.05 & 0 & 4,26 \\
\hline I.98 & 0 & 4,26 & & I. 32 & 1 & 4,26 \\
\hline I.32 & 1 & 4,24 & & I. 36 & 0 & 4,22 \\
\hline I.36 & 0 & 4,21 & & I. 43 & 1 & 4,00 \\
\hline I. 40 & 0 & 4,21 & & I. 40 & 0 & 4,00 \\
\hline I.52 & 0 & 4,21 & & I. 42 & 0 & 4,11 \\
\hline I.05 & 0 & 4,12 & & I. 41 & 0 & 4,11 \\
\hline I.13 & 0 & 3,85 & & I. 13 & 0 & 3,96 \\
\hline I.18 & 0 & 3,79 & & I. 100 & 1 & 3,89 \\
\hline I.39 & 0 & 3,76 & & I. 18 & 0 & 3,70 \\
\hline I.100 & 1 & 3,76 & & I. 39 & 0 & 3,70 \\
\hline I.16 & 0 & 3,68 & & I. 54 & 0 & 3,70 \\
\hline I.37 & 0 & 3,53 & & I. 16 & 0 & 3,56 \\
\hline I.54 & 0 & 3,47 & & I. 73 & 0 & 3,56 \\
\hline I.06 & 0 & 3,41 & & I. 37 & 0 & 3,56 \\
\hline I.19 & 0 & 3,35 & & I.06 & 0 & 3,37 \\
\hline I.73 & 0 & 3,29 & & I. 19 & 0 & 3,22 \\
\hline I.17 & 1 & 3,26 & & I.09 & 0 & 3,30 \\
\hline
\end{tabular}


Avaliação de risco de violência contra mulher

\begin{tabular}{|c|c|c|c|c|c|}
\hline I. 20 & 1 & 3,12 & I.49 & 0 & 3,11 \\
\hline I.09 & 0 & 3,09 & I. 17 & 1 & 3,07 \\
\hline I. 49 & 0 & 3,03 & I. 20 & 1 & 2,93 \\
\hline I. 55 & 1 & 3,03 & I. 55 & 1 & 2,81 \\
\hline I. 47 & 0 & 2,76 & I. 47 & 0 & 2,76 \\
\hline I. 29 & 0 & 2,71 & I. 29 & 0 & 2,70 \\
\hline I. 87 & 1 & 2,56 & I.33 & 1 & 2,67 \\
\hline I. 33 & 1 & 2,53 & I. 31 & 1 & 2,56 \\
\hline I. 48 & 0 & 2,47 & I. 87 & 1 & 2,44 \\
\hline I. 31 & 1 & 2,38 & I.48 & 0 & 2,33 \\
\hline I. 50 & 0 & 2,24 & I.50 & 0 & 2,22 \\
\hline I. 56 & 1 & 2,21 & I.56 & 1 & 2,19 \\
\hline I.97 & 0 & 2,00 & I. 97 & 0 & 1,93 \\
\hline
\end{tabular}

Legenda: Tipo de

$$
\text { item: } \mathrm{I}=
$$

Comportamental

$0=$ Subjetivo 
Avaliação de risco de violência contra mulher

\begin{tabular}{|c|c|c|c|c|c|c|}
\hline \multicolumn{2}{|l|}{ Todos } & \multicolumn{5}{|c|}{ Só Homens } \\
\hline Pergunta & $\begin{array}{l}\text { Tipo de } \\
\text { item }\end{array}$ & $\begin{array}{c}\text { Média de } \\
\text { Periculosidade }\end{array}$ & & Pergunta & $\begin{array}{l}\text { Tipo de } \\
\text { item }\end{array}$ & $\begin{array}{c}\text { Média de } \\
\text { Periculosidade }\end{array}$ \\
\hline I.69 & 1 & 8,03 & & I.63 & 1 & 8,86 \\
\hline I. 80 & 1 & 8,03 & & I.69 & 1 & 8,71 \\
\hline I.68 & 1 & 7,79 & & I.68 & 1 & 8,14 \\
\hline I. 79 & 1 & 7,65 & & I.78 & 1 & 8,00 \\
\hline I.76 & 1 & 7,50 & & I. 80 & 1 & 8,00 \\
\hline I.78 & 1 & 7,38 & & I.79 & 1 & 8,00 \\
\hline I.62 & 1 & 7,03 & & I. 07 & 1 & 7,57 \\
\hline I. 77 & 1 & 7,03 & & I. 88 & 1 & 7,14 \\
\hline I.07 & 1 & 7,00 & & I.76 & 1 & 7,14 \\
\hline I.72 & 0 & 6,91 & & I. 26 & 1 & 6,86 \\
\hline I. 88 & 1 & 6,91 & Risco severo & I.72 & 0 & 6,71 \\
\hline $\mathrm{I} .35$ & 1 & 6,85 & & I. 89 & 1 & 6,71 \\
\hline I.63 & 1 & 6,74 & & I. 35 & 1 & 6,57 \\
\hline I. 83 & 1 & 6,68 & & I. 83 & 1 & 6,71 \\
\hline I. 27 & 1 & 6,65 & & I. 27 & 1 & 6,57 \\
\hline I. 82 & 1 & 6,65 & & I. 82 & 1 & 6,57 \\
\hline I.94 & 0 & 6,53 & & I. 28 & 1 & 6,57 \\
\hline $\mathrm{I} .75$ & 1 & 6,38 & & I. 81 & 0 & 6,57 \\
\hline I.64 & 1 & 6,35 & & I. 38 & 0 & 6,43 \\
\hline I.93 & 0 & 6,26 & & I.91 & 0 & 6,29 \\
\hline I. 89 & 1 & 6,21 & & I.77 & 1 & 6,14 \\
\hline I.95 & 0 & 6,21 & & I.70 & 1 & 6,14 \\
\hline I. 26 & 1 & 6,18 & & I.75 & 1 & 6,14 \\
\hline I. 85 & 1 & 6,18 & & I.64 & 1 & 5,86 \\
\hline I. 28 & 1 & 6,12 & & I.93 & 0 & 5,86 \\
\hline I. 57 & 1 & 6,09 & & I.95 & 0 & 5,86 \\
\hline I. 81 & 0 & 6,03 & & I.94 & 0 & 5,71 \\
\hline I.70 & 1 & 5,97 & & I.11 & 1 & 5,71 \\
\hline I.91 & 0 & 5,91 & & I.85 & 1 & 5,57 \\
\hline I.67 & 1 & 5,82 & & I.42 & 0 & 5,86 \\
\hline I. 86 & 1 & 5,82 & & I.67 & 1 & 5,86 \\
\hline I. 22 & 0 & 5,65 & & I.86 & 1 & 5,14 \\
\hline I.61 & 1 & 5,65 & & I.22 & 0 & 5,14 \\
\hline I. 59 & 1 & 5,62 & & I.61 & 1 & 5,00 \\
\hline I.03 & 1 & 5,59 & & I.34 & 1 & 6,00 \\
\hline I. 23 & 0 & 5,44 & & I.62 & 1 & 6,00 \\
\hline I. 84 & 1 & 5,38 & & I.45 & 1 & 5,86 \\
\hline I.01 & 1 & 5,35 & & I.14 & 1 & 5,57 \\
\hline I. 14 & 1 & 5,32 & & I.46 & 0 & 5,43 \\
\hline I.74 & 1 & 5,32 & & I.03 & 1 & 5,29 \\
\hline I. 34 & 1 & 5,29 & & I.92 & 0 & 5,29 \\
\hline I.92 & 0 & 5,26 & & I.12 & 0 & 5,29 \\
\hline
\end{tabular}


Avaliação de risco de violência contra mulher

\begin{tabular}{|c|c|c|c|c|c|c|}
\hline I. 38 & 0 & 5,21 & \multirow{25}{*}{ Risco grave } & I. 21 & 1 & 5,29 \\
\hline I.02 & 0 & 5,18 & & I. 30 & 1 & 5,29 \\
\hline I. 58 & 1 & 5,18 & & I.59 & 1 & 5,14 \\
\hline I. 15 & 0 & 5,15 & & I. 23 & 0 & 5,14 \\
\hline I.04 & 0 & 5,12 & & I.02 & 0 & 5,14 \\
\hline I. 45 & 1 & 5,12 & & I.01 & 1 & 5,14 \\
\hline I.08 & 1 & 5,09 & & I.74 & 1 & 5,14 \\
\hline I. 10 & 0 & 5,03 & & I.57 & 1 & 5,00 \\
\hline I. 21 & 1 & 4,94 & & I. 40 & 0 & 5,00 \\
\hline I.71 & 1 & 4,94 & & I. .58 & 1 & 4,86 \\
\hline I. 30 & 1 & 4,91 & & I. 15 & 0 & 4,86 \\
\hline I. 46 & 0 & 4,88 & & I. 84 & 1 & 4,86 \\
\hline I.90 & 0 & 4,88 & & I.53 & 0 & 4,86 \\
\hline I.60 & 1 & 4,85 & & I.60 & 1 & 4,71 \\
\hline I.65 & 1 & 4,85 & & I. 24 & 0 & 4,71 \\
\hline I. 12 & 0 & 4,79 & & I.99 & 0 & 4,71 \\
\hline I. 53 & 0 & 4,76 & & I.04 & 0 & 4,57 \\
\hline I. 11 & 1 & 4,74 & & I.08 & 1 & 4,57 \\
\hline I. 24 & 0 & 4,65 & & I.90 & 0 & 4,57 \\
\hline I.99 & 0 & 4,62 & & I. 41 & 0 & 5,57 \\
\hline I.96 & 0 & 4,59 & & I.51 & 0 & 4,57 \\
\hline I.66 & 1 & 4,56 & & I. 44 & 0 & 4,57 \\
\hline I. 25 & 1 & 4,47 & & I. 10 & 0 & 5,43 \\
\hline I. 42 & 0 & 4,47 & & I.71 & 1 & 4,29 \\
\hline I. 51 & 0 & 4,44 & & I.96 & 0 & 4,29 \\
\hline I. 41 & 0 & 4,41 & \multirow{20}{*}{$\begin{array}{c}\text { Risco } \\
\text { Moderado }\end{array}$} & I. 43 & 1 & 5,29 \\
\hline I. 44 & 0 & 4,32 & & I. 65 & 1 & 4,14 \\
\hline I. 43 & 1 & 4,26 & & I.66 & 1 & 4,14 \\
\hline I.98 & 0 & 4,26 & & I. 16 & 0 & 4,14 \\
\hline I. 32 & 1 & 4,24 & & I. 32 & 1 & 4,14 \\
\hline I. 36 & 0 & 4,21 & & I.36 & 0 & 4,14 \\
\hline I. 40 & 0 & 4,21 & & I. 18 & 0 & 4,14 \\
\hline I. 52 & 0 & 4,21 & & I. 25 & 1 & 4,00 \\
\hline I.05 & 0 & 4,12 & & I. 17 & 1 & 4,00 \\
\hline I. 13 & 0 & 3,85 & & I.39 & 0 & 4,00 \\
\hline I. 18 & 0 & 3,79 & & I.52 & 0 & 3,86 \\
\hline I. 39 & 0 & 3,76 & & I.55 & 1 & 3,86 \\
\hline I. 100 & 1 & 3,76 & & I.19 & 0 & 3,86 \\
\hline I. 16 & 0 & 3,68 & & I. 20 & 1 & 3,86 \\
\hline I. 37 & 0 & 3,53 & & I.05 & 0 & 3,57 \\
\hline I. 54 & 0 & 3,47 & & I.06 & 0 & 3,57 \\
\hline I.06 & 0 & 3,41 & & I.98 & 0 & 3,43 \\
\hline I.19 & 0 & 3,35 & & I.13 & 0 & 3,43 \\
\hline I.73 & 0 & 3,29 & & I.37 & 0 & 3,43 \\
\hline I.17 & 1 & 3,26 & & I.100 & 1 & 3,29 \\
\hline
\end{tabular}


Avaliação de risco de violência contra mulher

\begin{tabular}{|c|c|c|c|c|c|}
\hline I. 20 & 1 & 3,12 & I. 29 & 0 & 3,29 \\
\hline I.09 & 0 & 3,09 & I. 47 & 0 & 3,00 \\
\hline I. 49 & 0 & 3,03 & I. 87 & 1 & 3,00 \\
\hline I.55 & 1 & 3,03 & I.48 & 0 & 3,00 \\
\hline I. 47 & 0 & 2,76 & I.49 & 0 & 2,71 \\
\hline I. 29 & 0 & 2,71 & I.54 & 0 & 2,57 \\
\hline I. 87 & 1 & 2,56 & I. 33 & 1 & 2,00 \\
\hline I. 33 & 1 & 2,53 & I.73 & 0 & 2,29 \\
\hline I. 48 & 0 & 2,47 & I.09 & 0 & 2,29 \\
\hline I. 31 & 1 & 2,38 & I.50 & 0 & 2,29 \\
\hline I.50 & 0 & 2,24 & I.56 & 1 & 2,29 \\
\hline I.56 & 1 & 2,21 & I.97 & 0 & 2,29 \\
\hline I.97 & 0 & 2,00 & I. 31 & 1 & 1,71 \\
\hline
\end{tabular}

Legenda: Tipo de item: $\mathrm{I}=$ Comportamental

$0=$ Subjetivo 
Anexo 10 - Comparação entre grupo de profissionais e grupo da sociedade civil 
Avaliação de risco de violência contra mulher

Estatística por grupo de participantes

\begin{tabular}{|c|c|c|c|c|}
\hline Sociedade civil & $\mathrm{N}$ & Média & Desvio padrão & $\begin{array}{l}\text { Erro padrão da } \\
\text { média }\end{array}$ \\
\hline Sim & 6 & 3,83 & 1,602 & ,654 \\
\hline Não & 28 & 5,68 & 1,416 &, 268 \\
\hline Sim & 6 & 4,33 & 1,751 &, 715 \\
\hline Não & 28 & 5,36 & 1,890 & ,357 \\
\hline Sim & 6 & 5,17 & 1,602 & ,654 \\
\hline Não & 28 & 5,68 & 1,219 &, 230 \\
\hline Sim & 6 & 4,67 & 1,033 &, 422 \\
\hline Não & 28 & 5,21 & 1,449 &, 274 \\
\hline Sim & 6 & 3,83 & 1,169 & ,477 \\
\hline Não & 28 & 4,18 & 2,074 &, 392 \\
\hline Sim & 6 & 3,33 & 1,966 &, 803 \\
\hline Não & 28 & 3,43 & 1,597 & ,302 \\
\hline Sim & 6 & 6,50 & 2,429 & ,992 \\
\hline Não & 28 & 7,11 & 1,449 &, 274 \\
\hline Sim & 6 & 5,33 & 1,033 & ,422 \\
\hline Não & 28 & 5,04 & 1,201 &, 227 \\
\hline Sim & 6 & 2,33 &, 816 &, 333 \\
\hline Não & 28 & 3,25 & 1,175 & ,222 \\
\hline Sim & 6 & 6,83 & 1,329 &, 543 \\
\hline Não & 28 & 4,64 & 1,283 & ,242 \\
\hline Sim & 6 & 6,00 & ,632 &, 258 \\
\hline Não & 28 & 4,46 & 1,710 & ,323 \\
\hline Sim & 6 & 5,00 & 2,191 &, 894 \\
\hline Não & 28 & 4,75 & 1,456 & ,275 \\
\hline Sim & 6 & 4,33 & 1,211 & ,494 \\
\hline Não & 28 & 3,75 & 1,531 & ,289 \\
\hline Sim & 6 & 5,67 & 1,366 & ,558 \\
\hline Não & 28 & 5,25 & 1,578 & ,298 \\
\hline Sim & 6 & 4,67 & 1,366 & ,558 \\
\hline Não & 28 & 5,25 & 1,506 & ,285 \\
\hline Sim & 6 & 3,17 & 1,941 &, 792 \\
\hline Não & 28 & 3,79 & 1,287 & ,243 \\
\hline Sim & 6 & 3,17 & 1,329 & ,543 \\
\hline Não & 28 & 3,29 & 1,150 & ,217 \\
\hline Sim & 6 & 2,67 & ,816 & ,333 \\
\hline Não & 28 & 4,04 & 1,319 & 249 \\
\hline Sim & 6 & 3,67 & 1,751 &, 715 \\
\hline Não & 28 & 3,29 & 1,084 & ,205 \\
\hline Sim & 6 & 3,83 & 1,169 & ,477 \\
\hline Não & 28 & 2,96 & 1,621 & ,306 \\
\hline Sim & 6 & 5,33 & 1,506 & ,615 \\
\hline Não & 28 & 4,86 & 1,353 & ,256 \\
\hline Sim & 6 & 5,33 & 1,366 & ,558 \\
\hline Não & 28 & 5,71 & 1,436 &, 271 \\
\hline Sim & 6 & 4,67 & 1,506 & ,615 \\
\hline Não & 28 & 5,61 & 1,548 & 292 \\
\hline Sim & 6 & 4,00 & 1,414 & ,577 \\
\hline Não & 28 & 4,79 & 1,397 & ,264 \\
\hline
\end{tabular}


Avaliação de risco de violência contra mulher

\begin{tabular}{|c|c|c|c|c|}
\hline Sim & 6 & 5,17 & 408, & , 167 \\
\hline Não & 28 & 4,32 & 1,188 & 225 \\
\hline Sim & 6 & 6,00 & 1,789 & ,730 \\
\hline Não & 28 & 6,21 & 1,424 & 269 \\
\hline Sim & 6 & 5,50 & 1,517 & 619 \\
\hline Não & 28 & 6,89 & 1,397 & 264 \\
\hline Sim & 6 & 6,33 & 1,033 & ,422 \\
\hline Não & 28 & 6,07 & 1,698 & ,321 \\
\hline Sim & 6 & 4,67 & 1,633 & 667, \\
\hline Não & 28 & 2,29 & 1,740 & ,329 \\
\hline Sim & 6 & 5,33 & 1,211 & ,494 \\
\hline Não & 28 & 4,82 & 1,492 & ,282 \\
\hline Sim & 6 & 2,83 & 1,329 & ,543 \\
\hline Não & 28 & 2,29 & 1,150 & ,217 \\
\hline Sim & 6 & 4,00 & 1,095 & ,447 \\
\hline Não & 28 & 4,29 & 1,357 & ,256 \\
\hline Sim & 6 & 2,83 & 1,472 & 601 \\
\hline Não & 28 & 2,46 & 1,319 & 249 \\
\hline Sim & 6 & 6,50 & 1,761 & ,719 \\
\hline Não & 28 & 5,04 & 2,063 & ,390 \\
\hline Sim & 6 & 5,83 & 1,329 & ,543 \\
\hline Não & 28 & 7,07 & 1,489 & 281 \\
\hline Sim & 6 & 4,67 & 1,211 & ,494 \\
\hline Não & 28 & 4,11 & 1,423 & 269 \\
\hline Sim & 6 & 3,67 & 1,211 & ,494 \\
\hline Não & 28 & 3,50 & 1,347 & ,255 \\
\hline Sim & 6 & 6,50 & 1,378 & ,563 \\
\hline Não & 28 & 4,93 & 1,824 &, 345 \\
\hline Sim & 6 & 3,83 & 1,169 & ,477 \\
\hline Não & 28 & 3,75 & 1,206 & ,228 \\
\hline Sim & 6 & 3,83 & 1,169 & ,477 \\
\hline Não & 28 & 4,29 & 1,462 & ,276 \\
\hline Sim & 6 & 4,00 & 2,000 & ,816 \\
\hline Não & 28 & 4,50 & 2,028 & ,383 \\
\hline Sim & 6 & 4,67 & 2,160 & ,882 \\
\hline Não & 28 & 4,43 & 1,550 & ,293 \\
\hline Sim & 6 & 5,00 & 2,098 & 856 \\
\hline Não & 28 & 4,11 & 1,641 & 310 \\
\hline Sim & 6 & 5,17 & ,983 & ,401 \\
\hline Não & 28 & 4,14 & 1,627 & ,307 \\
\hline Sim & 6 & 3,50 & 1,049 & ,428 \\
\hline Não & 28 & 5,46 & 2,269 & ,429 \\
\hline Sim & 6 & 4,17 & 2,229 & ,910 \\
\hline Não & 28 & 5,04 & 1,815 & ,343 \\
\hline Sim & 6 & 2,83 & 1,329 & ,543 \\
\hline Não & 28 & 2,75 & 1,430 & ,270 \\
\hline Sim & 6 & 2,83 & 1,602 & 654 \\
\hline Não & 28 & 2,39 & 1,227 & ,232 \\
\hline Sim & 6 & 2,67 & 1,966 &, 803 \\
\hline Não & 28 & 3,11 & 1,474 & 279 \\
\hline
\end{tabular}


Avaliação de risco de violência contra mulher

\begin{tabular}{|c|c|c|c|c|}
\hline Sim & 6 & 2,17 & 1,169 & ,477 \\
\hline Não & 28 & 2,25 & 1,206 & ,228 \\
\hline Sim & 6 & 4,00 & ,894 & ,365 \\
\hline Não & 28 & 4,54 & 1,453 & ,274 \\
\hline Sim & 6 & 4,17 & 1,472 & 601 \\
\hline Não & 28 & 4,21 & 1,548 & ,293 \\
\hline Sim & 6 & 5,00 & 1,265 & ,516 \\
\hline Não & 28 & 4,71 & 1,410 & ,267 \\
\hline Sim & 6 & 3,83 & 2,229 & ,910 \\
\hline Não & 28 & 3,39 & 1,474 & ,279 \\
\hline Sim & 6 & 2,67 & 1,366 & ,558 \\
\hline Não & 28 & 3,11 & 1,729 & ,327 \\
\hline Sim & 6 & 3,17 & 1,722 & ,703 \\
\hline Não & 28 & 2,00 & 1,054 & 199 \\
\hline Sim & 6 & 7,00 & 1,414 & ,577 \\
\hline Não & 28 & 5,89 & 1,474 & ,279 \\
\hline Sim & 6 & 5,83 & 1,602 & 654 \\
\hline Não & 28 & 5,04 & ,962 & , 182 \\
\hline Sim & 6 & 6,83 & 1,329 &, 543 \\
\hline Não & 28 & 5,36 & 1,129 & ,213 \\
\hline Sim & 6 & 5,83 & 1,941 & ,792 \\
\hline Não & 28 & 4,64 & 1,569 & 296 \\
\hline Sim & 6 & 6,17 & 1,169 & ,477 \\
\hline Não & 28 & 5,54 & 1,644 & ,311 \\
\hline Sim & 6 & 8,17 & ,983 & ,401 \\
\hline Não & 28 & 6,79 & 1,475 & ,279 \\
\hline Sim & 6 & 7,33 & 1,366 &, 558 \\
\hline Não & 28 & 6,61 & 1,423 & ,269 \\
\hline Sim & 6 & 6,17 & 1,722 & ,703 \\
\hline Não & 28 & 6,39 & 1,663 & ,314 \\
\hline Sim & 6 & 4,50 & 1,049 & ,428 \\
\hline Não & 28 & 4,93 & 1,538 & ,291 \\
\hline Sim & 6 & 4,83 & ,983 & ,401 \\
\hline Não & 28 & 4,50 & 1,528 & ,289 \\
\hline Sim & 6 & 5,33 & 2,422 & ,989 \\
\hline Não & 28 & 5,93 & 1,585 & ,300 \\
\hline Sim & 6 & 8,00 & ,894 & ,365 \\
\hline Não & 28 & 7,75 & 1,266 & ,239 \\
\hline Sim & 6 & 8,17 & ,753 & ,307 \\
\hline Não & 28 & 8,00 & 1,361 & ,257 \\
\hline Sim & 6 & 5,00 & 2,757 & 1,125 \\
\hline Não & 28 & 6,18 & 1,847 & ,349 \\
\hline Sim & 6 & 5,00 & 2,191 & ,894 \\
\hline Não & 28 & 4,93 & 1,585 & ,300 \\
\hline Sim & 6 & 6,83 & 1,472 & 601 \\
\hline Não & 28 & 6,93 & 1,720 & ,325 \\
\hline Sim & 6 & 3,00 & 1,095 & ,447 \\
\hline Não & 28 & 3,36 & 1,496 & ,283 \\
\hline Sim & 6 & 5,83 & ,753 & ,307 \\
\hline Não & 28 & 5,21 & 1,134 & ,214 \\
\hline
\end{tabular}


Avaliação de risco de violência contra mulher

\begin{tabular}{|c|c|c|c|c|}
\hline Sim & 6 & 6,00 & 2,608 & 1,065 \\
\hline Não & 28 & 6,46 & 1,551 & ,293 \\
\hline Sim & 6 & 7,17 & 1,169 & ,477 \\
\hline Não & 28 & 7,57 & 1,597 & ,302 \\
\hline Sim & 6 & 8,00 & ,894 & ,365 \\
\hline Não & 28 & 6,82 & 1,722 &, 326 \\
\hline Sim & 6 & 6,50 & 2,588 & 1,057 \\
\hline Não & 28 & 7,57 & 1,526 & ,288 \\
\hline Sim & 6 & 6,33 & 2,338 & ,955 \\
\hline Não & 28 & 7,93 &, 858 & ,162 \\
\hline Sim & 6 & 7,00 & 2,280 & ,931 \\
\hline Não & 28 & 8,25 & 1,005 & ,190 \\
\hline Sim & 6 & 5,67 & 1,751 & ,715 \\
\hline Não & 28 & 6,11 & 2,006 & ,379 \\
\hline Sim & 6 & 6,67 & 1,366 &, 558 \\
\hline Não & 28 & 6,64 & 1,062 & ,201 \\
\hline Sim & 6 & 6,67 & 1,633 & ,667 \\
\hline Não & 28 & 6,68 & 1,020 & 193 \\
\hline Sim & 6 & 5,50 &, 837 &, 342 \\
\hline Não & 28 & 5,36 & 1,311 & ,248 \\
\hline Sim & 6 & 6,33 & 1,211 & ,494 \\
\hline Não & 28 & 6,14 & 1,239 & ,234 \\
\hline Sim & 6 & 5,50 & 1,049 & ,428 \\
\hline Não & 28 & 5,89 & 1,499 & ,283 \\
\hline Sim & 6 & 1,33 & ,516 & ,211 \\
\hline Não & 28 & 2,82 & 1,389 & ,263 \\
\hline Sim & 6 & 7,00 & 1,095 & ,447 \\
\hline Não & 28 & 6,89 & 1,286 & ,243 \\
\hline Sim & 6 & 6,50 & 1,761 & ,719 \\
\hline Não & 28 & 6,14 & 1,297 & ,245 \\
\hline Sim & 6 & 4,33 & 1,211 & ,494 \\
\hline Não & 28 & 5,00 & 1,805 &, 341 \\
\hline Sim & 6 & 5,50 & 1,049 & ,428 \\
\hline Não & 28 & 6,00 & 1,155 & ,218 \\
\hline Sim & 6 & 4,67 & 2,503 & 1,022 \\
\hline Não & 28 & 5,39 & 1,750 &, 331 \\
\hline Sim & 6 & 6,17 & 1,722 & ,703 \\
\hline Não & 28 & 6,29 & 1,560 & ,295 \\
\hline Sim & 6 & 5,67 & 1,211 & ,494 \\
\hline Não & 28 & 6,71 & 1,863 &, 352 \\
\hline Sim & 6 & 6,00 & 1,897 & ,775 \\
\hline Não & 28 & 6,25 & 1,323 &, 250 \\
\hline Sim & 6 & 6,17 & 1,941 & ,792 \\
\hline Não & 28 & 4,25 & 1,898 & ,359 \\
\hline Sim & 6 & 2,17 & ,753 & ,307 \\
\hline Não & 28 & 1,96 & 1,290 & ,244 \\
\hline Sim & 6 & 3,50 & 2,588 & 1,057 \\
\hline Não & 28 & 4,43 & 1,709 &, 323 \\
\hline Sim & 6 & 5,00 & 2,000 & ,816 \\
\hline Não & 28 & 4,54 & 1,232 & ,233 \\
\hline
\end{tabular}


Avaliação de risco de violência contra mulher

\begin{tabular}{lcccc} 
Sim & 6 & 3,17 & 2,137 &, 872 \\
Não & 28 & 3,89 & 1,397 &, 264 \\
\hline
\end{tabular}


Teste de amostras independentes

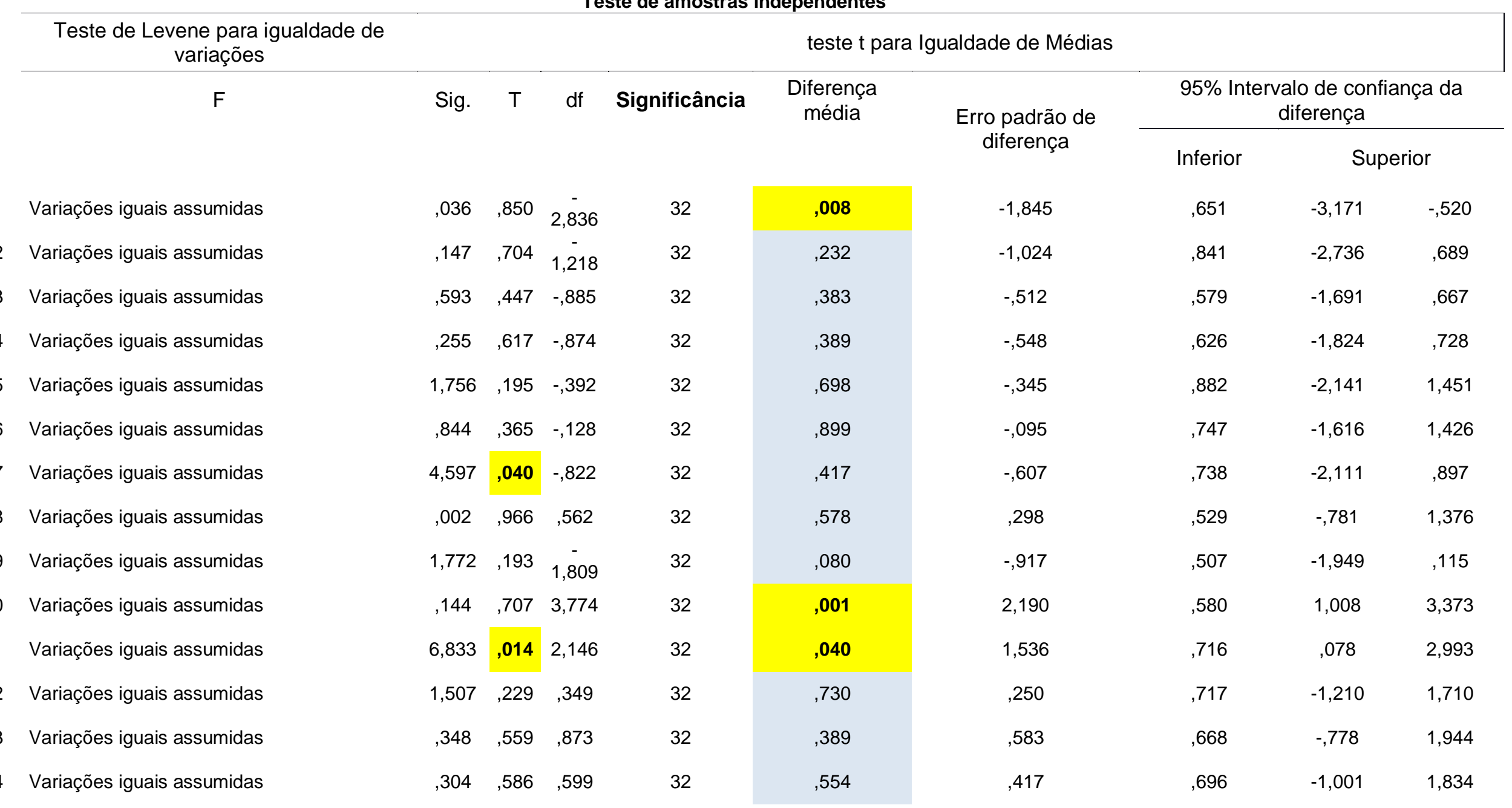




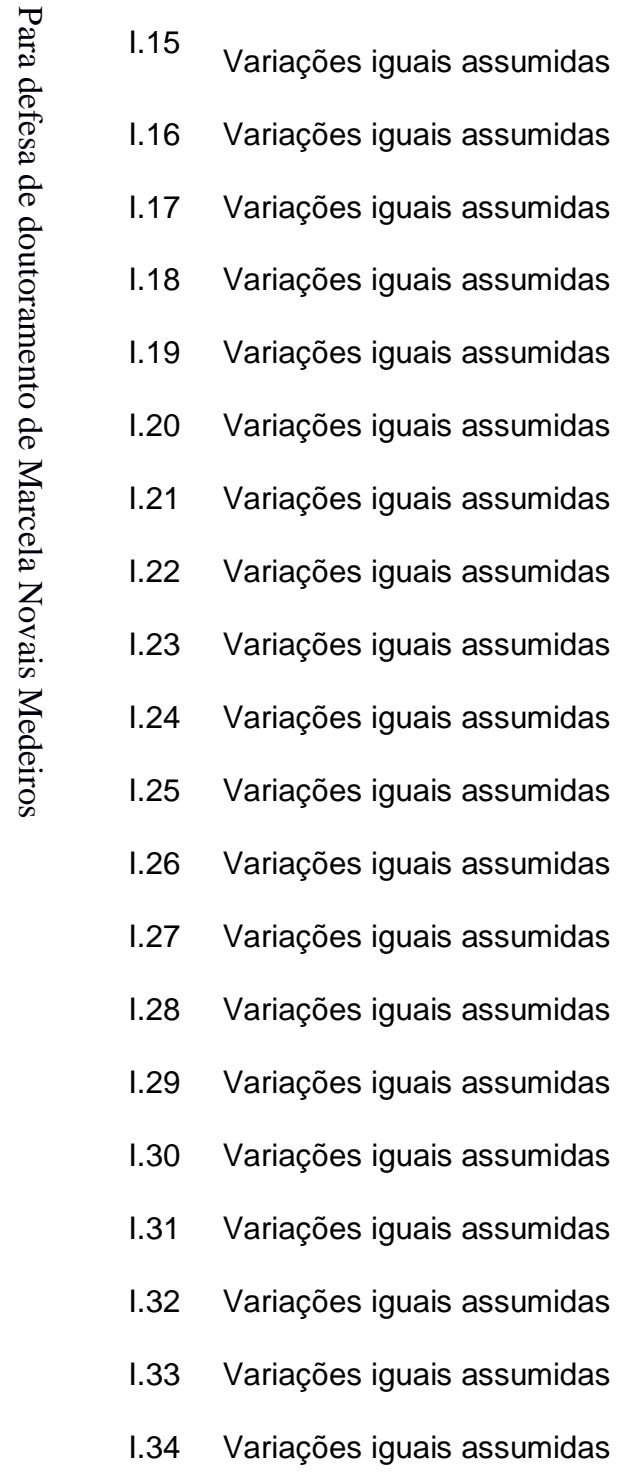

\begin{tabular}{|c|c|c|c|c|c|}
\hline 196 & 661 &,- 873 & 32 & 389, &,- 583 \\
\hline 2,456 & 127, &,- 976 & 32 & ,336 &,- 619 \\
\hline 165, & 687, &,- 224 & 32 & ,824 &,- 119 \\
\hline 2,474 & ,126 & $2, \overline{427}$ & 32 & ,021 & $-1,369$ \\
\hline 1,009 & ,323 & 698 & 32 & 490, & ,381 \\
\hline 1,298 & ,263 & 1,239 & 32 & 224 & 869, \\
\hline ,034 & 855 & ,768 & 32 & ,448 & ,476 \\
\hline 199, & 658 &,- 594 & 32 & ,557, & -381 \\
\hline 123, & ,728 & $\begin{array}{c}- \\
1,356\end{array}$ & 32 & 184, & -,940 \\
\hline 262, & 612 & $\overline{1,248}$ & 32 & 221 & -,786 \\
\hline 5,880 & ,021 & 1,703 & 32 & 098, & ,845 \\
\hline 188, & 667, &,- 320 & 32 & 751, &,- 214 \\
\hline 066, & 799 & 2,186 & 32 & 036, & $-1,393$ \\
\hline ,508 & ,481 &, 361 & 32 & 720, & 262 \\
\hline 170, & 683, & 3,071 & 32 & ,004 & 2,381 \\
\hline 1,302 & 262 & ,784 & 32 & 439, & ,512 \\
\hline ,000 & 997, & 1,032 & 32 & 310 & ,548 \\
\hline 2,005 & 166 &,- 481 & 32 & 634, &,- 286 \\
\hline 086, & ,772 & 610, & 32 & ,546 & 369, \\
\hline 152 & 699, & 1,612 & 32 & 117, & 1,464 \\
\hline
\end{tabular}

\begin{tabular}{lll}
, 668 & $-1,944$ &, 778 \\
, 634 & $-1,910$ &, 672 \\
, 531 & $-1,200$ &, 962 \\
, 564 & $-2,518$ &,- 220 \\
, 545 &,- 730 & 1,492 \\
, 701 &,- 560 & 2,298 \\
, 620 &,- 787 & 1,739 \\
, 641 & $-1,687$ &, 926 \\
, 693 & $-2,353$ &, 472 \\
, 630 & $-2,069$ &, 497 \\
, 496 &,- 166 & 1,856 \\
, 669 & $-1,576$ & 1,148 \\
, 637 & $-2,691$ &,- 095 \\
, 725 & $-1,216$ & 1,739 \\
, 775 &,- 802 & 3,960 \\
, 653 &,- 818 & 1,842 \\
, 531 &,- 534 & 1,629 \\
, 594 & $-1,495$ &, 923 \\
, 605 &,- 862 & 1,601 \\
, 908 &,- 386 & 3,315 \\
\hline
\end{tabular}




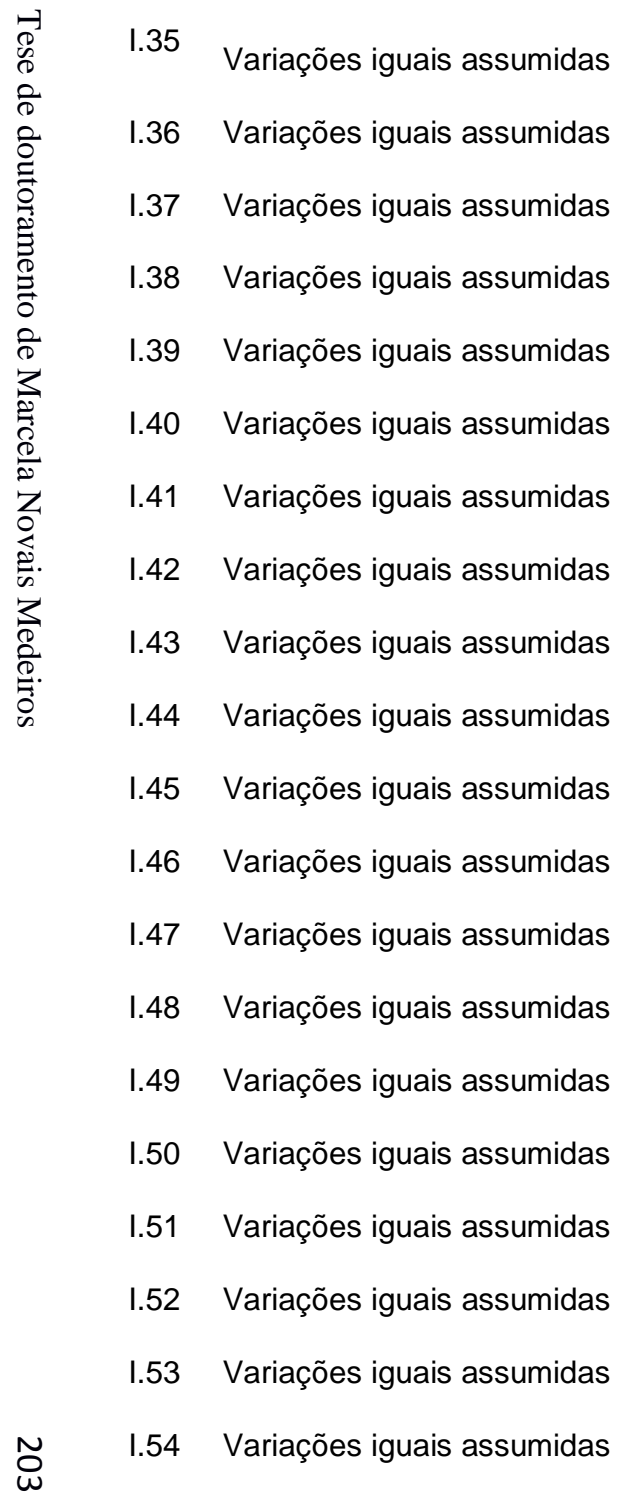

\begin{tabular}{|c|c|c|c|c|c|}
\hline 226, & 638, & 1,878 & 32 & 069, & $-1,238$ \\
\hline 114, & 737, & 893 & 32 & 378, & 560, \\
\hline 113, & 739, & 279, & 32 & 782, & 167, \\
\hline ,802 & ,377 & 1,982 & 32 & 056, & 1,571 \\
\hline ,096, & 759, & 154 & 32 & 878, & 083, \\
\hline 1,104 & 301, & -,708 & 32 & 484, &,- 452 \\
\hline ,011 & 916, &,- 549 & 32 & ,587, &,- 500 \\
\hline ,977 & 330, & ,319 & 32 & 752, & 238 \\
\hline 176, & 678, & 1,154 & 32 & 257, & 893, \\
\hline 639, & 430, & 1,474 & 32 & 150, & 1,024 \\
\hline 6,269 & ,018 & 2,055 & 32 & 048, & $-1,964$ \\
\hline 881 & 355 & 1,024 & 32 & 313, &,- 869 \\
\hline 776, & 385, & 131 & 32 & 897, & ,083 \\
\hline 418, & 522, & ,757 & 32 & 454, & ,440, \\
\hline 994 & ,326 &,- 627 & 32 & 535, &,- 440 \\
\hline ,004 & 949, &,- 154 & 32 & ,878 &,- 083 \\
\hline 2,135 & 154, &,- 863 & 32 & 395, &,- 536 \\
\hline ,040, & ,842 & -,069 & 32 & ,946 &,- 048 \\
\hline 116 & ,736 & ,457 & 32 & 651 & 286 \\
\hline 267, & 609, & 606 & 32 & 549, & ,440, \\
\hline
\end{tabular}

\begin{tabular}{lll}
, 659 & $-2,581$ &, 104 \\
, 626 &,- 716 & 1,835 \\
, 597 & $-1,049$ & 1,382 \\
, 793 &,- 043 & 3,186 \\
, 540 & $-1,016$ & 1,183 \\
, 639 & $-1,754$ &, 849 \\
, 910 & $-2,354$ & 1,354 \\
, 747 & $-1,283$ & 1,759 \\
, 774 &,- 683 & 2,469 \\
, 694 &,- 391 & 2,438 \\
, 956 & $-3,911$ &,- 017 \\
, 848 & $-2,597$ &, 859 \\
, 637 & $-1,213$ & 1,380 \\
, 582 &,- 745 & 1,625 \\
, 702 & $-1,871$ &, 990 \\
, 540 & $-1,183$ & 1,016 \\
, 621 & $-1,801$ &, 729 \\
, 691 & $-1,456$ & 1,360 \\
, 625 &,- 987 & 1,558 \\
, 727 & $-1,040$ & 1,921 \\
\hline
\end{tabular}




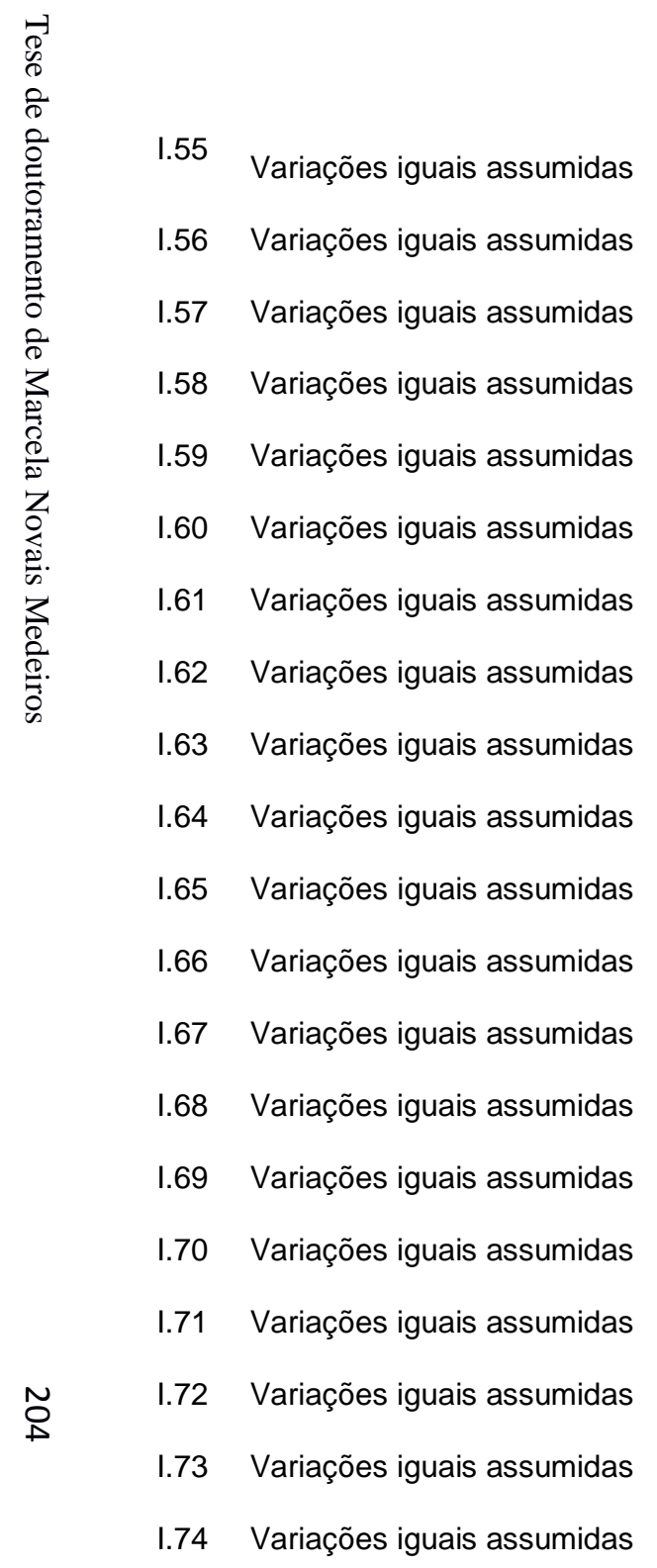

\begin{tabular}{|c|c|c|c|c|c|}
\hline 1,601 & 215, &,- 584 & 32 & 563, & -,440 \\
\hline 1,378 & 249, & 2,191 & 32 & 036, & 1,167 \\
\hline 236, & 631 & 1,680 & 32 & 103, & 1,107 \\
\hline 2,667 & 112, & 1,631 & 32 & 113, & 798, \\
\hline 000, & 985, & 2,822 & 32 & 008, & 1,476 \\
\hline 285, & ,597, & 1,621 & 32 & 115, & 1,190 \\
\hline 466, & 500, & ,888 & 32 & 381, & 631, \\
\hline 696, & 410, & 2,178 & 32 & 037, & 1,381 \\
\hline ,065 & 801 & 1,141 & 32 & 262, & 726, \\
\hline 211, & 649, &,- 301 & 32 & 766 &,- 226 \\
\hline 1,000 & ,325 &,- 647 & 32 & 522, &,- 429 \\
\hline 2,955 & 095, & ,509 & 32 & 614, & 333, \\
\hline 3,145 & 086, &,- 759 & 32 & 453, &,- 595 \\
\hline 895, & 351, & ,457 & 32 & 651, & 250, \\
\hline 1,359 & 252 & 288, & 32 & 775, & 167, \\
\hline 898, & 350, & $1, \overline{299}$ & 32 & 203, & $-1,179$ \\
\hline 919, & 345, & ,094 & 32 & 926, & ,071 \\
\hline ,021 & 885, & -,126 & 32 & 901, & -095 \\
\hline 2,506 & 123, &,- 551 & 32 & 585, &,- 357 \\
\hline 1,904 & 177, & 1,270 & 32 & 213, & 619, \\
\hline
\end{tabular}

\begin{tabular}{lll}
, 755 & $-1,977$ & 1,096 \\
, 532 &, 082 & 2,251 \\
, 659 &,- 235 & 2,450 \\
, 489 &,- 198 & 1,794 \\
, 523 &, 411 & 2,542 \\
, 734 &,- 305 & 2,686 \\
, 710 &,- 816 & 2,078 \\
, 634 &, 090 & 2,672 \\
, 636 &,- 570 & 2,022 \\
, 752 & $-1,759$ & 1,306 \\
, 662 & $-1,778$ &, 920 \\
, 655 & $-1,001$ & 1,667 \\
, 784 & $-2,192$ & 1,002 \\
, 547 &,- 863 & 1,363 \\
, 578 & $-1,011$ & 1,344 \\
, 907 & $-3,026$ &, 669 \\
, 762 & $-1,481$ & 1,624 \\
, 757 & $-1,638$ & 1,447 \\
, 648 & $-1,677$ &, 963 \\
, 487 &,- 374 & 1,612 \\
\hline
\end{tabular}




\begin{tabular}{|c|c|c|c|c|c|}
\hline 2,807 & 104, &,- 587 & 32 & ,561 &,- 464 \\
\hline 650 & ,426 &,- 585 & 32 & ,563 &,- 405 \\
\hline 1,281 & 266 & 1,616 & 32 & 116, & 1,179 \\
\hline 5,238 & ,029 & $\overline{1,372}$ & 32 & 179, & $-1,071$ \\
\hline 19,534 & ,000 & 2, $\overline{9} 20$ & 32 & ,006, & $-1,595$ \\
\hline 6,471 & ,016 & $\begin{array}{c}- \\
2,154\end{array}$ & 32 & ,039, & $-1,250$ \\
\hline 177, & 677 &,- 497 & 32 & 622 &,- 440 \\
\hline ,008 & 930 & ,047 & 32 & 962 & ,024 \\
\hline 885, & ,354 &,- 023 & 32 & 982 &,- 012 \\
\hline 1,713 & 200 & 254 & 32 & 801 & ,143 \\
\hline ,058, & 811 & ,343 & 32 & ,734 & ,190 \\
\hline 1,966 & 171 &,- 607 & 32 & ,548 &,- 393 \\
\hline 3,140 & ,086 & 2,560 & 32 & ,015, & $-1,488$ \\
\hline ,502 & ,484 & ,189 & 32 & ,851 & ,107 \\
\hline 2,058 & 161 & ,575 & 32 & ,569, & ,357 \\
\hline 902 & ,349 &,- 859 & 32 & 397 &,- 667 \\
\hline ,005 & 942 &,- 976 & 32 & ,336 &,- 500 \\
\hline 1,016 & ,321 &,- 855 & 32 & 399 &,- 726 \\
\hline 457, & ,504 &,- 167 & 32 & 869 &,- 119 \\
\hline 1,153 & 291 & $\begin{array}{c}- \\
1,310\end{array}$ & 32 & 199 & $-1,048$ \\
\hline
\end{tabular}

\begin{tabular}{lll}
, 791 & $-2,076$ & 1,147 \\
, 692 & $-1,814$ & 1,005 \\
, 729 &,- 307 & 2,664 \\
, 781 & $-2,662$ &, 519 \\
, 546 & $-2,708$ &,- 482 \\
, 580 & $-2,432$ &,- 068 \\
, 886 & $-2,244$ & 1,363 \\
, 501 &,- 998 & 1,045 \\
, 512 & $-1,055$ & 1,031 \\
, 562 & $-1,002$ & 1,287 \\
, 555 &,- 941 & 1,322 \\
, 647 & $-1,711$ &, 925 \\
, 581 & $-2,672$ &,- 304 \\
, 566 & $-1,046$ & 1,260 \\
, 621 &,- 907 & 1,622 \\
, 776 & $-2,248$ &, 915 \\
, 512 & $-1,544$ &, 544 \\
, 849 & $-2,456$ & 1,003 \\
, 714 & $-1,573$ & 1,335 \\
, 799 & $-2,676$ &, 581 \\
\hline & &
\end{tabular}


1.95 Variações iguais assumidas

$\begin{array}{llll}3,887 & 057 & -, 389 & 32\end{array}$

, 700

$\begin{array}{llll}, 006 & 941 & 2,237 & 32\end{array}$

, 700

$-, 250$

32

$, 032 \quad 1,917$

$\begin{array}{llll}1,122 & 297 & - & 1,102\end{array}$

, 715

,202

$\begin{array}{lllll}4,308 & , 046 & 32\end{array}$

,279

$-, 929$

, 460

, 464

$\begin{array}{llcll}3,957 & 055 & - & 1,051\end{array}$

, 301

$-, 726$

$\begin{array}{ccc}, 642 & -1,559 & 1,059 \\ , 857 & , 171 & 3,662 \\ , 550 & -, 918 & 1,322 \\ , 843 & -2,646 & , 788 \\ , 621 & -, 801 & 1,729 \\ , 691 & -2,134 & , 681\end{array}$


Anexo 11 - Comparação entre grupo de profissionais e grupo da sociedade civil com a amostra total 
Avaliação de risco de violência contra a mulher

\begin{tabular}{|c|c|c|c|c|c|c|c|c|c|c|c|c|c|c|}
\hline $\begin{array}{l}\text { Todos } \\
\text { com } \\
\text { sociedade } \\
\text { civil } \\
\end{array}$ & & & & & & Toc & los sem s & ocied & de c & vil & & & & \\
\hline Item & $\begin{array}{l}\text { Ti } \\
\text { po } \\
\text { de } \\
\text { ite } \\
\text { m }\end{array}$ & $\begin{array}{l}\text { Média de } \\
\text { Periculos } \\
\text { idade }\end{array}$ & $\begin{array}{l}\text { Desv } \\
\text { io } \\
\text { Pad } \\
\text { rão }\end{array}$ & $\begin{array}{c}\text { Máxi } \\
\text { mo }\end{array}$ & $\begin{array}{l}\text { Míni } \\
\text { mo }\end{array}$ & $\begin{array}{c}\text { Gru } \\
\text { po }\end{array}$ & & $\begin{array}{l}\text { Ite } \\
\text { m }\end{array}$ & $\begin{array}{l}\text { Ti } \\
\text { po } \\
\text { de } \\
\text { ite } \\
\text { m }\end{array}$ & $\begin{array}{c}\text { Média de } \\
\text { Periculos } \\
\text { idade }\end{array}$ & $\begin{array}{l}\text { Desv } \\
\text { io } \\
\text { Pad } \\
\text { rão }\end{array}$ & $\begin{array}{c}\text { Máxi } \\
\text { mo }\end{array}$ & $\begin{array}{l}\text { Míni } \\
\text { mo }\end{array}$ & $\begin{array}{c}\text { Gru } \\
\text { po }\end{array}$ \\
\hline I.69 & 1 & 8,03 & 1,27 & 9 & 4 & 1 & & $\begin{array}{l}\text { I. } 8 \\
0\end{array}$ & 1 & 8,25 & 1,00 & 9 & 6 & 1 \\
\hline I. 80 & 1 & 8,03 & 1,36 & 9 & 3 & 1 & & I.69 & 1 & 8,00 & 1,36 & 9 & 4 & 1 \\
\hline I.68 & 1 & 7,79 & 1,20 & 9 & 4 & 1 & & I. 79 & 1 & 7,93 & 0,86 & 9 & 7 & 1 \\
\hline I.79 & 1 & 7,65 & 1,35 & 9 & 3 & 1 & & I.68 & 1 & 7,75 & 1,27 & 9 & 4 & 1 \\
\hline I.76 & 1 & 7,50 & 1,52 & 9 & 2 & 1 & & I.76 & 1 & 7,57 & 1,60 & 9 & 2 & 1 \\
\hline I.78 & 1 & 7,38 & 1,76 & 9 & 3 & 1 & & I.78 & 1 & 7,57 & 1,53 & 9 & 3 & 1 \\
\hline I.62 & 1 & 7,03 & 1,49 & 9 & 4 & 1 & & I. .07 & 1 & 7,11 & 1,45 & 9 & 4 & 1 \\
\hline I.77 & 1 & 7,03 & 1,66 & 9 & 1 & 1 & & I. 35 & 1 & 7,07 & 1,49 & 9 & 4 & 1 \\
\hline I.07 & 1 & 7,00 & 1,63 & 9 & 3 & 1 & & I. 72 & 0 & 6,93 & 1,72 & 9 & 1 & 1 \\
\hline I. 72 & 0 & 6,91 & 1,66 & 9 & 1 & 1 & & I. 27 & 1 & 6,89 & 1,40 & 9 & 3 & 1 \\
\hline I. 88 & 1 & 6,91 & 1,24 & 9 & 4 & 1 & $\begin{array}{c}\text { Risco } \\
\text { severo }\end{array}$ & I. 88 & 1 & 6,89 & 1,29 & 9 & 4 & 1 \\
\hline I. 35 & 1 & 6,85 & 1,52 & 9 & 4 & 1 & & I. 77 & 1 & 6,82 & 1,72 & 9 & 1 & 1 \\
\hline I.63 & 1 & 6,74 & 1,42 & 9 & 4 & 1 & & I.62 & 1 & 6,79 & 1,47 & 9 & 4 & 1 \\
\hline I. 83 & 1 & 6,68 & 1,12 & 9 & 4 & 1 & & I.94 & 0 & 6,71 & 1,86 & 9 & 1 & 1 \\
\hline I. 27 & 1 & 6,65 & 1,50 & 9 & 3 & 1 & & I. 83 & 1 & 6,68 & 1,02 & 9 & 5 & 1 \\
\hline I. 82 & 1 & 6,65 & 1,10 & 9 & 4 & 1 & & I. 82 & 1 & 6,64 & 1,06 & 9 & 5 & 1 \\
\hline I.94 & 0 & 6,53 & 1,80 & 9 & 1 & 1 & & I.63 & 1 & 6,61 & 1,42 & 9 & 4 & 1 \\
\hline I.75 & 1 & 6,38 & 1,74 & 9 & 2 & 1 & & I. 75 & 1 & 6,46 & 1,55 & 9 & 4 & 1 \\
\hline I.64 & 1 & 6,35 & 1,65 & 9 & 4 & 1 & & I.64 & 1 & 6,39 & 1,66 & 9 & 4 & 1 \\
\hline I.93 & 0 & 6,26 & 1,56 & 9 & 2 & 1 & & I.93 & 0 & 6,29 & 1,56 & 9 & 2 & 1 \\
\hline I. 89 & 1 & 6,21 & 1,37 & 9 & 4 & 1 & & I. .95 & 0 & 6,25 & 1,32 & 8 & 4 & 1 \\
\hline I.95 & 0 & 6,21 & 1,41 & 8 & 4 & 1 & & I. 26 & 1 & 6,21 & 1,42 & 9 & 4 & 1 \\
\hline I. 26 & 1 & 6,18 & 1,47 & 9 & 3 & 1 & & I.70 & 1 & 6,18 & 1,85 & 9 & 2 & 1 \\
\hline I. 85 & 1 & 6,18 & 1,22 & 8 & 4 & 1 & & I. 85 & 1 & 6,14 & 1,24 & 8 & 4 & 1 \\
\hline I. 28 & 1 & 6,12 & 1,59 & 9 & 1 & 1 & & I. 89 & 1 & 6,14 & 1,30 & 9 & 4 & 1 \\
\hline I.57 & 1 & 6,09 & 1,50 & 9 & 4 & 1 & & I. 81 & 0 & 6,11 & 2,01 & 9 & 1 & 1 \\
\hline I. 81 & 0 & 6,03 & 1,95 & 9 & 1 & 1 & & I. 28 & 1 & 6,07 & 1,70 & 9 & 1 & 1 \\
\hline I.70 & 1 & 5,97 & 2,04 & 9 & 1 & 1 & & I.91 & 0 & 6,00 & 1,15 & 8 & 4 & 1 \\
\hline I.91 & 0 & 5,91 & 1,14 & 8 & 4 & 1 & & I. 67 & 1 & 5,93 & 1,59 & 9 & 2 & 1 \\
\hline I.67 & 1 & 5,82 & 1,73 & 9 & 2 & 1 & & I. .57 & 1 & 5,89 & 1,47 & 9 & 4 & 1 \\
\hline I. 86 & 1 & 5,82 & 1,42 & 8 & 3 & 1 & & I. 86 & 1 & 5,89 & 1,50 & 8 & 3 & 1 \\
\hline I. 22 & 0 & 5,65 & 1,41 & 9 & 3 & 1 & & I. 22 & 0 & 5,71 & 1,44 & 9 & 3 & 1 \\
\hline I.61 & 1 & 5,65 & 1,57 & 9 & 1 & 1 & & I.01 & 1 & 5,68 & 1,42 & 8 & 3 & 1 \\
\hline I.59 & 1 & 5,62 & 1,28 & 9 & 2 & 2 & & I.03 & 1 & 5,68 & 1,22 & 8 & 3 & 2 \\
\hline I.03 & 1 & 5,59 & 1,28 & 8 & 3 & 2 & & I. 23 & 0 & 5,61 & 1,55 & 9 & 2 & 2 \\
\hline I. 23 & 0 & 5,44 & 1,56 & 9 & 2 & 2 & & I.61 & 1 & 5,54 & 1,64 & 9 & 1 & 2 \\
\hline I. 84 & 1 & 5,38 & 1,23 & 8 & 3 & 2 & & I. 45 & 1 & 5,46 & 2,27 & 9 & 1 & 2 \\
\hline I.01 & 1 & 5,35 & 1,59 & 8 & 1 & 2 & & I. 92 & 0 & 5,39 & 1,75 & 8 & 1 & 2 \\
\hline I.14 & 1 & 5,32 & 1,53 & 8 & 2 & 2 & & I.02 & 0 & 5,36 & 1,89 & 9 & 1 & 2 \\
\hline I.74 & 1 & 5,32 & 1,09 & 7 & 3 & 2 & & I. 59 & 1 & 5,36 & 1,13 & 7 & 2 & 2 \\
\hline
\end{tabular}


Avaliação de risco de violência contra a mulher

\begin{tabular}{|c|c|c|c|c|c|c|c|c|c|c|c|c|c|c|}
\hline I. 34 & 1 & 5,29 & 2,07 & 9 & 2 & 2 & \multirow{27}{*}{$\begin{array}{l}\text { Risco } \\
\text { grave }\end{array}$} & I. 84 & 1 & 5,36 & 1,31 & 8 & 3 & 2 \\
\hline I.92 & 0 & 5,26 & 1,88 & 9 & 1 & 2 & & I. 14 & 1 & 5,25 & 1,58 & 8 & 2 & 2 \\
\hline I. 38 & 0 & 5,21 & 1,84 & 9 & 2 & 2 & & I. 15 & 0 & 5,25 & 1,51 & 8 & 2 & 2 \\
\hline I.02 & 0 & 5,18 & 1,88 & 9 & 1 & 2 & & I.04 & 0 & 5,21 & 1,45 & 9 & 2 & 2 \\
\hline I.58 & 1 & 5,18 & 1,11 & 8 & 3 & 2 & & I.74 & 1 & 5,21 & 1,13 & 7 & 3 & 2 \\
\hline I. 15 & 0 & 5,15 & 1,48 & 8 & 2 & 2 & & I.08 & 1 & 5,04 & 1,20 & 8 & 3 & 2 \\
\hline I.04 & 0 & 5,12 & 1,39 & 9 & 2 & 2 & & I. 34 & 1 & 5,04 & 2,06 & 9 & 2 & 2 \\
\hline I. 45 & 1 & 5,12 & 2,23 & 9 & 1 & 2 & & I. 46 & 0 & 5,04 & 1,82 & 8 & 1 & 2 \\
\hline I.08 & 1 & 5,09 & 1,16 & 8 & 3 & 2 & & I. .58 & 1 & 5,04 & 0,96 & 7 & 3 & 2 \\
\hline I. 10 & 0 & 5,03 & 1,53 & 9 & 1 & 2 & & I.90 & 0 & 5,00 & 1,81 & 9 & 1 & 2 \\
\hline I. 21 & 1 & 4,94 & 1,37 & 8 & 1 & 2 & & I. .38 & 0 & 4,93 & 1,82 & 9 & 2 & 2 \\
\hline I.71 & 1 & 4,94 & 1,67 & 8 & 1 & 2 & & I.65 & 1 & 4,93 & 1,54 & 8 & 2 & 2 \\
\hline I. 30 & 1 & 4,91 & 1,44 & 7 & 3 & 2 & & I.71 & 1 & 4,93 & 1,59 & 8 & 1 & 2 \\
\hline I. 46 & 0 & 4,88 & 1,89 & 8 & 1 & 2 & & I. 21 & 1 & 4,86 & 1,35 & 7 & 1 & 2 \\
\hline I.90 & 0 & 4,88 & 1,72 & 9 & 1 & 2 & & I. 30 & 1 & 4,82 & 1,49 & 7 & 3 & 2 \\
\hline I.60 & 1 & 4,85 & 1,67 & 9 & 1 & 2 & & I. 24 & 0 & 4,79 & 1,40 & 7 & 2 & 2 \\
\hline I.65 & 1 & 4,85 & 1,46 & 8 & 2 & 2 & & I. 12 & 0 & 4,75 & 1,46 & 8 & 2 & 2 \\
\hline I. 12 & 0 & 4,79 & 1,57 & 8 & 1 & 2 & & I. .53 & 0 & 4,71 & 1,41 & 8 & 2 & 2 \\
\hline I.53 & 0 & 4,76 & 1,37 & 8 & 2 & 2 & & I. 10 & 0 & 4,64 & 1,28 & 7 & 1 & 2 \\
\hline I.11 & 1 & 4,74 & 1,68 & 8 & 2 & 2 & & I.60 & 1 & 4,64 & 1,57 & 8 & 1 & 2 \\
\hline I. 24 & 0 & 4,65 & 1,41 & 7 & 2 & 2 & & I. .51 & 0 & 4,54 & 1,45 & 8 & 2 & 2 \\
\hline I.99 & 0 & 4,62 & 1,37 & 8 & 2 & 2 & & I.99 & 0 & 4,54 & 1,23 & 8 & 2 & 2 \\
\hline I.96 & 0 & 4,59 & 2,02 & 9 & 2 & 2 & & I.41 & 0 & 4,50 & 2,03 & 9 & 1 & 2 \\
\hline I.66 & 1 & 4,56 & 1,44 & 7 & 1 & 2 & & I.66 & 1 & 4,50 & 1,53 & 7 & 1 & 2 \\
\hline I. 25 & 1 & 4,47 & 1,13 & 7 & 2 & 2 & & I. 11 & 1 & 4,46 & 1,71 & 8 & 2 & 2 \\
\hline I. 42 & 0 & 4,47 & 1,64 & 7 & 1 & 2 & & I. 42 & 0 & 4,43 & 1,55 & 7 & 1 & 2 \\
\hline I.51 & 0 & 4,44 & 1,37 & 8 & 2 & 2 & & I.98 & 0 & 4,43 & 1,71 & 9 & 1 & 2 \\
\hline I. 41 & 0 & 4,41 & 2,00 & 9 & 1 & 3 & & I. 25 & 1 & 4,32 & 1,19 & 7 & 2 & 3 \\
\hline I. 44 & 0 & 4,32 & 1,57 & 8 & 2 & 3 & & I. 32 & 1 & 4,29 & 1,36 & 7 & 2 & 3 \\
\hline I. 43 & 1 & 4,26 & 1,73 & 8 & 1 & 3 & & I. .40 & 0 & 4,29 & 1,46 & 7 & 2 & 3 \\
\hline I.98 & 0 & 4,26 & 1,88 & 9 & 1 & 3 & & I.96 & 0 & 4,25 & 1,90 & 9 & 2 & 3 \\
\hline I. 32 & 1 & 4,24 & 1,30 & 7 & 2 & 3 & & I. .52 & 0 & 4,21 & 1,55 & 8 & 2 & 3 \\
\hline I. 36 & 0 & 4,21 & 1,39 & 8 & 2 & 3 & & I.05 & 0 & 4,18 & 2,07 & 9 & 1 & 3 \\
\hline I. 40 & 0 & 4,21 & 1,41 & 7 & 2 & 3 & & I.44 & 0 & 4,14 & 1,63 & 8 & 2 & 3 \\
\hline I. 52 & 0 & 4,21 & 1,51 & 8 & 2 & 3 & & I. 36 & 0 & 4,11 & 1,42 & 8 & 2 & 3 \\
\hline I.05 & 0 & 4,12 & 1,93 & 9 & 1 & 3 & & I.43 & 1 & 4,11 & 1,64 & 8 & 2 & 3 \\
\hline I.13 & 0 & 3,85 & 1,48 & 8 & 1 & 3 & & I. 18 & 0 & 4,04 & 1,32 & 7 & 2 & 3 \\
\hline I. 18 & 0 & 3,79 & 1,34 & 7 & 2 & 3 & $\begin{array}{c}\text { Risco } \\
\text { Moder } \\
\text { ado }\end{array}$ & $\begin{array}{l}\text { I. } 10 \\
0\end{array}$ & 1 & 3,89 & 1,40 & 6 & 1 & 3 \\
\hline I. 39 & 0 & 3,76 & 1,18 & 6 & 1 & 3 & & I. 16 & 0 & 3,79 & 1,29 & 8 & 2 & 3 \\
\hline I. 100 & 1 & 3,76 & 1,54 & 6 & 1 & 3 & & I. 13 & 0 & 3,75 & 1,53 & 8 & 1 & 3 \\
\hline I.16 & 0 & 3,68 & 1,41 & 8 & 1 & 3 & & I.39 & 0 & 3,75 & 1,21 & 6 & 1 & 3 \\
\hline I. 37 & 0 & 3,53 & 1,31 & 6 & 1 & 3 & & I. 37 & 0 & 3,50 & 1,35 & 6 & 1 & 3 \\
\hline I. 54 & 0 & 3,47 & 1,60 & 8 & 1 & 3 & & I.06 & 0 & 3,43 & 1,60 & 6 & 1 & 3 \\
\hline I.06 & 0 & 3,41 & 1,64 & 6 & 1 & 3 & & I. .54 & 0 & 3,39 & 1,47 & 6 & 1 & 3 \\
\hline I.19 & 0 & 3,35 & 1,20 & 7 & 2 & 3 & & I.73 & 0 & 3,36 & 1,50 & 7 & 1 & 3 \\
\hline
\end{tabular}


Avaliação de risco de violência contra a mulher

\begin{tabular}{|c|c|c|c|c|c|c|c|c|c|c|c|c|c|}
\hline I.73 & 0 & 3,29 & 1,43 & 7 & 1 & 3 & I. 17 & 1 & 3,29 & 1,15 & 5 & 1 & 3 \\
\hline I. 17 & 1 & 3,26 & 1,16 & 5 & 1 & 3 & I. 19 & 0 & 3,29 & 1,08 & 5 & 2 & 3 \\
\hline I. 20 & 1 & 3,12 & 1,57 & 6 & 1 & 3 & I.09 & 0 & 3,25 & 1,17 & 5 & 1 & 3 \\
\hline I.09 & 0 & 3,09 & 1,16 & 5 & 1 & 3 & I. 49 & 0 & 3,11 & 1,47 & 6 & 1 & 3 \\
\hline I. 49 & 0 & 3,03 & 1,55 & 6 & 1 & 3 & I. .55 & 1 & 3,11 & 1,73 & 6 & 1 & 3 \\
\hline I. 55 & 1 & 3,03 & 1,66 & 6 & 1 & 3 & I. 20 & 1 & 2,96 & 1,62 & 6 & 1 & 3 \\
\hline I. 47 & 0 & 2,76 & 1,39 & 6 & 1 & 3 & I. 87 & 1 & 2,82 & 1,39 & 6 & 1 & 3 \\
\hline I. 29 & 0 & 2,71 & 1,93 & 7 & 1 & 3 & I. 47 & 0 & 2,75 & 1,43 & 6 & 1 & 3 \\
\hline I. 87 & 1 & 2,56 & 1,40 & 6 & 1 & 3 & I. 33 & 1 & 2,46 & 1,32 & 5 & 1 & 3 \\
\hline I. 33 & 1 & 2,53 & 1,33 & 5 & 1 & 3 & I. 48 & 0 & 2,39 & 1,23 & 5 & 1 & 3 \\
\hline I. 48 & 0 & 2,47 & 1,28 & 5 & 1 & 3 & I. 29 & 0 & 2,29 & 1,74 & 7 & 1 & 3 \\
\hline I. 31 & 1 & 2,38 & 1,18 & 5 & 1 & 3 & I. 31 & 1 & 2,29 & 1,15 & 5 & 1 & 3 \\
\hline I. 50 & 0 & 2,24 & 1,18 & 6 & 1 & 3 & I. .50 & 0 & 2,25 & 1,21 & 6 & 1 & 3 \\
\hline I. 56 & 1 & 2,21 & 1,25 & 6 & 1 & 3 & $\begin{array}{l}\text { I.56 } \\
\text { I.9 }\end{array}$ & 1 & 2,00 & 1,05 & 5 & 1 & 3 \\
\hline I.97 & 0 & 2,00 & 1,21 & 5 & 1 & 3 & 7 & 0 & 1,96 & 1,29 & 5 & 1 & 3 \\
\hline
\end{tabular}

$$
\begin{gathered}
\text { Legenda: } \\
\text { tipo de } \\
\text { item: I = } \\
\text { Comporta } \\
\text { mental e } 0 \\
= \\
\text { Subjetivo }
\end{gathered}
$$




\section{nexo 12 - Comparação entre grupo profissionais psicossociais} e grupo de profissionais jurídicos e da segurança 
Avaliação de risco de violência contra a mulher

\begin{tabular}{|c|c|c|c|c|c|}
\hline Item & Profissionais & $\mathrm{N}$ & Média & $\begin{array}{l}\text { Desvio } \\
\text { padrão }\end{array}$ & $\begin{array}{c}\text { Erro padrão } \\
\text { da média }\end{array}$ \\
\hline \multirow{2}{*}{ I. .01} & $\begin{array}{l}\text { Jurídicos e da } \\
\text { segurança }\end{array}$ & 11 & 5,55 & 1,293 & ,390 \\
\hline & Psicossociais & 17 & 5,76 & 1,522 & ,369 \\
\hline \multirow[t]{2}{*}{ I.02 } & $\begin{array}{l}\text { Jurídicos e da } \\
\text { segurança }\end{array}$ & 11 & 5,18 & 1,168 &, 352 \\
\hline & Psicossociais & 17 & 5,47 & 2,267 &, 550 \\
\hline \multirow{2}{*}{ I.03 } & $\begin{array}{l}\text { Jurídicos e da } \\
\text { segurança }\end{array}$ & 11 & 5,82 & 1,471 & ,444 \\
\hline & Psicossociais & 17 & 5,59 & 1,064 &, 258 \\
\hline \multirow[t]{2}{*}{ I.04 } & $\begin{array}{l}\text { Jurídicos e da } \\
\text { segurança }\end{array}$ & 11 & 4,64 & 1,567 &, 472 \\
\hline & Psicossociais & 17 & 5,59 & 1,278 & ,310 \\
\hline \multirow[t]{2}{*}{ I.05 } & $\begin{array}{l}\text { Jurídicos e da } \\
\text { segurança }\end{array}$ & 11 & 3,64 & 2,063 & ,622 \\
\hline & Psicossociais & 17 & 4,53 & 2,065 &, 501 \\
\hline \multirow[t]{2}{*}{ I.06 } & $\begin{array}{l}\text { Jurídicos e da } \\
\text { segurança }\end{array}$ & 11 & 3,00 & 1,183 &, 357 \\
\hline & Psicossociais & 17 & 3,71 & 1,795 & ,435 \\
\hline \multirow[t]{2}{*}{ I.07 } & $\begin{array}{l}\text { Jurídicos e da } \\
\text { segurança }\end{array}$ & 11 & 7,64 & 1,502 &, 453 \\
\hline & Psicossociais & 17 & 6,76 & 1,348 &, 327 \\
\hline \multirow[t]{2}{*}{ I.08 } & $\begin{array}{l}\text { Jurídicos e da } \\
\text { segurança }\end{array}$ & 11 & 4,82 & 1,079 & ,325 \\
\hline & Psicossociais & 17 & 5,18 & 1,286 & ,312 \\
\hline \multirow[t]{2}{*}{ I.09 } & $\begin{array}{l}\text { Jurídicos e da } \\
\text { segurança }\end{array}$ & 11 & 3,00 & ,894 &, 270 \\
\hline & Psicossociais & 17 & 3,41 & 1,326 & ,322 \\
\hline \multirow[t]{2}{*}{ I. 10} & $\begin{array}{l}\text { Jurídicos e da } \\
\text { segurança }\end{array}$ & 11 & 5,18 & 1,079 &, 325 \\
\hline & Psicossociais & 17 & 4,29 & 1,312 & ,318 \\
\hline \multirow[t]{2}{*}{ I. 11} & $\begin{array}{l}\text { Jurídicos e da } \\
\text { segurança }\end{array}$ & 11 & 5,18 & 1,662 &, 501 \\
\hline & Psicossociais & 17 & 4,00 & 1,620 & ,393 \\
\hline \multirow[t]{2}{*}{ I. 12} & $\begin{array}{l}\text { Jurídicos e da } \\
\text { segurança }\end{array}$ & 11 & 4,82 & 1,471 &, 444 \\
\hline & Psicossociais & 17 & 4,71 & 1,490 &, 361 \\
\hline \multirow[t]{2}{*}{ I. 13} & $\begin{array}{l}\text { Jurídicos e da } \\
\text { segurança }\end{array}$ & 11 & 4,00 & 1,342 & ,405 \\
\hline & Psicossociais & 17 & 3,59 & 1,661 & ,403 \\
\hline \multirow[t]{2}{*}{ I. 14} & $\begin{array}{l}\text { Jurídicos e da } \\
\text { segurança }\end{array}$ & 11 & 5,82 & 1,662 &, 501 \\
\hline & Psicossociais & 17 & 4,88 & 1,453 &, 352 \\
\hline \multirow[t]{2}{*}{ I. 15} & $\begin{array}{l}\text { Jurídicos e da } \\
\text { segurança }\end{array}$ & 11 & 5,64 & ,924 &, 279 \\
\hline & Psicossociais & 17 & 5,00 & 1,768 & ,429 \\
\hline \multirow[t]{2}{*}{ I. 16} & $\begin{array}{l}\text { Jurídicos e da } \\
\text { segurança }\end{array}$ & 11 & 3,36 & ,924 &, 279 \\
\hline & Psicossociais & 17 & 4,06 & 1,435 & ,348 \\
\hline \multirow[t]{2}{*}{ I. 17} & $\begin{array}{l}\text { Jurídicos e da } \\
\text { segurança }\end{array}$ & 11 & 3,64 & 1,027 & ,310 \\
\hline & Psicossociais & 17 & 3,06 & 1,197 & ,290 \\
\hline I. 18 & $\begin{array}{l}\text { Jurídicos e da } \\
\text { segurança }\end{array}$ & 11 & 3,91 &, 831 &, 251 \\
\hline
\end{tabular}


Avaliação de risco de violência contra a mulher

\begin{tabular}{|c|c|c|c|c|c|}
\hline & Psicossociais & 17 & 4,12 & 1,576 & ,382 \\
\hline \multirow[t]{2}{*}{ I. 19} & $\begin{array}{l}\text { Jurídicos e da } \\
\text { segurança }\end{array}$ & 11 & 3,36 & 1,120 & ,338 \\
\hline & Psicossociais & 17 & 3,24 & 1,091 & ,265 \\
\hline \multirow[t]{2}{*}{ I. 20} & $\begin{array}{l}\text { Jurídicos e da } \\
\text { segurança }\end{array}$ & 11 & 2,82 & 1,779 &, 536 \\
\hline & Psicossociais & 17 & 3,06 & 1,560 & ,378 \\
\hline \multirow{2}{*}{ I. 21} & $\begin{array}{l}\text { Jurídicos e da } \\
\text { segurança }\end{array}$ & 11 & 4,55 & 1,809 &, 545 \\
\hline & Psicossociais & 17 & 5,06 & ,966 & ,234 \\
\hline \multirow[t]{2}{*}{ I. 22} & $\begin{array}{l}\text { Jurídicos e da } \\
\text { segurança }\end{array}$ & 11 & 5,91 & 1,300 & ,392 \\
\hline & Psicossociais & 17 & 5,59 & 1,543 & ,374 \\
\hline \multirow[t]{2}{*}{$\mathrm{I} .23$} & $\begin{array}{l}\text { Jurídicos e da } \\
\text { segurança }\end{array}$ & 11 & 5,82 & 1,328 & ,400 \\
\hline & Psicossociais & 17 & 5,47 & 1,700 & ,412 \\
\hline \multirow[t]{2}{*}{ I. 24} & $\begin{array}{l}\text { Jurídicos e da } \\
\text { segurança }\end{array}$ & 11 & 5,00 & 1,483 & ,447 \\
\hline & Psicossociais & 17 & 4,65 & 1,367 & ,331 \\
\hline \multirow{2}{*}{ I. 25} & $\begin{array}{l}\text { Jurídicos e da } \\
\text { segurança }\end{array}$ & 11 & 4,45 & 1,036 & ,312 \\
\hline & Psicossociais & 17 & 4,24 & 1,300 & ,315 \\
\hline \multirow{2}{*}{ I. 26} & $\begin{array}{l}\text { Jurídicos e da } \\
\text { segurança }\end{array}$ & 11 & 6,45 & 1,809 &, 545 \\
\hline & Psicossociais & 17 & 6,06 & 1,144 & ,277 \\
\hline \multirow[t]{2}{*}{$\mathrm{I} .27$} & $\begin{array}{l}\text { Jurídicos e da } \\
\text { segurança }\end{array}$ & 11 & 6,91 & 1,640 & ,495 \\
\hline & Psicossociais & 17 & 6,88 & 1,269 & ,308 \\
\hline \multirow[t]{2}{*}{$\mathrm{I} .28$} & $\begin{array}{l}\text { Jurídicos e da } \\
\text { segurança }\end{array}$ & 11 & 6,00 & 2,324 & ,701 \\
\hline & Psicossociais & 17 & 6,12 & 1,219 & ,296 \\
\hline \multirow[t]{2}{*}{ I. 29} & $\begin{array}{l}\text { Jurídicos e da } \\
\text { segurança }\end{array}$ & 11 & 2,00 & 1,265 & \\
\hline & Psicossociais & 17 & 2,47 & 2,004 & ,486 \\
\hline \multirow[t]{2}{*}{ I. 30} & $\begin{array}{l}\text { Jurídicos e da } \\
\text { segurança }\end{array}$ & 11 & 4,45 & 1,368 & ,413 \\
\hline & Psicossociais & 17 & 5,06 & 1,560 & ,378 \\
\hline \multirow{2}{*}{ I. 31} & $\begin{array}{l}\text { Jurídicos e da } \\
\text { segurança }\end{array}$ & 11 & 2,55 & 1,508 & ,455 \\
\hline & Psicossociais & 17 & 2,12 & ,857 & ,208 \\
\hline \multirow{2}{*}{ I. 32} & $\begin{array}{l}\text { Jurídicos e da } \\
\text { segurança }\end{array}$ & 11 & 4,00 & 1,549 & ,467 \\
\hline & Psicossociais & 17 & 4,47 & 1,231 & ,298 \\
\hline \multirow[t]{2}{*}{$\mathrm{I} .33$} & $\begin{array}{l}\text { Jurídicos e da } \\
\text { segurança }\end{array}$ & 11 & 2,45 & 1,128 & \\
\hline & Psicossociais & 17 & 2,47 & 1,463 & ,355 \\
\hline \multirow[t]{2}{*}{ I. 34} & $\begin{array}{l}\text { Jurídicos e da } \\
\text { segurança }\end{array}$ & 11 & 4,91 & 1,758 & \\
\hline & Psicossociais & 17 & 5,12 & 2,288 &, 555 \\
\hline \multirow[t]{2}{*}{$\mathrm{I} .35$} & $\begin{array}{l}\text { Jurídicos e da } \\
\text { segurança }\end{array}$ & 11 & 6,45 & 1,293 & \\
\hline & Psicossociais & 17 & 7,47 & 1,505 &, 365 \\
\hline \multirow[t]{2}{*}{ I. 36} & $\begin{array}{l}\text { Jurídicos e da } \\
\text { segurança }\end{array}$ & 11 & 4,45 & 1,635 & \\
\hline & Psicossociais & 17 & 3,88 & 1,269 & \\
\hline
\end{tabular}


Avaliação de risco de violência contra a mulher

\begin{tabular}{|c|c|c|c|c|c|}
\hline \multirow[t]{2}{*}{ I. 37} & $\begin{array}{l}\text { Jurídicos e da } \\
\text { segurança }\end{array}$ & 11 & 3,82 & 1,168 & ,352 \\
\hline & Psicossociais & 17 & 3,29 & 1,448 & ,351 \\
\hline \multirow[t]{2}{*}{ I. 38} & $\begin{array}{l}\text { Jurídicos e da } \\
\text { segurança }\end{array}$ & 11 & 5,36 & 2,111 & ,636 \\
\hline & Psicossociais & 17 & 4,65 & 1,618 & ,392 \\
\hline \multirow[t]{2}{*}{ I. 39} & $\begin{array}{l}\text { Jurídicos e da } \\
\text { segurança }\end{array}$ & 11 & 3,73 & 1,489 & ,449 \\
\hline & Psicossociais & 17 & 3,76 & 1,033 &, 250 \\
\hline \multirow[t]{2}{*}{ I. 40} & $\begin{array}{l}\text { Jurídicos e da } \\
\text { segurança }\end{array}$ & 11 & 4,64 & 1,502 & ,453 \\
\hline & Psicossociais & 17 & 4,06 & 1,435 & ,348 \\
\hline \multirow{2}{*}{ I. 41} & $\begin{array}{l}\text { Jurídicos e da } \\
\text { segurança }\end{array}$ & 11 & 5,09 & 2,166 & ,653 \\
\hline & Psicossociais & 17 & 4,12 & 1,900 & ,461 \\
\hline \multirow[t]{2}{*}{ I. 42} & $\begin{array}{l}\text { Jurídicos e da } \\
\text { segurança }\end{array}$ & 11 & 4,73 & 1,489 & ,449 \\
\hline & Psicossociais & 17 & 4,24 & 1,602 & ,389 \\
\hline \multirow[t]{2}{*}{ I.43 } & $\begin{array}{l}\text { Jurídicos e da } \\
\text { segurança }\end{array}$ & 11 & 4,91 & 1,973 & ,595 \\
\hline & Psicossociais & 17 & 3,59 & 1,176 & ,285 \\
\hline \multirow[t]{2}{*}{ I. 44} & $\begin{array}{l}\text { Jurídicos e da } \\
\text { segurança }\end{array}$ & 11 & 4,27 & 1,902 &, 574 \\
\hline & Psicossociais & 17 & 4,06 & 1,478 & ,358 \\
\hline \multirow{2}{*}{ I. 45} & $\begin{array}{l}\text { Jurídicos e da } \\
\text { segurança }\end{array}$ & 11 & 4,73 & 2,102 & ,634 \\
\hline & Psicossociais & 17 & 5,94 & 2,304 & ,559 \\
\hline \multirow{2}{*}{ I.46 } & $\begin{array}{l}\text { Jurídicos e da } \\
\text { segurança }\end{array}$ & 11 & 4,55 & 1,809 &, 545 \\
\hline & Psicossociais & 17 & 5,35 & 1,801 & ,437 \\
\hline \multirow[t]{2}{*}{ I. 47} & $\begin{array}{l}\text { Jurídicos e da } \\
\text { segurança }\end{array}$ & 11 & 2,91 & 1,375 &, 415 \\
\hline & Psicossociais & 17 & 2,65 & 1,498 & ,363 \\
\hline \multirow[t]{2}{*}{ I. 48} & $\begin{array}{l}\text { Jurídicos e da } \\
\text { segurança }\end{array}$ & 11 & 2,18 & 1,168 & ,352 \\
\hline & Psicossociais & 17 & 2,53 & 1,281 & ,311 \\
\hline \multirow[t]{2}{*}{ I. 49} & $\begin{array}{l}\text { Jurídicos e da } \\
\text { segurança }\end{array}$ & 11 & 2,64 & 1,362 & ,411 \\
\hline & Psicossociais & 17 & 3,41 & 1,502 & ,364 \\
\hline \multirow[t]{2}{*}{ I. 50} & $\begin{array}{l}\text { Jurídicos e da } \\
\text { segurança }\end{array}$ & 11 & 2,27 & 1,104 & ,333 \\
\hline & Psicossociais & 17 & 2,24 & 1,300 & ,315 \\
\hline \multirow[t]{2}{*}{ I. 51} & $\begin{array}{l}\text { Jurídicos e da } \\
\text { segurança }\end{array}$ & 11 & 4,73 & 1,348 & ,407 \\
\hline & Psicossociais & 17 & 4,41 & 1,543 & ,374 \\
\hline \multirow[t]{2}{*}{ I. 52} & $\begin{array}{l}\text { Jurídicos e da } \\
\text { segurança }\end{array}$ & 11 & 4,27 & 1,272 & ,384 \\
\hline & Psicossociais & 17 & 4,18 & 1,741 & ,422 \\
\hline \multirow[t]{2}{*}{ I. 53} & $\begin{array}{l}\text { Jurídicos e da } \\
\text { segurança }\end{array}$ & 11 & 4,91 & 1,136 & ,343 \\
\hline & Psicossociais & 17 & 4,59 & 1,583 & ,384 \\
\hline \multirow[t]{2}{*}{ I. 54} & $\begin{array}{l}\text { Jurídicos e da } \\
\text { segurança }\end{array}$ & 11 & 3,55 & 1,368 & ,413 \\
\hline & Psicossociais & 17 & 3,29 & 1,572 & ,381 \\
\hline I. 55 & Jurídicos e da & 11 & 3,27 & 2,102 & ,634 \\
\hline
\end{tabular}


Avaliação de risco de violência contra a mulher

\begin{tabular}{|c|c|c|c|c|c|}
\hline \multicolumn{6}{|c|}{ segurança } \\
\hline & Psicossociais & 17 & 3,00 & 1,500 & ,364 \\
\hline \multirow{2}{*}{ I.56 } & $\begin{array}{l}\text { Jurídicos e da } \\
\text { segurança }\end{array}$ & 11 & 2,09 & 1,300 & ,392 \\
\hline & Psicossociais & 17 & 1,94 & ,899 & ,218 \\
\hline \multirow[t]{2}{*}{ I. 57} & $\begin{array}{l}\text { Jurídicos e da } \\
\text { segurança }\end{array}$ & 11 & 6,55 & 1,368 & ,413 \\
\hline & Psicossociais & 17 & 5,47 & 1,419 &, 344 \\
\hline \multirow[t]{2}{*}{ I. .58} & $\begin{array}{l}\text { Jurídicos e da } \\
\text { segurança }\end{array}$ & 11 & 5,00 & 1,000 & ,302 \\
\hline & Psicossociais & 17 & 5,06 & ,966 & ,234 \\
\hline \multirow[t]{2}{*}{ I.59 } & $\begin{array}{l}\text { Jurídicos e da } \\
\text { segurança }\end{array}$ & 11 & 5,64 &, 809 & ,244 \\
\hline & Psicossociais & 17 & 5,18 & 1,286 &, 312 \\
\hline \multirow{2}{*}{ I.60 } & $\begin{array}{l}\text { Jurídicos e da } \\
\text { segurança }\end{array}$ & 11 & 4,45 & 1,214 &, 366 \\
\hline & Psicossociais & 17 & 4,76 & 1,786 & ,433 \\
\hline \multirow{2}{*}{ I.61 } & $\begin{array}{l}\text { Jurídicos e da } \\
\text { segurança }\end{array}$ & 11 & 5,55 & 2,018 & ,608 \\
\hline & Psicossociais & 17 & 5,53 & 1,419 &, 344 \\
\hline \multirow{2}{*}{ I.62 } & $\begin{array}{l}\text { Jurídicos e da } \\
\text { segurança }\end{array}$ & 11 & 7,36 & 1,433 & ,432 \\
\hline & Psicossociais & 17 & 6,41 & 1,417 &, 344 \\
\hline \multirow[t]{2}{*}{ I.63 } & $\begin{array}{l}\text { Jurídicos e da } \\
\text { segurança }\end{array}$ & 11 & 6,36 & 1,120 & ,338 \\
\hline & Psicossociais & 17 & 6,76 & 1,602 & ,389 \\
\hline \multirow{2}{*}{ I. 64} & $\begin{array}{l}\text { Jurídicos e da } \\
\text { segurança }\end{array}$ & 11 & 5,64 & 1,206 &, 364 \\
\hline & Psicossociais & 17 & 6,88 & 1,764 & ,428 \\
\hline \multirow[t]{2}{*}{ I.65 } & $\begin{array}{l}\text { Jurídicos e da } \\
\text { segurança }\end{array}$ & 11 & 4,45 & 1,214 & ,366 \\
\hline & Psicossociais & 17 & 5,24 & 1,678 & ,407 \\
\hline \multirow{2}{*}{ I.66 } & $\begin{array}{l}\text { Jurídicos e da } \\
\text { segurança }\end{array}$ & 11 & 4,64 & 1,362 & ,411 \\
\hline & Psicossociais & 17 & 4,41 & 1,661 & ,403 \\
\hline \multirow{2}{*}{ I.67 } & $\begin{array}{l}\text { Jurídicos e da } \\
\text { segurança }\end{array}$ & 11 & 5,64 & 1,120 & ,338 \\
\hline & Psicossociais & 17 & 6,12 & 1,833 & ,445 \\
\hline \multirow[t]{2}{*}{ I.68 } & $\begin{array}{l}\text { Jurídicos e da } \\
\text { segurança }\end{array}$ & 11 & 8,00 & 1,095 &, 330 \\
\hline & Psicossociais & 17 & 7,59 & 1,372 &, 333 \\
\hline \multirow[t]{2}{*}{ I.69 } & $\begin{array}{l}\text { Jurídicos e da } \\
\text { segurança }\end{array}$ & 11 & 8,45 & ,934 & ,282 \\
\hline & Psicossociais & 17 & 7,71 & 1,532 & ,371 \\
\hline \multirow[t]{2}{*}{ I.70 } & $\begin{array}{l}\text { Jurídicos e da } \\
\text { segurança }\end{array}$ & 11 & 6,73 & 2,054 & ,619 \\
\hline & Psicossociais & 17 & 5,82 & 1,667 & ,404 \\
\hline \multirow[t]{2}{*}{ I. 71} & $\begin{array}{l}\text { Jurídicos e da } \\
\text { segurança }\end{array}$ & 11 & 5,18 & 1,168 &, 352 \\
\hline & Psicossociais & 17 & 4,76 & 1,821 & ,442 \\
\hline \multirow[t]{2}{*}{ I.72 } & $\begin{array}{l}\text { Jurídicos e da } \\
\text { segurança }\end{array}$ & 11 & 6,82 & 2,272 & ,685 \\
\hline & Psicossociais & 17 & 7,00 & 1,323 &, 321 \\
\hline I.73 & $\begin{array}{l}\text { Jurídicos e da } \\
\text { segurança }\end{array}$ & 11 & 3,09 & 1,300 & ,392 \\
\hline
\end{tabular}


Avaliação de risco de violência contra a mulher

\begin{tabular}{|c|c|c|c|c|c|}
\hline & Psicossociais & 17 & 3,53 & 1,625 & ,394 \\
\hline \multirow[t]{2}{*}{$\mathrm{I} .74$} & $\begin{array}{l}\text { Jurídicos e da } \\
\text { segurança }\end{array}$ & 11 & 5,55 & ,934 & ,282 \\
\hline & Psicossociais & 17 & 5,00 & 1,225 & ,297 \\
\hline \multirow[t]{2}{*}{ I.75 } & $\begin{array}{l}\text { Jurídicos e da } \\
\text { segurança }\end{array}$ & 11 & 6,64 & 1,206 & ,364 \\
\hline & Psicossociais & 17 & 6,35 & 1,766 & ,428 \\
\hline \multirow{2}{*}{ I.76 } & $\begin{array}{l}\text { Jurídicos e da } \\
\text { segurança }\end{array}$ & 11 & 7,55 & 2,067 & ,623 \\
\hline & Psicossociais & 17 & 7,59 & 1,278 & ,310 \\
\hline \multirow[t]{2}{*}{ I.77 } & $\begin{array}{l}\text { Jurídicos e da } \\
\text { segurança }\end{array}$ & 11 & 6,27 & 2,149 & ,648 \\
\hline & Psicossociais & 17 & 7,18 & 1,334 & ,324 \\
\hline \multirow[t]{2}{*}{ I. 78} & $\begin{array}{l}\text { Jurídicos e da } \\
\text { segurança }\end{array}$ & 11 & 7,36 & 1,629 & ,491 \\
\hline & Psicossociais & 17 & 7,71 & 1,490 & ,361 \\
\hline \multirow[t]{2}{*}{ I. 79} & $\begin{array}{l}\text { Jurídicos e da } \\
\text { segurança }\end{array}$ & 11 & 7,91 &, 831 &, 251 \\
\hline & Psicossociais & 17 & 7,94 & ,899 & ,218 \\
\hline \multirow[t]{2}{*}{ I. 80} & $\begin{array}{l}\text { Jurídicos e da } \\
\text { segurança }\end{array}$ & 11 & 8,36 & 1,027 & ,310 \\
\hline & Psicossociais & 17 & 8,18 & 1,015 & ,246 \\
\hline \multirow{2}{*}{ I. 81} & $\begin{array}{l}\text { Jurídicos e da } \\
\text { segurança }\end{array}$ & 11 & 6,27 & 2,533 & ,764 \\
\hline & Psicossociais & 17 & 6,00 & 1,658 & ,402 \\
\hline \multirow[t]{2}{*}{ I. 82} & $\begin{array}{l}\text { Jurídicos e da } \\
\text { segurança }\end{array}$ & 11 & 6,36 & 1,027 & ,310 \\
\hline & Psicossociais & 17 & 6,82 & 1,074 & ,261 \\
\hline \multirow[t]{2}{*}{ I. 83} & $\begin{array}{l}\text { Jurídicos e da } \\
\text { segurança }\end{array}$ & 11 & 7,00 & 1,183 & ,357 \\
\hline & Psicossociais & 17 & 6,47 &, 874 & ,212 \\
\hline \multirow[t]{2}{*}{ I. 84} & $\begin{array}{l}\text { Jurídicos e da } \\
\text { segurança }\end{array}$ & 11 & 5,91 & 1,044 & ,315 \\
\hline & Psicossociais & 17 & 5,00 & 1,369 & ,332 \\
\hline \multirow[t]{2}{*}{ I. 85} & $\begin{array}{l}\text { Jurídicos e da } \\
\text { segurança }\end{array}$ & 11 & 6,09 & 1,375 & ,415 \\
\hline & Psicossociais & 17 & 6,18 & 1,185 & ,287 \\
\hline \multirow[t]{2}{*}{ I.86 } & $\begin{array}{l}\text { Jurídicos e da } \\
\text { segurança }\end{array}$ & 11 & 5,45 & 1,440 & ,434 \\
\hline & Psicossociais & 17 & 6,18 & 1,510 & ,366 \\
\hline \multirow{2}{*}{ I. 87} & $\begin{array}{l}\text { Jurídicos e da } \\
\text { segurança }\end{array}$ & 11 & 2,55 &, 820 &, 247 \\
\hline & Psicossociais & 17 & 3,00 & 1,658 & ,402 \\
\hline \multirow[t]{2}{*}{ I. 88} & $\begin{array}{l}\text { Jurídicos e da } \\
\text { segurança }\end{array}$ & 11 & 6,73 & 1,555 & ,4 \\
\hline & Psicossociais & 17 & 7,00 & 1,118 & ,271 \\
\hline \multirow[t]{2}{*}{ I. 89} & $\begin{array}{l}\text { Jurídicos e da } \\
\text { segurança }\end{array}$ & 11 & 6,27 & 1,104 & \\
\hline & Psicossociais & 17 & 6,06 & 1,435 & ,348 \\
\hline \multirow[t]{2}{*}{ I.90 } & $\begin{array}{l}\text { Jurídicos e da } \\
\text { segurança }\end{array}$ & 11 & 5,00 & 1,483 & \\
\hline & Psicossociais & 17 & 5,00 & 2,031 & ,493 \\
\hline \multirow[t]{2}{*}{ I.91 } & $\begin{array}{l}\text { Jurídicos e da } \\
\text { segurança }\end{array}$ & 11 & 5,82 & 1,079 & \\
\hline & Psicossociais & 17 & 6,12 & 1,219 & \\
\hline
\end{tabular}


Avaliação de risco de violência contra a mulher

\begin{tabular}{|c|c|c|c|c|c|}
\hline \multirow[t]{2}{*}{ I.92 } & $\begin{array}{l}\text { Jurídicos e da } \\
\text { segurança }\end{array}$ & 11 & 5,09 & 1,375 & ,415 \\
\hline & Psicossociais & 17 & 5,59 & 1,970 & ,478 \\
\hline \multirow{2}{*}{ I.93 } & $\begin{array}{l}\text { Jurídicos e da } \\
\text { segurança }\end{array}$ & 11 & 5,82 & 1,722 & ,519 \\
\hline & Psicossociais & 17 & 6,59 & 1,417 & ,344 \\
\hline \multirow{2}{*}{ I.94 } & $\begin{array}{l}\text { Jurídicos e da } \\
\text { segurança }\end{array}$ & 11 & 6,27 & 2,195 & ,662 \\
\hline & Psicossociais & 17 & 7,00 & 1,620 & ,393 \\
\hline \multirow[t]{2}{*}{ I.95 } & $\begin{array}{l}\text { Jurídicos e da } \\
\text { segurança }\end{array}$ & 11 & 6,18 & 1,250 & ,377 \\
\hline & Psicossociais & 17 & 6,29 & 1,404 &, 340 \\
\hline \multirow[t]{2}{*}{ I.96 } & $\begin{array}{l}\text { Jurídicos e da } \\
\text { segurança }\end{array}$ & 11 & 4,09 & 2,468 &, 744 \\
\hline & Psicossociais & 17 & 4,35 & 1,498 & ,363 \\
\hline \multirow[t]{2}{*}{ I.97 } & $\begin{array}{l}\text { Jurídicos e da } \\
\text { segurança }\end{array}$ & 11 & 1,73 & 1,421 & ,428 \\
\hline & Psicossociais & 17 & 2,12 & 1,219 & ,296 \\
\hline \multirow[t]{2}{*}{ I.98 } & $\begin{array}{l}\text { Jurídicos e da } \\
\text { segurança }\end{array}$ & 11 & 3,73 & 1,348 & ,407 \\
\hline & Psicossociais & 17 & 4,88 & 1,799 & ,436 \\
\hline \multirow[t]{2}{*}{ I.99 } & $\begin{array}{l}\text { Jurídicos e da } \\
\text { segurança }\end{array}$ & 11 & 4,45 & 1,036 & ,312 \\
\hline & Psicossociais & 17 & 4,59 & 1,372 & ,333 \\
\hline \multirow[t]{2}{*}{ I. 100} & $\begin{array}{l}\text { Jurídicos e da } \\
\text { segurança }\end{array}$ & 11 & 4,09 &, 831 &, 251 \\
\hline & Psicossociais & 17 & 3,76 & 1,678 & ,407 \\
\hline
\end{tabular}


Teste de amostras independentes

\begin{tabular}{|c|c|c|c|c|c|c|c|c|c|c|}
\hline & $\begin{array}{l}\text { Teste de Levene para igualdade de } \\
\text { variações }\end{array}$ & & & & & \multicolumn{2}{|c|}{ teste t para Igualdade de Médias } & & & \\
\hline & \multirow[t]{2}{*}{ F } & \multirow[t]{2}{*}{ Sig. } & \multirow[t]{2}{*}{$\mathrm{t}$} & \multirow[t]{2}{*}{ df } & \multirow[t]{2}{*}{$\begin{array}{c}\text { Sig. (2 } \\
\text { extremidades) }\end{array}$} & \multirow[t]{2}{*}{$\begin{array}{l}\text { Diferença } \\
\text { média }\end{array}$} & \multirow{2}{*}{$\begin{array}{l}\text { Erro padrão de } \\
\text { diferença }\end{array}$} & \multicolumn{3}{|c|}{$\begin{array}{l}\text { 95\% Intervalo de confiança da } \\
\text { diferença }\end{array}$} \\
\hline & & & & & & & & Inferior & & \\
\hline \multirow{2}{*}{ I.01 } & Variações iguais assumidas &, 326 &, 573 &,- 394 & 26 & 697 &,- 219 &, 557 & $-1,363$ & ,925 \\
\hline & Variações iguais não assumidas & & &,- 408 & 23,937 & 687 &,- 219 & ,537 & $-1,328$ & 889 \\
\hline \multirow{2}{*}{ I.02 } & Variações iguais assumidas & 3,252 & ,083 &,- 389 & 26 & ,701 &,- 289 & ,743 & $-1,816$ & $1,23 \mathrm{c}$ \\
\hline & Variações iguais não assumidas & & &,- 442 & 25,068 & ,662 &,- 289 & ,653 & $-1,633$ & $1,05 t$ \\
\hline \multirow{2}{*}{ I.03 } & Variações iguais assumidas & 1,180 & ,287 &, 481 & 26 & ,635 &, 230 & ,478 &,- 754 & 1,213 \\
\hline & Variações iguais não assumidas & & & ,448 & 16,721 & 660 & 230 & ,513 &,- 854 & 1,314 \\
\hline \multirow{2}{*}{ I.04 } & Variações iguais assumidas & 1,543 & ,225 & $1, \overline{762}$ & 26 & ,090 &,- 952 &, 540 & $-2,062$ &, 158 \\
\hline & Variações iguais não assumidas & & & $\begin{array}{c}- \\
1,685\end{array}$ & 18,336 &, 109 &,- 952 &, 565 & $-2,137$ & ,233 \\
\hline \multirow{2}{*}{ I.05 } & Variações iguais assumidas & ,041 &, 842 & $\begin{array}{c}- \\
1,118\end{array}$ & 26 &, 274 &,- 893 &, 799 & $-2,535$ & ,749 \\
\hline & Variações iguais não assumidas & & & $1, \overline{118}$ & 21,521 & ,276 &,- 893 &, 799 & $-2,551$ &, 765 \\
\hline \multirow{2}{*}{ I.06 } & Variações iguais assumidas & 3,094 & ,090 & $\overline{-}, 149$ & 26 &, 261 &,- 706 & ,614 & $-1,969$ &, 557 \\
\hline & Variações iguais não assumidas & & & $\overline{-}, 254$ & 25,967 &, 221 &,- 706 &, 563 & $-1,863$ & 451 \\
\hline \multirow{2}{*}{ I.07 } & Variações iguais assumidas & ,091 &, 766 & 1,599 & 26 &, 122 &, 872 &, 545 &,- 249 & 1,992 \\
\hline & Variações iguais não assumidas & & & 1,561 & 19,783 & ,134 & ,872 & ,558 &,- 294 & 2,037 \\
\hline
\end{tabular}


Variações iguais assumidas

Variações iguais não assumidas

Variações iguais assumidas

14

Variações iguais não assumidas

Variações iguais assumidas

15

Variações iguais não assumidas

Variações iguais assumidas

$\stackrel{ }{\bullet}$

16

Variações iguais não assumidas

17

Variações iguais assumidas

Variações iguais não assumidas

,564 , 460 $\quad 26$

24,565

$, 328 \quad, 572 \quad 1,574$

1,527

26

19,368

$4,026 \quad 055 \quad 1,096$

26

25,184

,699 ,411 $\quad$ 1,422

1,559

682 417 $\quad 1,315$

1,360

$$
\text { ,336 }
$$

, 063 
I.18 Variações iguais assumidas

Variações iguais não assumidas

Variações iguais assumidas

I.19 Variações iguais não assumidas

Variações iguais assumidas

I. 20

Variações iguais não assumidas

Variações iguais assumidas

I.21 Variações iguais não assumidas

Variações iguais assumidas

I.22

Variações iguais não assumidas

Variações iguais assumidas

I. 23

Variações iguais não assumidas

Variações iguais assumidas

I.24

Variações iguais não assumidas

Variações iguais assumidas

I. 25

Variações iguais não assumidas

N $\quad$ I.26 Variações iguais assumidas

Variações iguais não assumidas

I.27

Variações iguais assumidas

Variações iguais não assumidas

\begin{tabular}{|c|c|c|c|}
\hline \multirow[t]{2}{*}{13,025} & ,001 &,- 402 & 26 \\
\hline & &,- 456 & 25,246 \\
\hline \multirow[t]{2}{*}{,051 } & ,823 & ,301 & 26 \\
\hline & & ,299 & 21,087 \\
\hline \multirow[t]{2}{*}{,433 } & ,517 &,- 377 & 26 \\
\hline & &,- 367 & 19,425 \\
\hline \multirow{2}{*}{5,549} & ,026 &,- 980 & 26 \\
\hline & &,- 865 & 13,741 \\
\hline \multirow[t]{2}{*}{,325 } &, 574 & ,570 & 26 \\
\hline & & ,592 & 24,051 \\
\hline \multirow[t]{2}{*}{,386 } & ,540 & ,573 & 26 \\
\hline & & 605 & 24,930 \\
\hline \multirow[t]{2}{*}{, 314} & ,580 & ,646 & 26 \\
\hline & & ,634 & 20,195 \\
\hline \multirow[t]{2}{*}{,321 } & ,576 & ,470 & 26 \\
\hline & & ,494 & 24,726 \\
\hline \multirow[t]{2}{*}{4,224} &, 050 & ,712 & 26 \\
\hline & & ,647 & 15,209 \\
\hline \multirow[t]{2}{*}{,578 } & ,454 & ,049 & 26 \\
\hline & &, 046 & 17,595 \\
\hline
\end{tabular}

,- 209
,- 209
, 128
, 128
,- 241
,- 241
,- 513
,- 513
, 321
, 321
, 348
, 348
, 353
, 353
, 219
, 219
, 396
, 396
, 027
, 027

\begin{tabular}{|c|c|c|}
\hline ,518 & $-1,274$ & ,857 \\
\hline ,457 & $-1,150$ & ,733 \\
\hline ,427 &,- 749 & 1,005 \\
\hline ,429 &,- 764 & 1,020 \\
\hline ,638 & $-1,551$ & 1,070 \\
\hline ,656 & $-1,612$ & 1,131 \\
\hline, 524 & $-1,590$ &, 564 \\
\hline, 594 & $-1,789$ & ,762 \\
\hline ,563 &,- 836 & 1,478 \\
\hline, 542 &,- 798 & 1,440 \\
\hline ,606 &,- 899 & 1,594 \\
\hline
\end{tabular}




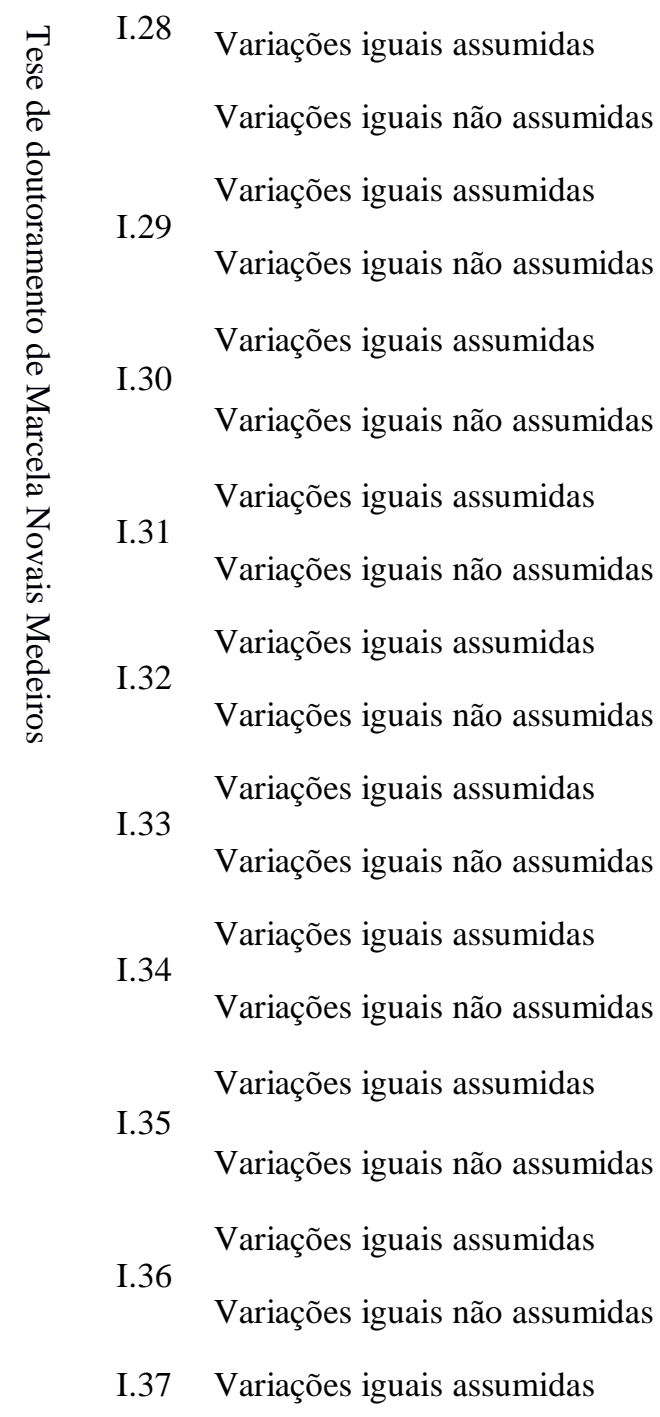

\begin{tabular}{|c|c|c|c|}
\hline \multirow[t]{2}{*}{2,424} & ,132 &,- 176 & 26 \\
\hline & &,- 155 & 13,607 \\
\hline \multirow[t]{2}{*}{2,356} & ,137 &,- 692 & 26 \\
\hline & &,- 762 & 25,999 \\
\hline \multirow[t]{2}{*}{,355 } & ,557 & 1,049 & 26 \\
\hline & & 1,079 & 23,503 \\
\hline \multirow[t]{2}{*}{5,903} & ,022 & ,960 & 26 \\
\hline & & ,856 & 14,235 \\
\hline \multirow[t]{2}{*}{, 852} & ,364 &,- 893 & 26 \\
\hline & &,- 849 & 17,963 \\
\hline \multirow[t]{2}{*}{1,454} & ,239 &,- 031 & 26 \\
\hline & &,- 033 & 25,058 \\
\hline \multirow[t]{2}{*}{3,783} & ,063 &,- 257 & 26 \\
\hline & &,- 272 & 25,093 \\
\hline \multirow[t]{2}{*}{,575 } & ,455 & $1, \overline{8} 40$ & 26 \\
\hline & & $\overline{-}$ & 23,786 \\
\hline \multirow[t]{2}{*}{,221 } & ,642 & 1,041 & 26 \\
\hline & & ,985 & 17,641 \\
\hline ,713 & ,406 & 1,006 & 26 \\
\hline
\end{tabular}

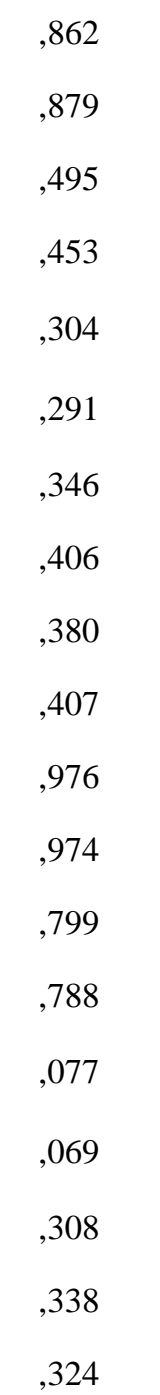

$\begin{array}{r}-, 118 \\ -, 118 \\ -, 471 \\ -, 471 \\ -, 604 \\ -, 604 \\ , 428 \\ , 428 \\ -, 471 \\ -, 471 \\ -, 016 \\ -, 016 \\ -, 209 \\ -, 209 \\ -1,016 \\ -1,016 \\ , 572 \\ , 524 \\ \hline, 02 \\ \hline, 46 \\ \hline\end{array}$

\begin{tabular}{|c|c|c|}
\hline ,669 & $-1,493$ & 1,258 \\
\hline ,760 & $-1,753$ & 1,518 \\
\hline ,680 & $-1,868$ & ,927 \\
\hline ,618 & $-1,740$ & ,799 \\
\hline ,576 & $-1,789$ &, 580 \\
\hline ,560 & $-1,761$ &, 552 \\
\hline ,446 &,- 488 & 1,344 \\
\hline, 500 &,- 643 & 1,498 \\
\hline, 527 & $-1,554$ & 613 \\
\hline ,554 & $-1,635$ & 694 \\
\hline ,520 & $-1,085$ & 1,053 \\
\hline ,491 & $-1,028$ & ,996 \\
\hline ,813 & $-1,879$ & 1,462 \\
\hline ,767 & $-1,789$ & 1,372 \\
\hline, 552 & $-2,151$ & ,119 \\
\hline ,534 & $-2,119$ & ,087 \\
\hline ,550 &,- 558 & 1,702 \\
\hline ,581 &,- 650 & 1,795 \\
\hline ,521 &,- 547 & 1,595 \\
\hline
\end{tabular}




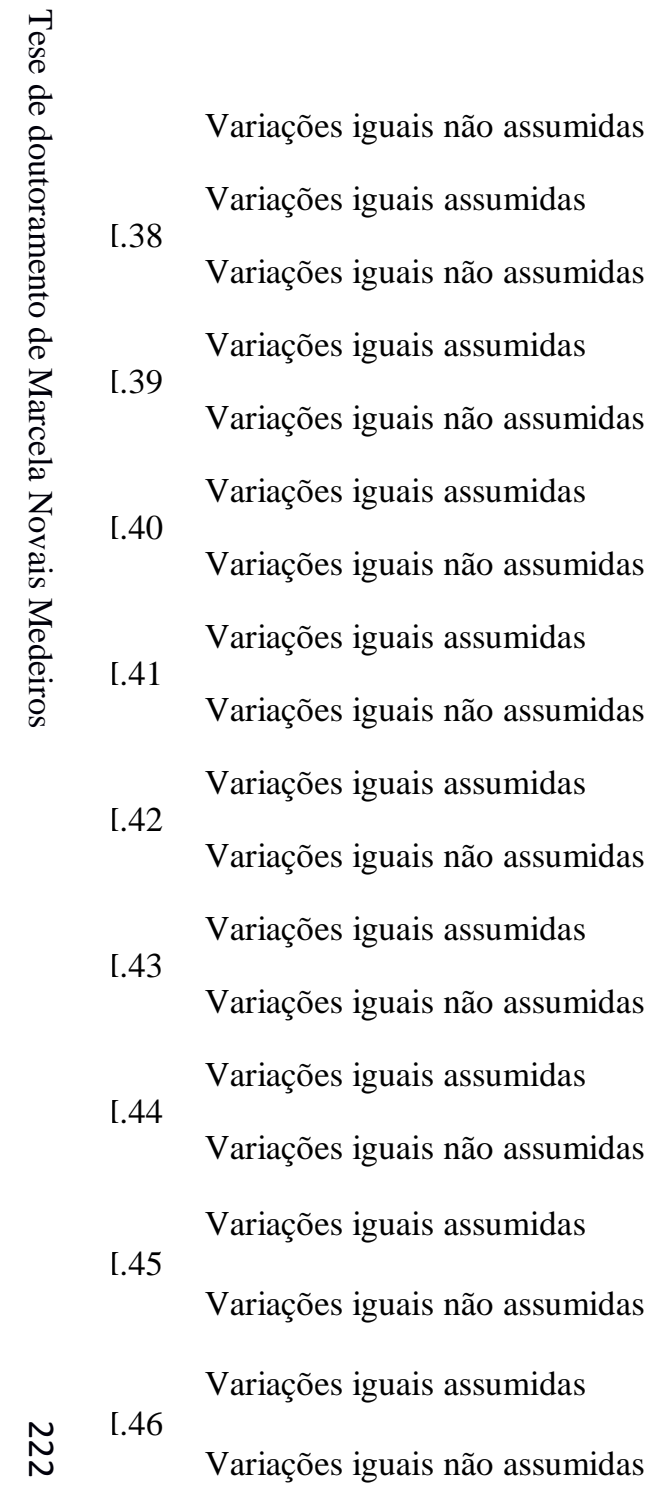

\begin{tabular}{|c|c|c|c|c|c|}
\hline & & 1,054 & 24,583 & ,302 &, 524 \\
\hline \multirow[t]{2}{*}{1,442} & ,241 & 1,016 & 26 & ,319 & ,717 \\
\hline & & ,958 & 17,472 & ,351 & ,717 \\
\hline \multirow[t]{2}{*}{2,094} & , 160 &,- 079 & 26 & ,938 &,- 037 \\
\hline & &,- 073 & 16,208 & ,943 &,- 037 \\
\hline \multirow[t]{2}{*}{,029 } & 865 & 1,022 & 26 & ,316 &, 578 \\
\hline & & 1,011 & 20,776 &, 323 &, 578 \\
\hline \multirow[t]{2}{*}{,194 } & 663 & 1,254 & 26 & ,221 & ,973 \\
\hline & & 1,218 & 19,429 & ,238 & ,973 \\
\hline \multirow[t]{2}{*}{,049 } & ,827 &, 815 & 26 & ,422 & 492 \\
\hline & & 829 & 22,644 & ,416 & ,492 \\
\hline \multirow[t]{2}{*}{3,679} & ,066 & 2,228 & 26 & ,035 & 1,321 \\
\hline & & 2,003 & 14,643 & ,064 & 1,321 \\
\hline \multirow[t]{2}{*}{,973 } & ,333 & ,334 & 26 & ,741 & ,214 \\
\hline & & ,316 & 17,653 & ,755 &, 214 \\
\hline \multirow[t]{2}{*}{, 148 } & ,704 & $\overline{-}$ & 26 & ,171 & $-1,214$ \\
\hline & & $1, \overline{437}$ & 22,931 & ,164 & $-1,214$ \\
\hline \multirow[t]{2}{*}{,377 } & ,545 & $\overline{-}$ & 26 & ,258 &,- 807 \\
\hline & & $\begin{array}{c}- \\
1,156\end{array}$ & 21,428 & ,261 &,- 807 \\
\hline
\end{tabular}

$\begin{array}{lll}, 497 & -, 501 & 1,549 \\ , 706 & -, 734 & 2,167 \\ , 748 & -, 858 & 2,291 \\ , 475 & -1,015 & , 940 \\ , 514 & -1,126 & 1,051 \\ , 565 & -, 584 & 1,739 \\ , 571 & -, 611 & 1,766 \\ , 776 & -, 623 & 2,569 \\ , 799 & -, 697 & 2,644 \\ , 603 & -, 749 & 1,732 \\ , 594 & -, 737 & 1,721 \\ , 593 & , 102 & 2,539 \\ , 660 & -, 088 & 2,730 \\ , 640 & -1,102 & 1,529 \\ , 676 & -1,209 & 1,637 \\ , 862 & -2,986 & , 559 \\ , 845 & -2,962 & , 534 \\ , 698 & -2,242 & , 627 \\ , 699 & -2,259 & , 644\end{array}$




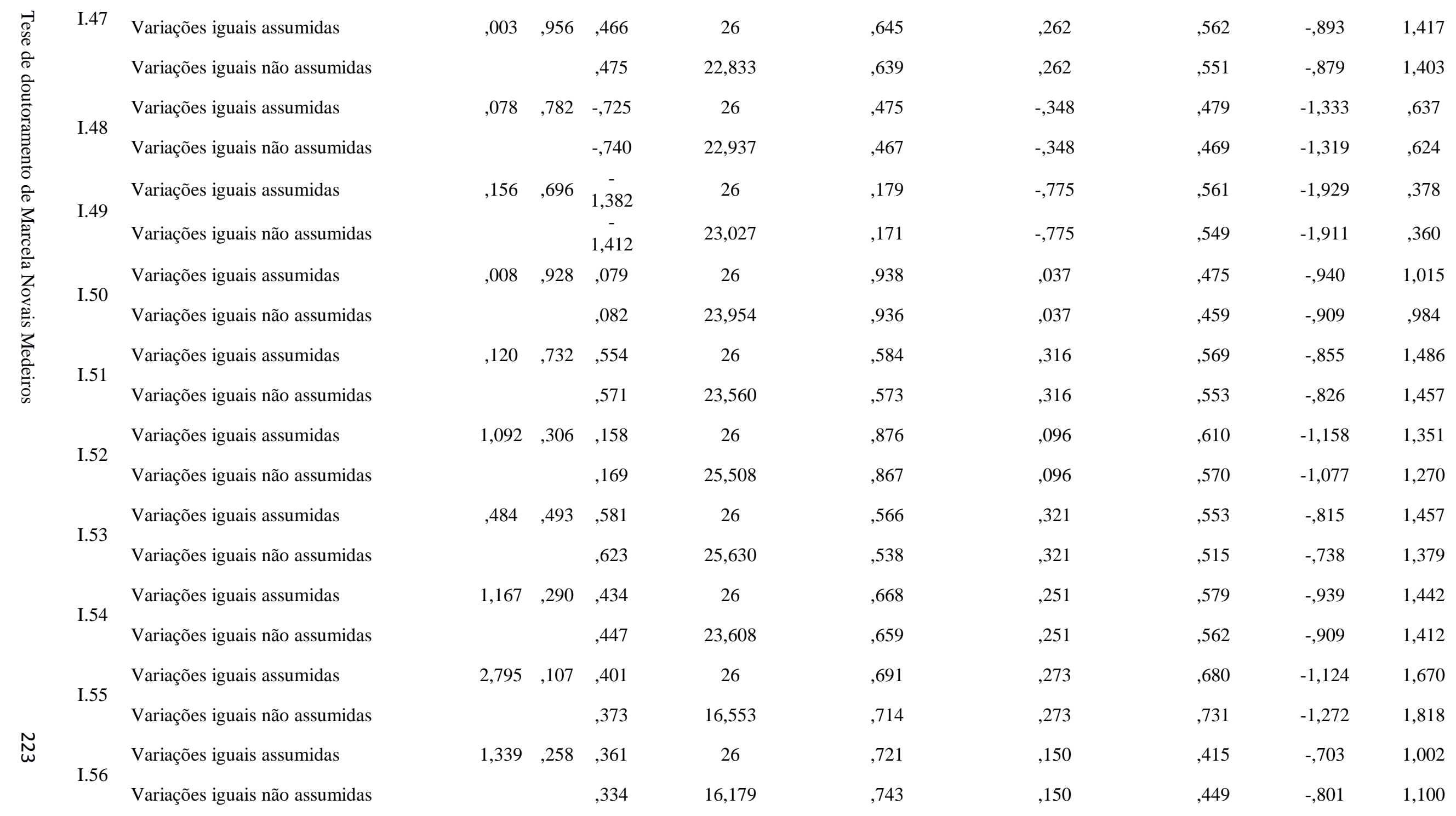




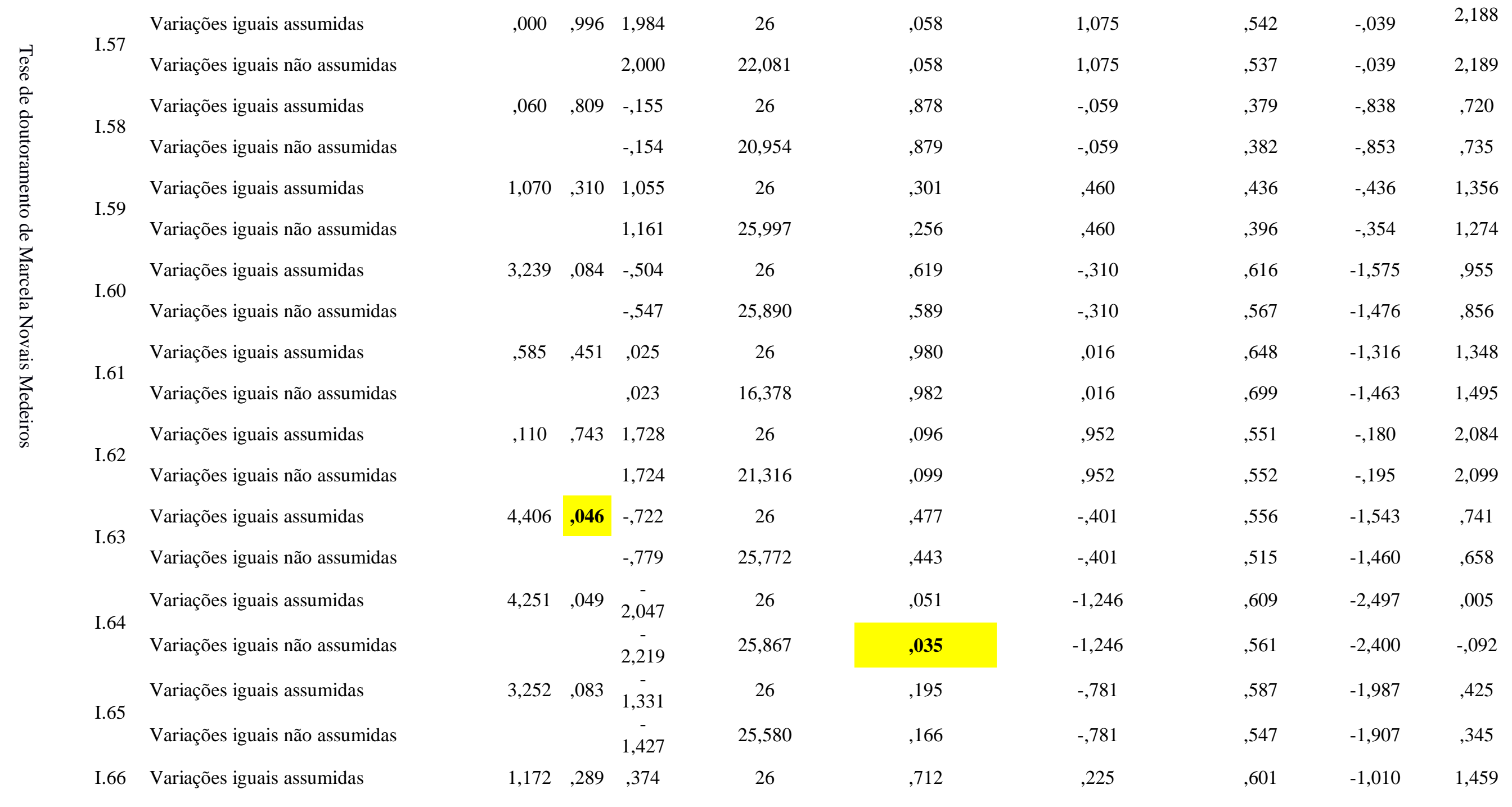




\begin{tabular}{|c|c|c|c|c|c|c|c|c|c|c|c|}
\hline & & Variações iguais não assumidas & & &, 391 & 24,389 &, 700 &, 225 &, 575 &,- 961 & 1,411 \\
\hline $\begin{array}{l}\vec{\theta} \\
\mathbb{b}_{0}\end{array}$ & \multirow{2}{*}{ I.67 } & Variações iguais assumidas & ,978 & ,332 &,- 779 & 26 & ,443 &,- 481 & ,618 & $-1,752$ &, 789 \\
\hline $\begin{array}{l}2 \\
0 \\
2\end{array}$ & & Variações iguais não assumidas & & &,- 862 & 25,961 & ,397 &,- 481 &, 558 & $-1,629$ & ,666 \\
\hline 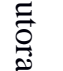 & \multirow{2}{*}{ I.68 } & Variações iguais assumidas & ,249 & ,622 &, 836 & 26 & 411 &, 412 & ,492 &,- 601 & 1,424 \\
\hline 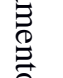 & & Variações iguais não assumidas & & & ,878 & 24,699 &, 388 & ,412 & 469 &,- 554 & 1,378 \\
\hline $\begin{array}{l}0 \\
0 \\
0 \\
0\end{array}$ & \multirow{2}{*}{ I.69 } & Variações iguais assumidas & 2,769 &, 108 & 1,451 & 26 &, 159 &, 749 &, 516 &,- 312 & 1,810 \\
\hline 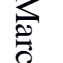 & & Variações iguais não assumidas & & & 1,606 & 25,958 &, 120 &, 749 & ,466 &,- 210 & 1,707 \\
\hline $\begin{array}{l}\ddot{2} \\
z \\
z\end{array}$ & \multirow{2}{*}{$\mathrm{I} .70$} & Variações iguais assumidas &, 000 & ,986 & 1,279 & 26 & ,212 & ,904 & ,706 &,- 548 & 2,356 \\
\hline . & & Variações iguais não assumidas & & & 1,222 & 18,269 &, 237 & ,904 &, 740 &,- 648 & 2,456 \\
\hline$\frac{3}{8}$ & \multirow{2}{*}{ I.71 } & Variações iguais assumidas & 1,911 &, 179 & 673 & 26 &, 507 &, 417 & ,620 &,- 857 & 1,691 \\
\hline है & & Variações iguais não assumidas & & &, 738 & 25,998 & 467 &, 417 &, 565 &,- 744 & 1,578 \\
\hline & \multirow{2}{*}{$\mathrm{I} .72$} & Variações iguais assumidas & 2,891 &, 101 &,- 268 & 26 & ,790 &,- 182 & ,677 & $-1,574$ & 1,210 \\
\hline & & Variações iguais não assumidas & & &,- 240 & 14,433 &, 813 &,- 182 &, 757 & $-1,800$ & 1,436 \\
\hline & \multirow{2}{*}{ I.73 } & Variações iguais assumidas &, 856 & ,363 &,- 751 & 26 & 459 &,- 439 &, 584 & $-1,638$ &, 761 \\
\hline & & Variações iguais não assumidas & & &,- 789 & 24,672 & ,438 &,- 439 &, 556 & $-1,584$ &, 707 \\
\hline & \multirow{2}{*}{$\mathrm{I} .74$} & Variações iguais assumidas &, 502 & 485 & 1,256 & 26 &, 220 &, 545 & ,434 &,- 347 & 1,438 \\
\hline & & Variações iguais não assumidas & & & 1,332 & 25,161 & ,195 &, 545 & ,409 &,- 297 & 1,388 \\
\hline & \multirow{2}{*}{$\mathrm{I} .75$} & Variações iguais assumidas & 3,883 &, 060 &, 465 & 26 & ,646 &, 283 & 609 &,- 969 & 1,536 \\
\hline & & Variações iguais não assumidas & & &, 504 & 25,871 & ,618 &, 283 &, 562 &,- 872 & 1,439 \\
\hline N & I.76 & Variações iguais assumidas & 617 & ,439 &,- 068 & 26 & ,946 &,- 043 & ,630 & $-1,337$ & 1,252 \\
\hline
\end{tabular}




\begin{tabular}{|c|c|c|c|c|c|c|c|c|c|c|}
\hline & Variações iguais não assumidas & & &,- 061 & 14,983 & ,952 &,- 043 & 696 & $-1,526$ & 1,441 \\
\hline \multirow{2}{*}{ I.77 } & Variações iguais assumidas & 1,336 & ,258 & $\begin{array}{c}- \\
1,378\end{array}$ & 26 & , 180 &,- 904 & 656 & $-2,252$ & ,444 \\
\hline & Variações iguais não assumidas & & & ${ }_{1,248}^{-}$ & 15,024 & ,231 &,- 904 & ,724 & $-2,447$ & ,640 \\
\hline \multirow{2}{*}{ I.78 } & Variações iguais assumidas & ,024 & ,877 &,- 572 & 26 & ,572 &,- 342 & ,598 & $-1,571$ & 887 \\
\hline & Variações iguais não assumidas & & &,- 561 & 20,079 & ,581 &,- 342 & ,610 & $-1,614$ & ,930 \\
\hline \multirow{2}{*}{ I.79 } & Variações iguais assumidas & 467 & 501 &,- 095 & 26 & ,925 &,- 032 & ,338 &,- 727 & 663 \\
\hline & Variações iguais não assumidas & & &,- 097 & 22,735 & 924 &,- 032 & ,332 &,- 720 & 656 \\
\hline \multirow{2}{*}{ I. 80} & Variações iguais assumidas & ,097 & ,758 & ,475 & 26 & 639 & 187 & ,394 &,- 624 & 998 \\
\hline & Variações iguais não assumidas & & & ,473 & 21,309 & ,641 & ,187 & ,396 &,- 635 & 1,009 \\
\hline \multirow{2}{*}{ I. 81} & Variações iguais assumidas & 1,843 & , 186 & 346 & 26 & ,732 & ,273 & ,789 & $-1,350$ & 1,895 \\
\hline & Variações iguais não assumidas & & & ,316 & 15,566 & ,756 & 273 & 863 & $-1,561$ & 2,107 \\
\hline \multirow{2}{*}{ I. 82} & Variações iguais assumidas & , 105 & 748 & 1,125 & 26 & 271 &,- 460 & ,409 & $-1,300$ & ,380 \\
\hline & Variações iguais não assumidas & & & $\overline{1,136}$ & 22,217 & ,268 &,- 460 & ,405 & $-1,299$ & ,379 \\
\hline \multirow{2}{*}{ I.83 } & Variações iguais assumidas & ,001 & 980 & 1,362 & 26 & 185 &, 529 & ,389 &,- 270 & 1,328 \\
\hline & Variações iguais não assumidas & & & 1,276 & 16,991 & ,219 & ,529 & 415 &,- 346 & 1,405 \\
\hline \multirow{2}{*}{ I. 84} & Variações iguais assumidas & 1,502 & ,231 & 1,873 & 26 & ,072 & 909 & ,485 &,- 089 & 1,907 \\
\hline & Variações iguais não assumidas & & & 1,986 & 25,161 & ,058 & 909 & ,458 &,- 033 & 1,851 \\
\hline \multirow{2}{*}{ I. 85} & Variações iguais assumidas & ,095 & ,760 &,- 175 & 26 & 862 &,- 086 & ,488 & $-1,089$ & ,918 \\
\hline & Variações iguais não assumidas & & &,- 170 & 19,156 & 867 &,- 086 &, 504 & $-1,141$ & ,970 \\
\hline
\end{tabular}


Variações iguais não assumidas

Variações iguais assumidas

Variações iguais assumidas

Variações iguais não assumidas

Variações iguais assumidas

Variações iguais assumidas

Variações iguais não assumidas

Variações iguais assumidas

Variações iguais não assumidas

Variações iguais assumidas

Variações iguais não assumidas

Variações iguais assumidas

1.93

Variações iguais não assumidas

Variações iguais assumidas

1.94 Variações iguais não assumidas

I.95 Variações iguais assumidas

\begin{tabular}{|c|c|c|c|}
\hline \multirow[t]{2}{*}{, 111} & ,742 & 1,258 & 26 \\
\hline & & $\begin{array}{c}- \\
1,271\end{array}$ & 22,253 \\
\hline \multirow[t]{2}{*}{3,835} & ,061 &,- 841 & 26 \\
\hline & &,- 963 & 24,729 \\
\hline \multirow[t]{2}{*}{2,865} & , 102 &,- 541 & 26 \\
\hline & &,- 504 & 16,644 \\
\hline \multirow[t]{2}{*}{,182 } & 673 & ,420 & 26 \\
\hline & & ,444 & 25,083 \\
\hline \multirow[t]{2}{*}{,376 } &, 545 & ,000 & 26 \\
\hline & & ,000 & 25,513 \\
\hline \multirow[t]{2}{*}{,456 } &, 505 &,- 663 & 26 \\
\hline & &,- 681 & 23,374 \\
\hline \multirow[t]{2}{*}{1,610} & ,216 &,- 728 & 26 \\
\hline & &,- 786 & 25,781 \\
\hline \multirow[t]{2}{*}{,177 } & 677 & $\overline{-}, \overline{291}$ & 26 \\
\hline & & $\begin{array}{c}- \\
1,237\end{array}$ & 18,469 \\
\hline \multirow[t]{2}{*}{, 385} &, 541 & $\begin{array}{c}- \\
1,009\end{array}$ & 26 \\
\hline & &,- 945 & 16,975 \\
\hline ,251 & ,621 &,- 215 & 26 \\
\hline
\end{tabular}

$$
, 220
$$$$
-, 722
$$$$
, 574
$$$$
-1,902
$$

\begin{tabular}{ll}
$-1,899$ &, 455 \\
$-1,566$ &, 656 \\
$-1,427$ &, 518 \\
$-1,310$ &, 764 \\
$-1,417$ &, 872 \\
,- 834 & 1,262 \\
,- 778 & 1,205 \\
$-1,463$ & 1,463 \\
$-1,369$ & 1,369 \\
$-1,228$ &, 629 \\
$-1,208$ &, 609 \\
$-1,901$ &, 907 \\
$-1,798$ &, 804 \\
$-1,996$ &, 456 \\
$-2,075$ &, 535 \\
$-2,209$ &, 754 \\
$-2,351$ &, 897 \\
$-1,184$ &, 959 \\
& \\
\hline
\end{tabular}


Variações iguais não assumidas

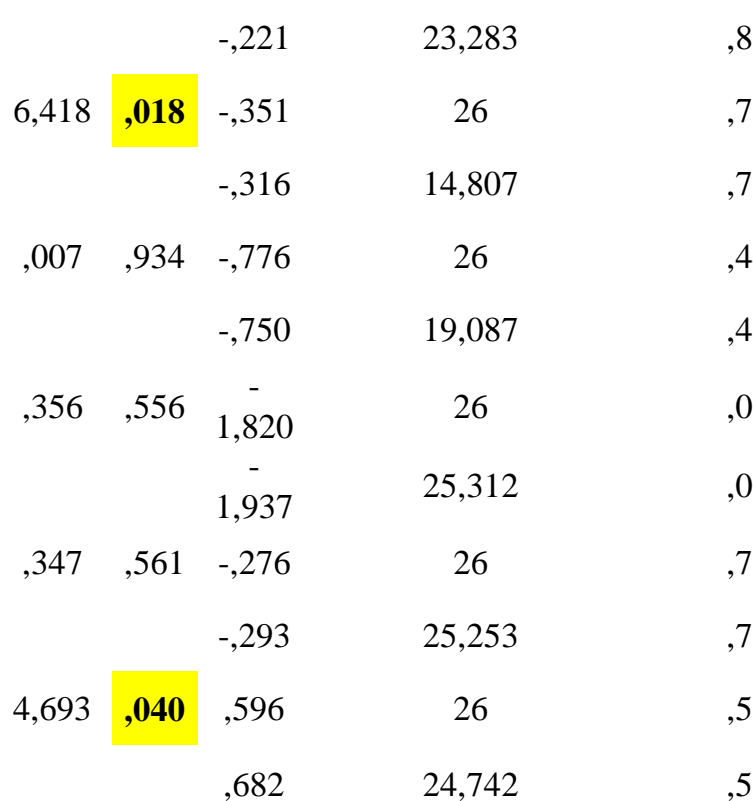

,- 112
,- 262
,- 262
,- 390
,- 390
$-1,155$
$-1,155$
,- 134
,- 134
, 326
, 326

$$
, 508
$$$$
\begin{array}{ll}
-1,162 \quad, 938 \\
\hline
\end{array}
$$

Variações iguais assumidas

Variações iguais não assumidas

,728

$$
, 747
$$$$
-1,797
$$$$
1,273
$$

Variações iguais assumidas

,445

$$
, 828
$$$$
-2,029 \quad 1,505
$$

Variações iguais não assumidas

, 682

, 501

,326

,503 $\quad-1,424 \quad, 644$

,520 $\quad-1,479$

$, 635 \quad-2,460 \quad, 150$

,596 $\quad-2,382 \quad, 072$

,485 $\quad-1,131 \quad$,863

,456 $\quad-1,073 \quad, 806$

$, 547 \quad-, 798 \quad 1,451$

,478

$-, 659$

1,311 
Anexo 13 - Comparação de cada tipo de profissional com a amostra total 
Avaliação de risco de violência contra a mulher

\begin{tabular}{|c|c|c|c|c|c|c|}
\hline \multirow{2}{*}{$\begin{array}{c}\text { Todos } \\
\text { Pergunta }\end{array}$} & \multirow[b]{2}{*}{ Tipo de item } & \multicolumn{5}{|c|}{ Só Profissionais Psicossociais } \\
\hline & & $\begin{array}{c}\text { Média de } \\
\text { Periculosidade }\end{array}$ & & Pergunta & Tipo de item & $\begin{array}{c}\text { Média de } \\
\text { Periculosidade }\end{array}$ \\
\hline I.69 & 1 & 8,03 & \multirow{33}{*}{ Risco severo } & I. 80 & 1 & 8,18 \\
\hline I. 80 & 1 & 8,03 & & I.79 & 1 & 7,94 \\
\hline I.68 & 1 & 7,79 & & I.69 & 1 & 7,71 \\
\hline I.79 & 1 & 7,65 & & I. 78 & 1 & 7,71 \\
\hline I.76 & 1 & 7,50 & & I.93 & 0 & 6,59 \\
\hline I.78 & 1 & 7,38 & & I.68 & 1 & 7,59 \\
\hline I.62 & 1 & 7,03 & & I.76 & 1 & 7,59 \\
\hline I.77 & 1 & 7,03 & & I. 35 & 1 & 7,47 \\
\hline I.07 & 1 & 7,00 & & I.72 & 0 & 7,00 \\
\hline I.72 & 0 & 6,91 & & I. 88 & 1 & 7,00 \\
\hline I. 88 & 1 & 6,91 & & I.94 & 0 & 7,00 \\
\hline I. 35 & 1 & 6,85 & & I.77 & 1 & 7,18 \\
\hline I.63 & 1 & 6,74 & & I.64 & 1 & 6,88 \\
\hline I. 83 & 1 & 6,68 & & I. 27 & 1 & 6,88 \\
\hline I. 27 & 1 & 6,65 & & I. 82 & 1 & 6,82 \\
\hline I. 82 & 1 & 6,65 & & I.07 & 1 & 6,76 \\
\hline I.94 & 0 & 6,53 & & I.63 & 1 & 6,76 \\
\hline I.75 & 1 & 6,38 & & I.83 & 1 & 6,47 \\
\hline I.64 & 1 & 6,35 & & I.62 & 1 & 6,41 \\
\hline I.93 & 0 & 6,26 & & I.75 & 1 & 6,35 \\
\hline I.89 & 1 & 6,21 & & I. 45 & 1 & 5,94 \\
\hline I.95 & 0 & 6,21 & & I.57 & 1 & 5,47 \\
\hline I. 26 & 1 & 6,18 & & I.95 & 0 & 6,29 \\
\hline I. 85 & 1 & 6,18 & & I. 85 & 1 & 6,18 \\
\hline I. 28 & 1 & 6,12 & & I. 86 & 1 & 6,18 \\
\hline I. 57 & 1 & 6,09 & & I.91 & 0 & 6,12 \\
\hline I. 81 & 0 & 6,03 & & I. 28 & 1 & 6,12 \\
\hline I.70 & 1 & 5,97 & & I.67 & 1 & 6,12 \\
\hline I.91 & 0 & 5,91 & & I. 26 & 1 & 6,06 \\
\hline I.67 & 1 & 5,82 & & I. 89 & 1 & 6,06 \\
\hline I. 86 & 1 & 5,82 & & I. 81 & 0 & 6,00 \\
\hline I. 22 & 0 & 5,65 & & I.70 & 1 & 5,82 \\
\hline I.61 & 1 & 5,65 & & I.01 & 1 & 5,76 \\
\hline I. 59 & 1 & 5,62 & & I. 22 & 0 & 5,59 \\
\hline I.03 & 1 & 5,59 & & I.03 & 1 & 5,59 \\
\hline I. 23 & 0 & 5,44 & & I.92 & 0 & 5,59 \\
\hline I. 84 & 1 & 5,38 & & I.04 & 0 & 5,59 \\
\hline I.01 & 1 & 5,35 & & I.61 & 1 & 5,53 \\
\hline I. 14 & 1 & 5,32 & & I. 23 & 0 & 5,47 \\
\hline I.74 & 1 & 5,32 & & I.02 & 0 & 5,47 \\
\hline I. 34 & 1 & 5,29 & & I.46 & 0 & 5,35 \\
\hline I.92 & 0 & 5,26 & & I.65 & 1 & 5,24 \\
\hline I.38 & 0 & 5,21 & & I.59 & 1 & 5,18 \\
\hline I.02 & 0 & 5,18 & & I.08 & 1 & 5,18 \\
\hline I.58 & 1 & 5,18 & & I.34 & 1 & 5,12 \\
\hline
\end{tabular}

Tese de doutoramento de Marcela Novais Medeiros 
Avaliação de risco de violência contra a mulher

\begin{tabular}{|c|c|c|c|c|c|c|}
\hline I. 15 & 0 & 5,15 & \multirow{22}{*}{ Risco grave } & I.58 & 1 & 5,06 \\
\hline I.04 & 0 & 5,12 & & I. 21 & 1 & 5,06 \\
\hline I. 45 & 1 & 5,12 & & I. 30 & 1 & 5,06 \\
\hline I.08 & 1 & 5,09 & & I. 84 & 1 & 5,00 \\
\hline I. 10 & 0 & 5,03 & & I. 15 & 0 & 5,00 \\
\hline I. 21 & 1 & 4,94 & & I.74 & 1 & 5,00 \\
\hline I.71 & 1 & 4,94 & & I. 90 & 0 & 5,00 \\
\hline I. 30 & 1 & 4,91 & & I. 14 & 1 & 4,88 \\
\hline I. 46 & 0 & 4,88 & & I.98 & 0 & 4,88 \\
\hline I.90 & 0 & 4,88 & & I.71 & 1 & 4,76 \\
\hline I.60 & 1 & 4,85 & & I.60 & 1 & 4,76 \\
\hline I.65 & 1 & 4,85 & & I. 12 & 0 & 4,71 \\
\hline I. 12 & 0 & 4,79 & & I. 38 & 0 & 4,65 \\
\hline I. 53 & 0 & 4,76 & & I. 10 & 0 & 4,29 \\
\hline I. 11 & 1 & 4,74 & & I. 24 & 0 & 4,65 \\
\hline I. 24 & 0 & 4,65 & & I.53 & 0 & 4,59 \\
\hline I.99 & 0 & 4,62 & & I.99 & 0 & 4,56 \\
\hline I.96 & 0 & 4,59 & & I.05 & 0 & 4,53 \\
\hline I.66 & 1 & 4,56 & & I. 32 & 1 & 4,47 \\
\hline I. 25 & 1 & 4,47 & & I.96 & 0 & 4,35 \\
\hline I. 42 & 0 & 4,47 & & I. 25 & 1 & 4,24 \\
\hline I. 51 & 0 & 4,44 & & I.51 & 0 & 4,41 \\
\hline I. 41 & 0 & 4,41 & \multirow{25}{*}{$\begin{array}{c}\text { Risco } \\
\text { Moderado }\end{array}$} & I.66 & 1 & 4,41 \\
\hline I. 44 & 0 & 4,32 & & I. 42 & 0 & 4,24 \\
\hline I. 43 & 1 & 4,26 & & I.52 & 0 & 4,18 \\
\hline I.98 & 0 & 4,26 & & I. 41 & 0 & 4,12 \\
\hline I. 32 & 1 & 4,24 & & I. 18 & 0 & 4,12 \\
\hline I. 36 & 0 & 4,21 & & I. 40 & 0 & 4,06 \\
\hline I. 40 & 0 & 4,21 & & I.44 & 0 & 4,06 \\
\hline I. 52 & 0 & 4,21 & & I. 16 & 0 & 4,06 \\
\hline I.05 & 0 & 4,12 & & I. 11 & 1 & 4,00 \\
\hline I. 13 & 0 & 3,85 & & I.36 & 0 & 3,88 \\
\hline I. 18 & 0 & 3,79 & & I. 100 & 1 & 3,76 \\
\hline I. 39 & 0 & 3,76 & & I.39 & 0 & 3,76 \\
\hline I. 100 & 1 & 3,76 & & I.06 & 0 & 3,71 \\
\hline I. 16 & 0 & 3,68 & & I. 13 & 0 & 3,59 \\
\hline I. 37 & 0 & 3,53 & & I.43 & 1 & 3,59 \\
\hline I. 54 & 0 & 3,47 & & I.73 & 0 & 3,53 \\
\hline I.06 & 0 & 3,41 & & I.09 & 0 & 3,41 \\
\hline I. 19 & 0 & 3,35 & & I.49 & 0 & 3,41 \\
\hline I.73 & 0 & 3,29 & & I. 37 & 0 & 3,29 \\
\hline I. 17 & 1 & 3,26 & & I.54 & 0 & 3,29 \\
\hline I. 20 & 1 & 3,12 & & I. 19 & 0 & 3,24 \\
\hline I.09 & 0 & 3,09 & & I. 20 & 1 & 3,06 \\
\hline I. 49 & 0 & 3,03 & & I.17 & 1 & 3,03 \\
\hline I. 55 & 1 & 3,03 & & I.55 & 1 & 3,00 \\
\hline I. 47 & 0 & 2,76 & & I.87 & 1 & 3,00 \\
\hline
\end{tabular}


Avaliação de risco de violência contra a mulher

\begin{tabular}{lll} 
I.29 & 0 & 2,71 \\
I.87 & 1 & 2,56 \\
I.33 I. & 2,53 \\
I.48 & 1 & 2,47 \\
I.31 & 0 & 2,38 \\
I.50 & 1 & 2,24 \\
I.56 & 0 & 2,21 \\
I.97 & 1 & I.47 \\
\hline
\end{tabular}

Legenda: Tipo de item: $\mathrm{I}$ = Comportamental

$0=$ Subjetivo 
Avaliação de risco de violência contra a mulher

\begin{tabular}{|c|c|c|c|c|c|c|}
\hline Todos & & \multicolumn{5}{|c|}{ Só Profissionais Juridicos e da segurança } \\
\hline Pergunta & Tipo de item & $\begin{array}{c}\text { Média de } \\
\text { Periculosidade }\end{array}$ & & Pergunta & $\begin{array}{l}\text { Tipo de } \\
\text { item }\end{array}$ & $\begin{array}{c}\text { Média de } \\
\text { Periculosidade }\end{array}$ \\
\hline I.69 & 1 & 8,03 & & I.93 & 0 & 8,82 \\
\hline I. 80 & 1 & 8,03 & & I.69 & 1 & 8,45 \\
\hline I.68 & 1 & 7,79 & & I. 80 & 1 & 8,36 \\
\hline I.79 & 1 & 7,65 & & I. 68 & 1 & 8,00 \\
\hline I.76 & 1 & 7,50 & & I.76 & 1 & 7,91 \\
\hline I.78 & 1 & 7,38 & & I.79 & 1 & 7,65 \\
\hline I.62 & 1 & 7,03 & & I.07 & 1 & 7,64 \\
\hline I.77 & 1 & 7,03 & & $\mathrm{I} .78$ & 1 & 7,36 \\
\hline I.07 & 1 & 7,00 & & I.62 & 1 & 7,36 \\
\hline I.72 & 0 & 6,91 & & I. 83 & 1 & 7,00 \\
\hline I. 88 & 1 & 6,91 & Risco severo & I. 27 & 1 & 6,91 \\
\hline I. 35 & 1 & 6,85 & & I. 72 & 0 & 6,82 \\
\hline I.63 & 1 & 6,74 & & I. 77 & 1 & 6,27 \\
\hline I.83 & 1 & 6,68 & & I. 88 & 1 & 6,73 \\
\hline I. 27 & 1 & 6,65 & & I. 70 & 1 & 6,73 \\
\hline I. 82 & 1 & 6,65 & & I. 35 & 1 & 6,45 \\
\hline I.94 & 0 & 6,53 & & I.63 & 1 & 6,36 \\
\hline I.75 & 1 & 6,38 & & I. 82 & 1 & 6,36 \\
\hline I.64 & 1 & 6,35 & & I.94 & 0 & 6,27 \\
\hline I.93 & 0 & 6,26 & & I. 75 & 1 & 6,64 \\
\hline I.89 & 1 & 6,21 & & I.64 & 1 & 5,64 \\
\hline I.95 & 0 & 6,21 & & I. 57 & 1 & 6,55 \\
\hline I. 26 & 1 & 6,18 & & I. 26 & 1 & 6,45 \\
\hline I.85 & 1 & 6,18 & & I. 89 & 1 & 6,27 \\
\hline I. 28 & 1 & 6,12 & & I. 81 & 0 & 6,27 \\
\hline I.57 & 1 & 6,09 & & I.95 & 0 & 6,18 \\
\hline I. 81 & 0 & 6,03 & & I. 85 & 1 & 6,09 \\
\hline I.70 & 1 & 5,97 & & I. 28 & 1 & 6,00 \\
\hline I.91 & 0 & 5,91 & & I. 22 & 0 & 5,91 \\
\hline I.67 & 1 & 5,82 & & I. 84 & 1 & 5,91 \\
\hline I. 86 & 1 & 5,82 & & I.91 & 0 & 5,82 \\
\hline I. 22 & 0 & 5,65 & & I. 14 & 1 & 5,82 \\
\hline I.61 & 1 & 5,65 & & I.03 & 1 & 5,82 \\
\hline I.59 & 1 & 5,62 & & I. 23 & 0 & 5,82 \\
\hline I.03 & 1 & 5,59 & & I.67 & 1 & 5,64 \\
\hline I. 23 & 0 & 5,44 & & I.59 & 1 & 5,64 \\
\hline I.84 & 1 & 5,38 & & I. 15 & 0 & 5,64 \\
\hline I.01 & 1 & 5,35 & & I.61 & 1 & 5,55 \\
\hline I. 14 & 1 & 5,32 & & I.01 & 1 & 5,55 \\
\hline I.74 & 1 & 5,32 & & I. 74 & 1 & 5,55 \\
\hline I.34 & 1 & 5,29 & & I. 86 & 1 & 5,45 \\
\hline I.92 & 0 & 5,26 & & I.92 & 0 & 5,09 \\
\hline I.38 & 0 & 5,21 & & I. 38 & 0 & 5,36 \\
\hline I.02 & 0 & 5,18 & & I.02 & 0 & 5,18 \\
\hline I.58 & 1 & 5,18 & & I.11 & 1 & 5,18 \\
\hline
\end{tabular}


Avaliação de risco de violência contra a mulher

\begin{tabular}{|c|c|c|c|c|c|c|}
\hline I. 15 & 0 & 5,15 & \multirow{22}{*}{ Risco grave } & I.71 & 1 & 5,18 \\
\hline I.04 & 0 & 5,12 & & I. 10 & 0 & 5,18 \\
\hline I. 45 & 1 & 5,12 & & I. 41 & 0 & 5,09 \\
\hline I.08 & 1 & 5,09 & & I. 58 & 1 & 5,00 \\
\hline I.10 & 0 & 5,03 & & I. 24 & 0 & 5,00 \\
\hline I. 21 & 1 & 4,94 & & I.90 & 0 & 5,00 \\
\hline I.71 & 1 & 4,94 & & I. 34 & 1 & 4,91 \\
\hline I.30 & 1 & 4,91 & & I.53 & 0 & 4,91 \\
\hline I. 46 & 0 & 4,88 & & I.43 & 1 & 4,91 \\
\hline I.90 & 0 & 4,88 & & I. 12 & 0 & 4,82 \\
\hline I.60 & 1 & 4,85 & & I.42 & 0 & 4,73 \\
\hline I.65 & 1 & 4,85 & & I.51 & 0 & 4,73 \\
\hline I. 12 & 0 & 4,79 & & I.45 & 1 & 4,73 \\
\hline I.53 & 0 & 4,76 & & I.04 & 0 & 4,64 \\
\hline I.11 & 1 & 4,74 & & I.66 & 1 & 4,64 \\
\hline I. 24 & 0 & 4,65 & & I.08 & 1 & 4,82 \\
\hline I.99 & 0 & 4,62 & & I. 40 & 0 & 4,64 \\
\hline I.96 & 0 & 4,59 & & I. 21 & 1 & 4,55 \\
\hline I.66 & 1 & 4,56 & & I.30 & 1 & 4,45 \\
\hline $\mathrm{I} .25$ & 1 & 4,47 & & I.46 & 0 & 4,55 \\
\hline I. 42 & 0 & 4,47 & & I.60 & 1 & 4,45 \\
\hline I.51 & 0 & 4,44 & & I.65 & 1 & 4,45 \\
\hline I.41 & 0 & 4,41 & \multirow{25}{*}{$\begin{array}{c}\text { Risco } \\
\text { Moderado }\end{array}$} & I.99 & 0 & 4,45 \\
\hline I. 44 & 0 & 4,32 & & I. 25 & 1 & 4,45 \\
\hline I. 43 & 1 & 4,26 & & I.44 & 0 & 4,27 \\
\hline I.98 & 0 & 4,26 & & I.32 & 1 & 4,00 \\
\hline I.32 & 1 & 4,24 & & I.36 & 0 & 4,45 \\
\hline I.36 & 0 & 4,21 & & I. 52 & 0 & 4,27 \\
\hline I. 40 & 0 & 4,21 & & I.96 & 0 & 4,09 \\
\hline I.52 & 0 & 4,21 & & I.100 & 1 & 4,09 \\
\hline I.05 & 0 & 4,12 & & I.13 & 0 & 4,00 \\
\hline I.13 & 0 & 3,85 & & I. 18 & 0 & 3,91 \\
\hline I. 18 & 0 & 3,79 & & I. 37 & 0 & 3,82 \\
\hline I.39 & 0 & 3,76 & & I.98 & 0 & 3,73 \\
\hline I. 100 & 1 & 3,76 & & I.39 & 0 & 3,73 \\
\hline I.16 & 0 & 3,68 & & I.05 & 0 & 3,64 \\
\hline I.37 & 0 & 3,53 & & I. 17 & 1 & 3,64 \\
\hline I.54 & 0 & 3,47 & & I. 54 & 0 & 3,55 \\
\hline I.06 & 0 & 3,41 & & I. 16 & 0 & 3,36 \\
\hline I. 19 & 0 & 3,35 & & I. 19 & 0 & 3,36 \\
\hline I.73 & 0 & 3,29 & & I. 55 & 1 & 3,27 \\
\hline I.17 & 1 & 3,26 & & I.73 & 0 & 3,09 \\
\hline I. 20 & 1 & 3,12 & & I.06 & 0 & 3,00 \\
\hline I.09 & 0 & 3,09 & & I.09 & 0 & 3,00 \\
\hline I. 49 & 0 & 3,03 & & I.47 & 0 & 2,91 \\
\hline I.55 & 1 & 3,03 & & I. 20 & 1 & 2,82 \\
\hline I. 47 & 0 & 2,76 & & I.49 & 0 & 2,64 \\
\hline
\end{tabular}


Avaliação de risco de violência contra a mulher

\begin{tabular}{|c|c|c|c|c|c|}
\hline I. 29 & 0 & 2,71 & I. 87 & 1 & 2,55 \\
\hline I. 87 & 1 & 2,56 & I. 31 & 1 & 2,55 \\
\hline I. 33 & 1 & 2,53 & I.33 & 1 & 2,45 \\
\hline I. 48 & 0 & 2,47 & I.50 & 0 & 2,27 \\
\hline I. 31 & 1 & 2,38 & I.48 & 0 & 2,18 \\
\hline I.50 & 0 & 2,24 & I.56 & 1 & 2,09 \\
\hline I. 56 & 1 & 2,21 & I. 29 & 0 & 2,00 \\
\hline I.97 & 0 & 2,00 & I.97 & 0 & 1,73 \\
\hline
\end{tabular}

Legenda: Tipo de item: $\mathrm{I}$ = Comportamental

$0=$ Subjetivo 